Leticia Urbano Cardoso de Castro

\author{
Comparação dos efeitos da ressuscitação com \\ Ringer lactato ou terlipressina sobre função renal \\ em modelo experimental de choque hemorrágico
}

Dissertação apresentada à Faculdade de Medicina da Universidade de São Paulo para obtenção do título de

Mestre em Ciências

Programa: Nefrologia Orientadora: Profa. Dra. Lúcia da Conceição Andrade 
Dados Internacionais de Catalogação na Publicação (CIP)

Preparada pela Biblioteca da

Faculdade de Medicina da Universidade de São Paulo

Creprodução autorizada pelo autor

\section{Castro, Leticia Urbano Cardoso de}

Comparação dos efeitos da ressuscitação com Ringer lactato ou terlipressina sobre função renal em modelo experimental de choque hemorrágico / Leticia Urbano Cardoso de Castro. -- São Paulo, 2015.

Dissertação(mestrado)--Faculdade de Medicina da Universidade de São Paulo. Programa de Nefrologia.

Orientadora: Lúcia da Conceição Andrade.

Descritores: 1.Choque hemorrágico 2.Terlipressina 3.Ringer's lactato 4.Lesão renal aguda 5.Apoptose 6.Aquaporina 2

USP/FM/DBD-253/15 
Dedicatória 
Dedico este trabalho as pessoas mais importantes em minha vida: minha mãe Elisabeth, meu pai Manoel e as minhas avós Ida e Maria 
AGRADECIMENTOS 
E apesar de todas as dificuldades em mais de três anos de trabalho, a dissertação está concluída. E como eu aprendi...

Cheguei ao Laboratório de Investigação Médica 12 (LIM 12) em Agosto de 2011, receosa com minha escolha de largar um emprego que, apesar de totalmente fora de minha formação em biologia, tinha uma estabilidade razoável, e fui com a cara e a coragem ingressar no mestrado. E apesar de todos os medos fui recebida de braços abertos por todos. E minha escolha me ensinou a lição de sempre persistir com minhas vontades e objetivos de vida, nunca desistir diante de obstáculos e manter a cabeça erguida.

Tenho muitas pessoas a agradecer que me ajudaram direta ou indiretamente no desenvolvimento deste trabalho:

A Dra. Lúcia da Conceição Andrade, minha incrível orientadora, que me recebeu e acolheu, sempre bem-humorada, de uma inteligência admirável e exemplo de médica, pesquisadora e pessoa.

Ao Dr. Antonio Carlos Seguro, grande médico e pesquisador, pela oportunidade de entrar no LIM 12 e fazer parte de uma equipe com tanto sucesso e tão querida por todos.

E a quem me trouxe ao LIM 12, minha amiga-irmã Talita Rojas, inclusive porque, se eu não falar dela, ela me mata! Ela me apoiou em tudo, me ensinou grande parte do que sei, me ajudou em tudo que precisei e sou imensamente grata por tê-la em minha vida! Ela me conhece desde que eu nasci e eu a amo muito e também o mais novo integrante do LIM 12 e minha paixão, Theo!

Aos que fizeram e fazem parte do meu dia-a-dia, tornando-o melhor e mais leve... Ana Carolina de Bragança, Daniele Canale, Daniela Ferreira, Janaína Garcia, Maria Heloísa Shimizu e Rildo Volpini. Muito obrigado pela oportunidade de fazer parte do grupo e por toda a aprendizagem! Admiro e gosto muito de vocês!

O LIM 12 é um laboratório maravilhoso e não existe igual! Quando eu entrei aqui conheci pessoas maravilhosas, as quais também agradeço! Muito obrigada a todos os alunos, funcionários e professores pela presença em minha vida! Tenho um carinho especial por cada um de vocês!

Este trabalho foi feito em parceria com o LIM 08 chefiado Prof. José Otávio Costa Auler Junior e não poderia deixar de agradecer a eles também.

Agradeço ao Dr. Luiz Marcelo Malbouisson que nos convidou e nos deu a oportunidade de fazermos parte deste trabalho tão maravilhoso e com uma importância tão grande para a medicina. A Keila Kazue Ida que além de ser uma colega de trabalho muito dedicada e me ajudou muito, se tornou uma amiga muito querida não só por mim, mas por todos no laboratório, e espero nunca perder o contato. A Dra. Denise Atzuki e ao Gilberto, que ajudaram tanto 
com meu projeto quando mais precisei, sempre com bom humor e disposição. Muito obrigada! Devo a vocês meus resultados!

Agradeço também a disciplina de Nefrologia da Faculdade de Medicina da USP e a pós-graduação de Nefrologia pela oportunidade de fazer parte do grupo.

Não poderia deixar de agradecer também as porquinhas que utilizamos no projeto e a todos os animais que são utilizados em pesquisa no mundo. Não teríamos esses avanços em pesquisa, vacinas e remédios para prevenção e cura de doenças se não fossem por vocês.

E a quem me deu todo o apoio e me incentivou a persistir com minha carreira, minha mãe Elisabeth e meu pai Manoel. Agradeço por terem me dado a vida e me apoiarem em tudo. Foi e ainda é uma fase muito difícil em minha vida, mas com a ajuda de vocês tenho certeza que conseguirei chegar onde quiser. Aos meus familiares também: irmãos, avós, tios, primos, eu amo vocês! E duas pessoas muito mais que especiais: a minha avó Maria que tem 91 anos e tem mais disposição que muita gente por aí e vai chegar facilmente aos 100 anos; e a minha avó Ida, que não está mais com a gente, mas têm minha saudade e meu pensamento todos os dias.

E finalmente, a pessoa que aguenta desde 2006 minhas fases mais estressantes e meus chiliques, quando eu queria desistir e ele me guiava para seguir em frente... A pessoa que eu escolhi para passar o resto da minha vida, para formar uma família. Ao meu noivo e meu orgulho Anderson Paes Gonçalves, agradeço muito por estar sempre ao meu lado em tudo, me apoiando, me acompanhando e crescendo junto comigo. Eu te amo muito.

Agradeço também a FAPESP pelo suporte e por acreditar em nossa pesquisa e em nossos pesquisadores. 
"Whatever tomorrow brings I'll be there With open arms and open eyes, yeah Whatever tomorrow brings I'll be there I'll be there"

Incubus - Drive 
Esta dissertação ou tese está de acordo com as seguintes normas, em vigor no momento desta publicação:

Referências: adaptado de International Committee of Medical Journals Editors (Vancouver).

Universidade de São Paulo. Faculdade de Medicina. Divisão de Biblioteca e Documentação. Guia de apresentação de dissertações, teses e monografias. Elaborado por Anneliese Carneiro da Cunha, Maria Julia de A. L. Freddi, Maria F. Crestana, Marinalva de Souza Aragão, Suely Campos Cardoso, Valéria Vilhena. 3a ed. São Paulo: Divisão de Biblioteca e Documentação; 2011.

Abreviaturas dos títulos dos periódicos de acordo com List of Journals Indexed in Index Medicus. 


\section{SUMÁRIO}

Lista de abreviaturas e siglas

Resumo.............................................................................1

Abstract.....................................................................................3

Introdução.........................................................................5

Objetivos.................................................................................14

Materiais e métodos....................................................................16

Resultados.......................................................................28

Discussão.........................................................................66

Conclusão..............................................................................74

Referências bibliográficas..................................................76

Trabalhos publicados e participação em congresso....................85 


\section{LISTA DE ABREVIATURAS E SIGLAS}

AQP - Aquaporina

ATC - ácido tricloroacético

ATP - adenosina trifosfato

BCL-2 - Proteína Célula B de Linfoma 2

Bic - bicarbonato

CEP - Comissão de ética e pesquisa

$\mathrm{CH}$ - choque hemorrágico

$\mathrm{Cl}$ - Cloro plasmático

$\mathrm{Cl}$. Creat - clearance de creatinina

Creat - creatinina plasmática

HAD - hormônio anti-diurético

$\mathrm{Hb}$ - hemoglobina

HE - hematoxilina-eosina

HS - hemorrhagic shock

IM - intramuscular

IRA - Injúria Renal Aguda

IV - intravenoso

K - Potássio plasmático

Lac - lactato

LIM - Laboratório de Investigação Médica

LR - lactated Ringer's

MAP - mean arterial pressure

Mg - Magnésio plasmático

MnSOD - superóxido dismutase dependente de manganês

$\mathrm{Na}$ - Sódio plasmático

NKCC2 - sódio potássio 2 cloros

Osm. Ur. - osmolalidade urinária

P - Fósforo plasmático

P - grau de significância

PAM - pressão arterial média

PAS - pressão arterial sistólica

$\mathrm{pO}_{2}$ - pressão parcial de oxigênio

RL - Ringer lactato

ROS - espécies reativas de oxigênio

SAMU - Sistema de Atendimento Móvel de Emergência

SIRS - síndrome de resposta inflamatória sistêmica

SOD - superóxido desmutase

TBARS - thiobarbituric acid reactive substances

TBS - tampão de Tris

TFG - taxa de filtração glomerular

TLP - terlipressin

TLP - terlipressina

Ur - Ureia plasmática

UTI - Unidade de Terapia Intensiva 
UV - Excreção urinária

UV Cl - excreção urinária de cloro

UV K - excreção urinária de potássio

UV Mg - excreção urinária de magnésio

UV Na - excreção urinária de sódio

UV P - excreção urinária de fósforo

UV Ur - excreção urinária de ureia

$\mathrm{V} 1 \mathrm{a}$ - receptor de vasopressina 1

$\mathrm{V} 2$ - receptor de vasopressina 2 


\section{RESUMO}

Castro LUC. Comparação dos efeitos da ressuscitação com Ringer lactato ou terlipressina sobre a função renal em modelo experimental de choque hemorrágico [Dissertação]. São Paulo: Faculdade de Medicina, Universidade de São Paulo; 2015.

As estratégias terapêuticas empregadas na ressuscitação do choque hemorrágico $(\mathrm{CH})$ são capazes de evitar a morte, mas seus efeitos colaterais podem causar muitas alterações orgânicas, inclusive nos rins. Sabemos que a reposição volêmica feita com solução cristaloide restaura a hemodinâmica, diminui a mortalidade, mas pode levar a edema de órgãos e tecidos, entre outras alterações. Sendo assim, o objetivo do atual estudo foi comparar os efeitos da ressuscitação com Ringer lactato (RL) ou terlipressina (TLP) na função renal em modelo experimental de $\mathrm{CH}$. Com este intuito, foi induzido o CH em suínos de 20-30 kg, por meio de sangramento pressão-controlada, até a obtenção e manutenção da pressão arterial média (PAM) em 40mmHg por 30 minutos. Os animais foram divididos em quatro grupos, sendo eles, o grupo Sham (feito apenas o procedimento anestésico), grupo Choque (indução de choque hemorrágico por 30 minutos) e os de instituição de estratégias de ressuscitação: grupo RL (indução de choque hemorrágico, e administração de RL de três vezes o volume de sangue retirado) e o grupo TLP (indução do choque e administração em bolus de $2 \mathrm{mg}$ de TLP). Os parâmetros hemodinâmicos, de função renal e tubular foram avaliados nos momentos: basal; imediatamente após o CH; 30, 60, 90 e 120 minutos após tratamento. Ao final do estudo, os animais foram eutanasiados aos 60 ou aos 120 minutos. Foram coletadas amostras de tecido renal para avaliação de histologia e de western blott. Observamos uma melhora na microcirculação dos animais tratados com RL; entretanto, houve uma normalização da expressão da proteína NKCC2 e aquaporina 2 no grupo TLP. Observamos que o escore de lesão renal foi igual nos dois grupos de intervenção, mas a expressão de Bax estava mais 
diminuída no grupo TLP. Concluímos que a TLP mostrou ser uma estratégia tão eficaz quanto o RL no resgate do choque hemorrágico, com um provável potencial de maior proteção renal.

Descritores: choque hemorrágico; terlipressina; Ringer's lactato; lesão renal aguda; apoptose; aquaporina 2. 


\section{ABSTRACT}

Castro LUC. Comparison of the effects of lactated Ringer's or terlipressin resuscitation on renal function in an experimental model of hemorrhagic shock

[Dissertation]. São Paulo: "Faculdade de Medicina, Universidade de São Paulo"; 2015.

Therapeutic strategies employed hemorrhagic shock (HS) resuscitation are able to prevent death, but its side effects can cause many organic dysfunction, including injury to the kidneys. It has been know that volume replacement with crystalloid solution can restore the hemodynamic status and decreases mortality; however, it can lead to organs and tissues edema, among other changes. Thus, the goal of this study was to compare the effects of resuscitation with lactated Ringer's (RL) or terlipressin (TLP) on renal function in an experimental model of HS. For this purpose, HS was induced in 20-30 kg swine, with pressure-controlled bleeding, to obtain and maintain the mean arterial pressure (MAP) of $40 \mathrm{mmHg}$ for 30 minutes. The animals were divided into four groups, namely, the Sham group (made only the anesthetic procedure), Shock group (induction of hemorrhagic shock for 30 minutes) and the institution of resuscitation strategies: RL group (induction of hemorrhagic shock, and RL administration of three times the volume of removed blood) and TLP group (induction of shock and administration in bolus of $2 \mathrm{mg}$ TLP). Hemodynamic parameters, renal and tubular function were evaluated at baseline; immediately after the HS; 30, 60, 90 and 120 minutes after treatment. At the end of the study, animals were euthanized after 60 or 120 minutes. Kidney tissue samples were collected for evaluation of histology and western blotting. We observed an improvement in microcirculation of animals treated with RL; however, there was a normalization of NKCC2 and aquaporin 2 protein expression in the TLP group. We observe that the kidney injury score was similar in both intervention groups, but Bax protein expression was more reduced than in the TLP group. We conclude that the TLP proved to be an 
effective strategy as RL in the rescue of hemorrhagic shock, with a likely potential for protect renal function.

Descriptors: shock hemorrhagic; terlipressin; Ringer's lactated; acute kidney injury; apoptosis; aquaporin 2. 
INTRODUÇÃO 
O trauma, conjunto de perturbações causadas subitamente por um agente físico, representa um problema de saúde pública de grande abrangência no Brasil e no mundo, com forte impacto na morbidade e mortalidade da população ${ }^{1}$. Todo ano 5,8 milhões de pessoas morrem decorrentes de algum evento relacionado ao trauma, tornando-o uma das principais causas de morte e invalidez, perdendo apenas para doenças oncológicas e cardiovasculares. No Brasil, o trauma é a $2^{\mathrm{a}}$ maior causa de morte, com aproximadamente $130 \mathrm{mil}$ mortes por ano. Estudos da Santa Casa de São Paulo mostraram que cerca de $40 \%$ desses pacientes são vítimas de acidentes provocados por veículos, e a grande maioria são jovens. Apenas na cidade de São Paulo, foram registrados pelo Resgate e pelo SAMU (Sistema de Atendimento Móvel de Emergência) cerca de 30 mil chamados decorrentes de algum evento relacionado ao trauma $1,2,3$.

Cerca de $40 \%$ dos óbitos relacionados ao trauma são causados pela hemorragia ou suas consequências ${ }^{3}$.

$\mathrm{O}$ choque hemorrágico $(\mathrm{CH})$ representa a $2^{\mathrm{a}}$ maior mortalidade em pacientes traumatizados e é caracterizado pela inadequada perfusão e oferta de oxigênio aos tecidos, causado pela perda sanguínea ${ }^{4}$. A mortalidade está diretamente ligada à grande perda de sangue ou à falência múltipla de órgãos 5 . A severidade do $\mathrm{CH}$ está relacionada a 4 classes de hemorragia, representadas na tabela $1^{6}$.

\begin{tabular}{|c|c|c|c|c|}
\hline \multicolumn{5}{|l|}{ Classification of hemorrhage } \\
\hline \multirow[b]{2}{*}{ Parameter } & \multicolumn{4}{|c|}{ Class } \\
\hline & I & ॥ & III & IV \\
\hline Blood loss (ml) & $<750$ & $750-1500$ & $1500-2000$ & $>2000$ \\
\hline Blood loss (\%) & $<15 \%$ & $15-30 \%$ & $30-40 \%$ & $>40 \%$ \\
\hline Pulse rate (beats/min) & $<100$ & $>100$ & $>120$ & $>140$ \\
\hline Blood pressure & Normal & Decreased & Decreased & Decreased \\
\hline Respiratory rate (breaths/min) & $14-20$ & $20-30$ & $30-40$ & $>35$ \\
\hline Urine output (ml/hour) & $>30$ & $20-30$ & $5-15$ & Negligible \\
\hline CNS symptoms & Normal & Anxious & Confused & Lethargic \\
\hline
\end{tabular}

Tabela 1: Quadro retirado de uma publicação (sem modificações) com a classificação da hemorragia ${ }^{6}$. 
Durante o $\mathrm{CH}$, o aporte de oxigênio torna-se inadequado, portanto, mesmo com a ressuscitação hemodinâmica, o $\mathrm{CH}$ está relacionado a lesões por isquemia/reperfusão, resposta inflamatória sistêmica, entre outras complicações, causando sequelas no metabolismo de todo o organismo ${ }^{7}$. Logo após o insulto de $\mathrm{CH}$, ocorre uma diminuição do consumo de oxigênio e da produção de calor do organismo, fatos explicados pela redução de sangue circulante. Após este primeiro momento, a situação se inverte e observa-se um aumento do consumo de oxigênio e de energia e elevação da temperatura corpórea, em uma tentativa de compensar os efeitos anteriores. Caso a perda sanguínea não seja revertida e, portanto, torne-se fatal, a morte do indivíduo será caracterizada por uma diminuição progressiva da produção de calor e do consumo de oxigênio ${ }^{8}$. A resposta hemodinâmica decorrente da perda de sangue é individual e muito variável. A perda abrupta de $10 \%$ do volume sanguíneo pode reduzir em $7 \%$ a pressão arterial e $21 \%$ o débito cardíaco. Se a perda for de $20 \%$, a pressão reduz em $15 \%$ e o débito cardíaco em $41 \%{ }^{9}$.

$\mathrm{Na}$ ocorrência de uma hemorragia, ocorrem graves alterações hemodinâmicas e metabólicas, intensificando o desequilíbrio homeostático ${ }^{9}$. Em uma tentativa de restabelecimento das funções vitais, o organismo e seus mecanismos de defesa tentam controlar os efeitos da hipovolemia; entretanto, quando a perda de sangue for superior a $40 \%$, esses mecanismos compensatórios ficam prejudicados. No primeiro momento do $\mathrm{CH}$ ocorre a ativação das catecolaminas que buscam manter a perfusão tecidual através do aumento do débito cardíaco e pressão arterial sistólica e desviam o sangue para órgãos nobres, como coração e cérebro 6,9.

A resposta ao $\mathrm{CH}$ nos órgãos, além de individual e variável não tem uniformidade. A resposta renal, por exemplo, depende da velocidade com que a perda sanguínea acontece. Em uma situação de perda lenta, o rim tem a oportunidade de regular o fluxo sanguíneo para os glomérulos justamedulares 9,10 . 
As alterações metabólicas decorrentes do choque hipovolêmico levam a hipóxia, comprometem o consumo de energia gerando um estado hipermetabólico. Esse estado hipermetabólico aumenta o consumo de glicose nos músculos ${ }^{3,8}$. A falta de glicose para suprimir a gliconeogênese, sugere uma conexão entra a gliconeogênese e hipermetabolismo, intolerância à glicose e aumento na produção de ureia. Se o choque persistir, o armazenamento de glicogênio ficará depletado e os níveis de glicose serão mantidos pela gliconeogênese hormonal ${ }^{8}$.

Distúrbios hidroeletrolíticos importantes também são conseqüência de uma hemorragia severa. Um grande sangramento estimula a glândula suprarrenal, aumentando a produção de aldosterona e consequentemente aumentando a retenção de sódio e água, fazendo com que o organismo mantenha parcialmente controlada a volemia. Para também tentar manter a homeostasia, nas primeiras horas após a perda volêmica, existe uma maior secreção de vasopressina (hormônio anti-diurético) pela hipófise, e aumento da reabsorção de água, podendo levar o paciente a oligúria ${ }^{5,9}$.

Hostmann et al. mostraram que a apoptose tem importante papel na lesão causada pela hemorragia. Camundongos foram submetidos ao $\mathrm{CH}$ de pressão controlada (em torno de $35 \mathrm{mmHg}$ ) e mantida por 60 minutos. Os animais foram então ressuscitados com solução salina 0,9\% durante 30 minutos. A análise de tecido de baço nos animais submetidos ao choque, mostrou um aumento na expressão do BAX, uma proteína pró-apoptótica, e uma diminuição da proteína Célula B de Linfoma 2 (BCL-2), proteína anti-apoptótica ${ }^{11}$.

Uma das complicações importantes do $\mathrm{CH}$ é a injuria renal aguda (IRA), resultante da abrupta redução da volemia ${ }^{12}$. Na IRA isquêmica a interrupção do fluxo sanguíneo para as células resulta em hipóxia que imediatamente reduz os citocromos mitocondriais e interrompe a fosforilação oxidativa. Durante o processo isquêmico, a falta de oxigênio leva à degeneração e morte celular, evidenciados pela degradação e diminuição dos níveis de adenosina trifosfato (ATP). Esses eventos comprometem a função normal celular e interferem nos 
processos de recuperação. Nos rins, as células epiteliais edemaciadas contribuem para a obstrução da luz tubular. Como consequência da depleção de ATP ocorre ruptura e desorganização do citoesqueleto, associado com a perda da polaridade ${ }^{13,14}$.

Sabe-se que os rins são frequentemente acometidos na lesão múltipla de órgãos decorrentes de um processo hemorrágico severo. Entretanto os mecanismos moleculares envolvidos responsáveis pelas alterações renais derivados do choque ainda são desconhecidos. Um estudo demonstrou que os canais de água, as aquaporinas (AQPs), têm importante participação neste mecanismo 15. As AQPs 1, 2, 3 e 4 são conhecidas pela participação na reabsorção de água regulada pela vasopressina ${ }^{16}$. A AQP2 é o canal de água de membrana apical das células principais do ducto coletor e é o alvo principal da vasopressina na regulação da reabsorção de água de ducto coletor. As AQPs 3 e 4 são responsáveis pelo transporte de água através da membrana basolateral das células principais do ducto coletor ${ }^{17}$.

Gong e colaboradores submeteram ratos ao $\mathrm{CH}$ por 1 hora com pressão controlada entre $35-45 \mathrm{mmHg}$. O sangue retirado foi reinfundido e os animais eutanasiados após 2 dias. Observou-se aumento significativo dos níveis de creatinina e ureia plasmática e diminuição no clearance de creatinina em relação ao grupo Sham, caracterizando a IRA. Além da IRA, o $\mathrm{CH}$ pode estar associado com o déficit de concentração urinária, evidenciado pela diminuição da osmolalidade urinária e da reabsorção de água livre de soluto. Corroborando esses dados, observou-se a expressão diminuída da proteína AQP2, p-AQP2(Ser 256) e AQP3 no tecido renal ${ }^{15}$.

Apesar de a reposição volêmica ser capaz de restaurar a diurese do paciente com $\mathrm{CH}$ de forma eficaz, não significa que a função renal esteja preservada. Entretanto, a taxa de mortalidade é reduzida quando ocorre a insuficiência renal com a presença de fluxo urinário ${ }^{5,9}$.

Apesar de todas as suas consequências hemodinâmicas e metabólicas, se o $\mathrm{CH}$ for tratado com procedimento terapêutico eficaz e em tempo hábil, o 
paciente pode ter uma recuperação satisfatória. Entretanto, os pacientes sobreviventes podem estar sujeitos a complicações como necrose tubular aguda e síndrome da angustia respiratória que podem se tornar irreversíveis 9,12.

A ressuscitação é caracterizada pela interrupção da fonte de sangramento e restauração do volume sanguíneo circulante. Desde a II Guerra Mundial, o foco terapêutico era no restabelecimento rápido do volume de sangue e dos parâmetros hemodinâmicos. Entretanto, existem divergências com relação ao tempo de ressuscitação após a hemorragia. Além disso, algumas questões têm que ser levadas em consideração: o tipo e a quantidade de fluido a ser administrados, a velocidade de infusão e o tempo de terapia até a chegada do paciente ao hospital ${ }^{6}$.

$\mathrm{Na}$ escolha da estratégia terapêutica para o $\mathrm{CH}$, além de se avaliar a efetividade na restauração hemodinâmica, é importante considerar também os efeitos colaterais da terapêutica, sendo essencial a escolha da terapia que menos agrave os danos celulares causados pelo colapso circulatório e pela inflamação sistêmica. Atualmente não há consenso sobre a estratégia ideal de ressuscitação no $\mathrm{CH}$, mas é reconhecido que esta deve incluir a prevenção da parada cardíaca e da progressão para o choque refratário, tal como resgate do choque prolongado. Neste sentido, tanto a reposição volêmica com soluções cristalóides como a administração de drogas vasoconstritoras, como a terlipressina (TLP) são capazes de restabelecer a função hemodinâmica e evitar a morte por hemorragia ${ }^{18}$.

Os cristalóides são a primeira escolha na reposição volêmica inicial no resgate do $\mathrm{CH}$ e o Ringer lactato (RL) é o mais utilizado, considerando-se os aspectos relacionados ao seu baixo custo, poucos efeitos colaterais diretos e sua concentração de sódio que se assemelha a do plasma 9,19.

O RL, quando utilizado em sua forma isotônica, deve ser administrado em um volume cerca de três vezes maior que o da perda estimada para que seus efeitos benéficos iniciais não sejam apenas transitórios, uma vez que atravessam facilmente a barreira endotelial e tendem a se acumular em maior 
quantidade no interstício. Devido ao grande volume necessário para ressuscitação volêmica, o RL é preferível em relação à solução salina a 0,9\%, cujo uso em grandes volumes está relacionado à ocorrência de acidose metabólica hiperclorêmica 6,20,21. A administração deste elevado volume de RL permite a expansão volêmica significativa, restabelecimento dos parâmetros hemodinâmicos e prevenção da morte por colapso cardiovascular. Entretanto, a administração de $\mathrm{RL}$ no $\mathrm{CH}$ frequentemente é acompanhada de edema intersticial e hipoperfusão de órgãos como intestino, fígado, rins e pulmão. Outros efeitos colaterais associados ao uso de RL na ressuscitação do $\mathrm{CH}$ incluem a exacerbação da inflamação sistêmica e a redução dos fatores de coagulação. Os mediadores inflamatórios aumentam a permeabilidade vascular e, portanto, também contribuem para a saída de fluido do compartimento intravascular e aumento do edema intersticial 22,23,24,25,26,27. Outro fator preocupante na administração de RL é que a expansão do volume plasmático que a solução proporciona é de curta duração ${ }^{9}$.

Como mencionado anteriormente, o $\mathrm{CH}$ leva a disfunções no balanço de água e eletrólitos. Observou-se também que existe comprometimento da morfologia renal mesmo com a reposição volêmica de RL. Pesquisadores franceses submeteram camundongos ao $\mathrm{CH}$ controlado com PAM de $35 \mathrm{mmHg}$ mantida por 2 horas. O sangue retirado foi reinfundido e administrou-se RL. Os níveis de Cistatina C plasmática, marcador de função renal, estavam elevados após 60 minutos de $\mathrm{CH}$ e esse aumento foi gradativo até 120 minutos. No $2^{\circ}$ e $6^{\circ}$ dia os animais ainda apresentavam níveis elevados de Cistatina $C$, demonstrando um comprometimento da taxa de filtração glomerular (TFG). Na análise morfológica do tecido renal, foi observado aumento no escore de lesão 2 e 6 dias após o insulto ${ }^{28}$.

A fase precoce do $\mathrm{CH}$ é caracterizada por uma resposta vasoconstritora como tentativa de minimizar a perda sanguínea. Sem o devido resgate e tratamento adequado, a hemorragia pode levar a vasodilatação, que responderá insatisfatoriamente as estratégias convencionais de ressuscitação. A estratégia 
para o tratamento pré-hospitalar para pacientes com hemorragia deve consistir em manter a PAM adequada e a perfusão de órgãos controlada até a chegada ao hospital 29.

A otimização do tempo para se normalizar a pressão arterial em pacientes não responsivos ao tratamento convencional do $\mathrm{CH}$ é imprescindível na tentativa de se evitar complicações. Neste sentido, o uso de fármacos vasoativos é um importante fator a ser considerado ${ }^{30}$. Segundo Heckbert et al. e Zenati et al., episódios hipotensivos de 1 a 10 minutos, caracterizados por pressão arterial sistólica (PAS) inferior a $50 \mathrm{mmHg}$ no local do trauma ou menor que $70 \mathrm{mmHg}$ na unidade de terapia intensiva (UTI), resultam em uma taxa de mortalidade de $88 \%$ e $60 \%$, respectivamente 30,31 . Corroborando com esses achados, Chan et al. observaram que a hipotensão no local do trauma (PAS inferior a $90 \mathrm{mmHg}$ ) associada à pressão arterial adequada na UTI resulta em $20 \%$ de mortalidade, enquanto a pressão arterial adequada no local do trauma e na UTI resultou em apenas $2 \%$ de mortalidade 32 .

A TLP, um fármaco sintético análogo à vasopressina, é indicada na terapia do $\mathrm{CH}$ por desviar o fluxo sanguíneo da circulação esplâncnica em direção ao coração, pulmões e cérebro, resultando em redução significativa do sangramento $33,34,35$. Por ser a pró-droga da lisina vasopressina, a TLP possui efeito vasoativo mais longo que a vasopressina (vasopressina 6 minutos; TLP 6 horas). Além disso, a TLP apresenta maior seletividade para receptores de arginina vasopressina 1a (V1a), deixando seu efeito vasoativo mais potente e diminuindo a freqüência de efeitos colaterais cardiovasculares 36. A TLP determina diminuição importante no fluxo sanguíneo hepático e esplênico e no tratamento de hipotensão arterial associada à sepse. Segundo Morelli et al, o uso da TLP é mais vantajoso que a vasopressina em relação à estabilização hemodinâmica, à necessidade de se associar norepinefrina, e à diminuição de lesões hepáticas ${ }^{37}$. Estudos apontam que a TLP vem mostrando potenciais benefícios no choque séptico e na síndrome hepato-renal. Nos rins a TLP aumenta o fluxo sanguíneo renal (via receptor V1) e a taxa de filtração 
glomerular; além de melhorar o fluxo sanguíneo na medula renal e consequentemente na microcirculação intra-renal ${ }^{38}$.

Um estudo comparou os efeitos da administração de solução salina, RL e da TLP no CH. Ratos foram submetidos à laparotomia, onde foram retiradas partes do fígado para que se estabeleça a hemorragia. Observou-se que a TLP foi capaz de reestabelecer a PAM e ajudar no controle do sangramento abdominal ${ }^{39}$.

Compararam-se também os efeitos da vasopressina, TLP e RL em modelo experimental de choque hemorrágico não controlado. Foi observado que o tratamento com vasopressina e TLP aumentou a PAM, diminuiu a mortalidade, a lesão pulmonar, os níveis séricos de lactato e de citocinas inflamatórias e induziu elevação de citocinas anti-inflamatórias. Entretanto, a TLP manteve a PAM estável por mais tempo quando comparado ao tratamento com vasopressina e RL ${ }^{40}$.

É importante considerar que apesar da efetividade na restauração hemodinâmica proporcionada pelo RL e TLP no $\mathrm{CH}$, nenhuma estratégia terapêutica é livre de limitações, podendo haver efeitos benéficos em alguns órgãos, em detrimento do agravamento de lesões em outros sistemas. Atualmente, não são encontrados na literatura estudos que comparam os parâmetros renais após a ressuscitação do $\mathrm{CH}$ controlado com RL ou TLP isoladamente. Por estes motivos, estudos controlados em modelos experimentais são necessários para se identificar o melhor método de ressuscitação e seu efeito sobre as variáveis renais. Assim, nosso estudo se justifica pela necessidade de se conhecer os efeitos das terapias do $\mathrm{CH}$ sobre as variáveis renais, com o intuito de se identificar a melhor estratégia; ou seja, aquela que evite o agravamento das lesões renais causadas pelo $\mathrm{CH}$. 
OBJETIVOS 
Nosso estudo tem como objetivo avaliar os efeitos renais da ressuscitação com Ringer lactato ou terlipressina sobre a função renal em modelo experimental de $\mathrm{CH}$. Para isso, avaliamos:

1. Pressão arterial média (PAM);

2. Função renal medida pelo clearance de creatinina;

3. Perfusão tecidual periférica, através de $\mathrm{pH}$, bicarbonato, e lactato plasmáticos;

4. Dosagens plasmáticas e excreção urinária (UV) de sódio, potássio, magnésio, fósforo, cloro, creatinina e ureia;

5. Proteínas transportadoras de sódio e água;

6. Apoptose (medida pela expressão da proteína Bax);

7. Estresse oxidativo em tecido renal;

8. Lesão histopatológica 
MATERIAIS E MÉTODOS 
Este estudo foi realizado em conjunto ao estudo "Comparação dos efeitos da ressuscitação com Ringer lactato, solução salina hipertônica e terlipressina sobre a perfusão e oxigenação cerebral em modelo experimental de choque hemorrágico", (projeto FAPESP Auxílio regular nº 2011/00348-1 e bolsa de doutorado da aluna Keila Kazue Ida, n²011/14386-2) no Laboratório de Investigação Médica 08 (LIM-08) e Laboratório de Investigação Médica 12 (LIM12) da Faculdade de Medicina da Universidade de São Paulo (FMUSP), após aprovação pela Comissão de Ética e Pesquisa (CEP) do Hospital das Clínicas (HC) da FMUSP sob o protocolo número 067/11 e 280/13.

\section{ANIMAIS}

Foram utilizados 46 suínos fêmeas com peso entre 20 e $30 \mathrm{~kg}$ e idade entre 3 e 4 meses. Foi instituído jejum alimentar prévio de 12 horas com acesso livre à água e foi feito exame físico e laboratorial dos animais sendo excluídos os portadores de qualquer anomalia que comprometesse o estudo. Foram considerados critérios de exclusão: concentração de hemoglobina plasmática menor que $9 \mathrm{~g} / \mathrm{dL}$, valores anormais de gasometria no momento basal, sinais clínicos de infecção e deterioração hemodinâmica precoce (perda sanguínea < $500 \mathrm{~mL}$ associada à PAM $<60 \mathrm{mmHg}$ nos primeiros 10 minutos). Na eventualidade da presença de um dos critérios de exclusão, o animal teve a anestesia revertida e foi devolvido ao fornecedor. Um médico veterinário esteve responsável pelo cuidado dos animais desde a sua chegada ao laboratório até o final do experimento, em que os animais sobreviventes foram eutanasiados seguindo as normas atuais de uso de animais em laboratório de pesquisa. 


\section{PROCEDIMENTO ANESTÉSICO}

A técnica anestésica utilizada em todos os animais do estudo foi constituída por midazolam (Dormium - Cristália Produtos Químicos Farmacêuticos Ltda., Itapira/SP, Brasil) $(0,25 \mathrm{mg} / \mathrm{kg})$ e cetamina (Ketamin S+, Cristália Produtos Químicos Farmacêuticos Ltda., Itapira/SP, Brasil) (5 mg/kg) pela via intramuscular (IM) como medicação pré-anestésica e propofol (Propovan - Cristália Produtos Químicos Farmacêuticos Ltda., Itapira/SP, Brasil) (3,0 mg/ kg) pela via intravenosa (IV) para indução da anestesia, após se estabelecer o acesso venoso com um catéter 24G (Abbocath T plus - Abbott, São Paulo/SP, Brasil) introduzido na veia marginal da orelha. Após intubação orotraqueal, os animais foram posicionados em decúbito dorsal e ventilados mecanicamente (Premium - Drager, Alemanha) em modo volume-controlado com volume corrente de $8 \mathrm{~mL} / \mathrm{kg}$, frequência respiratória ajustada de modo a manter normocapnia. Para tanto, foi administrado pancurônio (Pancuron Cristália Produtos Químicos Farmacêuticos Ltda., Itapira/SP, Brasil) em bolus $(0,1 \mathrm{mg} / \mathrm{kg})$ seguido de infusão $(5 \mathrm{mcg} / \mathrm{kg} / \mathrm{min})$, a qual foi mantida durante o experimento por meio de bomba de infusão (ANNE - Abbott, São Paulo/SP, Brasil). O plano anestésico foi mantido com isofluorano vaporizado em fração inspirada de oxigênio de 0,4 .

\section{INSTRUMENTAÇÃO}

Uma vez que os animais estiveram em plano anestésico adequado, foi iniciada a instrumentação hemodinâmica, em que a veia jugular interna direita foi dissecada para introdução do catéter de artéria pulmonar de $110 \mathrm{~cm}$ de comprimento (7,5 F - Baxter Healthcare Corp. Irvine, EUA). O sistema transdutor-registrador foi preenchido com solução salina heparinizada e zerado à pressão atmosférica com o transdutor de pressão posicionado ao nível da 
linha axilar média. Uma vez observada curva característica de átrio direito (Monitor Philips Intellivue MP50, Alemanha) o balão foi insuflado com 1,5 mL de ar e a introdução do cateter prosseguiu, constatando-se sua passagem pelo ventrículo direito e tronco da artéria pulmonar por meio da verificação do traçado característico. Ao se observar alteração do traçado com "achatamento da curva", a pressão de oclusão da artéria pulmonar foi considerada e o catéter então fixado.

A artéria e veia femoral, preferencialmente do lado esquerdo, foram dissecadas e foi introduzida uma sonda uretral número 10 (Sonda uretral Embramed, São Paulo, Brasil) com a extremidade cortada para retirada do sangue e reposição volêmica. Ambos os procedimentos foram realizados sob técnica asséptica e após administração de $1 \mathrm{~g}$ de cefazolina IV.

$\mathrm{Na}$ artéria femoral do membro contra-lateral foi introduzido um catéter 5F (Pulsiocath PV 2015L20 - Dixtal Biomédica Ind. e Com. Ltda, São Paulo, Brasil) para obtenção da pressão arterial sistêmica, volume de sangue intratorácico e conteúdo extravascular de água pulmonar (Monitor Philips Intellivue MP50, Alemanha), sendo estes dois últimos por meio do método transpulmonar, utilizando-se catéter de artéria pulmonar (via proximal) para injeção de solução indicadora (solução glicosada $3^{\circ} \mathrm{C}$ ). Todos os catéteres foram mantidos desobstruídos por meio de uma solução heparinizada $(5 \mathrm{U} / \mathrm{mL}$ de heparina) administrada na taxa de $3 \mathrm{~mL} /$ hora.

Após instrumentação hemodinâmica sistêmica, os animais foram posicionados em decúbito ventral para introdução de um catéter epidural (Perisafe - BD, São Paulo/SP, Brasil) no espaço atlanto-occipital. Em seguida, foi realizada trepanação de um orifício no crânio no hemisfério direito, $10 \mathrm{~mm}$ lateralmente à linha média e $10 \mathrm{~mm}$ rostralmente à sutura coronariana, para introdução de um catéter cerebral intraparenquimal (Neurovent-PTO Raumedic AG, Alemanha). 


\section{PROCEDIMENTO EXPERIMENTAL}

Após a instrumentação cirúrgica do animal, foi instituído um período de 30 minutos para estabilidade paramétrica antes da coleta dos parâmetros basais. $\mathrm{O}$ protocolo de $\mathrm{CH}$ se iniciou com a retirada de sangue em bolsa de coleta de sangue (Baxter, São Paulo, SP, Brasil), na taxa de 50 a $70 \mathrm{~mL} / \mathrm{min}$, para alcançar uma PAM de 40 mmHg em 20 minutos, limitando-se à retirada de até $60 \%$ da volemia do animal (7\% do peso corporal). Ao se atingir a PAM de $40 \mathrm{mmHg}$, esta foi mantida durante 30 minutos por meio de reposição ou retirada de alíquotas de $60 \mathrm{~mL}$ de sangue. Em seguida, os animais foram randomizados em um dos grupos, exceto o grupo Sham, ao qual não foi instituído o procedimento de choque:

- Grupo Sham n=6: os animais neste grupo foram submetidos apenas ao procedimento cirúrgico, sem a indução do choque hemorrágico;

- Grupo Choque n=12: foi instituído o protocolo do $\mathrm{CH}$ nos animais, sem nenhum tipo de tratamento de ressuscitação;

- Grupo Ringer Lactato (RL) n=14: foi instituído o protocolo de $\mathrm{CH}$ e depois foi feita a reposição volêmica $(100 \mathrm{~mL} / \mathrm{min})$ utilizando $\mathrm{RL}$ em volume três vezes superior ao retirado para induzir o $\mathrm{CH}^{41}$.

- Grupo Terlipressina (TLP) n=14: foi instituído o protocolo de $\mathrm{CH}$ e depois feita a administração de TLP (Glypressin - Ferring Pharmaceuticals, São Paulo/SP, Brasil) em bolus de 2 mg ${ }^{42}$.

A aleatorização foi feita por meio de programa de computador (www.randomization.com) e as informações a respeito do grupo ficaram em envelopes fechados até o momento no qual foi iniciado o $\mathrm{CH}$, após a fase de 
instrumentação específica. Cada envelope foi numerado e foram abertos de maneira consecutiva. Os papeis dentro dos envelopes pardos foram colocados e lacrados por pessoa que não participa do estudo. O objetivo é garantir a alocação cega.

Ao final do experimento, os animais sobreviventes foram eutanasiados aos 60 ou 120 minutos e foram coletadas amostras de tecido renal para as avaliações bioquímicas, análise de western blotting e histologia. A eutanásia foi realizada seguindo-se as normas atuais de uso de animais em laboratório de pesquisa, por meio da administração IV de cloreto de potássio nos animais sob anestesia geral com isofluorano. (Figura 1).

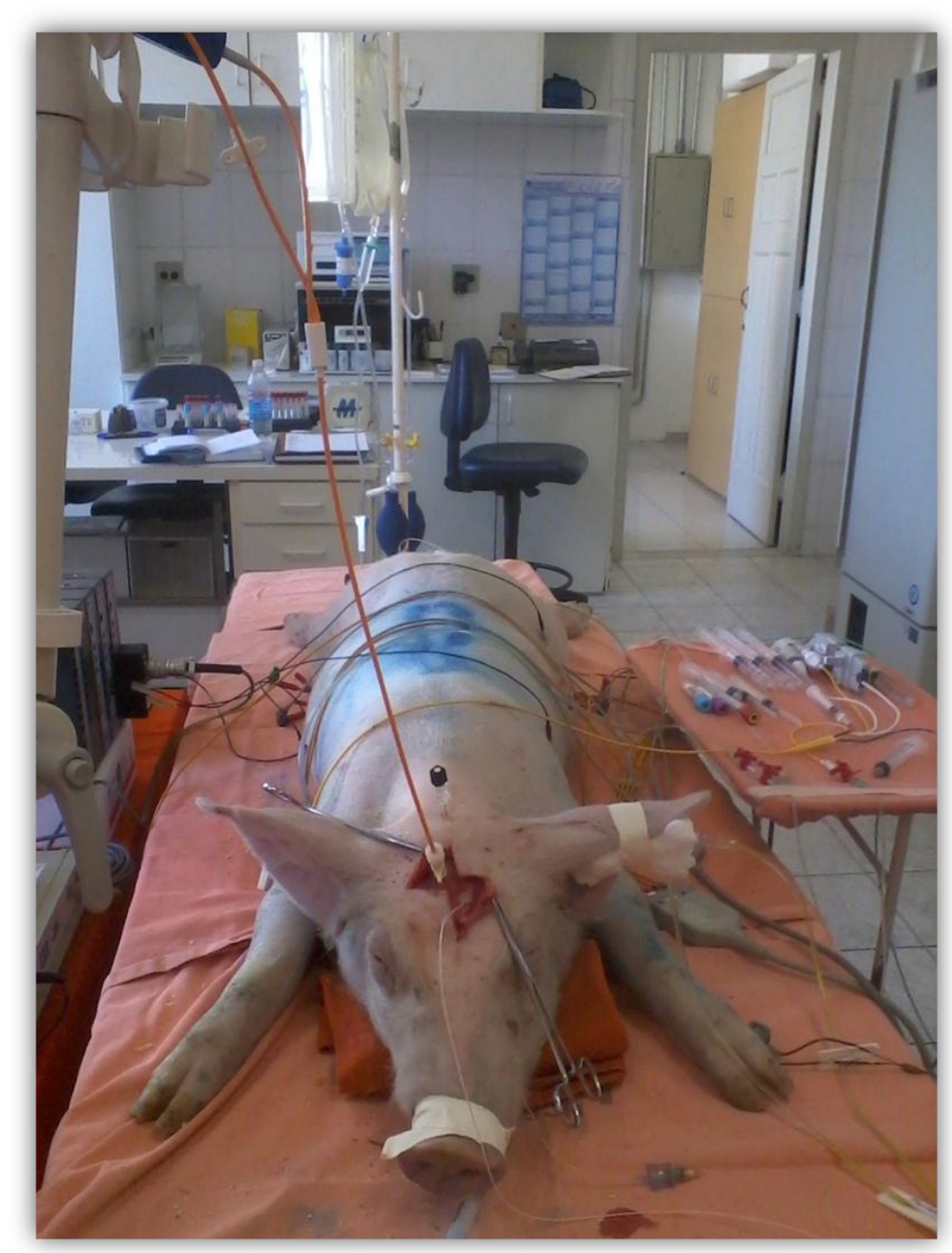

Figura 1 - Foto do porco no procedimento experimental, preparado do procedimento anestésico e estabilização. 


\section{MOMENTOS DE AVALIAÇÃO}

O estudo teve duração aproximada de 230 minutos, sendo 90 minutos iniciais para instrumentação do animal e estabilização da anestesia, 50 minutos para indução e manutenção do $\mathrm{CH}$ e 60 ou 120 minutos de avaliação do tratamento, conforme figura 2.

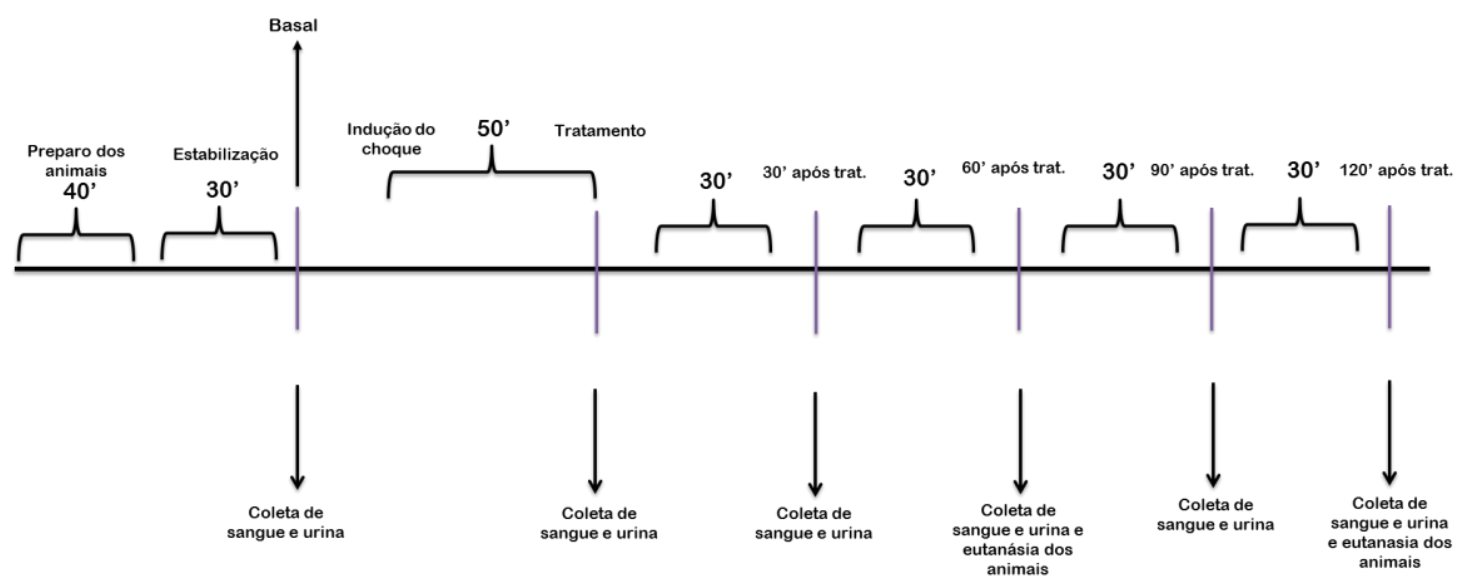

Figura 2 - Delineamento do experimento e momentos de coleta.

Os animais foram divididos em dois grupos para eutanásia e coleta de tecido: aos 60 e aos 120 minutos após tratamento. Após a coleta os tecidos foram guardados em ultrafreezer $-70^{\circ} \mathrm{C}$.

\section{ANÁLISES DE PLASMA E URINA}

Foram realizadas gasometria no sangue arterial e eletrólitos (sódio, potássio, magnésio, fósforo, cloro), creatinina e ureia no plasma e na urina. As amostras de sangue arterial foram coletadas da artéria femoral ao fim dos períodos, em seringas heparinizadas, sendo a agulha vedada para se evitar o contato do sangue com o ar ambiente. O exame de cada amostra foi realizado em analisador de pH e gases sanguíneos (Gasômetro ABL555 - Radiometer - 
Copenhagen). As concentrações de ureia foram dosadas por método cinético UV (Cobas C111 da Roche) e as de creatinina foram por Jaffé (Cobas C111 da Roche). Os eletrólitos foram dosados por eletrodo de íon seletivo no aparelho ABL800 Flex da Radiometer.

As amostras de urina foram coletadas ao fim de cada período para também dosagem dos eletrólitos citados, creatinina e ureia. A diurese dos animais foi medida e coletada ao fim de todos os tempos e os resultados foram demonstrados em $\mathrm{ml} / \mathrm{kg}$. A osmolalidade urinária foi medida através de osmômetro (Advanced Osmometer, modelo 3D3).

Os resultados foram demonstrados os valores de plasma e a UV dos parâmetros citados.

\section{ESTUDO DA EXTRAÇÃO DE PROTEÍNAS}

Os tecidos de medula renal congelados em $-70^{\circ} \mathrm{C}$, foram homogenados em uma solução de K-Hepes (200mM Mannitol, 80mM Hepes, 41mM KOH; pH 7.5) contendo inibidores de proteases (Cocktail Protease Inhibitor, Sigma Chemical Company, St. Louis, MO). Todo o procedimento foi feito no gelo. O homogenato foi então centrifugado a $4000 \mathrm{~g}$ por 30 minutos a $4^{\circ} \mathrm{C}$ para remoção das células e resíduos celulares. O sobrenadante foi coletado e armazenado em freezer $-70{ }^{\circ} \mathrm{C}$ para a análise das proteínas. A medida da concentração da proteína foi feita pelo método de Bradford (Bioagency).

As amostras de proteína foram submetidas à eletroforese em minigel de poliacrilamida $10 \%$ para AQP2, V1 e V2, 12\% para BAX e MnSOD, de 8\% para NKCC2. Após a transferência das proteínas para a membrana de PVDF (Amersham Hybond-P, GE Healthcare, UK), os blots foram tratados com leite em pó desnatado 5\% diluído em TBS-T por 1 hora e incubados com anticorpos específicos diluídos em TBS-T. A marcação foi feita através da peroxidase (HRP)-conjugated secondary antibody. A normatização foi feita 
com uma nova hibridização das membranas com o anticorpo para Actina. Os anticorpos utilizados foram:

AQP2 - Diluição para tecidos aos 60 minutos: 1:500 (Santa Cruz BiotechnologyInc, CA, EUA), anticorpo secundário anti-goat diluição 1:10000 (Sigma) com 0,1\% de leite desnatado e Actina 1:1000 (Santa Cruz BiotechnologyInc, CA, EUA); Diluição para tecidos aos 120 minutos 1:1000 (Santa Cruz BiotechnologyInc, CA, EUA), anticorpo secundário anti-goat diluição 1:10000 (Sigma) com 0,1\% de leite desnatado e Actina 1:1000 (Santa Cruz BiotechnologyInc, CA, EUA);

BAX - Diluição para tecidos aos 60 minutos: 1:500 (Santa Cruz BiotechnologyInc, CA, EUA), anticorpo secundário anti-mouse 1:2000 (Sigma) com 0,1\% de leite desnatado e Actina 1:5000 (Santa Cruz BiotechnologyInc, CA, EUA); Diluição para tecidos aos 120 minutos: 1:1000 (Santa Cruz BiotechnologyInc, CA, EUA), anticorpo secundário anti-mouse 1:2000 (Sigma) com 0,1\% de leite desnatado e Actina 1:2000 (Santa Cruz BiotechnologyInc, CA, EUA);

NKCC2 - Diluição para tecidos aos 60 minutos: 1:100 (Santa Cruz BiotechnologyInc, CA, EUA), anticorpo secundário anti-goat 1:2000 (Sigma) com 0,1\% de leite desnatado e Actina 1:2000 (Santa Cruz BiotechnologyInc, CA, EUA); Diluição para tecidos aos 120 minutos: 1:500 (Santa Cruz BiotechnologyInc, CA, EUA), anticorpo secundário anti-goat 1:10000 (Sigma) com 0,1\% de leite desnatado e Actina 1:2000 (Santa Cruz BiotechnologyInc, CA, EUA);

MnSOD - Diluição para tecidos aos 60 e 120 minutos: 1:2000 (Cayman Chemical), anticorpo secundário anti-rabbit 1:2000 (Sigma) com 0,1\% de leite desnatado e Actina 1:2000 (Santa Cruz BiotechnologyInc, CA, EUA);

V1 - Diluição para tecidos aos 60 e 120 minutos: 1:1000 (Santa Cruz BiotechnologyInc, CA, EUA), anticorpo secundário anti-goat 1:10000 (Sigma) 
com 0,1\% de leite desnatado e Actina 1:1000 (Santa Cruz BiotechnologyInc, CA, EUA);

V2 - Diluição para tecidos aos 60 e 120 minutos: 1:1000 (Santa Cruz BiotechnologyInc, CA, EUA), anticorpo secundário anti-goat 1:10000 (Sigma) com 0,1\% de leite desnatado e Actina 1:1000 (Santa Cruz BiotechnologyInc, CA, EUA);

As imagens dos blots foram obtidas usando-se sistema de quimioluminescência Amersham ECL Western Blotting Detection (GE Healthcare, UK) e foto documentação Alliance 4.2 (Uvitec, UK) e quantificadas com densitometria. As bandas obtidas foram analisadas por densitometria utilizando-se o programa Scion Image for Windows (IBM PC). As bandas foram normatizadas pela densitometria das bandas originadas pela hibridização da actina ${ }^{43}$.

\section{DOSAGEM DE ESTRESSE OXIDATIVO}

O estresse oxidativo foi avaliado determinando os níveis no tecido de córtex renal de TBARS (thiobarbituric acid reactive substances), um marcador da peroxidação lipídica, através do ensaio do ácido tiobarbitúrico. O ácido tiobarbitúrico reage com lipídios oxidados, gerando malondialdeído.

Uma alíquota de $0,2 \mathrm{ml}$ de solução protéica extraído de córtex renal (o método de extração é o mesmo usado na extração de proteínas para Western Blott) foi diluída em $0,8 \mathrm{ml}$ de água destilada. Após, $1 \mathrm{ml}$ de ácido tricloroacético (ATC) 17,5\% e $1 \mathrm{ml}$ de ácido tiobarbitúrico, $\mathrm{pH}$ 2, foram adicionados. As amostras foram levadas a $80^{\circ} \mathrm{C}$ por 20 minutos e a seguir, colocadas em gelo. Um mililitro de ATC 70\% foi adicionado e, posteriormente, a mistura incubada por 20 minutos. As amostras foram centrifugadas a $2000 \mathrm{rpm}$, por 15 minutos. A densidade ótica do sobrenadante foi lida a $534 \mathrm{~nm}$ contra um 
reagente "blank" em espectofotômetro. Os níveis teciduais de TBARS estão expressos como nmol/prot/ $\mathrm{mL}^{44}$.

\section{ANÁLISE HISTOLÓGICA - ESCORE DE LESÃO TECIDUAL RENAL}

As amostras de tecidos de córtex renal foram desidratadas, diafanizadas e incluídas em parafina. Após inclusão em parafina, obtiveram-se cortes de 4 $\mu \mathrm{m}$, que foram corados pela reação de hematoxilina-eosina (HE) para avaliação das lesões renais.

Para avaliação da extensão das áreas acometidas por lesões renais, entre 40 a 60 campos medindo $0,245 \mathrm{~mm}^{2}$ foram sequencialmente analisados. Cada campo foi avaliado através de scores que variavam de 0 a 4 , de acordo com o seguinte critério: 0 , menos do que $5 \%$ da área apresentando edema celular, degeneração vacuolar, necrose e descamação; I, entre 5-25\% da área com comprometimento; II, 25-50\% da área apresentando lesões renais; III, alterações envolvendo entre $50-75 \%$ do campo analisado; IV, mais do que $75 \%$ da área analisada apresentando lesões renais. Em seguida, um escore médio para cada porco foi calculado ${ }^{45}$.

\section{ANÁLISE ESTATÍSTICA}

Os resultados obtidos foram avaliados estatisticamente por meio de provas paramétricas empregando-se análise de variância (ANOVA) para medidas repetidas seguida do teste de Newman-Keuls para comparação dos diferentes momentos de avaliação dentro de um mesmo grupo. Na mortalidade foi utilizada a curva Kaplan-Meier O grau de significância estabelecido para 
análise estatística foi menor que $5 \%(p<0,05)$. Os dados são apresentados com Média \pm erro padrão. 
RESULTADOS 


\section{Mortalidade}

Na tabela 2, abaixo, segue o número de animais em cada período por grupo. Aos 60 minutos foi feito eutanásia de 4 animais no grupo Sham, 3 animais no grupo Choque, 5 animais no grupo RL e 5 animais no grupo TLP (Tabela2).

\begin{tabular}{|l|l|l|l|l|l|l|}
\hline & Basal & Choque & 30' pós trat & 60' pós trat & 90' pós trat & 120' pós trat \\
\hline Sham & N=6 & N=6 & N=6 & N=6 & N=2 & N=2 \\
\hline Choque & N=12 & N=12 & N=10 & N=6 & N=3 & N=3 \\
\hline RL & $\mathrm{N}=15$ & N=15 & N=14 & N=13 & N=9 & N=9 \\
\hline TLP & N=14 & N=14 & N=14 & N=14 & N=8 & N=8 \\
\hline
\end{tabular}

Tabela 2 - Quantidade de animais utilizados no experimento em seus respectivos tempos.

Nos animais que foram eutanasiados aos 120 minutos, não observamos óbitos no grupo Sham, nem no grupo RL. Apenas um animal veio a óbito no grupo tratado com TLP, porém sem significância estatística. A mortalidade do grupo $\mathrm{CH}$ foi maior em comparação aos tratados, o que já era o esperado, pois os animais não receberam nenhum tipo de ressuscitação (Figura 3).

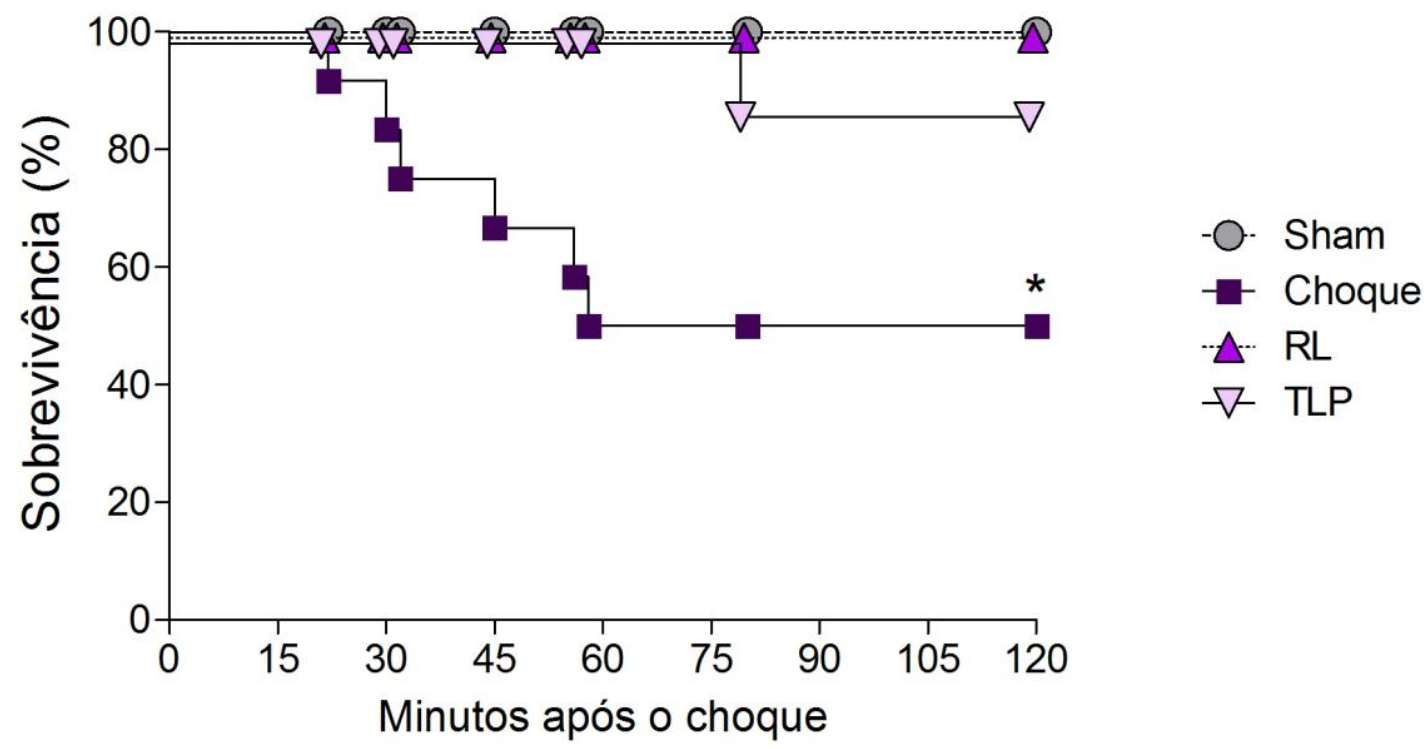

Figura 3 - Sobrevivência (\%) aos 120 minutos após choque hemorrágico, utilizando a curva Kaplan-Meier. Os animais tratados com RL e TLP após o CH foram comparados aos não-tratados (grupo Choque) e ao grupo Sham, que não foi submetido ao $\mathrm{CH}$. *difere significativamente do grupo Sham $(\mathrm{p}=0.0007)$. 


\section{Pressão arterial média $(\mathrm{mmHg})$}

Observamos como já esperado, uma diminuição da PAM nos animais submetidos ao $\mathrm{CH}$. Houve restabelecimento parcial da PAM nos dois grupos tratados até os 30 minutos. Embora estatisticamente significante em relação ao grupo Choque, a PAM nos grupos RL e TLP permaneceu significantemente menor em relação ao grupo Sham (Tabela 3 e figura 4).

\begin{tabular}{lllllll}
\hline PAM & Basal & Choque & $\mathbf{3 0}^{\prime}$ após trat & $\mathbf{6 0}^{\prime}$ após trat & $\mathbf{9 0}^{\prime}$ após trat & $\mathbf{1 2 0}^{\prime}$ após trat \\
\hline Sham & $70,5 \pm 2,4$ & $77,0 \pm 3,7$ & $75,5 \pm 3,1$ & $72,5 \pm 2,3$ & $72 \pm 4,0$ & $71 \pm 1,0$ \\
Choque & $72,9 \pm 2,8$ & $40,0 \pm 1,1^{* * *}$ & $39,9 \pm 2,4^{* * *}$ & $48,7 \pm 4,0^{* *}$ & $47 \pm 9,8$ & $43,3 \pm 8,6^{*}$ \\
RL & $73,6 \pm 1,2$ & $42,8 \pm 1,3^{* * *}$ & $60 \pm 2,5^{* *},+++$ & $58 \pm 2,6^{*}$ & $54,8 \pm 1,7$ & $52,9 \pm 2,2$ \\
TLP & $70,8 \pm 1,4$ & $41,5 \pm 1,0^{* * *}$ & $64,2 \pm 2,2^{* *},+++$ & $60,1 \pm 3,4^{*}$ & $60,9 \pm 4,2$ & $56,9 \pm 3,7$ \\
\hline
\end{tabular}

Tabela 3 - Medidas de PAM nos períodos basal (em torno de 50 minutos de estabilização após a preparação cirúrgica do animal); choque (50 minutos de indução e manutenção do choque - 40mmHg); 30 , 60, 90 e 120 minutos após tratamento nos grupos RL (Ringer Lactato, 3x o volume de sangue retirado), e TLP (Terlipressina, 2mg EV) e nos grupos não tratados Sham e Choque. ${ }^{* *} p<0.001$ vs Sham; ** $p<0.01$ vs Sham; * $\mathrm{p}<0.05$ vs Sham; $+++\mathrm{p}<0.05$ vs Choque.
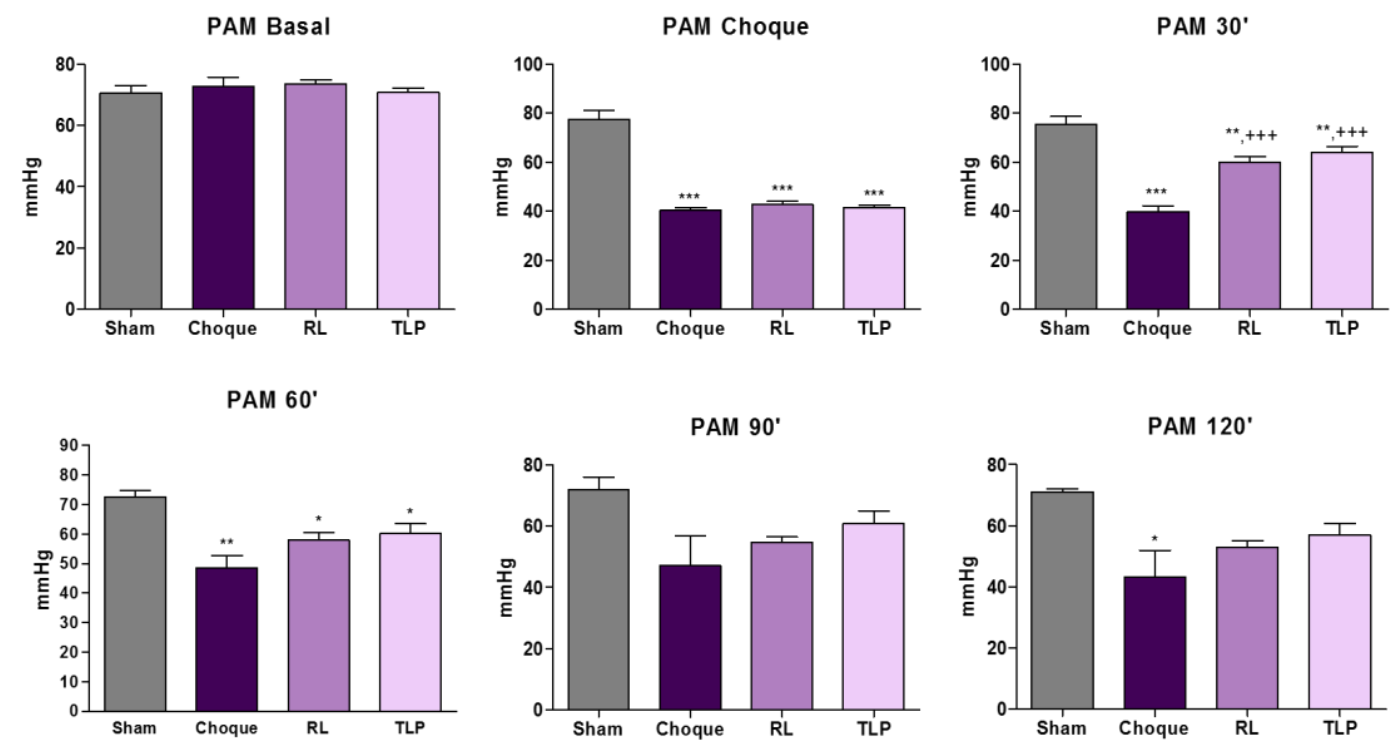

Figura 4 - Gráficos representando as medidas de PAM nos períodos basal (em torno de 50 minutos de estabilização após a preparação cirúrgica do animal); choque (50 minutos de indução e manutenção do choque -40mmHg); 30, 60, 90 e 120 minutos após tratamento nos grupos RL (Ringer Lactato, 3x o volume de sangue retirado), e TLP (Terlipressina, $2 \mathrm{mg}$ EV) e nos grupos não tratados Sham e Choque. ${ }^{* * *} \mathrm{p}<0.001$ vs Sham; ${ }^{* *} p<0.01$ vs Sham; ${ }^{*}<0.05$ vs Sham; $+++p<0.05$ vs Choque. 


\section{Hemoglobina (g/dL)}

Observamos uma queda importante da concentração de hemoglobina nos animais tratados com RL em todos os tempos pós tratamento. Nos outros grupos não houve diferença significativa (Tabela 4 e figura 5).

\begin{tabular}{lllllll}
\hline Hb & Basal & Choque & $\mathbf{3 0}^{\prime}$ após trat & $\mathbf{6 0}^{\prime}$ após trat & $\mathbf{9 0}^{\prime}$ após trat & $\mathbf{1 2 0}^{\prime}$ após trat \\
\hline Sham & $8,8 \pm 0,3$ & $8,9 \pm 0,3$ & $8,8 \pm 0,3$ & $8,9 \pm 0,3$ & $8,3 \pm 0,4$ & $7,4 \pm 0,00$ \\
Choque & $8,9 \pm 0,2$ & $8,5 \pm 0,3$ & $7,7 \pm 0,3$ & $7,9 \pm 0,3$ & $8,4 \pm 0,6$ & $7,4 \pm 0,0$ \\
RL & $8,6 \pm 0,2$ & $8,6 \pm 0,2$ & $5,6 \pm 0,3^{* * *,+++, \Delta \Delta \Delta}$ & $5,8 \pm 0,3^{* * *++++, \Delta \Delta \Delta}$ & $5,7 \pm 0,4^{*,++, \Delta \Delta}$ & $5,8 \pm 0,4^{\Delta}$ \\
TLP & $8,5 \pm 0,2$ & $8,02 \pm 0,3$ & $7,8 \pm 0,3$ & $7,7 \pm 0,3$ & $7,6 \pm 0,3$ & $7,5 \pm 0,4$ \\
\hline
\end{tabular}

Tabela 4 - Medidas de hemoglobina nos períodos basal (em torno de 50 minutos de estabilização após a preparação cirúrgica do animal); choque (50 minutos de indução e manutenção do choque - $40 \mathrm{mmHg}$ ); 30 , 60, 90 e 120 minutos após tratamento nos grupos RL (Ringer Lactato, 3x o volume de sangue retirado), e TLP (Terlipressina, $2 \mathrm{mg}$ EV) e nos grupos não tratados Sham e Choque. ${ }^{*} \mathrm{p}<0.05$ vs Sham; ${ }^{* * *} \mathrm{p}<0.001$ vs Sham; $++\mathrm{p}<0.001$ vs Choque $+++\mathrm{p}<0.001$ vs Choque; ${ }^{\Delta} \mathrm{p}<0.01$ vs TLP; ${ }^{\circ} \mathrm{p}<0.05$ vs TLP; $\Delta \Delta \Delta \mathrm{p}<0.001$ vs TLP.
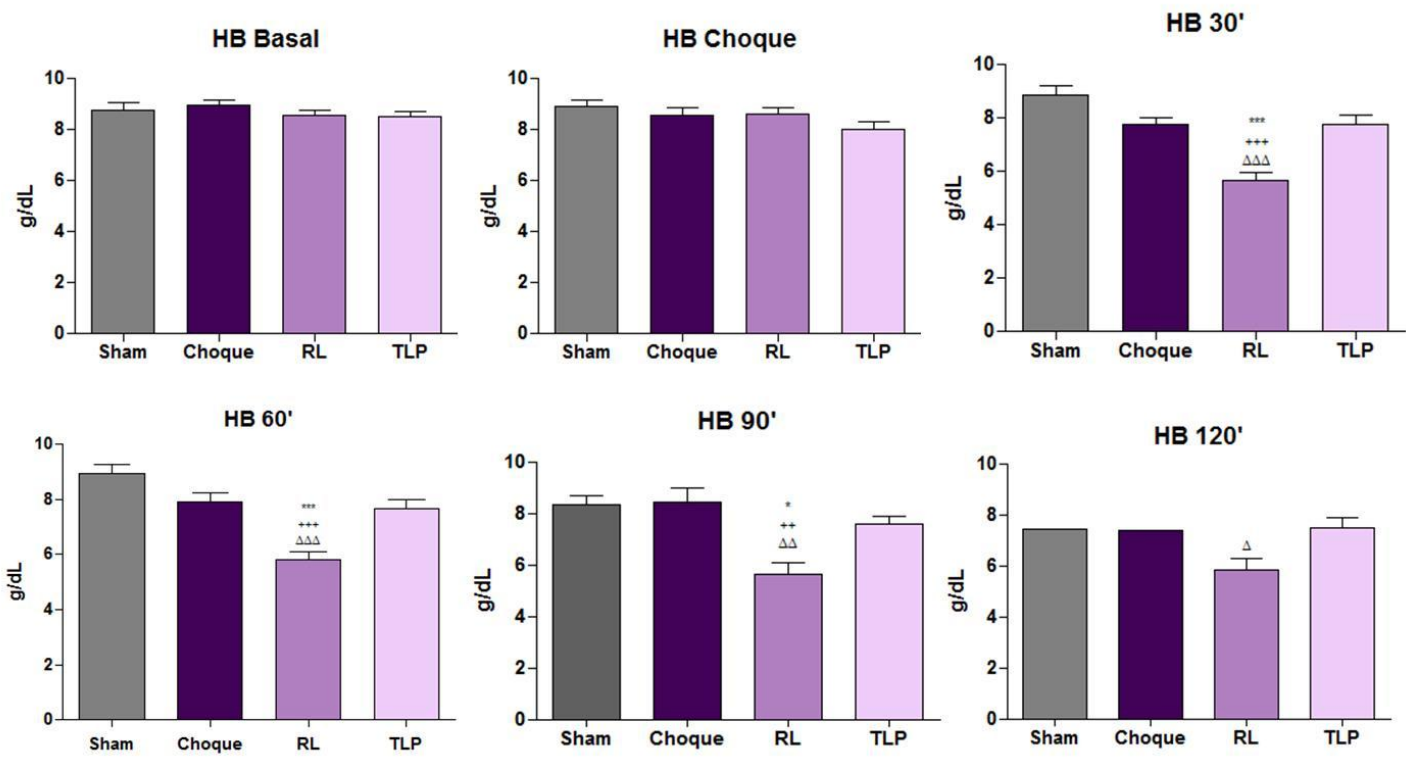

Figura 5 - Gráficos representando as medidas de hemoglobina nos períodos basal (em torno de 50 minutos de estabilização após a preparação cirúrgica do animal); choque (50 minutos de indução e manutenção do choque -40mmHg); 30, 60, 90 e 120 minutos após tratamento nos grupos RL (Ringer Lactato, 3x o volume de sangue retirado), e TLP (Terlipressina, $2 \mathrm{mg}$ EV) e nos grupos não tratados Sham e Choque. * $\mathrm{p}<0.05$ vs Sham; ${ }^{* *} \mathrm{p}<0.001$ vs Sham; $++\mathrm{p}<0.001$ vs Choque $+++\mathrm{p}<0.001$ vs Choque; ${ }^{\Delta \Delta} \mathrm{p}<0.01$ vs TLP; ${ }^{\Delta} \mathrm{p}<0.05$ vs TLP; ${ }^{\Delta \Delta \Delta} \mathrm{p}<0.001$ vs TLP. 


\section{Dosagem de $\mathrm{pH}$}

Houve importante queda do $\mathrm{pH}$ no grupo de animais submetidos ao $\mathrm{CH}$ sem tratamento. Apenas o tratamento com RL restabeleceu os níveis de $\mathrm{pH}$ aos parâmetros semelhantes aos do Sham. Importante ressaltar que o grupo TLP manteve o $\mathrm{pH}$ baixo (Tabela 5 e figura 6).

\begin{tabular}{lllllll}
\hline pH & Basal & Choque & $\mathbf{3 0}^{\prime}$ após trat & $\mathbf{6 0}^{\prime}$ após trat & $\mathbf{9 0}^{\prime}$ após trat & $\mathbf{1 2 0}^{\prime}$ após trat \\
\hline Sham & $7,4 \pm 0,01$ & $7,4 \pm 0,01$ & $7,4 \pm 0,00$ & $7,4 \pm 0,01$ & $7,4 \pm 0,00$ & $7,4 \pm 0,00$ \\
Choque & $7,4 \pm 0,01$ & $7,3 \pm 0,01^{*}$ & $7,3 \pm 0,04^{* *}$ & $7,2 \pm 0,04^{* *}$ & $7,4 \pm 0,01$ & $7,4 \pm 0,02$ \\
RL & $7,4 \pm 0,00$ & $7,3 \pm 0,02^{* *}$ & $7,3 \pm 0,02^{*}$ & $7,4 \pm 0,02^{*}$ & $7,4 \pm 0,02$ & $7,4 \pm 0,02$ \\
TLP & $7,4 \pm 0,01$ & $7,3 \pm 0,01^{* *}$ & $7,3 \pm 0,02^{*}$ & $7,3 \pm 0,02^{* *}$ & $7,3 \pm 0,02^{*}$ & $7,3 \pm 0,02^{*} \cdot$ \\
\hline
\end{tabular}

Tabela 5 - Dosagem de pH plasmático nos períodos basal (em torno de 50 minutos de estabilização após a preparação cirúrgica do animal); choque (50 minutos de indução e manutenção do choque - 40mmHg); 30 , 60, 90 e 120 minutos após tratamento nos grupos RL (Ringer Lactato, 3x o volume de sangue retirado), e TLP (Terlipressina, $2 \mathrm{mg}$ EV) e nos grupos não tratados Sham e Choque. * $\mathrm{p}<0.05$ vs Sham; ${ }^{* *} \mathrm{p}<0.01$ vs Sham; + $\mathrm{p}<0.05$ vs Choque; $\bullet \mathrm{p}<0.05$ vs RL.
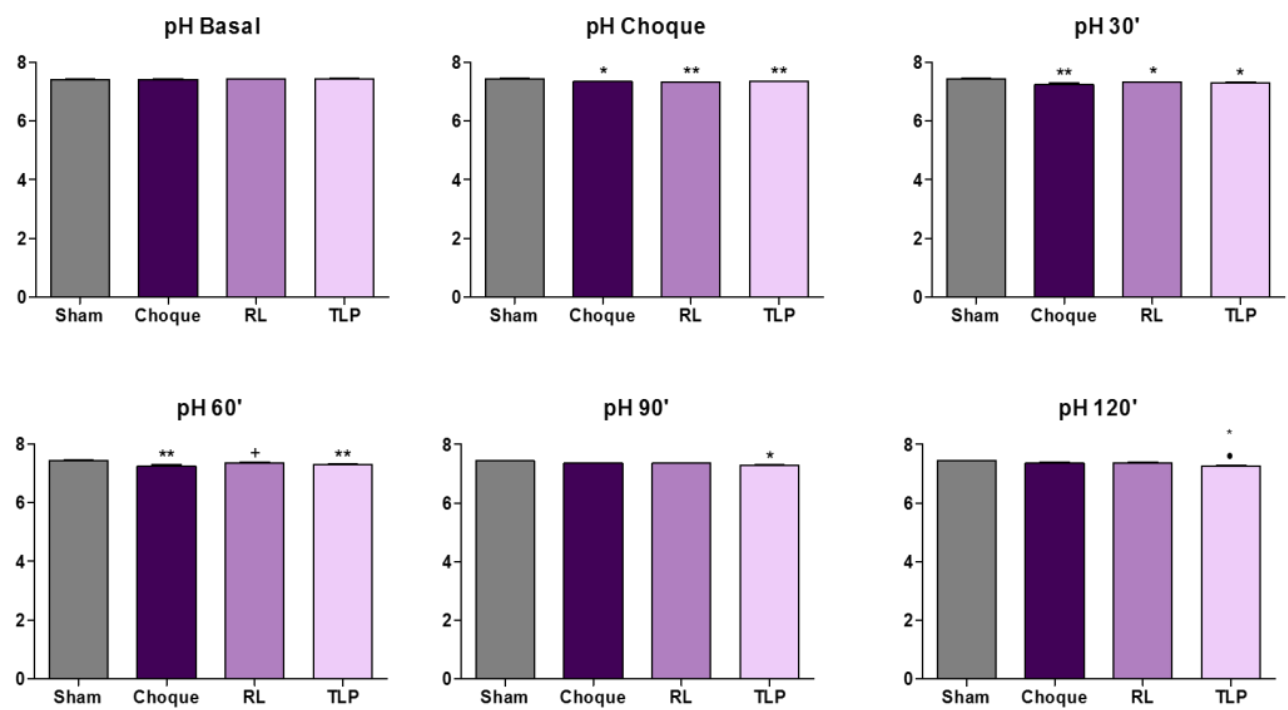

Figura 6 - Gráficos representando as medidas de $\mathrm{pH}$ nos períodos basal (em torno de 50 minutos de estabilização após a preparação cirúrgica do animal); choque (50 minutos de indução e manutenção do choque - 40mmHg); 30, 60, 90 e 120 minutos após tratamento nos grupos RL (Ringer Lactato, 3x o volume de sangue retirado), e TLP (Terlipressina, $2 \mathrm{mg}$ EV) e nos grupos não tratados Sham e Choque. ${ }^{*} \mathrm{p}<0.05 \mathrm{vs}$ Sham; ** $\mathrm{p}<0.01$ vs Sham; $+\mathrm{p}<0.05$ vs Choque; $\bullet \mathrm{p}<0.05$ vs RL. 


\section{Bicarbonato (mEq/L)}

Houve uma diminuição significativa nos níveis de bicarbonato após o insulto de $\mathrm{CH}$. O grupo tratado com TLP demostrou uma tendência a apresentar menores níveis de bicarbonato em todos os tempos (Tabela 6 e figura 7).

\begin{tabular}{lllllll}
\hline Bic & Basal & Choque & $\mathbf{3 0}^{\prime}$ após trat & $\mathbf{6 0}^{\prime}$ após trat & $\mathbf{9 0}^{\prime}$ após trat & $\mathbf{1 2 0}^{\prime}$ após trat \\
\hline Sham & $26,5 \pm 0,8$ & $26,7 \pm 0,7$ & $26,9 \pm 0,9$ & $27,4 \pm 0,7$ & $27,3 \pm 1,4$ & $27,4 \pm 0,8$ \\
Choque & $26 \pm 0,7$ & $21,6 \pm 1,3^{*}$ & $17,9 \pm 2,1^{* *}$ & $18,1 \pm 2,4^{* *}$ & $24,5 \pm 1,8$ & $22,8 \pm 1,4$ \\
RL & $26,0 \pm 0,5$ & $18,7 \pm 0,8^{* * *},+$ & $19,2 \pm 0,8^{* *}$ & $21,5 \pm 0,8^{*}$ & $20,9 \pm 1,2$ & $22,2 \pm 1,1$ \\
TLP & $28,0 \pm 0,6$ & $22,8 \pm 1,1^{* * *}$ & $20,6 \pm 0,9^{* *}$ & $19,8 \pm 1,2^{* *}$ & $19,9 \pm 1,1$ & $19,1 \pm 1,4^{*}$ \\
\hline
\end{tabular}

Tabela 6 - Dosagem de bicarbonato plasmático nos períodos basal (em torno de 50 minutos de estabilização após a preparação cirúrgica do animal); choque (50 minutos de indução e manutenção do choque -40mmHg); 30, 60, 90 e 120 minutos após tratamento nos grupos RL (Ringer Lactato, 3x o volume de sangue retirado), e TLP (Terlipressina, $2 \mathrm{mg}$ EV) e nos grupos não tratados Sham e Choque. * $\mathrm{p}<0.05$ vs Sham; ${ }^{* *} \mathrm{p}<0.01$ vs Sham; ${ }^{* * *} \mathrm{p}<0.001$ vs Sham; $+\mathrm{p}<0.05$ vs Choque; $\bullet \mathrm{p}<0.05$ vs RL.
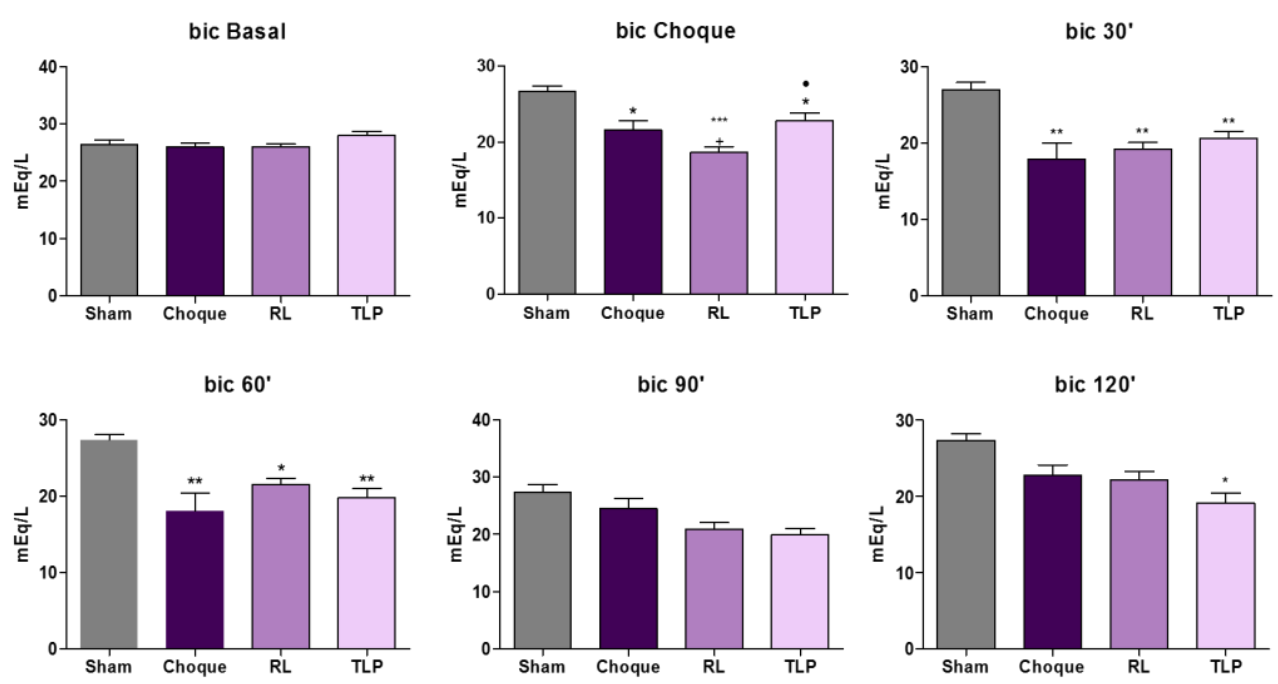

Figura 7 - Gráficos representando as medidas de bicarbonato nos períodos basal (em torno de 50 minutos de estabilização após a preparação cirúrgica do animal); choque (50 minutos de indução e manutenção do choque - 40mmHg); 30, 60, 90 e 120 minutos após tratamento nos grupos RL (Ringer Lactato, 3x o volume de sangue retirado), e TLP (Terlipressina, $2 \mathrm{mg}$ EV) e nos grupos não tratados Sham e Choque. ${ }^{*} \mathrm{p}<0.05$ vs Sham; ${ }^{* *} \mathrm{p}<0.01$ vs Sham; ${ }^{* * *} \mathrm{p}<0.001$ vs Sham; $+\mathrm{p}<0.05$ vs Choque; $\bullet \mathrm{p}<0.05$ vs RL. 


\section{Lactato (mmol/L)}

Observamos concentrações aumentadas de lactato em todos os animais submetidos ao $\mathrm{CH}$, tanto tratados como não tratados; entretanto no grupo tratado com TLP, esse aumento foi mais acentuado (Tabela 7 e figura 8).

\begin{tabular}{lcccccc}
\hline Lac & Basal & Choque & $\mathbf{3 0}^{\prime}$ após trat & $\mathbf{6 0}^{\prime}$ após trat & $\mathbf{9 0}^{\prime}$ após trat & $\mathbf{1 2 0}^{\prime}$ após trat \\
\hline Sham & $1,4 \pm 0,1$ & $1,4 \pm 0,1$ & $1,2 \pm 0,1$ & $1,2 \pm 0,2$ & $1,1 \pm 0,1$ & $1,2 \pm 0,1$ \\
Choque & $1,3 \pm 0,2$ & $4,2 \pm 0,7^{*}$ & $6,3 \pm 1,2^{* *}$ & $4,7 \pm 1,5$ & $4,1 \pm 1,4$ & $4,7 \pm 1,9$ \\
RL & $1,6 \pm 0,1$ & $6,1 \pm 0,6^{* *}$ & $5,9 \pm 0,7^{* *}$ & $4,9 \pm 0,7$ & $4,4 \pm 0,9$ & $3,9 \pm 0,9$ \\
TLP & $1,7 \pm 0,2$ & $5,6 \pm 0,7^{* *}$ & $7,1 \pm 0,9^{* *}$ & $7,9 \pm 1,0^{* * *}$ & $7,3 \pm 1,2$ & $7,6 \pm 1,4$ \\
\hline
\end{tabular}

Tabela 7 - Dosagem de lactato plasmático nos períodos basal (em torno de 50 minutos de estabilização após a preparação cirúrgica do animal); choque (50 minutos de indução e manutenção do choque 40mmHg); 30, 60, 90 e 120 minutos após tratamento nos grupos RL (Ringer Lactato, 3x o volume de sangue retirado), e TLP (Terlipressina, $2 \mathrm{mg}$ EV) e nos grupos não tratados Sham e Choque. * $\mathrm{p}<0.05$ vs Sham; ** $\mathrm{p}<0.01$ vs Sham; ${ }^{* * *} \mathrm{p}<0.001$ vs Sham.
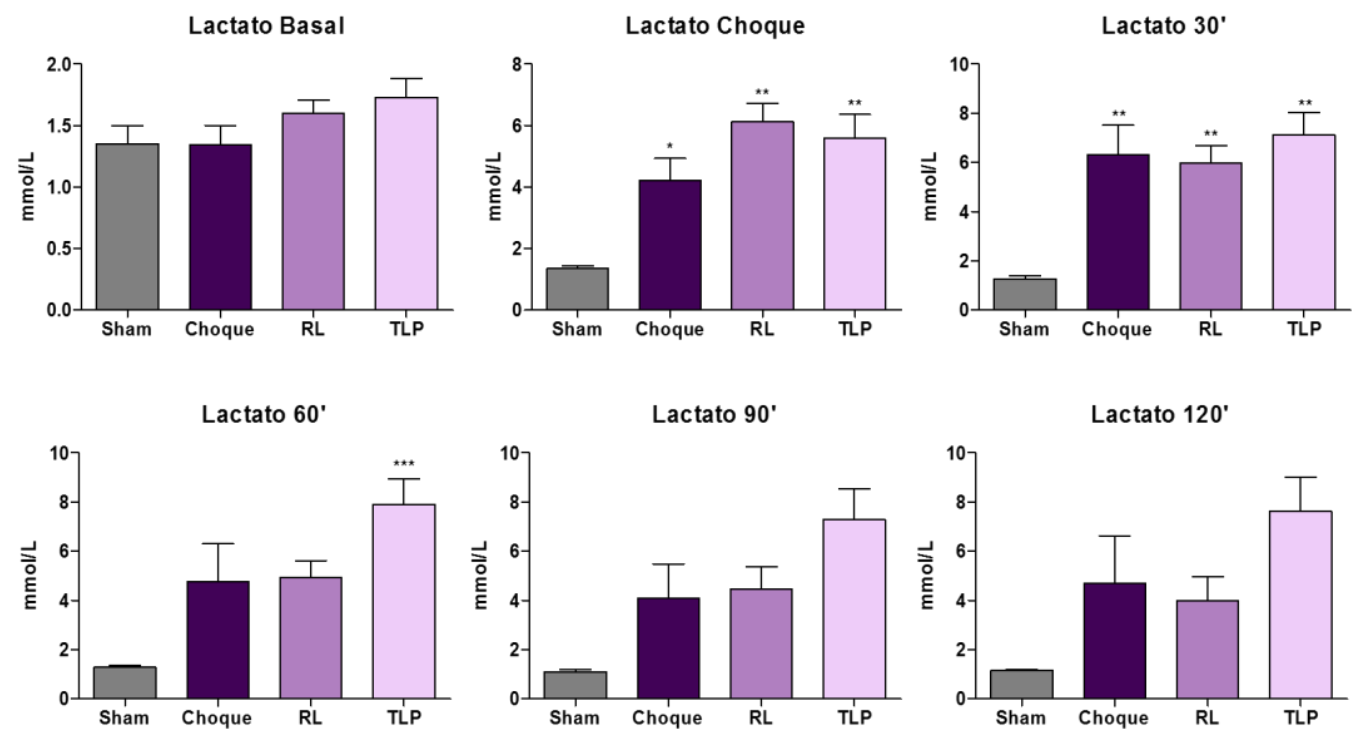

Figura 8 - Gráficos representando as medidas de lactato nos períodos basal (em torno de 50 minutos de estabilização após a preparação cirúrgica do animal); choque (50 minutos de indução e manutenção do choque - 40mmHg); 30, 60, 90 e 120 minutos após tratamento nos grupos RL (Ringer Lactato, 3x o volume de sangue retirado), e TLP (Terlipressina, $2 \mathrm{mg}$ EV) e nos grupos não tratados Sham e Choque. ${ }^{*} \mathrm{p}<0.05$ vs Sham; ${ }^{* *} \mathrm{p}<0.01$ vs Sham; ${ }^{* * *} \mathrm{p}<0.001$ vs Sham. 


\section{Creatinina plasmática $(\mathrm{mg} / \mathrm{dL})$}

Observamos aumento da creatinina plasmática após o insulto do $\mathrm{CH}$. Após os tratamentos, tanto no grupo RL como no grupo TLP, a concentração de creatinina foi parcialmente normalizada (Tabela 8 e figura 9).

\begin{tabular}{lllllll}
\hline Creat & Basal & Choque & $\mathbf{3 0}^{\prime}$ após trat & $\mathbf{6 0}^{\prime}$ após trat & $\mathbf{9 0}^{\prime}$ após trat & $\mathbf{1 2 0}^{\prime}$ após trat \\
\hline Sham & $0,8 \pm 0,1$ & $0,8 \pm 0,1$ & $0,8 \pm 0,1$ & $0,8 \pm 0,1$ & $0,8 \pm 0,1$ & $0,6 \pm 0,0$ \\
Choque & $0,9 \pm 0,1$ & $1,3 \pm 0,1^{* *}$ & $1,5 \pm 0,1^{* *}$ & $1,5 \pm 0,1^{* *}$ & $1,8 \pm 0,0$ & $2,1 \pm 0,0$ \\
RL & $0,9 \pm 0,0$ & $1,2 \pm 0,1^{* *}$ & $0,8 \pm 0,1^{+++}$ & $1 \pm 0,1^{++}$ & $1,2 \pm 0,1$ & $1,2 \pm 0,1$ \\
TLP & $0.9 \pm 0.1$ & $1.2 \pm 0.1^{* *}$ & $1.3 \pm 0.1^{*}, \bullet^{*},+$ & $1.3 \pm 0.1^{* *}, \bullet$ & $1.3 \pm 0.2$ & $1.3 \pm 0.2$
\end{tabular}

Tabela 8 - Dosagem de creatinina plasmático nos períodos basal (em torno de 50 minutos de estabilização após a preparação cirúrgica do animal); choque (50 minutos de indução e manutenção do choque 40mmHg); 30, 60, 90 e 120 minutos após tratamento nos grupos RL (Ringer Lactato, 3x o volume de sangue retirado), e TLP (Terlipressina, $2 \mathrm{mg}$ EV) e nos grupos não tratados Sham e Choque. ${ }^{* *} \mathrm{p}<0.01$ vs Sham; ${ }^{* * *}$ $\mathrm{p}<0.001$ vs Sham; * $\mathrm{p}<0.05$ vs Sham; $+\mathrm{p}<0.05$ vs Choque; $++\mathrm{p}<0.01$ vs Choque; $+++\mathrm{p}<0.001$ vs Choque; $\bullet \mathrm{p}<0.01$ vs RL.
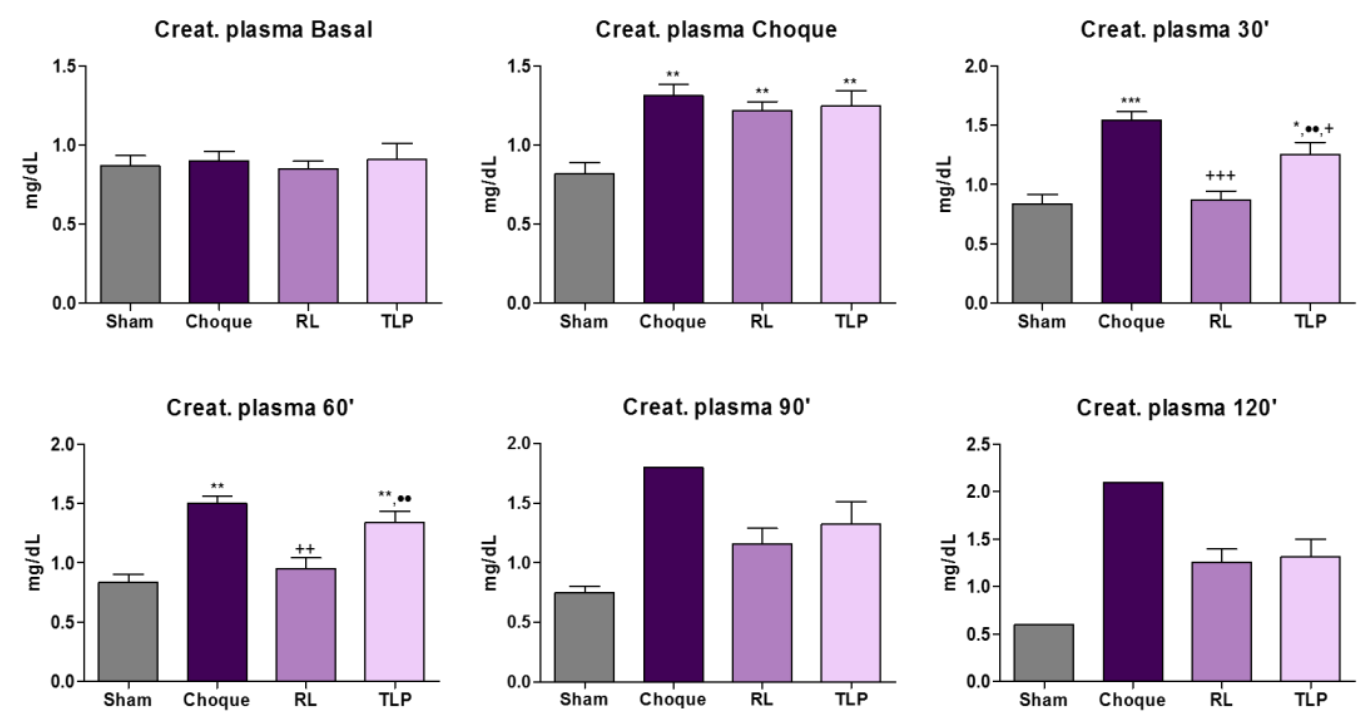

Figura 9 - Gráficos representando as medidas de creatinina plasmática nos períodos basal (em torno de 50 minutos de estabilização após a preparação cirúrgica do animal); choque (50 minutos de indução e manutenção do choque - 40mmHg); 30, 60, 90 e 120 minutos após tratamento nos grupos RL (Ringer Lactato, $3 x$ o volume de sangue retirado), e TLP (Terlipressina, 2mg EV) e nos grupos não tratados Sham e Choque. ${ }^{* *} \mathrm{p}<0.01$ vs Sham; ${ }^{* *} \mathrm{p}<0.001$ vs Sham; * $\mathrm{p}<0.05$ vs Sham; $+\mathrm{p}<0.05$ vs Choque; $++\mathrm{p}<0.01$ vs Choque; $+++\mathrm{p}<0.001$ vs Choque; $\bullet \bullet \mathrm{p}<0.01$ vs RL. 


\section{Clearance creatinina $(\mathrm{ml} / \mathrm{min})$}

Houve diminuição significativa no clearance de creatinina nos animais submetidos ao $\mathrm{CH}$. O grupo tratado com RL restabeleceu o clearance aos 30 e aos 60 minutos. No grupo tratado com TLP, entretanto, apesar de sem significância, houve uma tendência a continuação do restabelecimento aos 90 e 120 minutos (Tabela 9 e figura 10).

\begin{tabular}{lllllll}
\hline Cl. Creat & Basal & Choque & 30' após trat $^{\prime}$ & $\mathbf{6 0}^{\prime}$ após trat & $\mathbf{9 0}^{\prime}$ após trat & $\mathbf{1 2 0}^{\prime}$ após trat \\
\hline Sham & $57,9 \pm 7,8$ & $104,2 \pm 11,3$ & $75,9 \pm 13,1$ & $76,7 \pm 8,0$ & $93,5 \pm 0,0$ & $122,2 \pm-0,0$ \\
Choque & $83,9 \pm 10,9$ & $17,8 \pm 3,2^{* * *}$ & $3,4 \pm 0,9^{* *}$ & $3,7 \pm 1,3^{* * *}$ & $1,1 \pm 0,0$ & 0 \\
RL & $62,7 \pm 8,22$ & $24,9 \pm 3,7^{* * *}$ & $85,5 \pm 14,6$ & $52,0 \pm 10,8^{*+}$ & $20,1 \pm 6,9$ & $24,5 \pm 8,7$ \\
TLP & $70,6 \pm 11,3$ & $24,2 \pm 6,9^{* * *}$ & $34,0 \pm 7,8^{*}, \cdot$ & $24,3 \pm 7,6^{* *} \cdot$ & $94,2 \pm 44,4$ & $86,6 \pm 24,8$ \\
\hline
\end{tabular}

Tabela 9 - Medidas de clearance de creatinina nos períodos basal (em torno de 50 minutos de estabilização após a preparação cirúrgica do animal); choque (50 minutos de indução e manutenção do choque 40mmHg); 30, 60, 90 e 120 minutos após tratamento nos grupos RL (Ringer Lactato, 3x o volume de sangue retirado), e TLP (Terlipressina, $2 \mathrm{mg}$ EV) e nos grupos não tratados Sham e Choque. * $\mathrm{p}<0.05$ vs Sham; ** p $<0.01$ vs Sham; ${ }^{* * *}$ p $<0.001$ vs Sham; $++\mathrm{p}<0.01$ vs Choque; $\bullet p<0.05$ vs RL; $\bullet \bullet p<0.01$ vs RL.
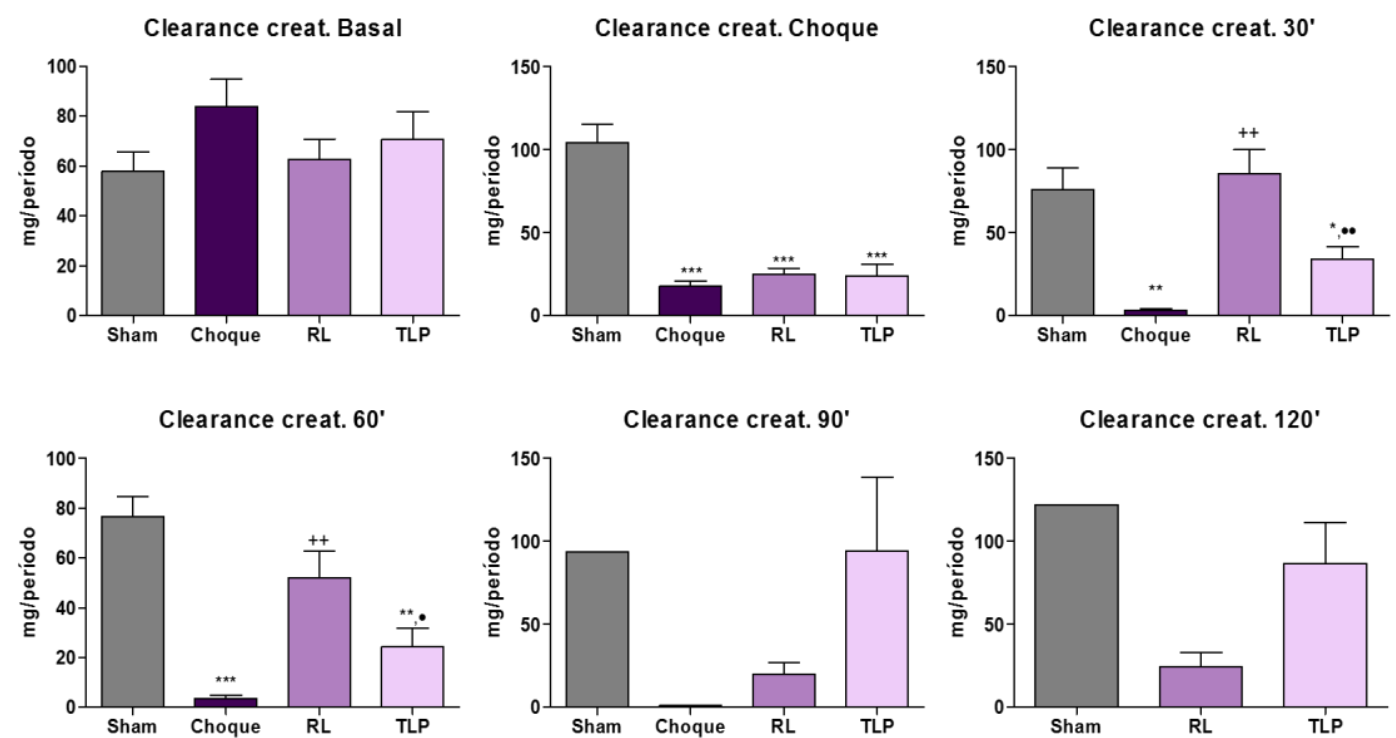

Figura 10 - Gráficos representando o clearance de creatinina nos períodos basal (em torno de 50 minutos de estabilização após a preparação cirúrgica do animal); choque (50 minutos de indução e manutenção do choque -40mmHg); 30, 60, 90 e 120 minutos após tratamento nos grupos RL (Ringer Lactato, 3x o volume de sangue retirado), e TLP (Terlipressina, $2 \mathrm{mg}$ EV) e nos grupos não tratados Sham e Choque. * $\mathrm{p}<0.05$ vs Sham; ${ }^{* *} \mathrm{p}<0.01$ vs Sham; ${ }^{* *} \mathrm{p}<0.001$ vs Sham; $++\mathrm{p}<0.01$ vs Choque; $\bullet \mathrm{p}<0.05$ vs RL; $\bullet p<0.01$ vs RL. 


\section{Sódio plasmático $(\mathrm{mEq} / \mathrm{L})$}

Observamos que o $\mathrm{CH}$ causou hiponatremia nos animais até os 60 minutos, e nenhum tratamento foi capaz de recuperação (Tabela 10 e figura 11).

\begin{tabular}{lllllll}
\hline Na & Basal & Choque & $\mathbf{3 0}^{\prime}$ após trat & $\mathbf{6 0}^{\prime}$ após trat & $\mathbf{9 0}^{\prime}$ após trat & $\mathbf{1 2 0}^{\prime}$ após trat \\
\hline Sham & $145,4 \pm 3,2$ & $149,2 \pm 5,9$ & $144,3 \pm 4,7$ & $146 \pm 4,4$ & $159 \pm 0,0$ & $135,5 \pm 10,5$ \\
Choque & $137,9 \pm 1,2^{*}$ & $140,6 \pm 5,3$ & $134,4 \pm 1,4$ & $132 \pm 4,3^{* *}$ & $151 \pm 0,0$ & $154 \pm 0,0$ \\
RL & $139 \pm 1,0^{*}$ & $131,8 \pm 1,8^{*}$ & $131,5 \pm 2,2^{*}$ & $131,3 \pm 1,2^{* *}$ & $132,4 \pm 1,9$ & $130,2 \pm 4,7$ \\
TLP & $142,1 \pm 1,6$ & $135,8 \pm 2,8$ & $139,4 \pm 2,5$ & $134,3 \pm 1,5^{* *}$ & $137,6 \pm 4,6$ & $127,3 \pm 2,9$ \\
\hline
\end{tabular}

Tabela 10 - Dosagem de sódio plasmático nos períodos basal (em torno de 50 minutos de estabilização após a preparação cirúrgica do animal); choque (50 minutos de indução e manutenção do choque 40mmHg); 30, 60, 90 e 120 minutos após tratamento nos grupos RL (Ringer Lactato, 3x o volume de sangue retirado), e TLP (Terlipressina, $2 \mathrm{mg}$ EV) e nos grupos não tratados Sham e Choque. ${ }^{* *} \mathrm{p}<0.01$ vs Sham; * $\mathrm{p}<0.05$ vs Sham; ${ }^{* * *} \mathrm{p}<0.001$ vs Sham.
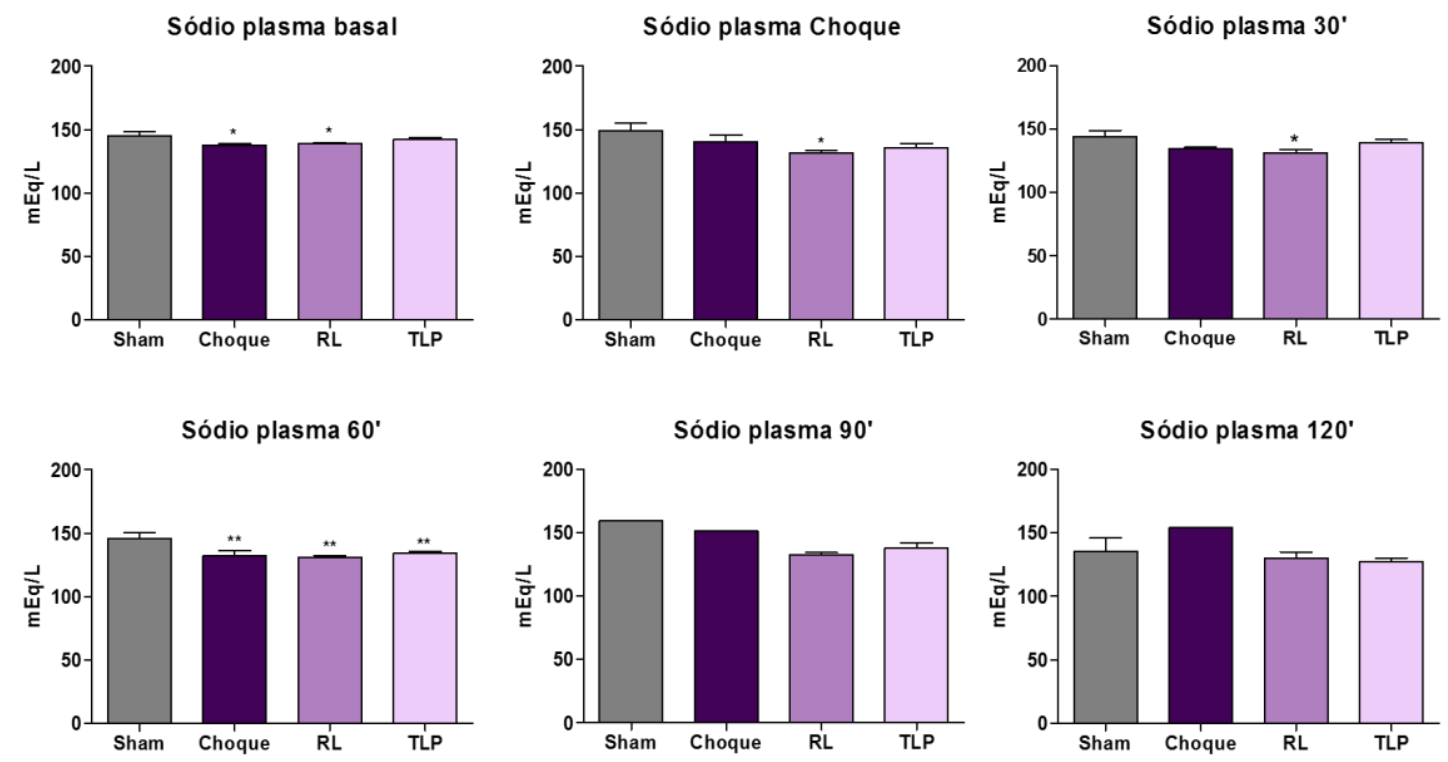

Figura 11 - Gráficos representando as medidas de sódio plasmático nos períodos basal (em torno de 50 minutos de estabilização após a preparação cirúrgica do animal); choque (50 minutos de indução e manutenção do choque - 40mmHg); 30, 60, 90 e 120 minutos após tratamento nos grupos RL (Ringer Lactato, 3x o volume de sangue retirado), e TLP (Terlipressina, $2 \mathrm{mg}$ EV) e nos grupos não tratados Sham e Choque. ${ }^{* *} \mathrm{p}<0.01$ vs Sham; * $\mathrm{p}<0.05$ vs Sham; ** $\mathrm{p}<0.001$ vs Sham. 


\section{Ureia plasmática $(\mathrm{mg} / \mathrm{dL})$}

Observamos um aumento da concentração de ureia plasmática nos animais de todos os grupos submetidos ao $\mathrm{CH}$, entretanto, esse aumento foi ainda maior no grupo tratado com TLP durante todo o tempo de experimento (Tabela 11 e figura 12).

\begin{tabular}{lllllll}
\hline Ur & Basal & Choque & $\mathbf{3 0}^{\prime}$ após trat & $\mathbf{6 0}^{\prime}$ após trat & $\mathbf{9 0}^{\prime}$ após trat & $\mathbf{1 2 0}^{\prime}$ após trat \\
\hline Sham & $20,3 \pm 2,3$ & $21,8 \pm 2,3$ & $23,8 \pm 2,9$ & $23,5 \pm 2,5$ & $18,5 \pm 0,5$ & $17 \pm 2,0$ \\
Choque & $20,5 \pm 2,3$ & $25,4 \pm 2,4$ & $27,3 \pm 2,2$ & $23,8 \pm 0,5$ & $29 \pm 0,0$ & $31 \pm 0,0$ \\
RL & $19,1 \pm 2,0$ & $24,9 \pm 2,4$ & $21,3 \pm 1,9{ }^{*}, \Delta \Delta$ & $22,4 \pm 2,2$ & $25,9 \pm 2,5$ & $26 \pm 3,9$ \\
TLP & $26,5 \pm 2,7$ & $32,9 \pm 3,1$ & $35,1 \pm 3,2^{+}$ & $37,2 \pm 3,22^{* *+++}, \cdot \cdot$ & $40,3 \pm 6,7$ & $41,4 \pm 5,1$ \\
\hline
\end{tabular}

Tabela 11 - Dosagem de ureia plasmática nos períodos basal (em torno de 50 minutos de estabilização após a preparação cirúrgica do animal); choque (50 minutos de indução e manutenção do choque $40 \mathrm{mmHg}$ ); 30, 60, 90 e 120 minutos após tratamento nos grupos RL (Ringer Lactato, 3x o volume de sangue retirado), e TLP (Terlipressina, $2 \mathrm{mg}$ EV) e nos grupos não tratados Sham e Choque. * $\mathrm{p}<0.05$ vs Sham; + $\mathrm{p}<0.05$ vs Choque; $\Delta \Delta \mathrm{p}<0.01$ vs TLP.
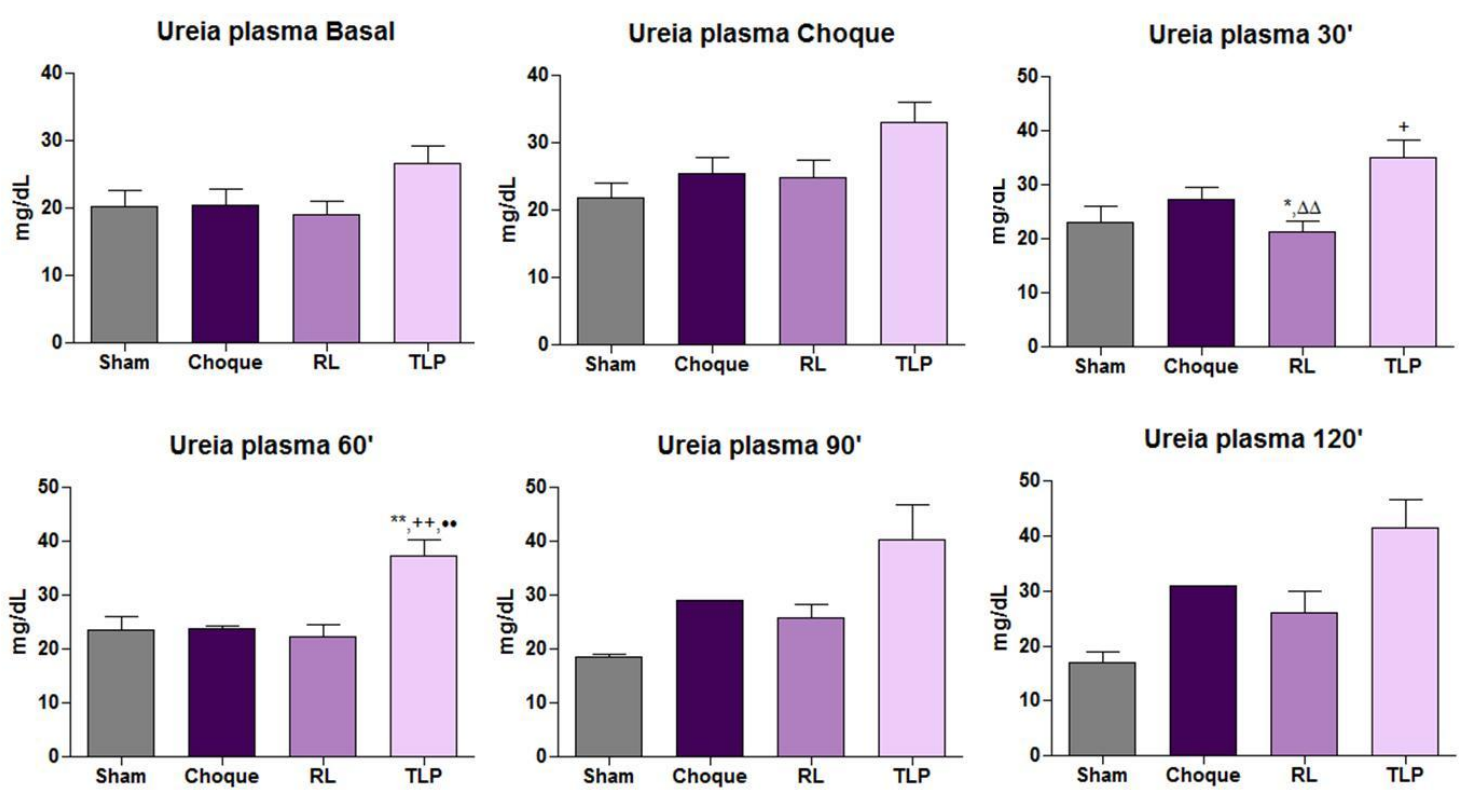

Figura 12 - Gráficos representando as medidas de ureia plasmática nos períodos basal (em torno de 50 minutos de estabilização após a preparação cirúrgica do animal); choque (50 minutos de indução e manutenção do choque - 40mmHg); 30, 60, 90 e 120 minutos após tratamento nos grupos RL (Ringer Lactato, 3x o volume de sangue retirado), e TLP (Terlipressina, $2 \mathrm{mg}$ EV) e nos grupos não tratados Sham e Choque. ${ }^{*} \mathrm{p}<0.05$ vs Sham; $+\mathrm{p}<0.05$ vs Choque; ${ }^{\Delta \Delta} \mathrm{p}<0.01$ vs TLP. 


\section{Fósforo plasmático $(\mathrm{mg} / \mathrm{dL})$}

$\mathrm{O} \mathrm{CH}$ levou os animais a apresentarem hiperfosfatemia em todos os tempos. $\mathrm{O}$ tratamento não reverteu esse quadro (Tabela 12 e figura 13).

\begin{tabular}{lllllll}
\hline P & Basal & Choque & $\mathbf{3 0}^{\prime}$ após trat & $\mathbf{6 0}^{\prime}$ após trat & $\mathbf{9 0}^{\prime}$ após trat & $\mathbf{1 2 0}^{\prime}$ após trat \\
\hline Sham & $8,3 \pm 0,6$ & $9,4 \pm 0,9$ & $9,7 \pm 0,7$ & $9,9 \pm 0,9$ & $11,0 \pm 1,0$ & $10,0 \pm 2,0$ \\
Choque & $8,8 \pm 0,5$ & $10,2 \pm 0,7$ & $12,3 \pm 0,9^{*}$ & $10,7 \pm 1,0$ & $13,0 \pm 0,0$ & $13,0 \pm 0,0$ \\
RL & $9,3 \pm 0,5$ & $12,7 \pm 0,8^{*},+$ & $8,1 \pm 0,4^{+++}$ & $8,4 \pm 0,51$ & $9,2 \pm 0,6$ & $9,8 \pm 1,0$ \\
TLP & $8,5 \pm 0,4$ & $9,8 \pm 0,56 \cdot$ & $10,8 \pm 0,5 \cdot \cdot$ & $11,9 \pm 0,6 \cdots$ & $10,4 \pm 1,0$ & $10,4 \pm 1,5$
\end{tabular}

Tabela 12 - Dosagem de fósforo plasmático nos períodos basal (em torno de 50 minutos de estabilização após a preparação cirúrgica do animal); choque (50 minutos de indução e manutenção do choque 40mmHg); 30, 60, 90 e 120 minutos após tratamento nos grupos RL (Ringer Lactato, 3x o volume de sangue retirado), e TLP (Terlipressina, $2 \mathrm{mg}$ EV) e nos grupos não tratados Sham e Choque. • p<0.05 vs RL; •• p $<0.01$ vs RL; $\bullet \bullet p<0.001$ vs RL; ${ }^{*}$ p $<0.05$ vs Sham; + p $<0.05$ vs Choque; $+++p<0.001$ vs Choque.
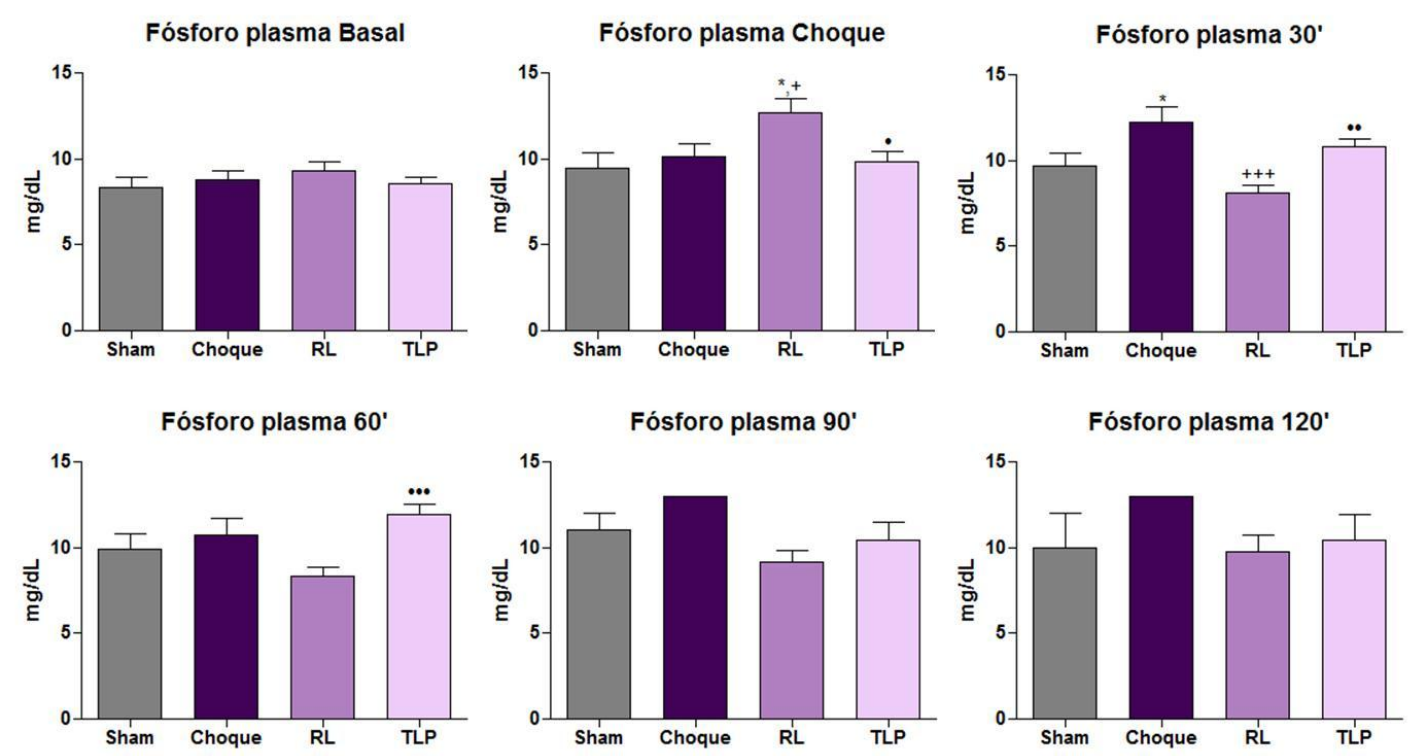

Figura 13 - Gráficos representando as medidas de fósforo plasmático nos períodos basal (em torno de 50 minutos de estabilização após a preparação cirúrgica do animal); choque (50 minutos de indução e manutenção do choque - 40mmHg); 30, 60, 90 e 120 minutos após tratamento nos grupos RL (Ringer Lactato, $3 x$ o volume de sangue retirado), e TLP (Terlipressina, 2mg EV) e nos grupos não tratados Sham e Choque. • $\mathrm{p}<0.05$ vs RL; $\bullet \mathrm{p}<0.01$ vs RL; $\bullet \bullet \mathrm{p}<0.001$ vs RL; * $\mathrm{p}<0.05$ vs Sham; $+\mathrm{p}<0.05$ vs Choque; +++ $\mathrm{p}<0.001$ vs Choque. 


\section{Magnésio plasmático (mg/dL)}

Observamos nos grupos submetidos ao $\mathrm{CH}$ a presença de hipermagnesemia e os grupos tratados recuperaram parcialmente os níveis de magnésio plasmático (Tabela 13 e figura 14).

\begin{tabular}{lllllll}
\hline Mg & Basal & Choque & $\mathbf{3 0}^{\prime}$ após trat & $\mathbf{6 0}^{\prime}$ após trat & $\mathbf{9 0}^{\prime}$ após trat & $\mathbf{1 2 0}^{\prime}$ após trat \\
\hline Sham & $1,9 \pm 0,1$ & $1,8 \pm 0,1$ & $1,8 \pm 0,1$ & $1,7 \pm 0,1$ & $2,1 \pm 0,1$ & $1,8 \pm 0,0$ \\
Choque & $1,8 \pm 0,1$ & $2,1 \pm 0,1$ & $2,2 \pm 0,1^{*}$ & $2,1 \pm 0,2$ & $2,9 \pm 0,0$ & $2,8 \pm 0,0$ \\
RL & $1,7 \pm 0,1$ & $2,3 \pm 0,1$ & $1,5 \pm 0,1^{+++}$ & $1,5 \pm 0,1^{+}$ & $1,7 \pm 0,1$ & $1,7 \pm 0,1$ \\
TLP & $1,8 \pm 0,1$ & $2,13 \pm 0,1$ & $1,9 \pm 0,1^{*}$ & $2,1 \pm 0,1^{*} \cdot$ & $1,9 \pm 0,2$ & $2,0 \pm 0,2$ \\
\hline
\end{tabular}

Tabela 13 - Dosagem de fósforo plasmático nos períodos basal (em torno de 50 minutos de estabilização após a preparação cirúrgica do animal); choque (50 minutos de indução e manutenção do choque 40mmHg); 30, 60, 90 e 120 minutos após tratamento nos grupos RL (Ringer Lactato, 3x o volume de sangue retirado), e TLP (Terlipressina, $2 \mathrm{mg}$ EV) e nos grupos não tratados Sham e Choque. • p<0.05 vs RL; •• $\mathrm{p}<0.01$ vs RL; $\bullet \bullet \mathrm{p}<0.001$ vs $R L ;{ }^{*} \mathrm{p}<0.05$ vs Sham; $+\mathrm{p}<0.05$ vs Choque; $+++\mathrm{p}<0.001$ vs Choque.
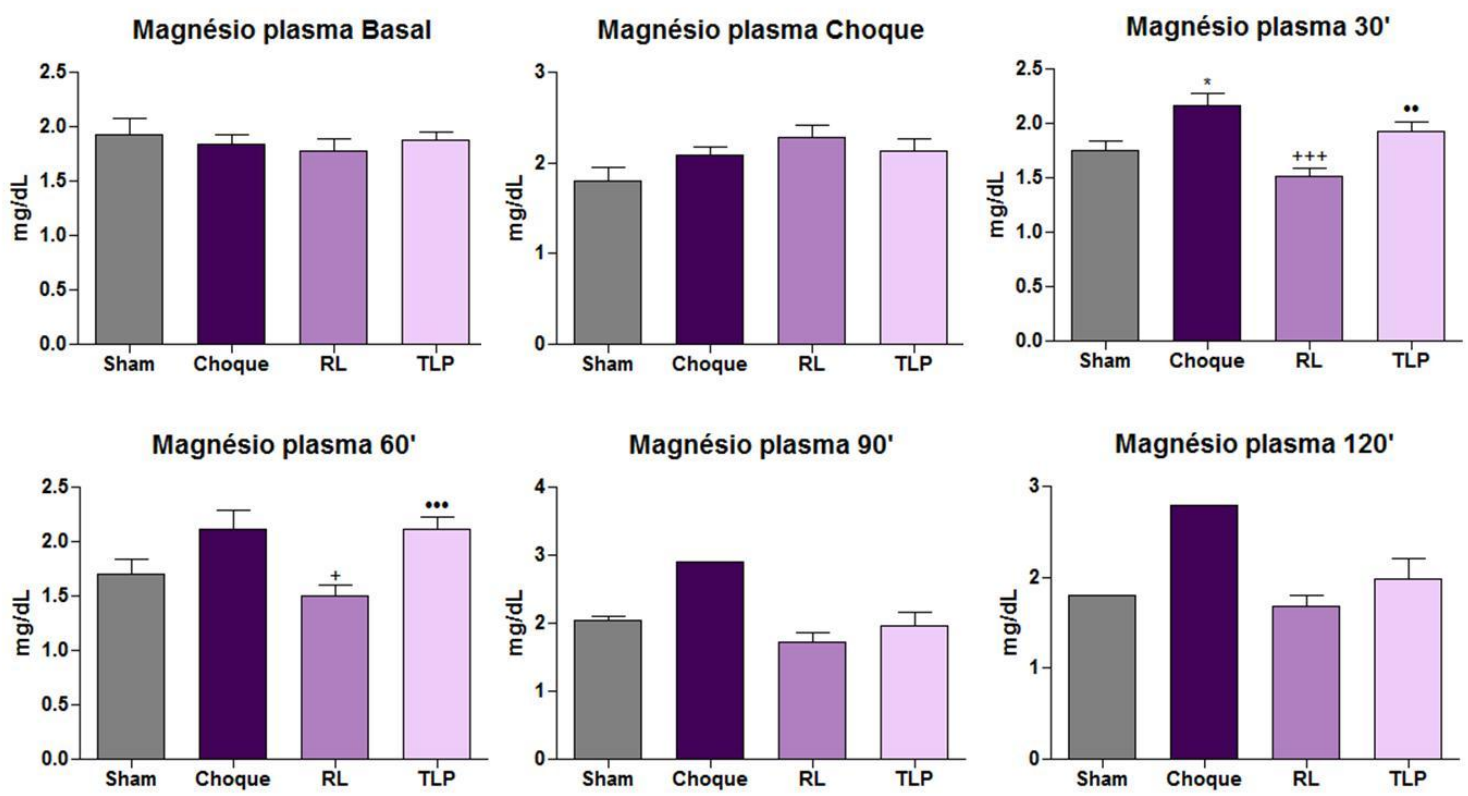

Figura 14 - Gráficos representando as medidas de magnésio plasmático nos períodos basal (em torno de 50 minutos de estabilização após a preparação cirúrgica do animal); choque (50 minutos de indução e manutenção do choque - 40mmHg); 30, 60, 90 e 120 minutos após tratamento nos grupos RL (Ringer Lactato, 3x o volume de sangue retirado), e TLP (Terlipressina, 2mg EV) e nos grupos não tratados Sham e Choque. • $\mathrm{p}<0.05$ vs RL; $\bullet \mathrm{p}<0.01$ vs RL; $\bullet \bullet \mathrm{p}<0.001$ vs RL; ${ }^{*} \mathrm{p}<0.05$ vs Sham; $+\mathrm{p}<0.05$ vs Choque; +++ $\mathrm{p}<0.001$ vs Choque. 


\section{Cloro plasmático $(\mathrm{mEq} / \mathrm{L})$}

O CH não modificou os níveis de cloro plasmático nos grupos. Porém, nos dois grupos tratados, observamos uma diminuição a partir dos 30 minutos após o tratamento (Tabela 14 e figura 15).

\begin{tabular}{|c|c|c|c|c|c|c|}
\hline $\mathrm{Cl}$ & Basal & Choque & $30^{\prime}$ após trat & $60^{\prime}$ após trat & 90' após trat & $120^{\prime}$ após trat \\
\hline Sham & $107,8 \pm 2,1$ & $111,3 \pm 4,6$ & $108,8 \pm 4,4$ & $115,2 \pm 7,7$ & $119 \pm 0,0$ & $104,5 \pm 15,5$ \\
\hline Choque & $105,4 \pm 2,4$ & $107,4 \pm 4,3$ & $106 \pm 4,7$ & $106,8 \pm 5,2$ & $117 \pm 0,0$ & $117 \pm 0,0$ \\
\hline RL & $100,5 \pm 1,6$ & $100,2 \pm 1,6$ & $99,1 \pm 2,1$ & $99,5 \pm 1,1^{* *}$ & $100,7 \pm 1,4$ & $94,3 \pm 4,6$ \\
\hline TLP & $103,7 \pm 2,2$ & $99,4 \pm 2,1$ & $102 \pm 2,1$ & $96,54 \pm 3,1$ * & $96,9 \pm 5,8$ & $90,9 \pm 3,2$ \\
\hline
\end{tabular}

Tabela 14 - Dosagem de cloro plasmático nos períodos basal (em torno de 50 minutos de estabilização após a preparação cirúrgica do animal); choque (50 minutos de indução e manutenção do choque 40mmHg); 30, 60, 90 e 120 minutos após tratamento nos grupos RL (Ringer Lactato, 3x o volume de sangue retirado), e TLP (Terlipressina, $2 \mathrm{mg}$ EV) e nos grupos não tratados Sham e Choque. * $<<0.05$ vs Sham; ${ }^{* *} \mathrm{p}<0.01$ vs Sham.
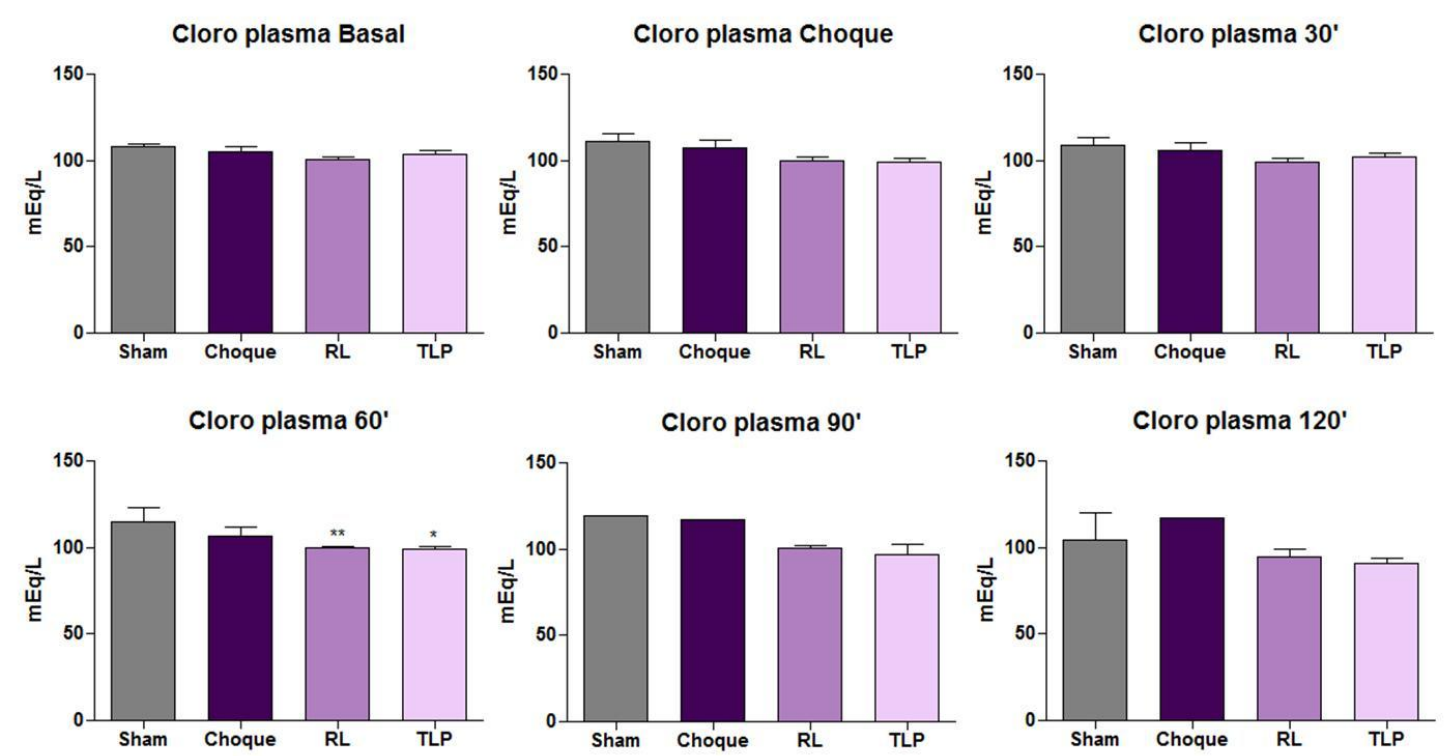

Figura 15 - Gráficos representando as medidas de cloro plasmático nos períodos basal (em torno de 50 minutos de estabilização após a preparação cirúrgica do animal); choque (50 minutos de indução e manutenção do choque - 40mmHg); 30, 60, 90 e 120 minutos após tratamento nos grupos RL (Ringer Lactato, $3 x$ o volume de sangue retirado), e TLP (Terlipressina, $2 \mathrm{mg}$ EV) e nos grupos não tratados Sham e Choque. ${ }^{*} \mathrm{p}<0.05$ vs Sham; ${ }^{* *} \mathrm{p}<0.01$ vs Sham. 


\section{Potássio plasmático $(\mathrm{mEq} / \mathrm{L})$}

Os animais em choque apresentaram hipercalemia. Os dois tratamentos mostraram uma tendência ao controle da concentração de potássio plasmático após 30 minutos do tratamento (Tabela 15 e figura 16).

\begin{tabular}{lllllll}
\hline K & Basal & Choque & 30' após trat $^{\prime}$ & $\mathbf{6 0}^{\prime}$ após trat & $\mathbf{9 0}^{\prime}$ após trat & $\mathbf{1 2 0}^{\prime}$ após trat \\
\hline Sham & $4,6 \pm 0,3$ & $4,8 \pm 0,2$ & $4,7 \pm 0,2$ & $5,1 \pm 0,3$ & $5,3 \pm 0,2$ & $4,9 \pm 0,2$ \\
Choque & $4,8 \pm 0,3$ & $5,9 \pm 0,4$ & $6,4 \pm 0,5^{* *}$ & $6,0 \pm 0,9$ & $6,9 \pm 0,0$ & $7,7 \pm 0,0$ \\
RL & $4,2 \pm 0,1$ & $6,4 \pm 0,4^{*}$ & $4,5 \pm 0,2^{+++}$ & $5,1 \pm 0,1$ & $5,7 \pm 0,2$ & $5,9 \pm 0,3$ \\
TLP & $4,3 \pm 0,1$ & $5,3 \pm 0,2 \cdot$ & $5,4 \pm 0,2^{\bullet+}+$ & $5,4 \pm 0,3$ & $5,5 \pm 0,4$ & $5,6 \pm 0,4$ \\
\hline
\end{tabular}

Tabela 15 - Dosagem de potássio plasmático nos períodos basal (em torno de 50 minutos de estabilização após a preparação cirúrgica do animal); choque (50 minutos de indução e manutenção do choque 40mmHg); 30, 60, 90 e 120 minutos após tratamento nos grupos RL (Ringer Lactato, 3x o volume de sangue retirado), e TLP (Terlipressina, $2 \mathrm{mg}$ EV) e nos grupos não tratados Sham e Choque. $\bullet \mathrm{p}<0.05$ vs $\mathrm{RL} ;+\mathrm{p}<$ 0.05 vs Choque; $+++\mathrm{p}<0.001$ vs Choque; ${ }^{*} \mathrm{p}<0.05$ vs Sham; ${ }^{* *} \mathrm{p}<0.01$ vs Sham.
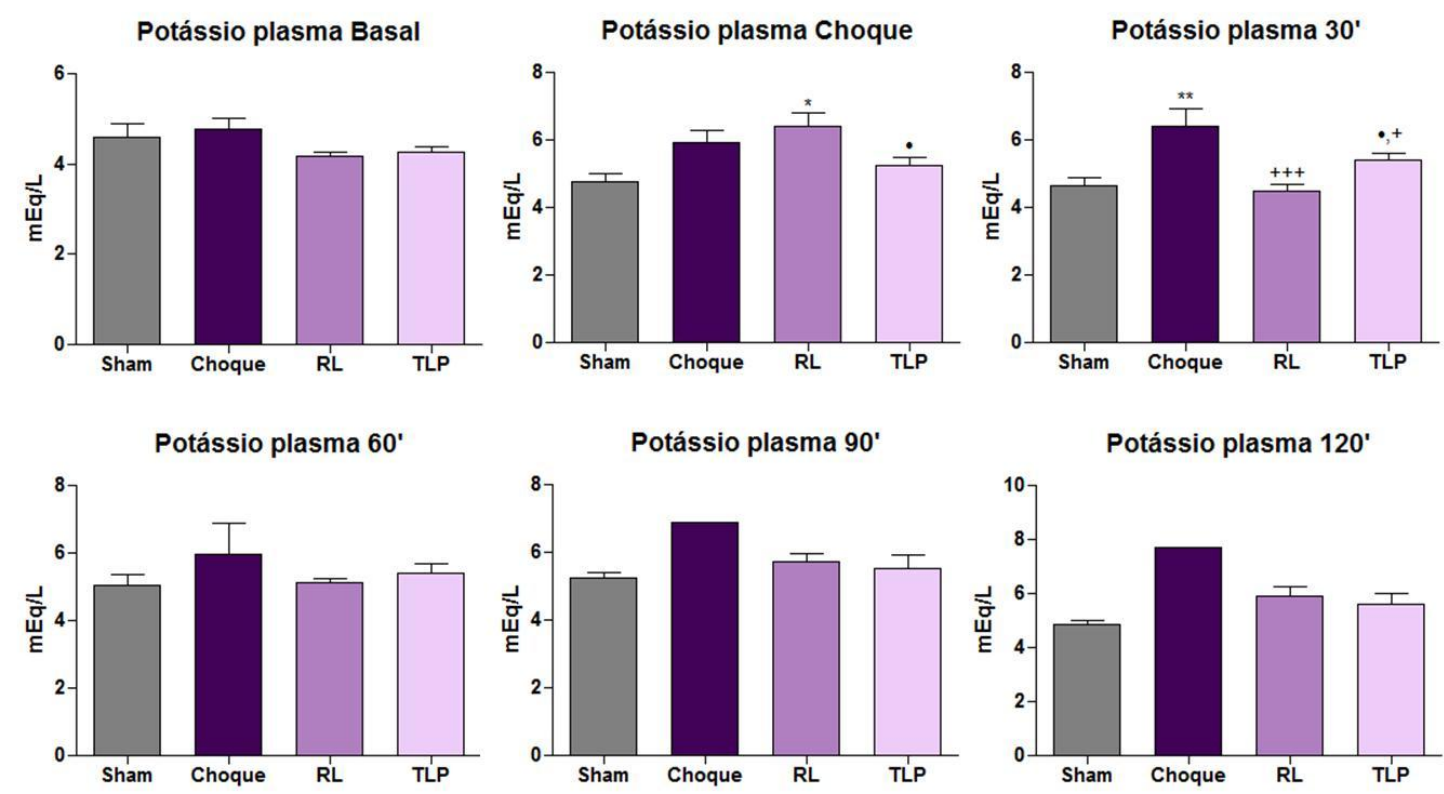

Figura 16 - Gráficos representando as medidas de potássio plasmático nos períodos basal (em torno de 50 minutos de estabilização após a preparação cirúrgica do animal); choque (50 minutos de indução e manutenção do choque - 40mmHg); 30, 60, 90 e 120 minutos após tratamento nos grupos RL (Ringer Lactato, $3 x$ o volume de sangue retirado), e TLP (Terlipressina, $2 \mathrm{mg}$ EV) e nos grupos não tratados Sham e Choque. $\bullet p<0.05$ vs RL; $+\mathrm{p}<0.05$ vs Choque; $+++\mathrm{p}<0.001$ vs Choque; ${ }^{*} \mathrm{p}<0.05$ vs Sham; ${ }^{* *} \mathrm{p}<0.01$ vs Sham. 


\section{UV de Sódio (mEq/período)}

Observamos aumento importante da excreção urinária de sódio aos 30 minutos após o tratamento com RL. Não observamos diferenças estatísticas em relação aos outros tempos. (Tabela 16 e figura 17).

\begin{tabular}{lllllll}
\hline UV Na & Basal & Choque & $\mathbf{3 0}^{\prime}$ após trat & $\mathbf{6 0}^{\prime}$ após trat & $\mathbf{9 0}^{\prime}$ após trat & $\mathbf{1 2 0}^{\prime}$ após trat \\
\hline Sham & $0,5 \pm 0,1$ & $1,2 \pm 0,7$ & $0,6 \pm 0,3$ & $0,6 \pm 0,2$ & $0,8 \pm 0,8$ & $0,8 \pm 0,3$ \\
Choque & $0,7 \pm 0,1$ & $0,6 \pm 0,3$ & $0,2 \pm 0,1$ & $0,2 \pm 0,1$ & $0,3 \pm 0,0$ & 0 \\
RL & $0,4 \pm 0,1$ & $0,4 \pm 0,2$ & $20,5 \pm 4,7^{* * *},++$ & $2,2 \pm 0,8$ & $0,2 \pm 0,1$ & $0,1 \pm 0,0$ \\
TLP & $0,5 \pm 0,1$ & $0,2 \pm 0,1$ & $0,2 \pm 0,0 \cdot \cdots$ & $0,5 \pm 0,3$ & $0,2 \pm 0,1$ & $0,3 \pm 0,1$ \\
\hline
\end{tabular}

Tabela 16 - Medidas de UV de sódio nos períodos basal (em torno de 50 minutos de estabilização após a preparação cirúrgica do animal); choque (50 minutos de indução e manutenção do choque - 40mmHg); 30 , 60, 90 e 120 minutos após tratamento nos grupos RL (Ringer Lactato, 3x o volume de sangue retirado), e TLP (Terlipressina, 2mg EV) e nos grupos não tratados Sham e Choque. ${ }^{* * *} \mathrm{p}<0.001$ vs Sham; $++\mathrm{p}<0.01$ vs Choque; $\cdots p<0.001$ vs RL.

UV sódio Basal

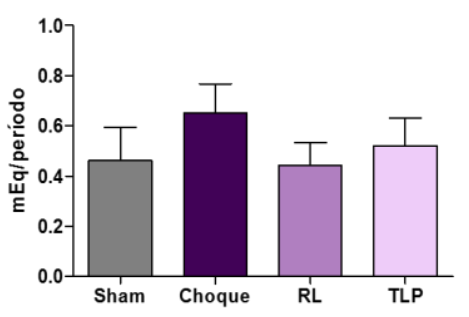

UV sódio $60^{\circ}$

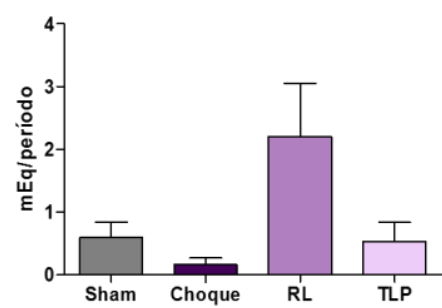

UV sódio Choque

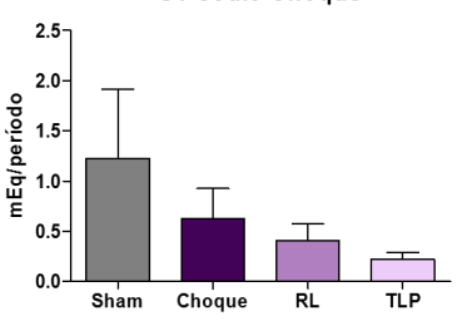

UV sódio $90^{\circ}$

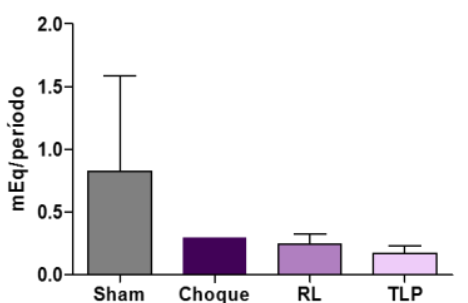

UV sódio 30'

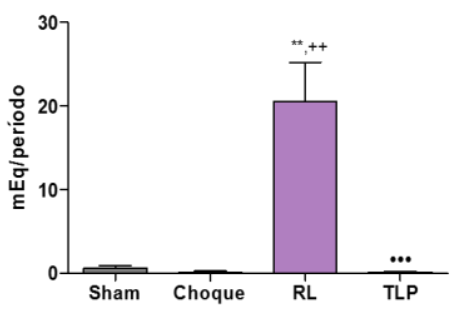

UV sódio $120^{\prime}$

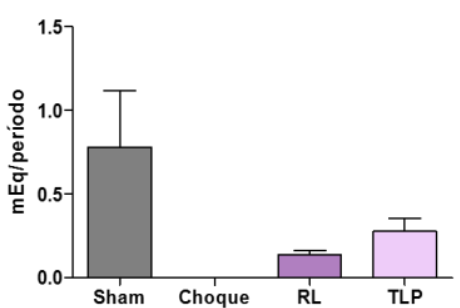

Figura 17 - Gráficos representando a excreção urinária de sódio nos períodos basal (em torno de 50 minutos de estabilização após a preparação cirúrgica do animal); choque (50 minutos de indução e manutenção do choque - 40mmHg); 30, 60, 90 e 120 minutos após tratamento nos grupos RL (Ringer Lactato, $3 x$ o volume de sangue retirado), e TLP (Terlipressina, $2 \mathrm{mg}$ EV) e nos grupos não tratados Sham e Choque. ${ }^{* *} \mathrm{p}<0.001$ vs Sham; ++ $\mathrm{p}<0.01$ vs Choque; $\bullet \bullet p<0.001$ vs RL. 


\section{UV de Potássio (mEq/período)}

Observamos uma diminuição significativa da excreção urinária de potássio logo após o $\mathrm{CH}$, com exceção do grupo RL que apresentou um aumento da excreção de potássio de 30 e 60 minutos após o tratamento (Tabela 17 e figura 18).

\begin{tabular}{lllllll}
\hline UV K & Basal & Choque & $\mathbf{3 0}^{\prime}$ após trat & $\mathbf{6 0}^{\prime}$ após trat & $\mathbf{9 0}^{\prime}$ após trat & $\mathbf{1 2 0}^{\prime}$ após trat \\
\hline Sham & $1,8 \pm 0,5$ & $4,5 \pm 1,4$ & $2,7 \pm 0,8$ & $2,7 \pm 0,5$ & $2,5 \pm 1,6$ & $2,6 \pm 1,7$ \\
Choque & $3,7 \pm 1,1$ & $1,5 \pm 0,4^{*}$ & $0,2 \pm 0,1$ & $0,1 \pm 0,0^{*}$ & $0,1 \pm 0,0$ & 0 \\
RL & $1,9 \pm 0,3$ & $1,8 \pm 0,3^{*}$ & $12,7 \pm 5,7$ & $2,3 \pm 0,6^{+}$ & $0,7 \pm 0,2$ & $0,6 \pm 0,2$ \\
TLP & $2,2 \pm 0,3$ & $1,8 \pm 0,8^{*}$ & $0,8 \pm 0,2$ & $0,9 \pm 0,3$ & $1,4 \pm 0,6$ & $1,5 \pm 0,7$ \\
\hline
\end{tabular}

Tabela 17 - Medidas de UV de potássio nos períodos basal (em torno de 50 minutos de estabilização após a preparação cirúrgica do animal); choque (50 minutos de indução e manutenção do choque $-40 \mathrm{mmHg}$ ); 30 , 60, 90 e 120 minutos após tratamento nos grupos RL (Ringer Lactato, 3x o volume de sangue retirado), e TLP (Terlipressina, $2 \mathrm{mg}$ EV) e nos grupos não tratados Sham e Choque. ${ }^{*} \mathrm{p}<0.05$ vs Sham; $+\mathrm{p}<0.05$ vs Choque.
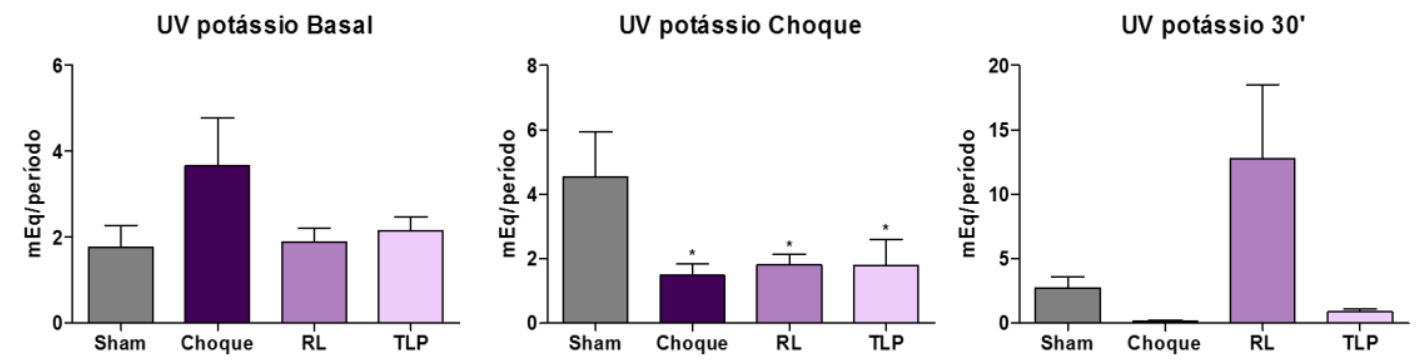

UV potássio $60^{\prime}$

UV potássio $90^{\prime}$

UV potássio $120^{\prime}$
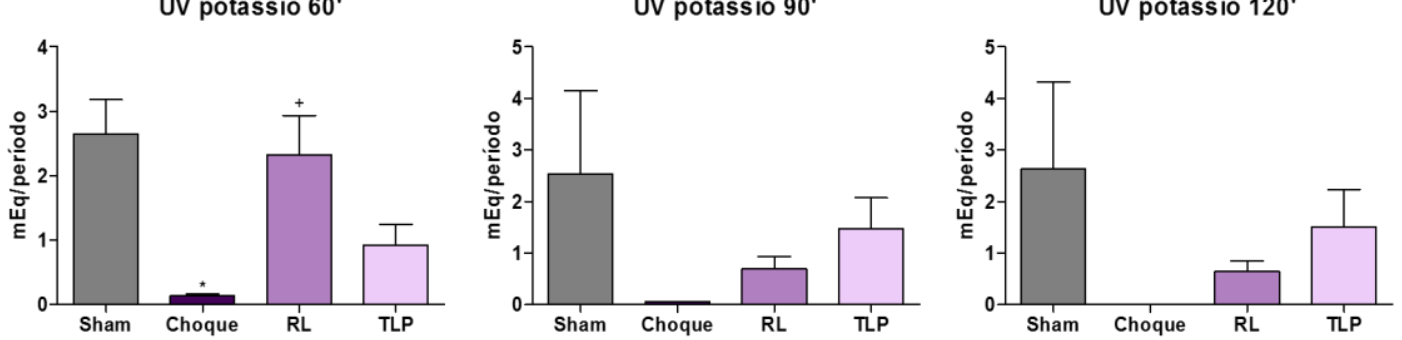

Figura 18 - Gráficos representando a excreção urinária de potássio nos períodos basal (em torno de 50 minutos de estabilização após a preparação cirúrgica do animal); choque (50 minutos de indução e manutenção do choque - 40mmHg); 30, 60, 90 e 120 minutos após tratamento nos grupos RL (Ringer Lactato, $3 x$ o volume de sangue retirado), e TLP (Terlipressina, $2 \mathrm{mg}$ EV) e nos grupos não tratados Sham e Choque. ${ }^{*} \mathrm{p}<0.05$ vs Sham; $+\mathrm{p}<0.05$ vs Choque. 


\section{UV de Cloro (mEq/período)}

A excreção urinária de cloro após o $\mathrm{CH}$ mostrou-se diminuída nos grupos Choque durante todo o experimento. No grupo RL ela se manteve durante o $\mathrm{CH}$ e teve um aumento acentuado aos 30 minutos, diminuindo em seguida (Tabela 18 e figura 19).

\begin{tabular}{lllllll}
\hline UV Cl & Basal & Choque & $\mathbf{3 0}^{\prime}$ após trat & $\mathbf{6 0}^{\prime}$ após trat & $\mathbf{9 0}^{\prime}$ após trat & $\mathbf{1 2 0}^{\prime}$ após trat \\
\hline Sham & $2,2 \pm 1,2$ & $4,3 \pm 1,7$ & $1,9 \pm 0,5$ & $1,7 \pm 0,3$ & $1,2 \pm 0,7$ & $1,5 \pm 0,8$ \\
Choque & $3,9 \pm 0,9$ & $1,6 \pm 0,4$ & $0,3 \pm 0,2$ & $0,2 \pm 0,1$ & $0,3 \pm 0,0$ & 0 \\
RL & $1,5 \pm 0,3$ & $1,4 \pm 0,4$ & $19,5 \pm 4,9^{* *},++$ & $3,7 \pm 1,3$ & $0,4 \pm 0,1$ & $0,4 \pm 0,2$ \\
TLP & $2,7 \pm 0,6$ & $1,3 \pm 0,62$ & $0,6 \pm 0,2 \cdots$ & $0,6 \pm 0,2$ & $0,7 \pm 0,4$ & $1,1 \pm 0,5$
\end{tabular}

Tabela 18 - Medidas de UV de cloro nos períodos basal (em torno de 50 minutos de estabilização após a preparação cirúrgica do animal); choque (50 minutos de indução e manutenção do choque - 40mmHg); 30 , 60, 90 e 120 minutos após tratamento nos grupos RL (Ringer Lactato, 3x o volume de sangue retirado), e TLP (Terlipressina, $2 \mathrm{mg}$ EV) e nos grupos não tratados Sham e Choque. ** $\mathrm{p}<0.01$ vs Sham; ++ $\mathrm{p}<0.01$ vs Choque; $\cdots p$ p $<0.001$ vs RL.
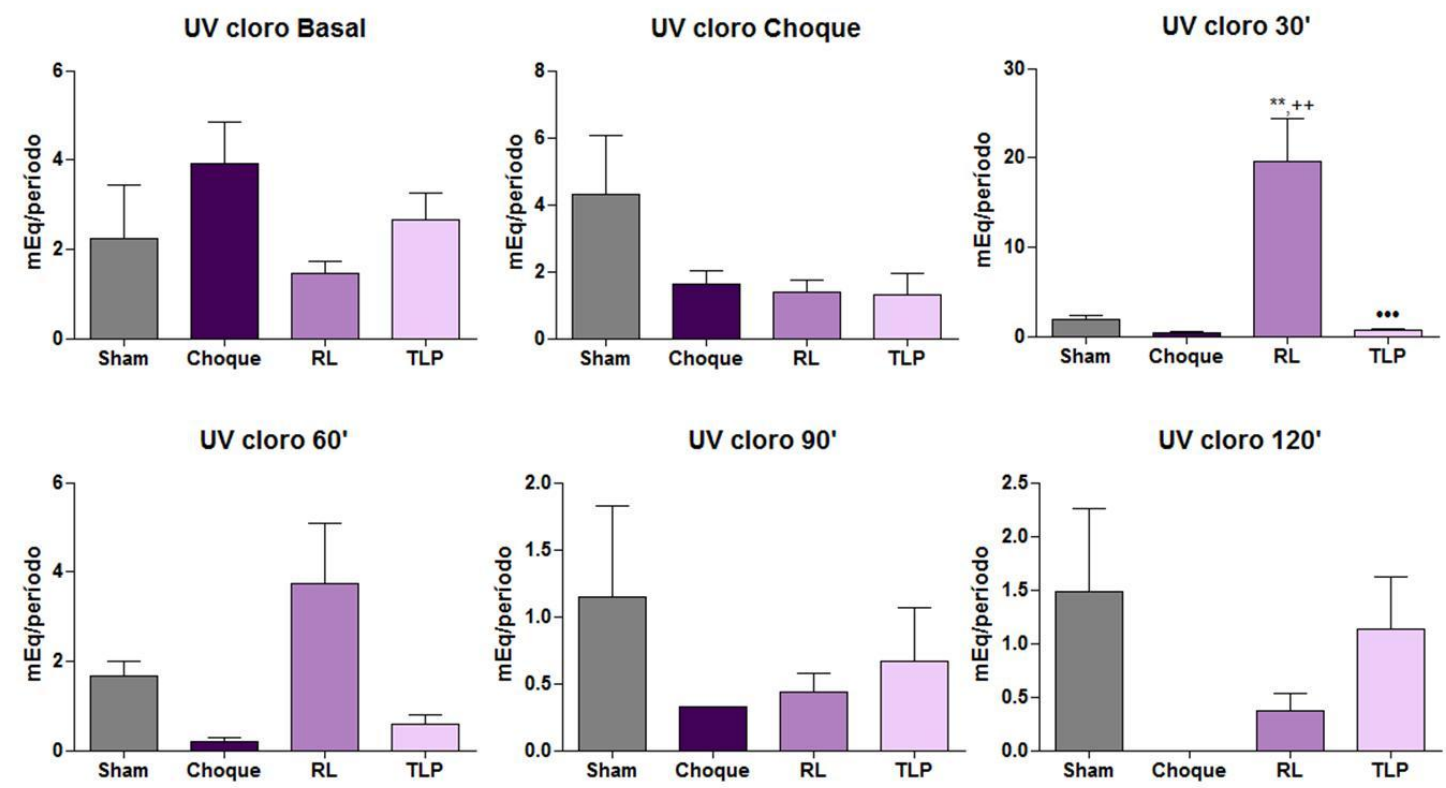

Figura 19 - Gráficos representando a excreção urinária de cloro nos períodos basal (em torno de 50 minutos de estabilização após a preparação cirúrgica do animal); choque (50 minutos de indução e manutenção do choque - 40mmHg); 30, 60, 90 e 120 minutos após tratamento nos grupos RL (Ringer Lactato, $3 x$ o volume de sangue retirado), e TLP (Terlipressina, $2 \mathrm{mg}$ EV) e nos grupos não tratados Sham e Choque. ${ }^{* *} \mathrm{p}<0.01$ vs Sham; $++\mathrm{p}<0.01$ vs Choque; $\bullet \bullet \mathrm{p}<0.001$ vs RL. 


\section{UV de Fósforo (mg/período)}

Observamos um aumento importante do UV de fósforo no grupo tratado com RL até os 60 minutos. Curioso observar que o grupo TLP apresentou uma importante excreção de fósforo aos 120 minutos, embora não significante (Tabela 19 e figura 20).

\begin{tabular}{lllllll}
\hline UV P & Basal & Choque & $\mathbf{3 0}^{\prime}$ após trat & $\mathbf{6 0}^{\prime}$ após trat & $\mathbf{9 0}^{\prime}$ após trat & 120' após trat $^{\prime}$ \\
\hline Sham & $1,7 \pm 1,4$ & $11,3 \pm 6,3$ & $7,4 \pm 3,8$ & $7,9 \pm 3,3$ & $2,8 \pm 2,2$ & $3,2 \pm 1,6$ \\
Choque & $4,3 \pm 2,3$ & $4,7 \pm 2,1$ & $1,2 \pm 0,8$ & $0,2 \pm 0,2$ & $1,1 \pm 0,0$ & 0 \\
RL & $1,9 \pm 1,2$ & $7,8 \pm 2,5$ & $74,1 \pm 20,8^{* *,+}$ & $14 \pm 4,6$ & $5,9 \pm 4,3$ & $3,8 \pm 3,0$ \\
TLP & $3,3 \pm 1,6$ & $2,4 \pm 1,4$ & $6,1 \pm 3,04 \cdot \cdot$ & $7,4 \pm 3,3$ & $3,5 \pm 2,3$ & $14,2 \pm 12,2$ \\
\hline
\end{tabular}

Tabela 19 - Medidas de UV de fósforo nos períodos basal (em torno de 50 minutos de estabilização após a preparação cirúrgica do animal); choque (50 minutos de indução e manutenção do choque $-40 \mathrm{mmHg}$ ); 30 , 60, 90 e 120 minutos após tratamento nos grupos RL (Ringer Lactato, 3x o volume de sangue retirado), e TLP (Terlipressina, 2mg EV) e nos grupos não tratados Sham e Choque. ${ }^{* *} \mathrm{p}<0.01$ vs Sham; $+\mathrm{p}<0.05$ vs Choque; $\bullet$ p $<0.01$ vs RL.
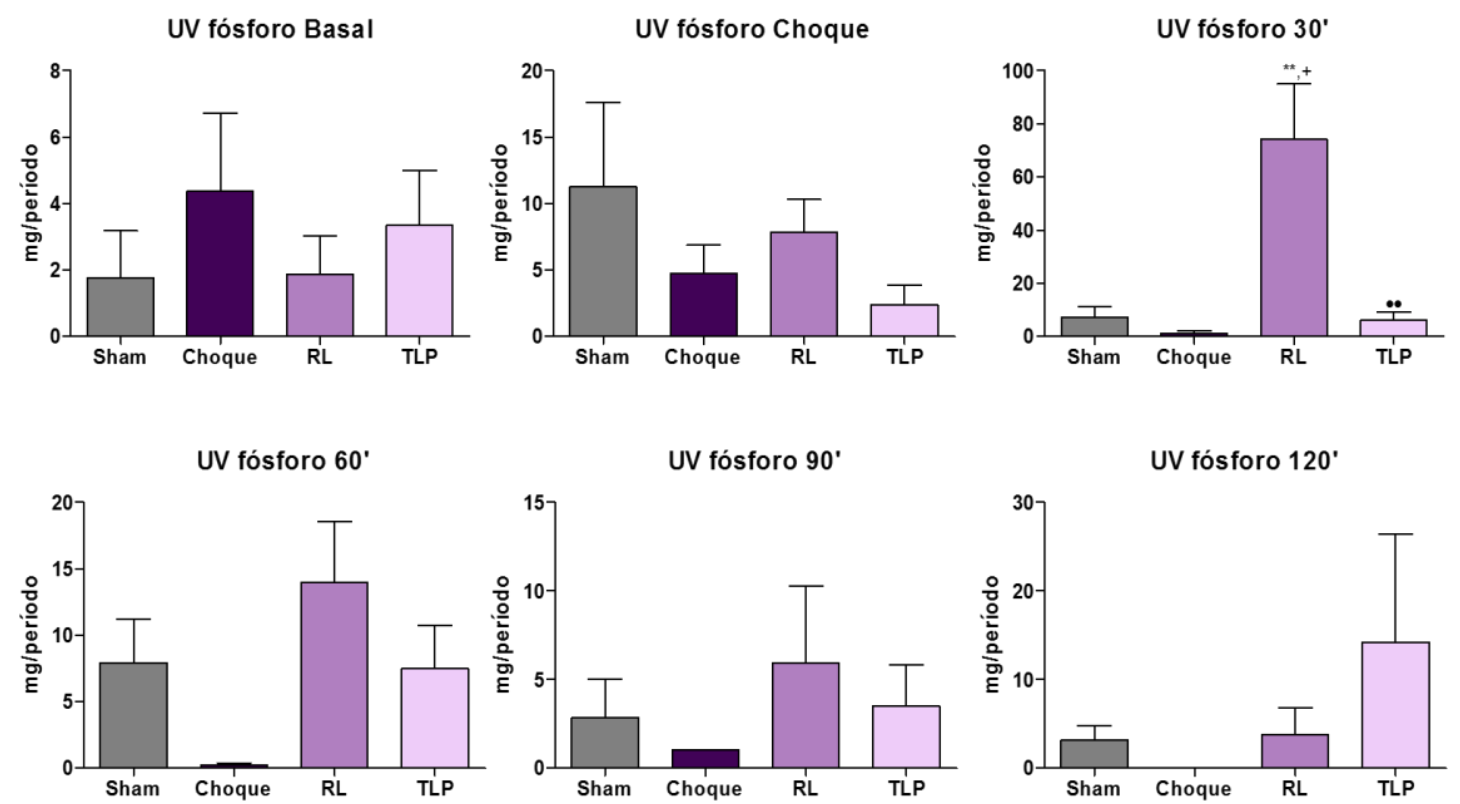

Figura 20 - Gráficos representando a excreção urinária de fósforo nos períodos basal (em torno de 50 minutos de estabilização após a preparação cirúrgica do animal); choque (50 minutos de indução e manutenção do choque - 40mmHg); 30, 60, 90 e 120 minutos após tratamento nos grupos RL (Ringer Lactato, $3 x$ o volume de sangue retirado), e TLP (Terlipressina, 2mg EV) e nos grupos não tratados Sham e Choque. ${ }^{* *} \mathrm{p}<0.01$ vs Sham; $+\mathrm{p}<0.05$ vs Choque; $\bullet \bullet p<0.01$ vs RL. 


\section{UV de Magnésio (mg/período)}

Observamos um aumento importante da excreção urinária de magnésio no grupo tratado com RL até os 60 minutos. Semelhante à excreção de potássio, cloro e fósforo, o grupo TLP manteve uma excreção acentuada de magnésio aos 120 minutos, embora não significativa (Tabela 20 e figura 21).

\begin{tabular}{lllllll}
\hline UV Mg & Basal & Choque & $\mathbf{3 0}^{\prime}$ após trat & $\mathbf{6 0}^{\prime}$ após trat & $\mathbf{9 0}^{\prime}$ após trat & $\mathbf{1 2 0}^{\prime}$ após trat \\
\hline Sham & $3,2 \pm 1,3$ & $1,8 \pm 0,4$ & $1,5 \pm 0,9$ & $1,2 \pm 0,4$ & $1,2 \pm 0,9$ & $0,7 \pm 0,5$ \\
Choque & $6,3 \pm 1,5$ & $1,2 \pm 0,2$ & $0,1 \pm 0,4$ & $0,3 \pm 0,1$ & $0,1 \pm 0,0$ & 0 \\
RL & $3,7 \pm 0,7$ & $2,2 \pm 0,6$ & $9,1 \pm 1,6^{* *++++}$ & $2,2 \pm 0,7$ & $0,4 \pm 0,1$ & $0,4 \pm 0,2$ \\
TLP & $5,2 \pm 0,9$ & $1,6 \pm 0,5$ & $2,6 \pm 1,0 \cdots$ & $2,0 \pm 0,6$ & $3,1 \pm 1,9$ & $3,3 \pm 0,8$ \\
\hline
\end{tabular}

Tabela 20 - Medidas de UV de magnésio nos períodos basal (em torno de 50 minutos de estabilização após a preparação cirúrgica do animal); choque (50 minutos de indução e manutenção do choque $-40 \mathrm{mmHg}$ ); 30, 60, 90 e 120 minutos após tratamento nos grupos RL (Ringer Lactato, 3x o volume de sangue retirado), e TLP (Terlipressina, mg EV) e nos grupos não tratados Sham e Choque. ${ }^{* *} \mathrm{p}<0.01$ vs Sham; +++ $\mathrm{p}<0.001$ vs Choque; $\cdots \bullet$ p $<0.001$ vs RL.

UV magnésio Basal

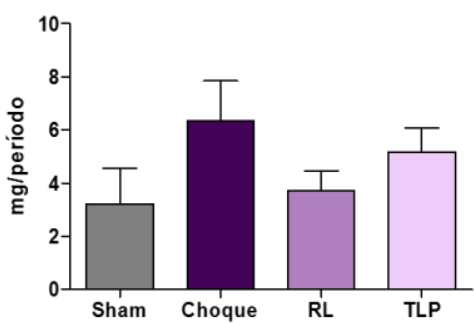

UV magnésio 60'

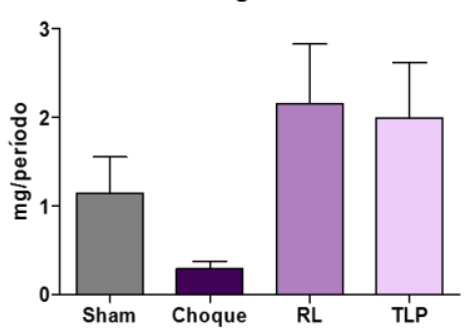

UV magnésio Choque

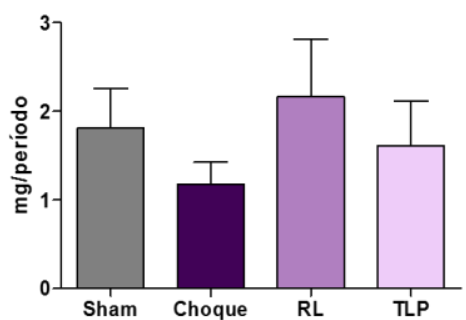

UV magnésio 90'

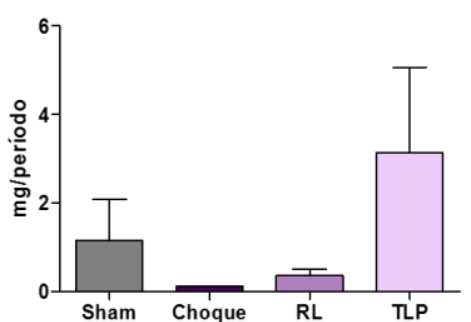

UV magnésio $30^{\circ}$

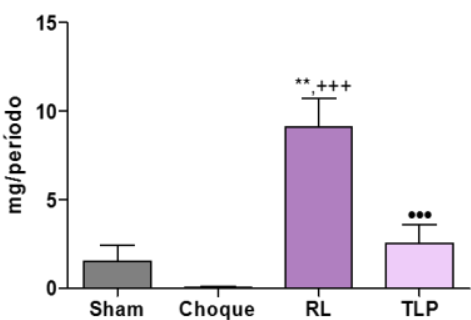

UV magnésio $120^{\circ}$

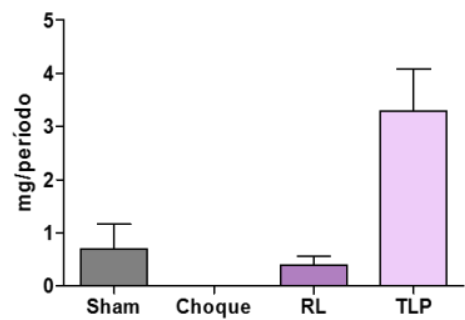

Figura 21 - Gráficos representando a excreção urinária de magnésio nos períodos basal (em torno de 50 minutos de estabilização após a preparação cirúrgica do animal); choque (50 minutos de indução e manutenção do choque - 40mmHg); 30, 60, 90 e 120 minutos após tratamento nos grupos RL (Ringer Lactato, $3 x$ o volume de sangue retirado), e TLP (Terlipressina, mg EV) e nos grupos não tratados Sham e Choque. ${ }^{* *} \mathrm{p}<0.01$ vs Sham; $+++\mathrm{p}<0.001$ vs Choque; $\bullet \bullet p<0.001$ vs RL. 


\section{UV de Ureia (mg/período)}

Observamos uma redução importante da excreção urinária de uréia no grupo $\mathrm{CH}$ em todos os momentos do experimento. No grupo RL observamos um aumento da UV de ureia aos 30 minutos após tratamento. O grupo TLP manteve a excreção urinária a níveis semelhantes ao grupo Sham (Tabela 21 e figura 22).

\begin{tabular}{lllllll}
\hline UV Ur & Basal & Choque & $\mathbf{3 0}^{\prime}$ após trat & $\mathbf{6 0}^{\prime}$ após trat & $\mathbf{9 0}^{\prime}$ após trat & $\mathbf{1 2 0}^{\prime}$ após trat \\
\hline Sham & $184,4 \pm 49,3$ & $371,8 \pm 88,1$ & $223,8 \pm 66,6$ & $210,4 \pm 43,4$ & $161,4 \pm 120$ & $162,9 \pm 113,1$ \\
Choque & $489,5 \pm 82,9$ & $117 \pm 22,9^{*}$ & $18,3 \pm 7,9$ & $15,5 \pm 2,2^{*}$ & $6,3 \pm 0,0$ & 0 \\
RL & $203,7 \pm 31,1$ & $140,9 \pm 280,6^{*}$ & $468,5 \pm 98,8^{*},++$ & $193,4 \pm 48,6^{+}$ & $58,2 \pm 21,6$ & $64,6 \pm 28,2$ \\
TLP & $428,3 \pm 94,3$ & $194,9 \pm 77,8$ & $103,3 \pm 24,4 \cdots$ & $87,6 \pm 27,9$ & $246,3 \pm 131,9$ & $282,6 \pm 103,6$ \\
\hline
\end{tabular}

Tabela 21 - Medidas de UV de ureia nos períodos basal (em torno de 50 minutos de estabilização após a preparação cirúrgica do animal); choque (50 minutos de indução e manutenção do choque - 40mmHg); 30 , 60, 90 e 120 minutos após tratamento nos grupos RL (Ringer Lactato, 3x o volume de sangue retirado), e TLP (Terlipressina, $2 \mathrm{mg}$ EV) e nos grupos não tratados Sham e Choque. * ${ }^{*}<0.05$ vs Sham; $+\mathrm{p}<0.05$ vs Choque; $++\mathrm{p}<0.01$ vs Choque; $\bullet \bullet p<0.001$ vs RL.
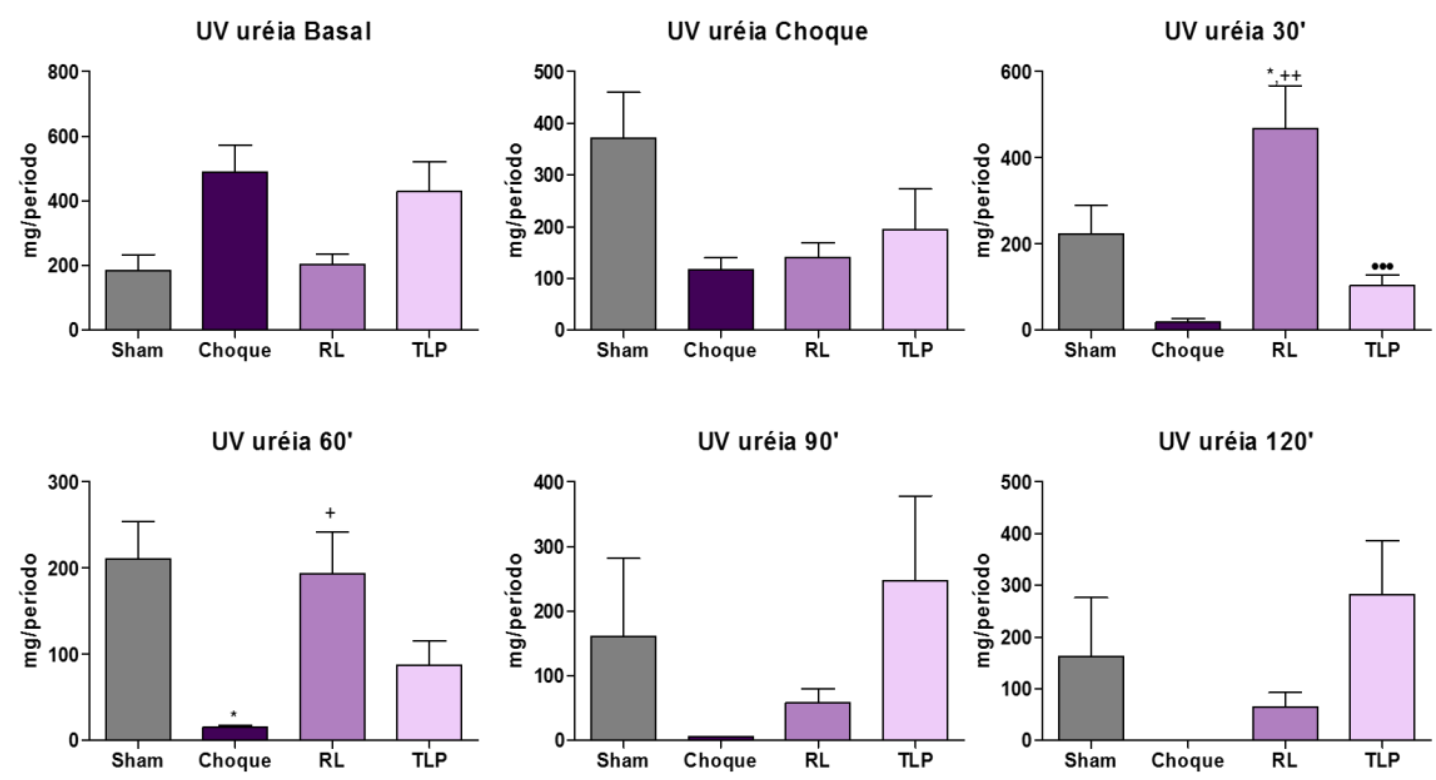

Figura 22 - Gráficos representando a excreção urinária de ureia nos períodos basal (em torno de 50 minutos de estabilização após a preparação cirúrgica do animal); choque (50 minutos de indução e manutenção do choque - 40mmHg); 30, 60, 90 e 120 minutos após tratamento nos grupos RL (Ringer Lactato, 3x o volume de sangue retirado), e TLP (Terlipressina, $2 \mathrm{mg}$ EV) e nos grupos não tratados Sham e Choque. ${ }^{*} \mathrm{p}<0.05$ vs Sham; $+\mathrm{p}<0.05$ vs Choque; $++\mathrm{p}<0.01$ vs Choque; $\bullet \bullet p<0.001$ vs RL. 


\section{Diurese $(\mathrm{ml} / \mathrm{kg})$}

Observamos uma diminuição da diurese nos animais após o insulto do CH. A administração de RL foi capaz de aumentar a diurese dos animais aos 30 e 60 minutos pós tratamento, como já era o esperado em conseqüência da grande expansão volêmica. Entretanto, o tratamento com TLP aos 90 e 120 minutos foi mais eficaz na manutenção da diurese dos animais (Tabela 22 e figura 23).

\begin{tabular}{lllllll}
\hline Diurese & Basal & Choque & $\mathbf{3 0}^{\prime}$ após trat & $\mathbf{6 0}^{\prime}$ após trat & $\mathbf{9 0}^{\prime}$ após trat & $\mathbf{1 2 0}^{\prime}$ após trat \\
\hline Sham & $15,3 \pm 6,7$ & $28,3 \pm 9,3$ & $16 \pm 4,9$ & $13,7 \pm 2,9$ & $14,5 \pm 7,5$ & $14,5 \pm 5,5$ \\
Choque & $37,4 \pm 6,8$ & $10,6 \pm 2,0$ & $2,3 \pm 0,9$ & $1,7 \pm 0,6$ & $2,5 \pm 0,0$ & $1 \pm 0,0$ \\
RL & $26,9 \pm 10,4$ & $12,9 \pm 3,1$ & $201,3 \pm 42,6^{* * *},+++$ & $32,1 \pm 9,2+$ & $10,4 \pm 4,5$ & $10,8 \pm 5,4$ \\
TLP & $26,4 \pm 4,6$ & $13,4 \pm 5,5$ & $9,1 \pm 2,1 \cdots$ & $12,7 \pm 4,1$ & $14 \pm 5,1$ & $15,6 \pm 5,2$
\end{tabular}

Tabela 22 - Medidas de diurese nos períodos basal (em torno de 50 minutos de estabilização após a preparação cirúrgica do animal); choque (50 minutos de indução e manutenção do choque - 40mmHg); 30, 60, 90 e 120 minutos após tratamento nos grupos RL (Ringer Lactato, 3x o volume de sangue retirado), e TLP (Terlipressina, $2 \mathrm{mg}$ EV) e nos grupos não tratados Sham e Choque. $\quad$ *** $\mathrm{p}<0.001$ vs Sham; +++ $\mathrm{p}^{<}$ 0.001 vs Choque; $\cdots \bullet p<0.001$ vs RL; $+\mathrm{p}<0.05$ vs Choque.
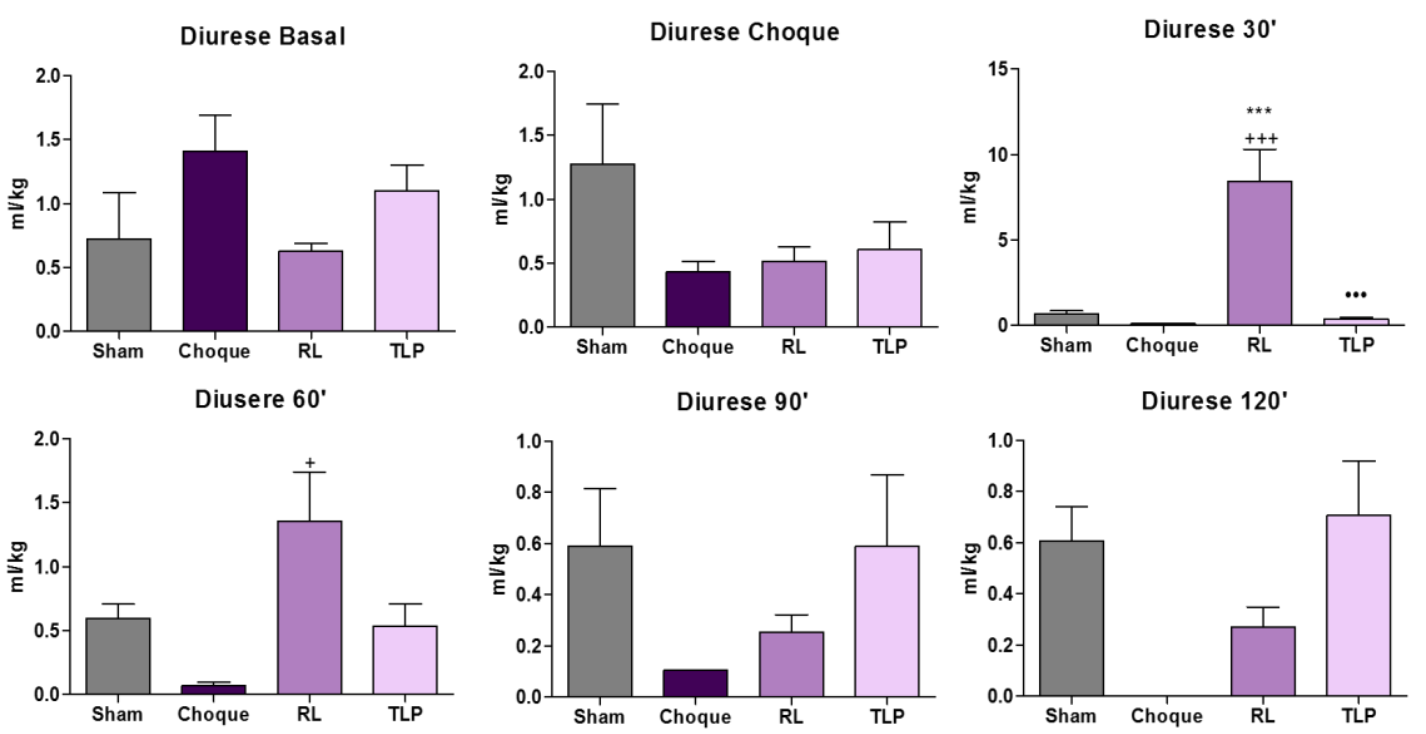

Figura 23 - Gráficos representando as medidas de diurese nos animais nos períodos basal (em torno de 50 minutos de estabilização após a preparação cirúrgica do animal); choque (50 minutos de indução e manutenção do choque -40mmHg); 30, 60, 90 e 120 minutos após tratamento nos grupos RL (Ringer Lactato, 3x o volume de sangue retirado), e TLP (Terlipressina, 2mg EV) e nos grupos não tratados Sham e Choque. ${ }^{* * *} \mathrm{p}<0.001$ vs Sham; $+++\mathrm{p}<0.001$ vs Choque; $\cdots$ p $<0.001$ vs $R L ;+p<0.05$ vs Choque. 


\section{Osmolalidade urinária}

Observou-se uma tendência a diminuição na osmolalidade urinária após 30 minutos de $\mathrm{CH}$, principalmente no grupo RL. O tratamento com TLP manteve relativamente constante a osmolalidade urinária durante todo o experimento (Tabela 23 e figura 24 ).

\begin{tabular}{lllllll}
\hline Osm. Ur & Basal & Choque & 30' após trat $^{\prime}$ & $\mathbf{6 0}^{\prime}$ após trat & 90' após trat $^{\prime}$ & 120' após trat $^{\prime}$ ap \\
\hline Sham & $735,8 \pm 96,1$ & $748,7 \pm 102,3$ & $739 \pm 85,7$ & $734,6 \pm 90,6$ & $636,5 \pm 59,5$ & $617,5 \pm 59,5$ \\
Choque & $563,4 \pm 95,7$ & $592,6 \pm 65,5$ & $446,5 \pm 154,5$ & $541,3 \pm 92,2$ & $276 \pm 0,0$ & $793 \pm 0,0$ \\
RL & $621,0 \pm 39,6$ & $629,3 \pm 37,3$ & $368,6 \pm 15,5^{\star \star *}$ & $464,7 \pm 27,8^{* *}$ & $459,6 \pm 31$ & $462,8 \pm 25,5$ \\
TLP & $659,0 \pm 46,8$ & $693,5 \pm 45,9$ & $593,4 \pm 54,4^{*}$ & $522 \pm 39,5^{*}$ & $535,7 \pm 27$ & $653 \pm 91,2$ \\
\hline
\end{tabular}

Tabela 23 - Medidas de osmolalidade urinária nos períodos basal (em torno de 50 minutos de estabilização após a preparação cirúrgica do animal); choque (50 minutos de indução e manutenção do choque 40mmHg); 30, 60, 90 e 120 minutos após tratamento nos grupos RL (Ringer Lactato, 3x o volume de sangue retirado), e TLP (Terlipressina, $2 \mathrm{mg}$ EV) e nos grupos não tratados Sham e Choque. ** $\mathrm{p}<0.001$ vs Sham; •• $\mathrm{p}<0.01$ vs RL; ${ }^{* *} \mathrm{p}<0.01$ vs Sham; ${ }^{\text {p }}<0.05$ vs Sham.
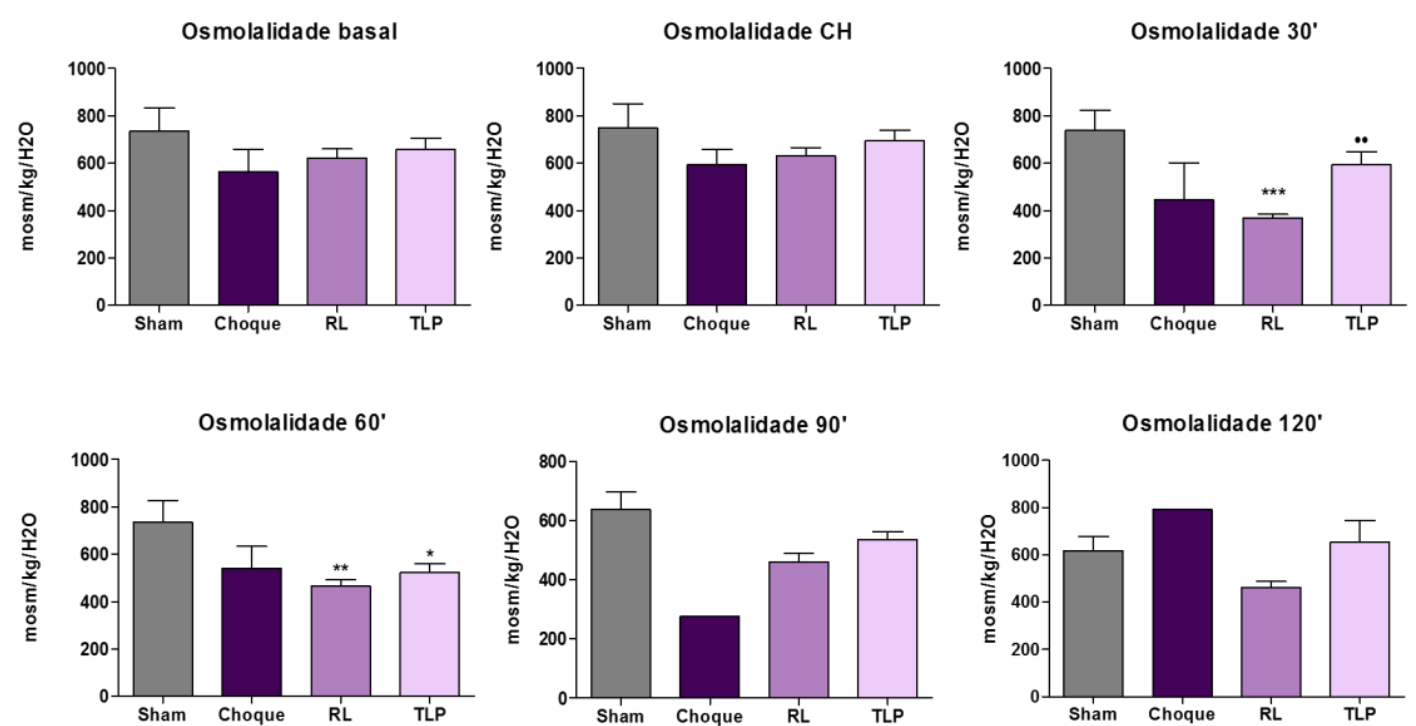

Figura 24 - Gráficos representando as medidas de osmolalidade urinária nos períodos basal (em torno de 50 minutos de estabilização após a preparação cirúrgica do animal); choque (50 minutos de indução e manutenção do choque -40mmHg); 30, 60, 90 e 120 minutos após tratamento nos grupos RL (Ringer Lactato, 3x o volume de sangue retirado), e TLP (Terlipressina, 2mg EV) e nos grupos não tratados Sham e Choque. ${ }^{* *} \mathrm{p}<0.001$ vs Sham; $\bullet p<0.01$ vs RL; ${ }^{* *} \mathrm{p}<0.01$ vs Sham; * $\mathrm{p}<0.05$ vs Sham. 


\section{Dosagem de estresse oxidativo de tecido de córtex renal - TBARS}

Não observamos diferença estatística aos 60 minutos pós tratamento entre os grupos. Aos 120 minutos todos os grupos submetidos ao $\mathrm{CH}$ apresentaram aumento no nível de TBARS e os dois tipos tratamento não foram capazes de normalizá-los (Figura 25).
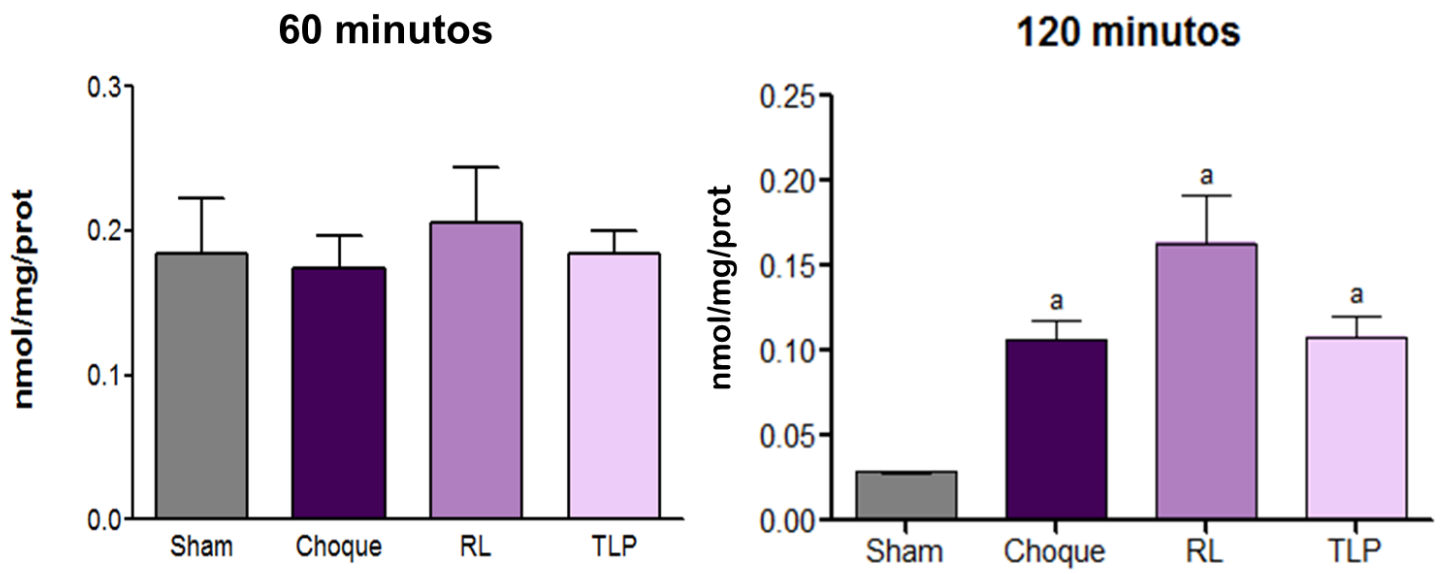

Figura 25 - Medidas de estresse oxidativo em tecido de córtex renal nos grupos Sham, Choque, RL e TLP nos períodos de 60 e 120 minutos após o tratamento. a p<0.05 vs Sham 


\section{Medida de escore de lesão renal}

Foram analisados os tecidos de cortex renal aos 60 minutos para obtenção do escore de lesão. Foi observado um alto escore de lesão nos animais do grupo Choque, e os dois tratamentos diminuíram a lesão renal nos animais (Figura 26).

\section{Escore de lesão}
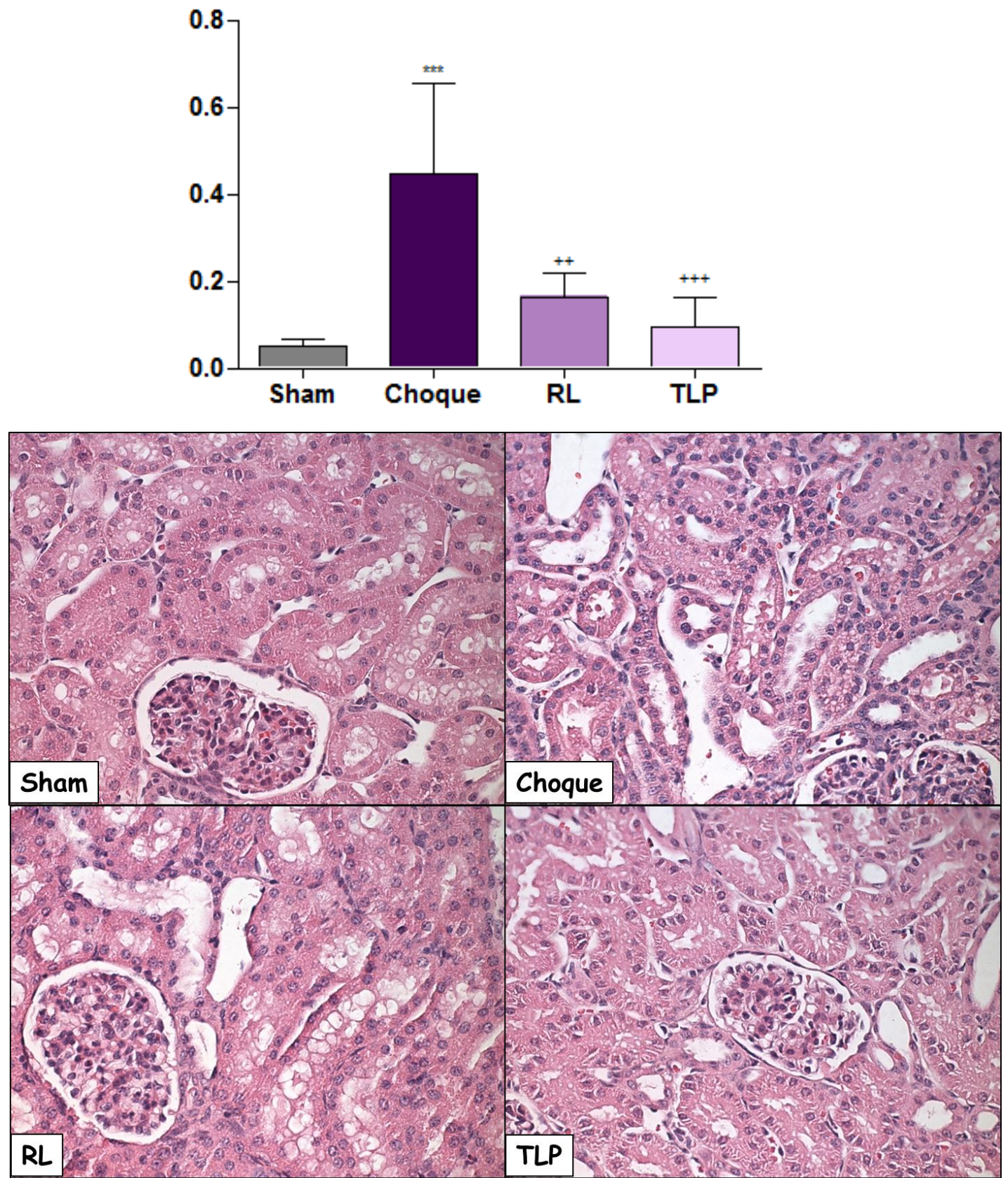

Figura 26 - Medidas do escore de lesão em tecido de córtex renal nos grupos Sham, Choque, RL e TLP no período de 60 minutos após o tratamento ${ }^{* * *} \mathrm{p}<0.001$ vs Sham; ${ }^{++} \mathrm{p}<0.01$ vs $\mathrm{CH} ;{ }^{+++} \mathrm{p}<0.001$ vs $\mathrm{CH}$. 


\section{Expressão de proteínas transportadoras de íons e água em tecido renal}

por Western Blott

As avaliações das proteínas transportadoras de sódio (NKCC2) e água (AQP2) foram feitas no tempo 60 e 120 minutos. Estas proteínas são importantes no mecanismo de concentração urinária.

\section{- Expressão da AQP2 aos 60 minutos}

Como era de se esperar, há uma diminuição da expressão da AQP2 no grupo choque aos 60 minutos. O grupo RL mantem também a expressão diminuída em relação ao grupo sham. No grupo TLP há manutenção da expressão da AQP2 e esta expressão é maior que nos grupos choque e RL (Tabela 24 e figura 27).

\begin{tabular}{l|clll}
\hline $\mathbf{6 0}$ minutos & Sham & Choque & RL & TLP \\
\hline AQP2 (\%) & $100 \pm 1,1$ & $52,5 \pm 3,2^{* * *}$ & $38,7 \pm 6,6^{* \star *}$ & $82,5 \pm 7,8^{++,} \cdots$ \\
\hline
\end{tabular}

Tabela 24 - Média e erro padrão referentes a expressão de AQP2 aos 60 minutos nos grupos Sham, Choque, RL e TLP. ${ }^{* * *}$ p $<0.001$ vs Sham; ++ p $<0.01$ vs Choque; $\bullet \bullet p<0.001$ vs RL 


\section{0 minutos}
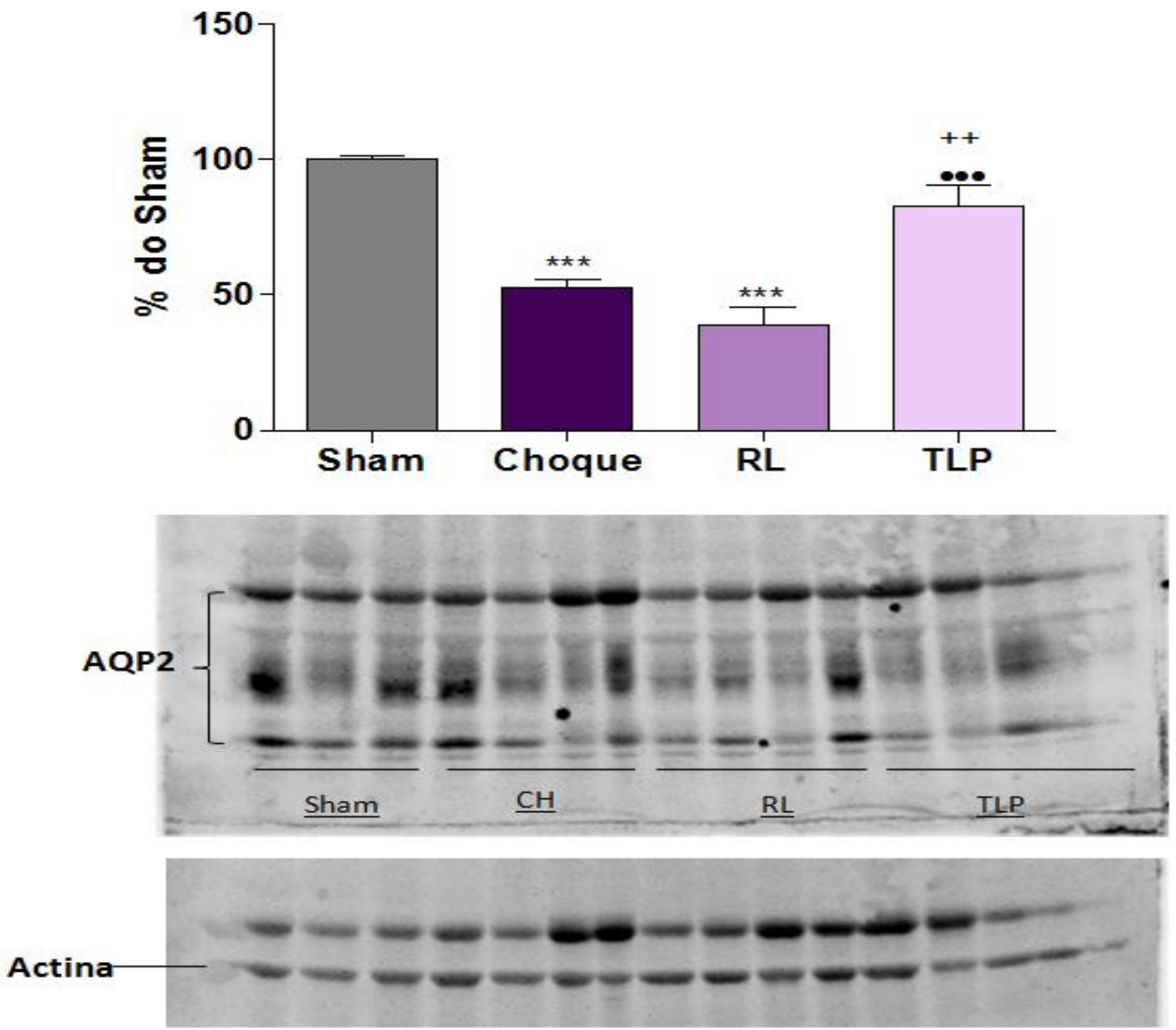

Figura 27 - Gráfico e bandas de gel de Western Blotting representando a expressão proteica de AQP2 em tecido renal nos grupos Sham, Choque, RL e TLP aos 60 minutos após o tratamento. ${ }^{* * *} \mathrm{p}<0.001$ vs Sham; $++\mathrm{p}<0.01$ vs Choque; $\cdots \cdot \mathrm{p}<0.001$ vs RL 


\section{- Expressão da AQP2 aos 120 minutos}

Houve normalização da expressão de AQP2 em medula renal nos animais tratados, após 120 minutos, com TLP, o qual não foi observado no grupo tratado com RL (Tabela 25 e figura 28).

\begin{tabular}{l|clll}
\hline $\mathbf{1 2 0}$ minutos & Sham & Choque & RL & TLP \\
\hline AQP2 (\%) & $96,7 \pm 3,3$ & $22,5 \pm 2,5^{\mathrm{a}}$ & $43,3 \pm 12,0^{\mathrm{a}}$ & $107,5 \pm 4,8^{\mathrm{b}}$ \\
\hline
\end{tabular}

Tabela 25 - Média e erro padrão referentes a expressão de AQP2 aos 120 minutos nos grupos Sham, Choque, RL e TLP. a $\mathrm{p}<0.001$ vs Sham; ${ }^{\mathrm{b}} \mathrm{p}<0.001$ vs $\mathrm{CH}$ e RL.

\section{0 minutos}
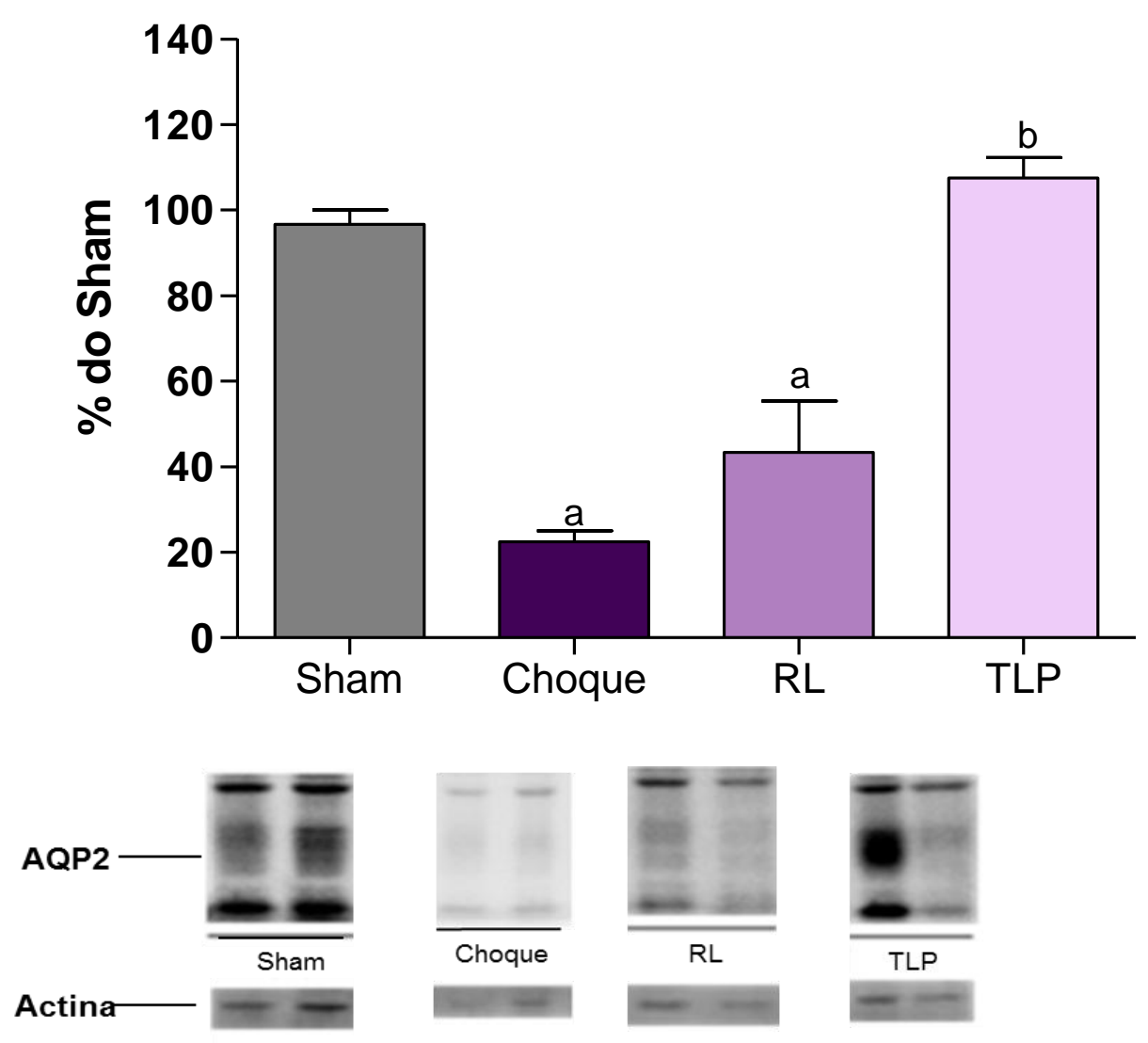

Figura 28 - Gráfico e bandas de gel de Western Blotting representando a expressão proteica de AQP2 em tecido renal nos grupos Sham, Choque, RL e TLP aos 120 minutos após o tratamento. ${ }^{a} \mathrm{p}<0.001$ vs Sham; ${ }^{b}$ $\mathrm{p}<0.001$ vs CH e RL. 


\section{- Expressão da proteína NKCC2 aos 60 minutos}

Como também era de se esperar a proteína NKCC2 estava diminuída no grupo choque. Entretanto, tanto o tratamento com RL e TLP mantiveram a expressão em níveis semelhantes ao grupo Sham (Tabela 26 e figura 29).

\begin{tabular}{l|clll}
\hline 60 minutos & Sham & Choque & RL & TLP \\
\hline NKCC2 (\%) & $99,3 \pm 0,7$ & $38,7 \pm 18,1^{*+}$ & $100 \pm 0,8^{++}$ & $90 \pm 6,1^{++}$ \\
\hline
\end{tabular}

Tabela 26 - Média e erro padrão referentes a expressão de NKCC2 aos 60 minutos dos grupos Sham, Choque, RL e TLP. ${ }^{* *} \mathrm{p}<0.01$ vs Sham; $++\mathrm{p}<0.01$ vs Choque.

\section{0 minutos}

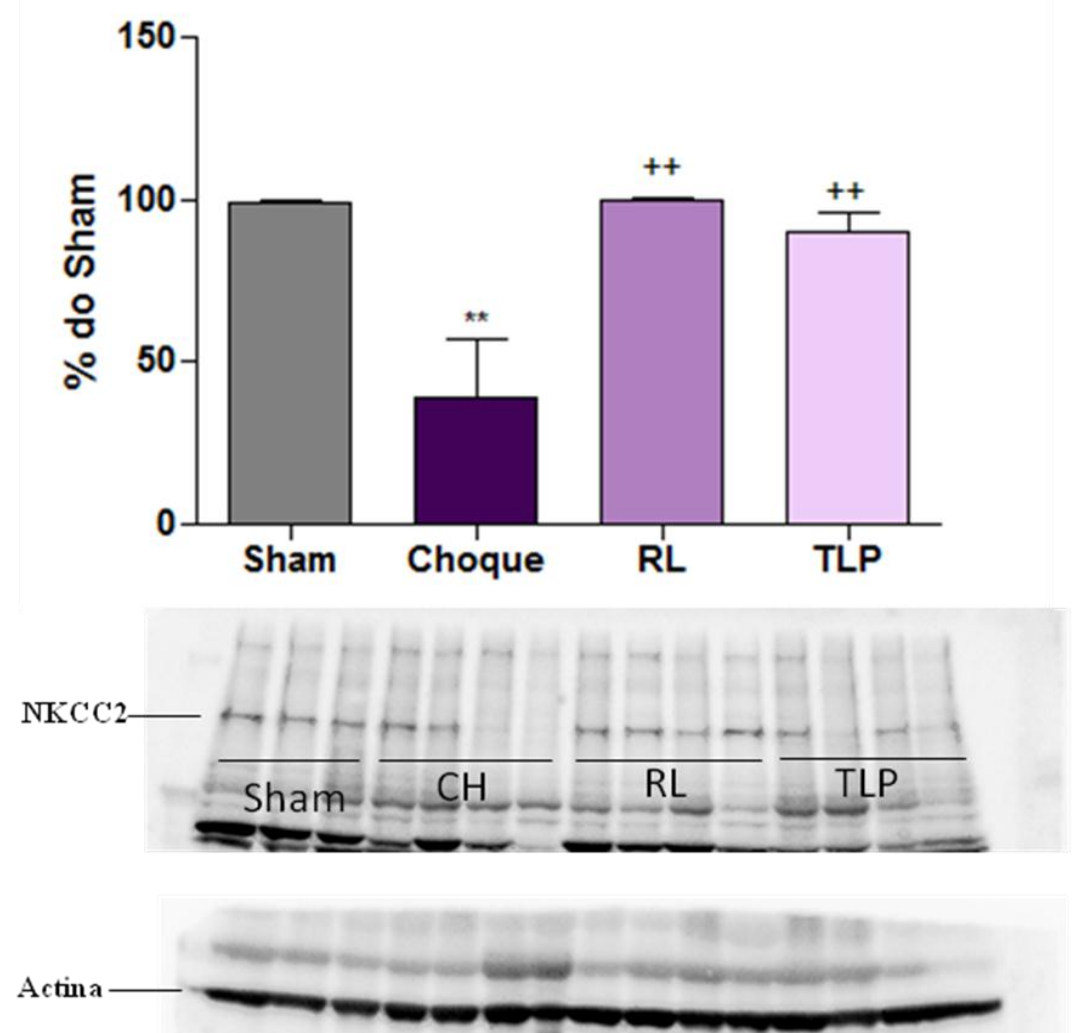

Figura 29 - Gráfico e bandas de gel de Western Blotting representando a expressão proteica de NKCC2 em tecido renal nos grupos Sham, Choque, RL e TLP aos 60 minutos após o tratamento ** $\mathrm{p}<0.01$ vs Sham; ++ $\mathrm{p}<0.01$ vs Choque. 


\section{- Expressão da proteína NKCC2 aos 120 minutos}

$\mathrm{O}$ insulto do $\mathrm{CH}$ diminuiu a expressão protéica de NKCC2. Ambos os tratamentos foram capazes de restaurar essa expressão, sendo que o tratamento com TLP a normalizou. (Tabela 27 e figura 30).

\begin{tabular}{l|clll}
\hline 120 minutos & Sham & Choque & RL & TLP \\
\hline NKCC2 (\%) & $101,7 \pm 1,7$ & $27,5 \pm 4,8^{\mathrm{a}}$ & $50,0 \pm 20,8^{\mathrm{b}}$ & $92,5 \pm 12,5^{\mathrm{c}, \mathrm{d}}$ \\
\hline
\end{tabular}

Tabela 27 - Média e erro padrão referentes a expressão de NKCC2 aos 120 minutos dos grupos Sham, Choque, RL e TLP. a $\mathrm{p}<0.01$ vs. Sham; ${ }^{b} \mathrm{p}<0.05$ vs. Sham; ${ }^{\mathrm{c}} \mathrm{p}<0.01$ vs. $\mathrm{CH}$; ${ }^{\mathrm{d}} \mathrm{p}<0.05$ vs. RL.

\section{0 minutos}

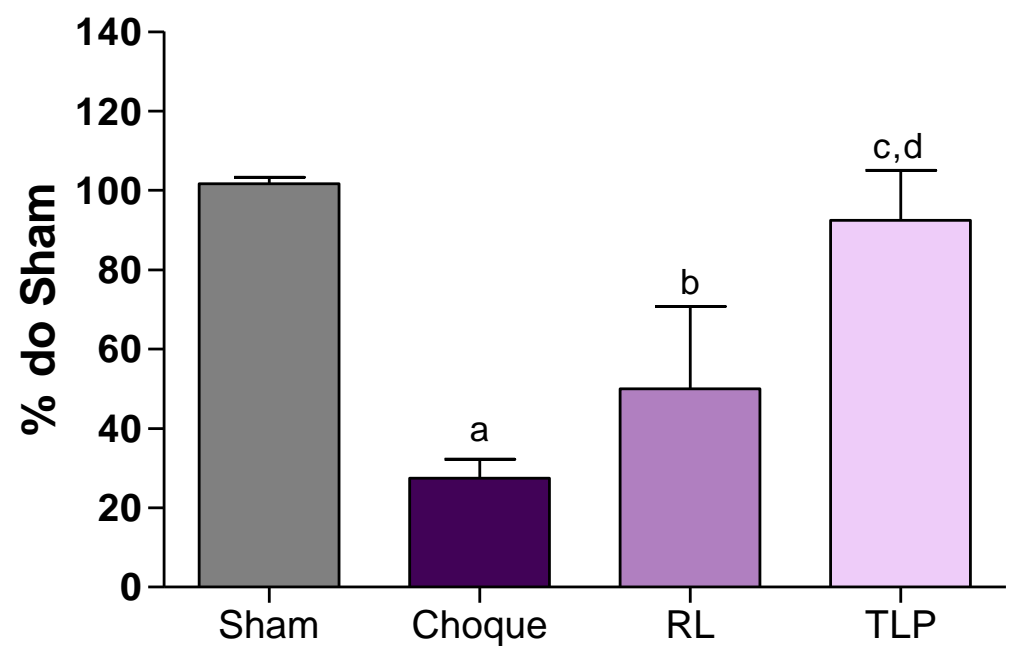

NKCC2

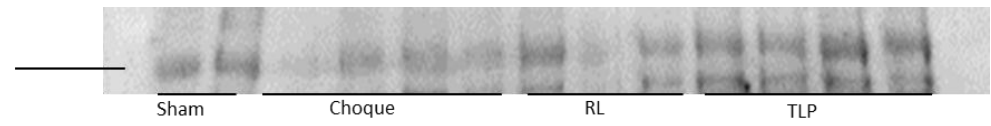

Actina

Figura 30 - Gráfico e bandas de gel de Western Blotting representando a expressão proteica de NKCC2 em tecido renal nos grupos Sham, Choque, RL e TLP aos 120 minutos após o tratamento. a $\mathrm{p}<0.01$ vs. Sham; b $\mathrm{p}<0.05$ vs. Sham; ${ }^{\mathrm{c}} \mathrm{p}<0.01$ vs. CH; d $\mathrm{p}<0.05$ vs. RL. 


\section{- Expressão dos receptores V1 e V2 aos 60 minutos}

A expressão do receptor V1 está aumentada no grupo choque em relação ao grupo sham. Tanto o tratamento com RL quanto o tratamento com TLP foi capaz de manter a expressão deste receptor (Tabela 28 e figura 31).

\begin{tabular}{l|clll}
\hline $\mathbf{6 0}$ minutos & Sham & Choque & RL & TLP \\
\hline V1 (\%) & $93,3 \pm 4,4$ & $130,5 \pm 6,8^{* *}$ & $80,0 \pm 4,6^{+++}$ & $107,5 \pm 4,8^{++,} \cdot \boldsymbol{~}$ \\
\hline
\end{tabular}

Tabela 28 - Média e erro padrão referentes a expressão de V1 aos 60 minutos dos grupos Sham, Choque, RL e TLP. ${ }^{* *} \mathrm{p}<0.01$ vs Sham; $+++\mathrm{p}<0.001$ vs Choque; $++\mathrm{p}<0.01$ vs Choque; $\bullet \bullet p<0.01$ vs RL.

\section{0 minutos}
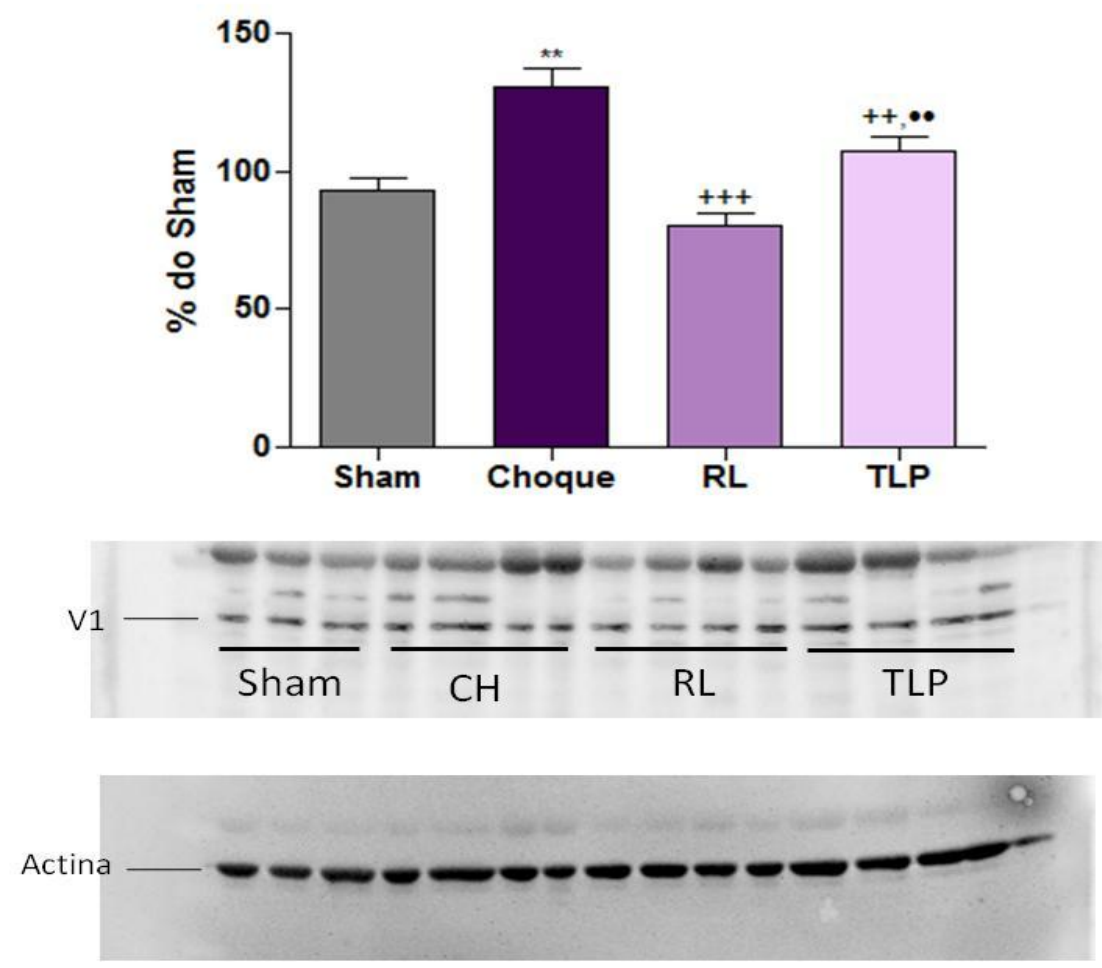

Figura 31 - Gráfico e bandas de gel de Western Blotting representando a expressão proteica de V1 em tecido renal nos grupos Sham, Choque, RL e TLP aos 60 minutos após o tratamento. ${ }^{* *}$ p $<0.01$ vs Sham; $+++\mathrm{p}<0.001$ vs Choque; $++\mathrm{p}<0.01$ vs Choque; $\bullet \bullet p<0.01$ vs RL. 
A apresentação da expressão do receptor V2 é muito semelhante a do receptor V1. Há um aumento importante da expressão deste receptor no grupo choque aos 60 minutos. Os grupos que foram tratados mantiveram a expressão do receptor semelhante ao grupo Sham (Tabela 29 e figura 32).

\begin{tabular}{l|llll}
\hline 60 minutos & Sham & Choque & RL & TLP \\
\hline V2 (\%) & $103,0 \pm 2,4$ & $144,3 \pm 8,1^{* *}$ & $103,3 \pm 2,7^{++}$ & $117,0 \pm 12,1^{+}$ \\
\hline
\end{tabular}

Tabela 29 - Média e erro padrão referentes a expressão de V2 aos 60 minutos dos grupos Sham, Choque, RL e TLP. ${ }^{* *} \mathrm{p}<0.01$ vs Sham; $++\mathrm{p}<0.01$ vs Choque; $+\mathrm{p}<0.05$ vs Choque

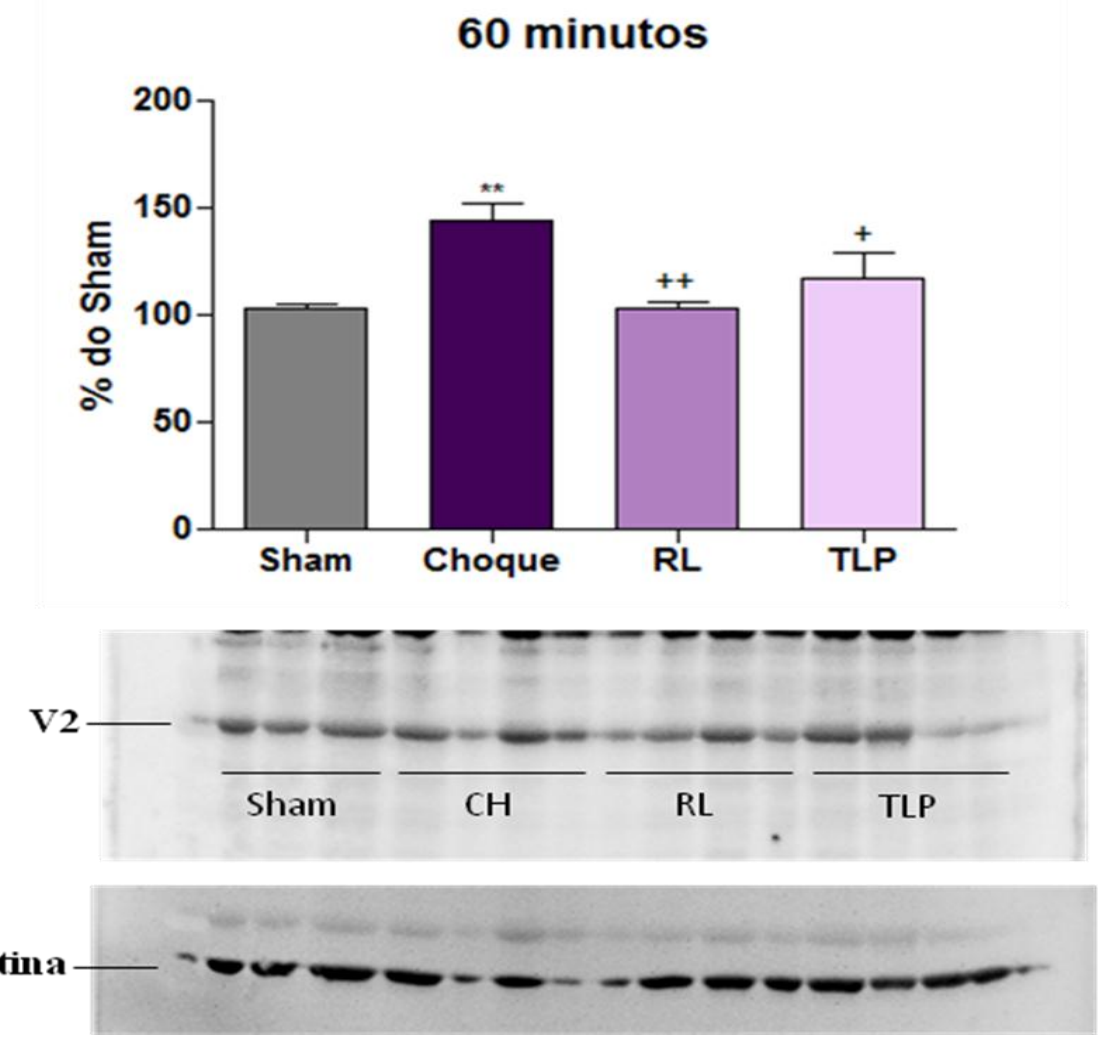

Figura 32 - Gráfico e bandas de gel de Western Blotting representando a expressão proteica de V2 em tecido renal nos grupos Sham, Choque, RL e TLP aos 60 minutos após o tratamento. ${ }^{* *}$ p $<0.01$ vs Sham; $++\mathrm{p}<0.01$ vs Choque; $+\mathrm{p}<0.05$ vs Choque. 


\section{- Expressão dos receptores V1 e V2 aos 120 minutos}

Aos 120 minutos há uma diminuição da expressão de V1 no grupo RL em relação a todos os outros grupos. O receptor V1 no grupo Choque se mantém elevado semelhante aos 60 minutos. No TLP também há uma elevação da expressão em relação ao Sham (Tabela 30 e figura 33).

\begin{tabular}{l|llll}
\hline $\mathbf{1 2 0}$ minutos & Sham & Choque & RL & TLP \\
\hline V1 (\%) & $100,0 \pm 0,6$ & $112,3 \pm 1,4^{*}$ & $74,0 \pm 6,7^{* * *},+++$ & $109,8 \pm 2,0^{*}, \cdots$ \\
\hline
\end{tabular}

Tabela 30 - Média e erro padrão referentes a expressão de V1 aos 120 minutos dos grupos Sham, Choque, RL e TLP. ${ }^{*} \mathrm{p}<0.05$ vs Sham; ${ }^{* * *} \mathrm{p}<0.001$ vs Sham; $+++\mathrm{p}<0.001$ vs Choque; $\bullet \bullet \bullet p<0.001$ vs RL.

\section{0 minutos}

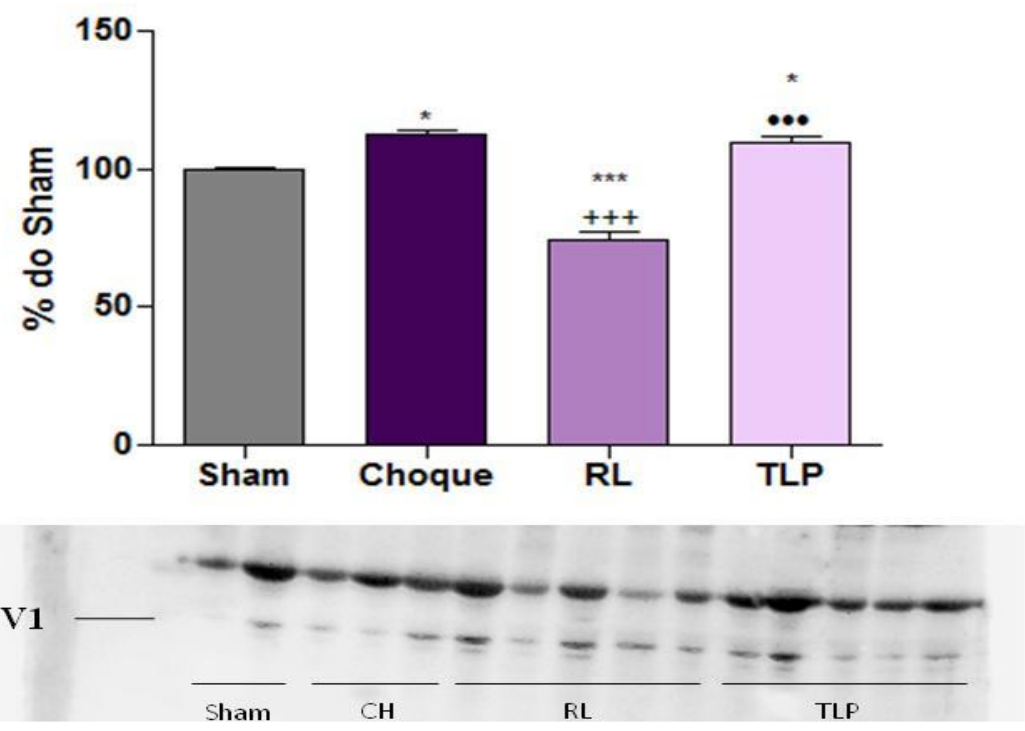

Actina

Figura 33 - Gráfico e bandas de gel de Western Blotting representando a expressão proteica de V1 em tecido renal nos grupos Sham, Choque, RL e TLP aos 120 minutos após o tratamento. * $\mathrm{p}<0.05$ vs Sham; *** p $<0.001$ vs Sham; +++ p $<0.001$ vs Choque; $\bullet \bullet p<0.001$ vs RL 
A expressão do receptor V2 aos 120 minutos se apresenta semelhante ao que foi encontrado aos 60 minutos. $\mathrm{O}$ grupo choque apresenta um aumento importante da expressão em relação aos outros grupos(Tabela 31 e figura 34).

\begin{tabular}{l|clll}
\hline 120 minutos & Sham & Choque & RL & TLP \\
\hline V2 (\%) & $98,3 \pm 4,4$ & $121,7 \pm 4,4^{* *}$ & $89,6 \pm 5,5++$ & $96,6 \pm 1,9++$ \\
\hline
\end{tabular}

Tabela 31 - Média e erro padrão referentes a expressão de V2 aos 120 minutos dos grupos Sham, Choque, RL e TLP. ${ }^{* *} \mathrm{p}<0.01$ vs Sham; $++\mathrm{p}<0.01$ vs Choque.

\section{0 minutos}

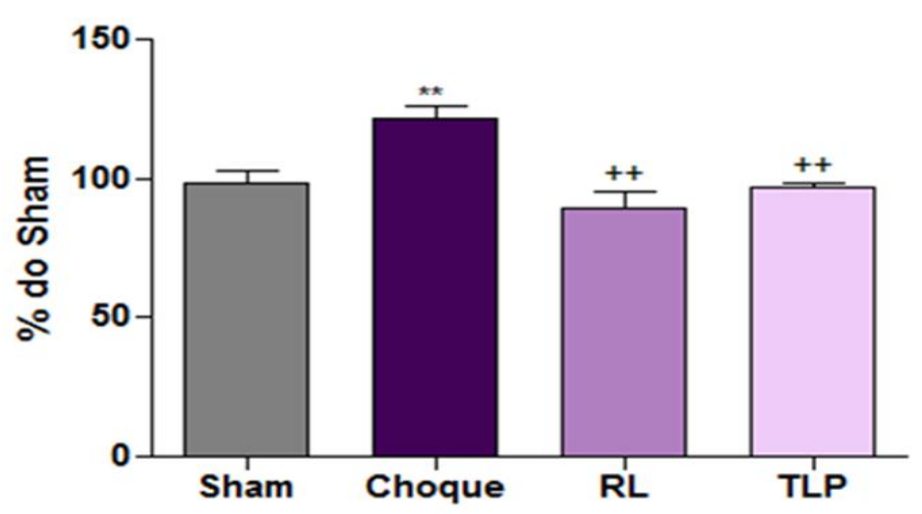

v2
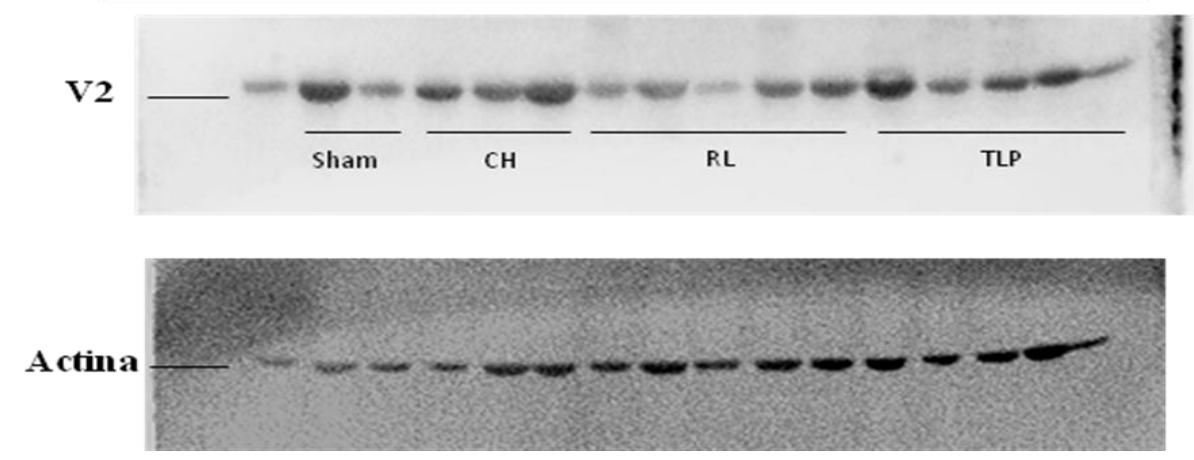

Figura 34 - Gráfico e bandas de gel de Western Blotting representando a expressão proteica de V2 em tecido renal nos grupos Sham, Choque, RL e TLP aos 120 minutos após o tratamento. ** $\mathrm{p}<0.01$ vs Sham; $++\mathrm{p}<0.01$ vs Choque. 


\section{- Expressão da proteína BAX em tecido renal aos 60}

Quanto à expressão de BAX, não houve diferença entre os grupos aos 60 minutos (Tabela 32 e figura 35).

\begin{tabular}{l|clll}
\hline 60 minutos & Sham & Choque & RL & TLP \\
\hline BAX (\%) & $99,0 \pm 0,6$ & $102,3 \pm 2,6$ & $94,5 \pm 7,6$ & $102,3 \pm 5,0$ \\
\hline
\end{tabular}

Tabela 32 - Média e erro padrão referentes a expressão de BAX aos 60 minutos dos grupos Sham, Choque, RL e TLP.

\section{0 minutos}
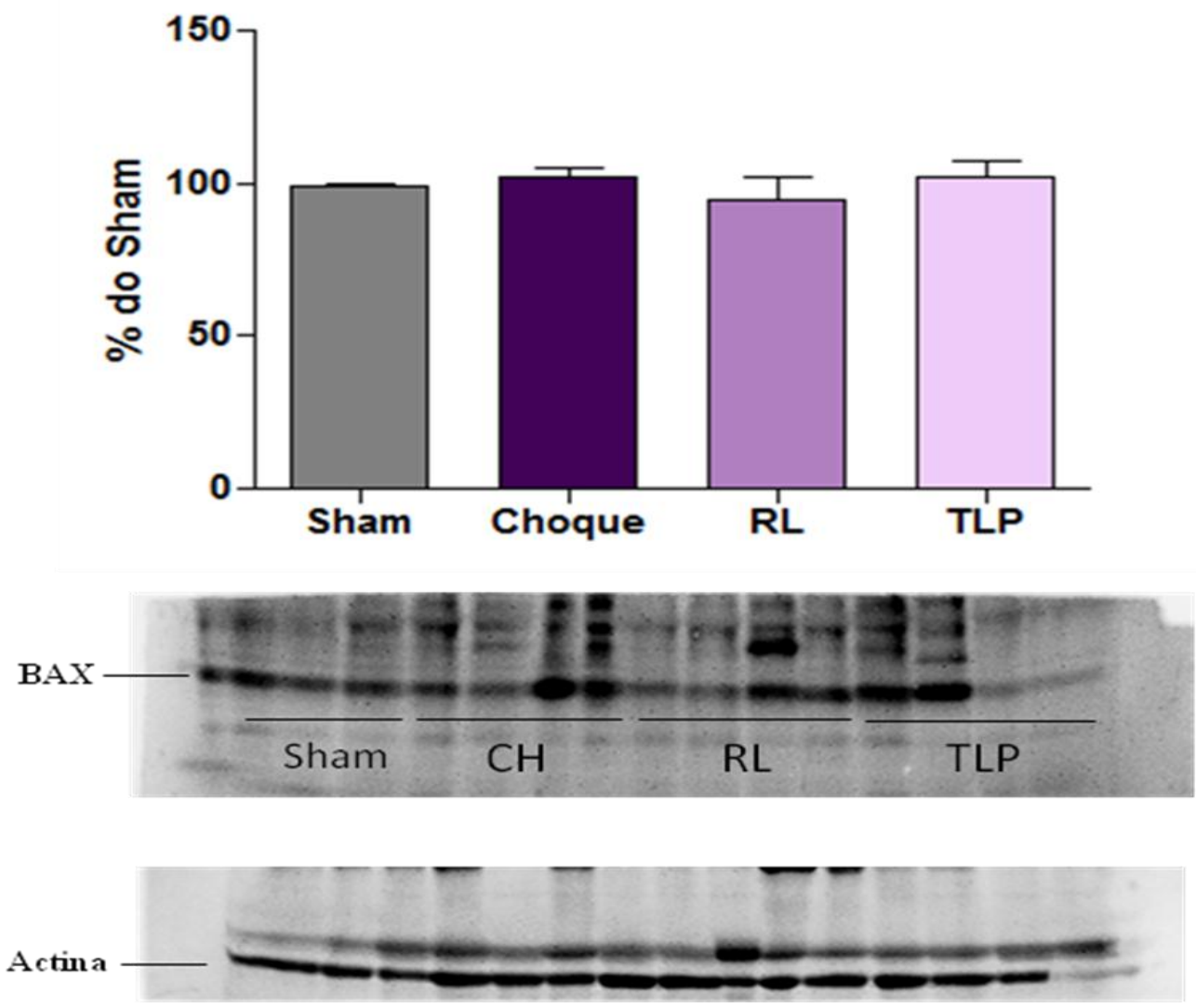

Figura 35 - Gráfico e bandas de gel de Western Blotting representando a expressão proteica de BAX em tecido renal nos grupos Sham, Choque, RL e TLP aos 60 minutos após o tratamento. 


\section{- Expressão da proteína BAX em tecido renal aos 120}

Aos 120 minutos, observamos níveis mais altos do marcador de apoptose BAX nos grupos Choque e RL, e uma normalização no grupo tratado com TLP, demonstrando assim uma proteção do tratamento no tecido renal (Tabela 33 e figura 36).

\begin{tabular}{l|clll}
\hline 120 minutos & Sham & Choque & RL & TLP \\
\hline BAX (\%) & $99,0 \pm 0,6$ & $138,8 \pm 5,1^{\mathrm{a}}$ & $130,0 \pm 10,0^{\mathrm{a}}$ & $97,5 \pm 8,5^{\mathrm{b}, \mathrm{c}}$ \\
\hline
\end{tabular}

Tabela 33 - Média e erro padrão referentes a expressão de BAX aos 120 minutos dos grupos Sham, Choque, RL e TLP. a $p<0.05$ vs. Sham; $b$ p $<0.01$ vs. CH; c $p<0.05$ vs RL.

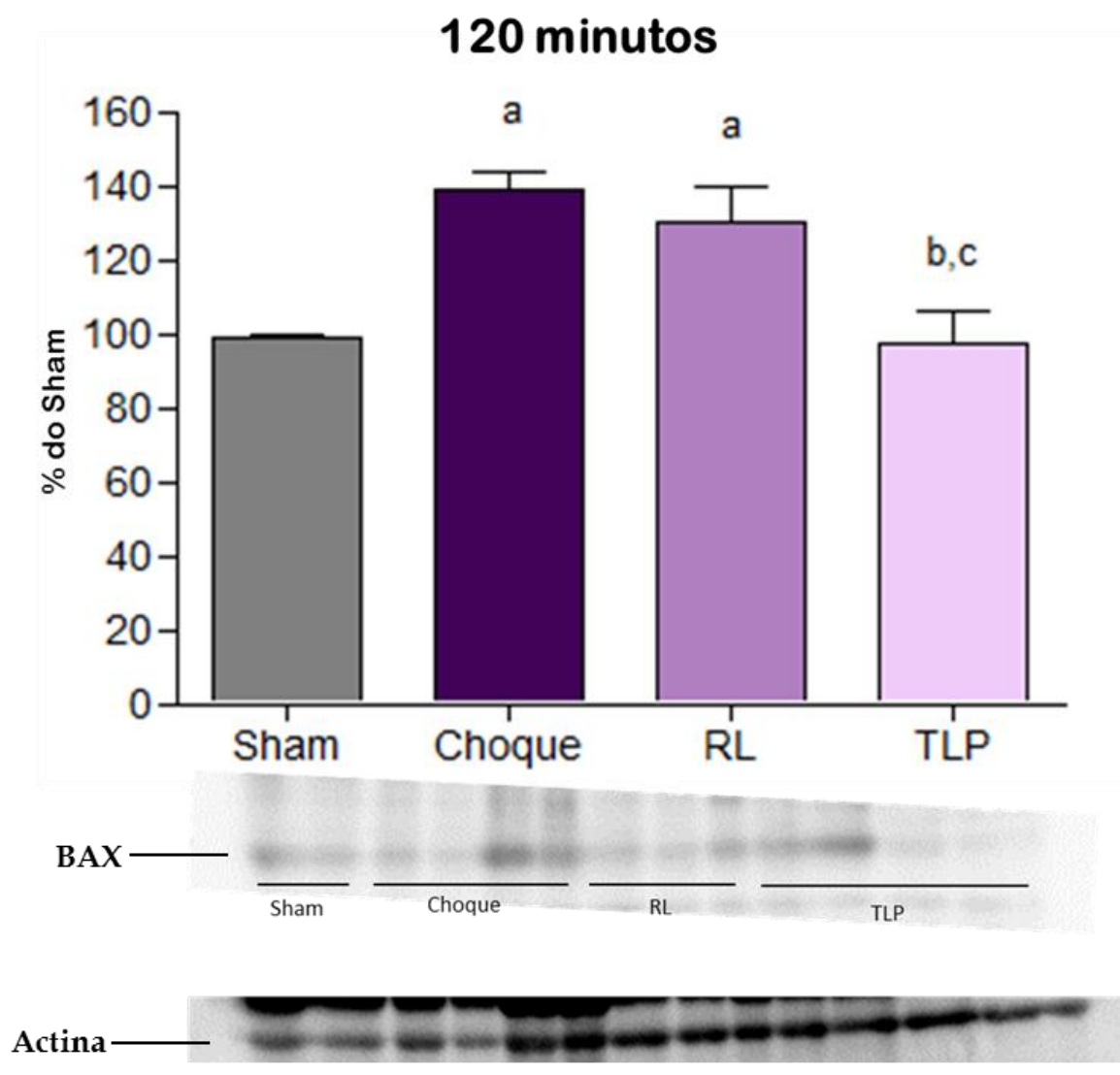

Figura 36 - Expressão proteica de BAX em tecido renal nos grupos Sham, Choque, RL e TLP aos 120 minutos após o tratamento. ${ }^{a} \mathrm{p}<0.05$ vs. Sham; ${ }^{b} \mathrm{p}<0.01$ vs. $\mathrm{CH} ;{ }^{c} \mathrm{p}<0.05$ vs RL. 


\section{- Expressão da proteína MnSOD em tecido renal aos 60 minutos}

Analisando a proteína MnSOD, não observamos diferença estatística em nenhum dos grupos estudados aos 60 minutos (Tabela 34 e figura 37 ).

\begin{tabular}{l|clll}
\hline $\mathbf{6 0}$ minutos & Sham & Choque & RL & TLP \\
\hline MnSOD (\%) & $97,5 \pm 2,5$ & $105,0 \pm 5,4$ & $99,2 \pm 1,1$ & $103,5 \pm 5,6$ \\
\hline
\end{tabular}

Tabela 34 - Média e erro padrão referentes à expressão de MnSOD aos 60 minutos dos grupos Sham, Choque, RL e TLP.

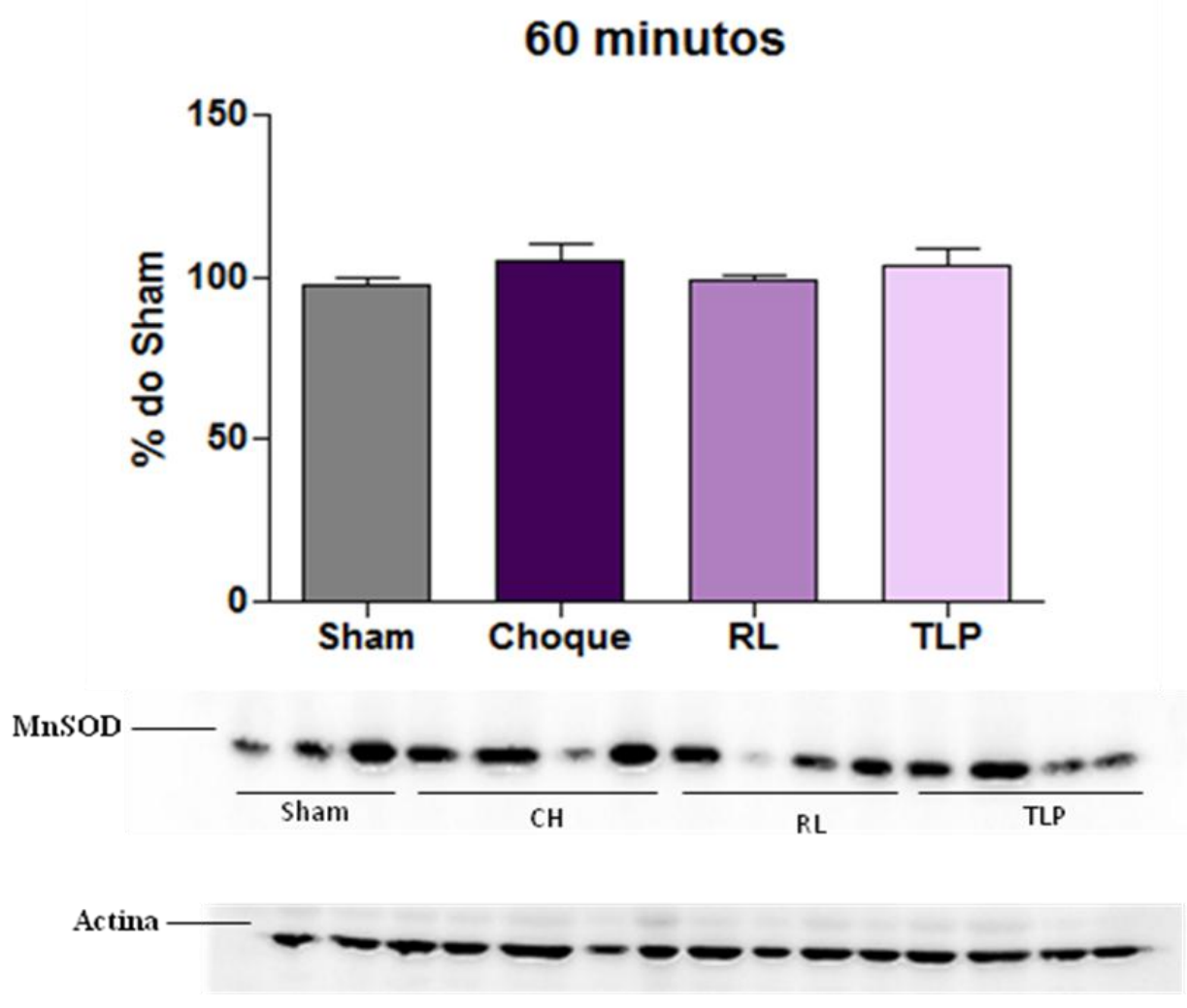

Figura 37 - Expressão protéica de MnSOD em tecido renal nos grupos Sham, Choque, RL e TLP aos 60 minutos após o tratamento. 


\section{- Expressão da proteína MnSOD em tecido renal aos 120 minutos}

Semelhante ao ocorrido aos 60 minutos, não houve diferença entre os grupos aos 120 minutos (Tabela 35 e figura38).

\begin{tabular}{l|clll}
\hline $\mathbf{1 2 0}$ minutos & Sham & Choque & RL & TLP \\
\hline MnSOD (\%) & $97,5 \pm 2,5$ & $103,7 \pm 2,4$ & $99,8 \pm 0,7$ & $96,6 \pm 1,9$ \\
\hline
\end{tabular}

Tabela 35 - Média e erro padrão referentes a expressão de MnSOD aos 120 minutos dos grupos Sham, Choque, RL e TLP.

\section{0 minutos}

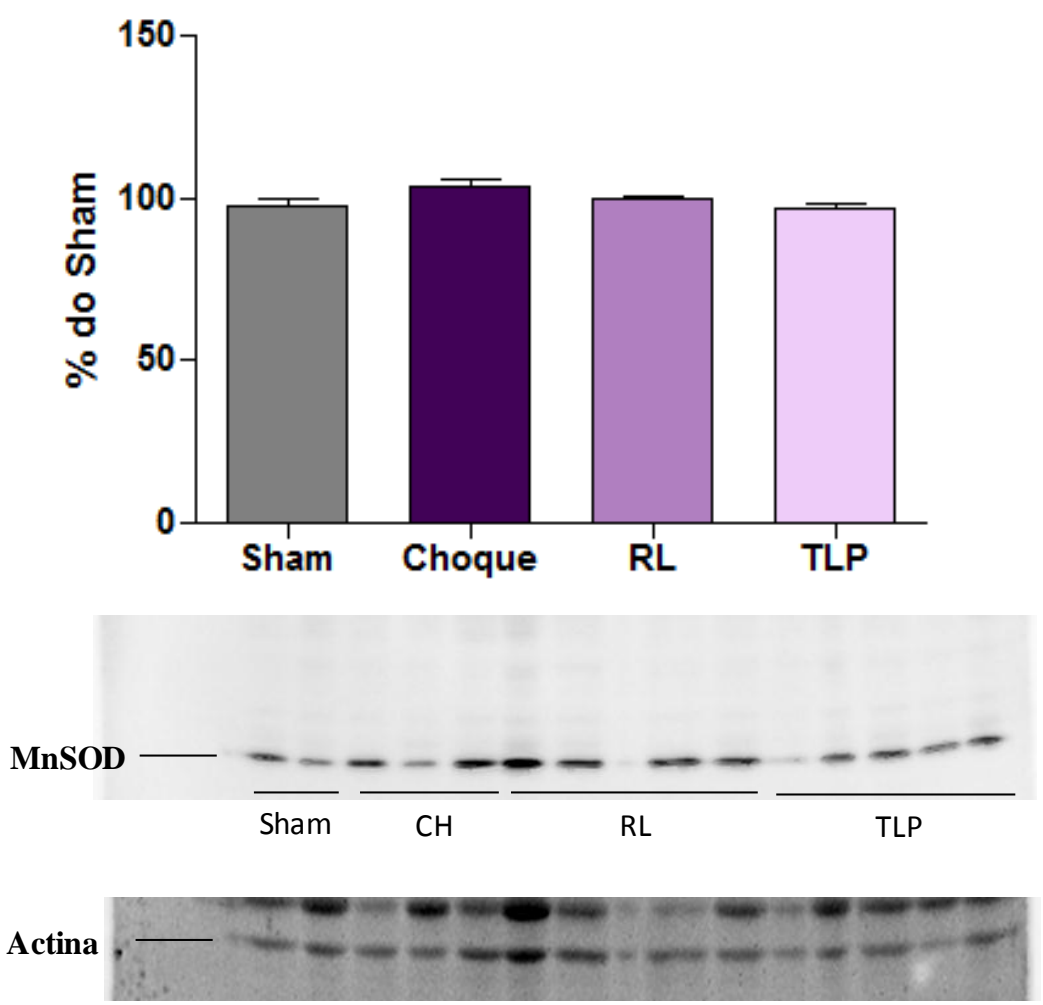

Figura 38 - Expressão proteica de MnSOD em tecido renal nos grupos Sham, Choque, RL e TLP aos 120 minutos após o tratamento. 
DISCUSSÃO 
$\mathrm{O} \mathrm{CH}$ continua sendo causa de alta mortalidade em pacientes com trauma severo. A mortalidade está diretamente ligada à grande perda sanguínea levando a falência múltipla de órgãos. A IRA é frequente e os rins são afetados diretamente pela queda brusca de $\mathrm{pO}_{2}$ microvascular e pela isquemia, aumentando ainda mais a mortalidade 5 .

O primeiro procedimento feito no atendimento pré-hospitalar para casos de $\mathrm{CH}$ é a reposição volêmica imediata com Ringer lactato, pois além de sua composição eletrolítica ser semelhante a do sangue, ele é capaz de aumentar e manter a PAM em níveis estáveis para que o paciente possa ser levado para o hospital e receber o tratamento adequado ${ }^{12}$.

Entretanto novos tratamentos imediatos para a fase pré-hospitalar vêm sendo estudados para que os socorristas tenham mais alternativas no resgate e, os pacientes, menos efeitos colaterais. Estudos envolvendo a administração de TLP no resgate pré-hospitalar do $\mathrm{CH}$ e seus efeitos ainda estão sendo desenvolvidos em modelos experimentais variados e o interesse em novas alternativas vem crescendo $8,39,40$.

A administração de TLP já é bem estabelecida no tratamento de algumas doenças. Na cirrose hepática, doença com alta morbidade e mortalidade, a lesão renal é a principal complicação. Metade dos pacientes com cirrose e lesão renal, vão a óbito em até um mês após diagnóstico da doença. Do restante, cerca de $20 \%$ desenvolvem síndrome hepato-renal. A TLP, associada à albumina, é o principal tratamento para síndrome hepato-renal tipo 1, melhorando a PAM e a perfusão renal. A TLP estimula os receptores de vasopressina localizados nas células da musculatura lisa causando vasoconstrição e, combinada com a albumina intravenosa, aumenta o volume arterial e melhora a redistribuição sanguínea para órgãos nobres 46.

Um estudo de 2012 comparou os efeitos do tratamento com TLP e RL em hemorragia severa de lesão hepática. Observou-se que a TLP foi capaz de restaurar a PAM e diminuir a mortalidade dos animais da mesma forma que o tratamento com RL ${ }^{39}$. 
Chien-Chang Lee e colaboradores submeteram ratos ao $\mathrm{CH}$ amputando $80 \%$ da cauda do animal com sangramento "aberto", mimetizando o que acontece com uma vítima de hemorragia. Após 30 minutos do início do sangramento, os animais receberam uma mistura de plasma com RL, e, após isso, foi feita administração de RL, vasopressina ou TLP. A TLP foi capaz de reestabelecer a PAM por mais tempo, se comparada aos outros grupos. Os tratamentos com vasopressina e TLP diminuiram os níveis de lactato, citocinas pró e anti-inflamatórias, além de diminuir a lesão pulmonar e a mortalidade ${ }^{40}$.

Sabe-se que a isquemia/reperfusão resultante do $\mathrm{CH}$ induz a síndrome de resposta inflamatória sistêmica (SIRS) e conseqüentemente falência múltipla de órgãos 47. Inicialmente, os rins são os principais órgãos afetados pela hipoperfusão, e isso se dá pela ativação do sistema medular adrenal simpático e do sistema renina-angiotensina-aldosterona. Apesar da incidência de IRA decorrente do $\mathrm{CH}$ ser atenuada com o resgate em tempo hábil e ressuscitação adequada, a IRA ainda é observada em aproximadamente $30 \%$ dos pacientes admitidos em Unidades de Terapia Intensiva (UTI) ${ }^{48}$.

Em nosso modelo experimental de $\mathrm{CH}$ observamos uma mortalidade extremamente elevada dos animais do grupo Choque, o que já era esperado, demonstrando assim, a gravidade de uma situação de perda elevada de sangue sem o devido tratamento em tempo hábil. Já o tratamento com RL e TLP aumentou a sobrevida dos animais de forma semelhante e ambos foram capazes de restaurar a PAM.

A TLP é muito usada no tratamento de hepatopatias e varizes esofágicas. Seus efeitos vasoconstritores na região esplâncnica promovem uma melhora na distribuição sanguínea e com isso restabelece a PAM e melhora a resistência vascular sistêmica em pacientes acometidos de cirrose e sepse 49,50.

Observou-se no grupo $\mathrm{CH}$, uma elevação da creatinina logo após a retirada do sangue dos animais, mostrando comprometimento da função renal. Aos 60 minutos de tratamento com RL, observou-se uma diminuição da creatinina, provavelmente causada pela diluição corpórea, já que nos tempos 
seguintes, essa redução não foi mais observada. Entretanto, aos 90 e aos 120 minutos após o tratamento com TLP, notou-se uma melhora da função renal, demonstrada pelo aumento do clearance de creatinina. Sabe-se que o tratamento com TLP em síndrome hepato renal é o mais indicado pela sua eficácia e estabilização dos níveis de creatinina ${ }^{50}$.

Não foram observadas grandes variações nos níveis de sódio plasmático entre os grupos. Aos 60 minutos, o grupo Choque apresentou uma queda de sódio plasmático, provavelmente devido a liberação da vasopressina induzida pelo choque. Os grupos tratados também apresentaram redução dos níveis plasmáticos de sódio, resultante da hemodiluição após expansão volêmica no grupo RL e a provável ação em receptor V2 da TLP. No grupo RL, a redução dos níveis plasmáticos de sódio também pode ser atribuída ao aumento na excreção urinária de sódio que se mostrou aumentada apenas nesse grupo, após a reposição volêmica elevada, o que leva a uma perda importante de todos os outros íons. É descrito na literatura que a administração de TLP pode reduzir os níveis de sódio plasmático. Yim e colaboradores analisaram pacientes com sangramento de varizes que foram tratados com TLP e observaram uma redução importante dos níveis de sódio plasmáticos. Entretanto, com a descontinuidade da administração da TLP, os níveis de sódio foram reestabelecidos gradativamente até a sua normalização ${ }^{51}$. A possível explicação para essa queda é que a TLP, além da sua ação vasoconstritora via receptor V1, age também no receptor V2 aumentando a reabsorção de água via AQP2, diminuição a concentração de sódio plasmático ${ }^{51}$.

Houve variação da ureia plasmática apenas no grupo RL, possivelmente devido à expansão volêmica.

O grupo $\mathrm{CH}$ apresentou hipercalemia, dado já esperado devido ao comprometimento da função renal, o que reduz a excreção urinária de potássio; além disso, esse mesmo grupo apresentou importante acidemia, como consequência da hipoperfusão tecidual 52 
O grupo RL desenvolveu hipomagnesemia, e em alguns períodos, hipofosfatemia. Acreditamos que estas alterações ocorram pela expansão volêmica, levando a uma maior perda renal destes íons, já que esses animais apresentavam hipermagnesuria e hiperfosfaturia ${ }^{53}$.

Interessante ressaltar que, apesar da expansão volêmica no grupo RL, não houve melhora da acidemia neste grupo em relação aos outros. A acidemia resultante da hipoperfusão por hipovolemia geralmente é revertida, uma vez que a reposição de fluidos, ou seja, a causa é tratada. Neste caso, entretanto, a perfusão orgânica insuficiente pode ter levado a lesões isquêmicas em órgãos como o fígado, dificultando a metabolização do lactato em excesso, originado do metabolismo anaeróbico e da solução de RL, impedindo, assim, a resolução da acidemia. Outra hipótese é que os níveis séricos de lactato seriam futuramente normalizados após o período de avaliação do estudo, ou seja, duas horas de $\mathrm{CH}$, uma vez que se observou redução gradual desta variável após o tratamento com RL. Observamos também níveis séricos elevados de lactato, ao longo dos períodos, nos animais tratados com TLP. Não houve diferença estatística entre os grupos Choque e tratamentos (RL e TLP). Da mesma maneira que o tratamento com RL, o tratamento com TLP pode ter mantido a perfusão orgânica insuficiente no fígado e em outros órgãos, mantendo assim a acidemia. Por outro lado, a ação vasoconstritora da TLP, pode levar a uma intensa vasoconstrição esplâncnica, reduzindo o fluxo sanguíneo para a microcirculação 50 .

Observamos que no grupo Choque, aos 90 e 120 minutos houve normalização dos níveis plasmáticos de bicarbonato. Entretanto estes dados podem estar falseados pelo número reduzido de animais sobreviventes.

Uma das causas da alta mortalidade no $\mathrm{CH}$, além do grande sangramento, é o estresse oxidativo devido à lesão celular. Isso é causado pela grande produção de espécies reativas de oxigênio (ROS) que são geradas no metabolismo, como por exemplo, o radical superóxido ${ }^{54}$. A ativação da ROS aumenta a resposta inflamatória do organismo, o que pode levar a uma 
síndrome de disfunção múltipla de órgãos. Em organismos saudáveis, sob condições normais, as ROS são remocidas por sistemas antioxidantes endógenos. Normalmente, a superóxido desmutase (SOD) reage com radicais de superóxido, gerando peróxido de hidrogênio que são quebrados pela glutationa peroxidase 1 e a pela catalase. Entretanto, quando ocorre um sangramento severo no organismo, a produção da ROS pela mitocôndria sobrecarrega a capacidade endógena de remoção, acarretando em peroxidação lipídica, despolarização da membrana, dano no DNA celular, levando as células à morte por apoptose e necrose ${ }^{54}$. Na análise de estresse oxidativo no tecido renal, não observamos elevação de TBARS aos 60 minutos em nenhum dos grupos. Aos 120 minutos, é notável o aumento de radicais livres em todos os grupos em relação ao Sham, de forma que nenhum dos tratamentos foi capaz de normalizar os níveis de TBARS. Além disso, não observamos diferença entre os grupos em relação a expressão proteica de MnSOD. Entretanto, em trabalho recentemente publicado, o tratamento com TLP foi capaz diminuir os níveis de TBARS em tecido cerebral, tanto aos 60 como aos 120 minutos, além de diminuir a expressão proteica de MnSOD no mesmo tecido ${ }^{55}$. Portanto, a ação protetora renal dos tratamentos não deve ser via estresse oxidativo diferentemente do que ocorre no cérebro.

A medida de escore de lesão renal leva em consideração a lesão de túbulos renais, portanto necrose tubular aguda. Observamos que já aos 60 minutos houve um aumento da lesão renal nos animais do grupo $\mathrm{CH}$. Os dois tratamentos foram capazes de proteger o tecido renal da lesão tubular induzida pelo $\mathrm{CH}$. Isto provavelmente ocorre pela capacidade de ambos os tratamentos manterem a pressão de perfusão no tecido renal.

A regulação na concentração urinária se dá principalmente pela produção de hormônios. A Angiotensina II aumenta a reabsorção de sódio e de água e assim regulando a pressão arterial e volume extracelular em casos de, por exemplo, hemorragia. A Angiotensina II também estimula os níveis de Aldosterona, que por sua vez, aumenta a reabsorção de sódio e secreção de 
potássio, principalmente pela ativação da bomba de sódio-potássio ATPase. Outro hormônio regulatório é o paratireóideo, que participa do aumento da reabsorção tubular de cálcio ${ }^{56}$.

A vasopressina tem como principal função regular da reabsorção de água. Em uma situação de aumento da osmolalidade dos líquidos corporais, a hipófise aumenta o liberação de vasopressina que, via receptor V2, irá aumentar a inserção de AQP2 na membrana apical das células dos túbulos distais e coletor, aumentando permeabilidade a água. Esse processo acaba por diminuir o volume urinário final poupando solutos importantes para manutenção da homeostasia 52. Além disso, sabe-se que o vasopressina também aumenta a expressão de NKCC2, proteína expressa na porção ascendente espessa da alça de Henle, pela mesma via descrita acima ${ }^{57}$. Na IRA observa-se uma desregulação destes dois transportadores. Em estudo recente, demonstramos em modelo experimental de sepsis induzindo IRA, diminuição dos transportadores AQP2 e NKCC2 no tecido renal ${ }^{58}$. Assim, como já era esperado e descrito na literatura ${ }^{15}$, houve uma importante redução da expressão AQP2 aos 60 e aos 120 minutos no grupo $\mathrm{CH}$. A TLP conseguiu restabelecer a expressão deste importante transportador de água, apesar de não termos observado diferenças significativas na osmolalidade urinária. Semelhante ao ocorrido com a AQP2 observamos diminuição da expressão de NKCC2 aos 60 e aos 120 minutos. A TLP também foi capaz de restabelecer a expressão desta proteína. Estes dados sugerem que o tratamento com TLP possa ter um efeito benéfico superior em relação ao tratamento com RL, já que o tratamento com RL foi capaz de mantar a expressão a expressão de NKCC2 apenas até 60 minutos, e não alterou a expressão de AQP2 já diminuída pela ação do $\mathrm{CH}$. Apesar destes resultados, não observamos diferença na expressão do receptor V2 nos grupos tratados em relação ao Sham. O que observamos foi aumento da expressão de V2 no grupo choque em relação aos outros três grupos. De forma semelhante, observamos aumento da expressão de V1 nos animais chocados. Ambos os tratamentos mantiveram a expressão deste receptor em níveis 
semelhantes ao do grupo Sham, porém, aos 120 minutos a expressão de V1 estava aumentada no grupo TLP em relação ao grupo Sham e RL. Fisiologicamente V1 é o receptor da vasopressina e possui ação vasoconstritora em uma situação de grande perda sanguínea, porém sabemos que este receptor e altamente sensível a TLP. O aumento de expressão dos receptores observados no grupo choque em ambos os tempos do estudo se devem, provavelmente, a um efeito compensatório na tentativa de reestabelecer o volume perdido, tanto por reabsorção de água via V2, como por vasoconstrição via V1. É interessante notar que a expansão volêmica do grupo RL e a ação vasoconstritora da TLP acaba por não permitir o aumento destes dois receptores aos 60 minutos, como é visto no grupo choque. Já aos 120 observamos aumento da expressão de V1 no grupo tratado com TLP, o que nos leva a crer que o efeito do tratamento já está diminuindo e, portanto observamos um aumento compensatório de V1.

Estudando as vias de apoptose, avaliamos a expressão da proteína BAX. Observamos aumento da expressão da proteína nos grupos CH e RL aos 120 minutos, enquanto que aos 60 minutos não foi possível observar diferença de expressão entre os grupos estudados. Demonstramos assim, que há maior morte celular com o passar do tempo de choque, mesmo nos animais tratados com RL em relação aos grupos TLP. Deb S. e colaboradores, da mesma forma, demonstraram que ratos submetidos à hemorragia apresentam expressão de BAX em tecido pulmonar aumentada, mesmo quando tratados com RL ${ }^{59}$. Estes resultados sugerem que o tratamento com TLP possa ter ação anti-apoptótica, já que a expressão de BAX neste grupo foi semelhante ao grupo Sham nos dois tempos estudados. Corroborando estes achados, em trabalho recentemente publicado com a participação de nosso grupo, observamos que o tratamento com TLP também diminuiu a expressão da BAX e aumentou a expressão de BCL-X em tecido cerebral de porcos submetidos ao choque, demonstrando novamente proteção na morte celular 55 . 
CONCLUSÃO 
De modo geral, a proteção tecidual renal analisada tanto histologicamente como pela função tubular e expressão das proteínas transportadoras de água e sódio, nos mostra que os dois tratamentos foram eficazes, sendo que o tratamento com TLP se mostrou mais eficiente em relação a filtração glomerular e a função tubular. Estes dados apoiam o uso de TLP no resgate de pacientes em $\mathrm{CH}$ no local do acidente. Assim, poderíamos diminuir o uso de grandes quantidades de volume, o que, a posteriori, poderia levar a edema e lesão de órgãos, ao mesmo tempo em que reestabeleceríamos a PAM de forma eficiente e segura até a chegada ao hospital. 
REFERÊTNCIAS BIBLIOGRÁFICAS 
1- Sociedade Brasileira de Atendimento Integrado ao Traumatizado, $\mathrm{O}$ que é Trauma? Disponível em: http://www.sbait.org.br/trauma.php> Acesso em 14 de abril de 2014.

2- Irineu Dias, Clínica Médica, TDAH X Trauma. Disponível em: http://tdah.com.br/paginas/gaetah/Boletim3.htm> Acesso em 14 de abril de 2014

3- Jacob M, Kumar P. The challenge in management of hemorrhagic shock in trauma. Med J Armed Forces India. 2014 Apr;70(2):163-9.

4- Chiara O, Pelosi P, Brazzi L, Bottino N, Taccone $\mathrm{P}$, Cimbanassi $S$, et al. Resuscitation from hemorrhagic shock: experimental model comparing normal saline, dextran, and hypertonic saline solutions. CritCare Med. 2003;31(7):1915-22.

5- Legrand M, Mik EG, Balestra GM, Lutter R, Pirracchio R, Payen D, et al. Fluid resuscitation does not improve renal oxygenation during hemorrhagic shock in rats. Anesthesiology. 2010;112(1):119-27.

6- Gutierrez G, Reines HD, Wulf-Gutierrez ME. Clinical review: hemorrhagic shock. CritCare. 2004;8(5):373-81.

7- Guyton AC, Holl JE. Débito cardíaco e choque circulatorio. In: Guyton AC, Holl JE, editors. Fisiologia Humana e Mecanismos das Doenças. Rio de Janeiro: Guanabara Koogan,1998. p. 152-169.

8- Gann DSI, Drucker WT. Hemorrhagic shock. J Trauma AcuteCareSurg. 2013 Nov; 75(5):888-95.

9- Fraga $\mathrm{AO}$, Auler Jr JOC. Choque Hemorrágico: Fisiopatologiae Reposição Volêmica. RevBrasAnestesiol 1999; 49: 3: $213-224$.

10- Braz LG, Vianna PT, Vane LA, Braz JR. Hemorrhagic shock volume replacement: does the solution make a difference in 
hemodynamic and renal effects? Rev Bras Anestesiol. 2001;51(2):11932.

11- Hostmann A, Jasse K, Schulze-Tanzil G, Robinson Y, Oberholzer A, Ertel W, Tschoeke SK. Biphasic onset of splenic apoptosis following hemorrhagic shock: critical implications for Bax, Bcl-2, and Mcl-1 proteins. Crit Care. 2008;12(1):R8.

12-Santos OF, Durão JR MS, Neto MC, Draib AS, Boim MA, Schor N. Insuficiencia Renal Aguda (Lesão Renal Aguda). In: Riella MC, editor. Principios de nefrologia e distúrbios hidroeletroliticos. Rio de Janeiro: Guanabara Koogan, 2010. p.355-368.

13-Sutton TA, Molitoris BA. Mechanisms of cellular injury in ischemic acute renal failure. SeminNephrol. 1998;18(5):490-7.

14-Schor N, Boim MA, Pavão dos Santos OF, editors. Insuficiencia renal aguda: fisiopatologia, clínica e tratamento. São Paulo: Sarvier, 1997. 17, 150.

15-Gong H, Wang W, Kwon TH, Jonassen T, Frøkiaer J, Nielsen S. Reduced renal expression of AQP2, p-AQP2 and AQP3 in haemorrhagic shock-induced acute renal failure. Nephrol Dial Transplant. 2003 Dec;18(12):2551-9.

16- Day RE, Kitchen P, Owen DS, Bland C, Marshall L, Conner AC, Bill RM, Conner MT. Human aquaporins: Regulators of transcellular water flow.Biochim Biophys Acta. 2014 May;1840(5):1492-506.

17- Nielsen S, Frøkiaer J, Marples D, Kwon TH, Agre $\mathrm{P}$, Knepper MA.Aquaporins in the kidney: from molecules to medicine.Physiol Rev. 2002 Jan;82(1):205-44.

18- Nordström CH. Cerebral energy metabolism and microdialysis in neurocritical care. Childs Nerv Syst. 2010;26(4):46572. 
19- Auler Jr JOC, Fantoni DT - Reposição Volêmica nos Estados de Choque Hemorrágico e Séptico. Rev Bras Anestesiol 1999; 49: 2: $126-138$.

20- Braz LG, Vianna PT, Vane LA, Braz JR. Hemorrhagic shock volume replacement: does the solution make a difference in hemodynamic and renal effects? Rev Bras Anestesiol. 2001;51(2):11932.

21-Schettino G, RezendeE, Mendes CL, Réa-Neto A, David CM, Lobo SM, et al. Consenso Brasileiro de Monitorização e Suporte Hemodinâmico - Parte III: Métodos Alternativos de Monitorização do Débito Cardíaco e da Volemia. Rev Bras Ter Intensiva. 2006 18(1):16176 .

22- Wang P, Ayala A, Dean RE, Hauptman JG, Ba ZF, DeJong GK, et al. Adequate crystalloid resuscitation restores but fails to maintain the active hepatocellular function following hemorrhagic shock. J Trauma. 1991;31(5):601-7; discussion 607-8.

23- Onen A, Cigdem MK, Deveci E, Kaya S, Turhanoğlu S, Yaldiz M. Effects of whole blood, crystalloid, and colloid resuscitation of hemorrhagic shock on renal damage in rats: an ultrastructural study. J Pediatr Surg. 2003;38(11):1642-9.

24- Alam HB, Stanton K, Koustova E, Burris D, Rich N, Rhee P. Effect of different resuscitation strategies on neutrophil activation in a swine model of hemorrhagic shock. Resuscitation. 2004;60(1):91-9.

25- Knotzer H, Pajk W, Maier S, Dünser MW, Ulmer H, Schwarz B, et al. Comparison of lactated Ringer's, gelatine and blood resuscitation on intestinal oxygen supply and mucosal tissue oxygen tension in haemorrhagic shock. Br J Anaesth. 2006;97(4):509-16.

26- Makley AT, Goodman MD, Friend LA, Deters JS, Johannigman JA, Dorlac WC, et al. Resuscitation with fresh whole 
blood ameliorates the inflammatory response after hemorrhagic shock. J Trauma. 2010;68(2):305-11.

27- Brown MD. Evidence-based emergency medicine. Hypertonic versus isotonic crystalloid for fluid resuscitation in critically ill patients. Ann Emerg Med. 2002;40(1):113-4.

28- Mayeur N1, Minville V, Jaafar A, Allard J, Al Saati T, Guilbeau-Frugier C, Fourcade O, Girolami JP, Schaak S, Tack I.Morphologic and functional renal impact of acute kidney injury after prolonged hemorrhagic shock in mice.Crit Care Med. 2011 Sep;39(9):2131-8.

29- Cossu AP, Mura P, De Giudici LM, Puddu D, Pasin L, Evangelista M, Xanthos T, Musu M1, Finco G. Vasopressin in hemorrhagic shock: a systematic review and meta-analysis of randomized animal trials.Biomed Res Int. 2014;2014:421291.

30- Heckbert SR, Vedder NB, Hoffman W, Winn RK, Hudson LD, Jurkovich GJ, et al. Outcome after hemorrhagic shock in trauma patients. J Trauma. 1998;45(3):545-9.

31-Zenati MS, Billiar TR, Townsend RN, Peitzman AB, Harbrecht BG. A brief episode of hypotension increases mortality in critically ill trauma patients. J Trauma. 2002;53(2):232-6; discussion 236-7.

32- Chan L, Bartfield JM, Reilly KM. The significance of out-ofhospital hypotension in blunt trauma patients. AcadEmerg Med. 1997;4(8):785-8.

33- Tsuneyoshi I, Onomoto M, Yonetani A, Kanmura Y. Lowdose vasopressin infusion in patients with severe vasodilatory hypotension after prolonged hemorrhage during general anesthesia. J Anesth. 2005;19(2):170-3.

34- Voelckel WG, Raedler C, Wenzel V, Lindner KH, Krismer AC, Schmittinger CA, et al. Arginine vasopressin, but not 
epinephrine, improves survival in uncontrolled hemorrhagic shock after liver trauma in pigs. Crit Care Med. 2003;31(4):1160-5.

35- Voelckel WG, Convertino VA, Lurie KG, Karlbauer A, Schöchl H, Lindner $\mathrm{KH}$, et al. Vasopressin for hemorrhagic shock management: revisiting the potential value in civilian and combat casualty care. J Trauma. 2010;69Suppl 1:S69-74.

36- Felix VN. Terlipressina como novo recurso terapêutico no choque séptico. Rev Bras TerIntensiva. 2006. 18(2):196-99.

37-Morelli A, Ertmer C, Rehberg S, Lange M, Orecchioni A, Cecchini V, et al. Continuous terlipressin versus vasopressin infusion in septic shock (TERLIVAP): a randomized, controlled pilot study. Crit Care. 2009;13(4):R130.

38- Ari E, Yilmaz Y, Kedrah AE, Alahdab Y, Cakalagaoglu F, Arikan $\mathrm{H}$, et al. Protective effect of the vasopressin agonist terlipressin in a rat model of contrast-induced nephropathy. Am J Nephrol. 2011;33(3):269-76.

39- Bayram B, Hocaoglu N, Atilla R, Kalkan S. Effects of terlipressin in a rat model of severe uncontrolled hemorrhage via liver injury.Am J Emerg Med. 2012 Sep;30(7):1176-82.

40- Lee CC, Lee MT, Chang SS, Lee SH, Huang YC, Yo CH, Lee $\mathrm{SH}$, Chen SC. A comparison of vasopressin, terlipressin, and lactated ringers for resuscitation of uncontrolled hemorrhagic shock in an animal model. PLoS One. 2014 Apr 23;9(4):e95821.

41- Martini WZ, Cortez DS, DubickMA.Comparisons of normal saline and lactated Ringer's resuscitation on hemodynamics, metabolic responses, and coagulation in pigs after severe hemorrhagic shock.Scand J Trauma ResuscEmerg Med. 2013 Dec $11 ; 21: 86$. 
42- Morelli A, Ertmer C, Westphal M."Terlipressin in the treatment of septic shock: the earlier the better"? BestPract Res ClinAnaesthesiol. 2008 Jun;22(2):317-21.

43- Burnette WN. "Western blotting": electrophoretic transfer of proteins from sodium dodecyl sulfate--polyacrylamide gels to unmodified nitrocellulose and radiographic detection with antibody and radioiodinated protein A. Anal Biochem. 1981;112(2):195-203.

44- Ohkawa H, Ohishi N, Yagi K. Assay for lipid peroxides in animal tissues by thiobarbituric acid reaction. Anal Biochem. 1979;95(2):351-8.

45- Miyaji T, Kato A, Yasuda H, Fujigaki Y, Hishida. A Role of the increase in p21 in cisplatin-induced acute renal failure in rats. J Am SocNephrol 12: 900-908.

46- EgerodIsraelsen M, Gluud LL, Krag A. Acute kidney injury and hepatorenal syndrome in cirrhosis.J GastroenterolHepatol. 2015 Feb;30(2):236-43.

47- Lee JH, Jo YH, Kim K, Lee JH, Rim KP, Kwon WY, Suh GJ, Rhee JE. Effect of N-acetylcysteine (NAC) on acute lung injury and acute kidney injury in hemorrhagic shock. Resuscitation. 2013 Jan;84(1):121-7.

48-Zhao ZG, Zhu HX, Zhang LM, Zhang YP, Niu CY. Mesenteric lymph drainage alleviates acute kidney injury induced by hemorrhagic shock without resuscitation.ScientificWorldJournal. 2014 Feb 25;2014:720836.

49- Meybohm P, Cavus E, Bein B, Steinfath M, Brand PA, Scholz J, et al. Cerebral metabolism assessed with microdialysis in uncontrolled hemorrhagic shock after penetrating liver trauma. AnesthAnalg. 2006;103(4):948-54.

50- Narahara Y, Kanazawa H, Taki Y, Kimura Y, Atsukawa M, Katakura T, Kidokoro H, Harimoto H, Fukuda T, Matsushita Y, 
Nakatsuka K, Sakamoto C. Effects of terlipressin on systemic, hepatic and renal hemodynamics in patients with cirrhosis.J GastroenterolHepatol. 2009 Nov;24(11):1791-7.

51- Yim SY, Seo YS, Jung CH, Kim TH, Kim ES, Keum B, Kim JH, An H, Yim HJ, Yeon JE, Jeen YT, Lee HS, Chun HJ, Byun KS, Um SH, Kim CD, Ryu HS. Risk Factors for Developing Hyponatremia DuringTerlipressin Treatment: A Retrospective Analyses in Variceal Bleeding.J ClinGastroenterol. 2014 Sep 11.

52-Spinella PC, Perkins JG, Grathwohl KW, Repine T, Beekley AC, Sebesta J, Jenkins D, Azarow K, Holcomb JB; 31st CSH Research Working Group. Fresh whole blood transfusions in coalition military, foreign national, and enemy combatant patients during Operation Iraqi Freedom at a U.S. combat support hospital. World J Surg. 2008 Jan;32(1):2-6. Epub 2007 Nov 9.

53- Fujita Y, Doi K, Harada D, Kamikawa S. Modulation of physiological hemostasis by irrigation solution: comparison of various irrigation solutions using a mouse brain surface bleeding model. J Neurosurg. 2010 Apr;112(4):824-8.

54- Powell RD, Swet JH, Kennedy KL, Huynh TT, Murphy MP, Mckillop IH, Evans SL. MitoQ modulates oxidative stress and decreases inflammation following hemorrhage.J Trauma Acute Care Surg. 2015 Mar;78(3):573-9.

55-Ida KK, Otsuki DA, Sasaki AT, Borges ES, Castro LU, Sanches TR, Shimizu MH, Andrade LC, Auler JO Jr, Dyson A, Smith KJ, Rocha FilhoJA, Malbouisson LM. Effects of terlipressin as early treatment for protection of brain in a model of haemorrhagic shock.Crit Care. 2015 Mar 13;19:107.

56-Guyton AC, Holl JE. Formação da Urina pelos Rins. In: Guyton AC, Holl JE, editors. Fisiologia Humana e Mecanismos das Doenças. Rio de Janeiro: Guanabara Koogan,1998. p. 191-212. 
57-Kwon TH, Laursen UH, MArples D, Maunsbach AB, Knepper MA, Frokiaer J, Nielsen S: Altered expression of renal AQPs and $\mathrm{Na}(+)$ transporters in rats with lithium-induced NDI. Am J Physiol Renal Physiol 279: 552-564, 2000.

58- Rodrigues CE, Sanches TR, Volpini RA, Shimizu MH, Kuriki PS, Camara NO, Seguro AC, Andrade L. Effects of continuous erythropoietin receptor activator in sepsis-induced acute kidney injury and multi-organ dysfunction.PLoS One. 2012;7(1):e29893.

59- Deb S, Sun L, Martin B, Talens E, Burris D, Kaufmann C, Rich N, Rhee P. Lactated ringer's solution and hetastarch but not plasma resuscitation after rat hemorrhagic shock is associated with immediate lung apoptosis by the up-regulation of the Bax protein. J Trauma. 2000 Jul;49(1):47-53. 


\section{Trabalfos publicadose}

participação em congresso 


\title{
Effects of terlipressin as early treatment for protection of brain in a model of haemorrhagic shock
}

Keila Kazue Ida ${ }^{1,2^{*}}$, Denise Aya Otsuki ${ }^{1}$, Adolfo Toshiro Cotarelli Sasaki ${ }^{1}$, Emilyn Silva Borges ${ }^{1}$, Letícia Urbano Cardoso Castro ${ }^{3}$, Talita Rojas Sanches ${ }^{3}$, Maria-Heloisa Massola Shimizu ${ }^{3}$, Lúcia Conceição Andrade ${ }^{3}$, José-Otávio Costa Auler Jr ${ }^{1}$, Alex Dyson ${ }^{4}$, Kenneth John Smith², Joel Avancini Rocha Filho ${ }^{5}$ and Luiz-Marcelo Sá Malbouisson ${ }^{1}$

\begin{abstract}
Introduction: We investigated whether treatment with terlipressin during recovery from hypotension due to haemorrhagic shock (HS) is effective in restoring cerebral perfusion pressure (CPP) and brain tissue markers of water balance, oxidative stress and apoptosis.

Methods: In this randomised controlled study, animals undergoing HS (target mean arterial pressure (MAP) $40 \mathrm{mmHg}$ for 30 minutes) were randomised to receive lactated Ringer's solution (LR group; $n=14$; volume equal to three times the volume bled), terlipressin (TERLI group; $n=14 ; 2$-mg bolus), no treatment (HAEMO group; $n=12$ ) or sham $(n=6)$. CPP, systemic haemodynamics (thermodilution technique) and blood gas analyses were registered at baseline, shock and 5, 30, 60 (T60), 90 and 120 minutes after treatment (T120). After the animals were killed, brain tissue samples were obtained to measure markers of water balance (aquaporin-4 (AQP4)), $\mathrm{Na}^{+}-\mathrm{K}^{+}-2 \mathrm{Cl}^{-}$co-transporter (NKCC1)), oxidative stress (thiobarbituric acid reactive substances (TBARS) and manganese superoxide dismutase (MnSOD)) and apoptotic damage (BCl-x and Bax).

Results: Despite the HS-induced decrease in cardiac output (CO) and hyperlactataemia, resuscitation with terlipressin recovered MAP and resulted in restoration of CPP and in cerebral protection expressed by normalisation of AQP4, NKCC1, TBARS and MnSOD expression and BCl-x/Bax ratio at T60 and T120 compared with sham animals. In the LR group, $\mathrm{CO}$ and blood lactate levels were recovered, but the CPP and MAP were significantly decreased and TBARS levels and AQP4, NKCC1 and MnSOD expression and BCl-x/Bax ratio were significantly increased at T60 and T120 compared with the sham group.
\end{abstract}

Conclusions: During recovery from HS-induced hypotension, terlipressin was effective in normalising CPP and cerebral markers of water balance, oxidative damage and apoptosis. The role of this pressor agent on brain perfusion in HS requires further investigation.

\footnotetext{
* Correspondence: keilaida@usp.br

'Laboratório de Investigação Médica (LIM-08), Disciplina de Anestesiologia,

Faculdade de Medicina, Universidade de São Paulo, Avenida Doutor Arnaldo,

455, $2^{\circ}$ andar, sala 2120, Cerqueira César, São Paulo, SP 01246-903, Brazil

${ }^{2}$ Department of Neuroinflammation, Institute of Neurology, University

College London (UCL), 1 Wakefield Street, 2nd floor, WC1N 1PJ, London, UK

Full list of author information is available at the end of the article
} 


\section{Introduction}

Haemorrhagic shock is the leading cause of early death in trauma patients [1]. During the pre-hospital period, haemorrhage contributes to death in $33 \%$ to $56 \%$ of cases, and it is the most common cause of death among those found dead upon the arrival of emergency medical services personnel [2]. Neurological signs such as altered mental state, which typically includes obtundation, disorientation, confusion, agitation and irritability, cannot be neglected, because cerebral hypoperfusion is a consequence in patients experiencing bleeding-associated hypotension [3-5]. In addition, animal studies of haemorrhagic shock have shown that cerebral ischaemia with cell damage begins at the onset of the haemodynamic impairment [6-8].

Under hypotensive conditions such as those in haemorrhagic shock, cerebral perfusion pressure (CPP) is sustained below the lower limits of autoregulation [8], which is detrimental to brain tissue oxygenation $[5,7,9]$. Cerebral ischaemia has been associated with dysregulation of aquaporin-4 (AQP4) and $\mathrm{Na}^{+}-\mathrm{K}^{+}-2 \mathrm{Cl}-$ co-transporter (NKCC1) in the astrocytes $[9,10]$ and Bcl-2 related apoptotic proteins in the neurons [11]. Oxidative stress is implicated in the neuronal apoptosis that occurs in haemorrhagic shock. It has been shown to accompany increased lipid peroxidation within the brain, as reflected by changes in the levels of thiobarbituric acid reactive substances (TBARS) and changes in the expression of antioxidant enzymes such as manganese superoxide dismutase (MnSOD) [12].

Standard resuscitation practice for haemorrhagic shock mandates use of high-volume crystalloids. However, such therapy can result in adverse effects such as interstitial oedema in the gut and cellular oedema in the heart [13], increases in the inflammatory cytokine profile [14] and increased intracranial pressure (ICP) [8]. Crystalloids may also fail to recover CPP and oxygenation within the brain $[8,15]$. Terlipressin is a synthetic, long-acting (4 to 6 hours) analogue of vasopressin. The structure of terlipressin contains a peptide that represents the natural hormone lysine vasopressin, the innate vasopressin analogue in pigs. Its structure is very similar to human arginine vasopressin, but the synthetic drug is characterised by a more specific $\mathrm{V}_{1}$ agonistic effect $\left(\mathrm{V}_{1}: \mathrm{V}_{2}\right.$ ratio $\left.=2.2: 1\right)$ compared with arginine-vasopressin $\left(\mathrm{V}_{1}: \mathrm{V}_{2}\right.$ ratio $\left.=1: 1\right)$. Terlipressin has been studied as a vasoactive drug in the management of catecholamine-resistant arterial hypotension in septic shock [16], liver failure [17] and acute gastrointestinal bleeding [18]. The effects of terlipressin consist of vasoconstrictive activity on vascular smooth muscle cells and a pronounced vasoconstriction within the splanchnic circulation that has been shown to redistribute blood flow to recover perfusion pressure to organs such as the liver, kidney and brain $[19,20]$ and to increase survival rates in animal studies of haemorrhagic shock [14,21]. It has been reported that terlipressin can improve CPP in patients with acute liver failure [17], septic shock [22] and traumatic brain injury with catecholamine-resistant shock [23]. However, the effects of terlipressin on cerebral haemodynamics during early treatment for haemorrhagic shock remain unclear, and no data are available comparing the effects of resuscitation with terlipressin with those of standard fluid.

We hypothesised that early recovery of haemorrhagic shock-induced hypotension with terlipressin could restore CPP and improve oxygenation of the brain. Therefore, the purpose of the present study was to investigate the effects of early administration of terlipressin on CPP and brain tissue oxygen pressure $\left(\mathrm{PbtO}_{2}\right)$, as well as on the regulation of tissue markers of water balance (that is, AQP4 and NKCC1), oxidative stress (that is, TBARS and MnSOD) and apoptosis (that is, Bax and Bcl-x) within the brain in a porcine model of haemorrhagic shock.

\section{Materials and methods Ethical approval}

This prospective randomised experimental study was approved by the Comissão de Ética em Pesquisa of the Hospital das Clínicas at Faculdade de Medicina of Universidade de São Paulo (067/11 and 280/13).

\section{Surgical preparation and monitoring}

Female Large White pigs $(n=46)$ weighing 20 to $30 \mathrm{~kg}$ were fasted for 12 hours with free access to water before the experiments. The animals were premedicated with ketamine $(5 \mathrm{mg} / \mathrm{kg}$ intramuscular) and midazolam $(0.25 \mathrm{mg} / \mathrm{kg}$ intramuscular), and anaesthesia was induced with propofol (7 mg/kg intravenous). After endotracheal intubation, anaesthesia was maintained with isoflurane vaporized in $40 \%$ oxygen, and the pigs were ventilated (Fabius GS Premium; Dräger, Lübeck, Germany) with a tidal volume of $8 \mathrm{ml} / \mathrm{kg}$ and positive end-expiratory pressure of $5 \mathrm{cmH}_{2} \mathrm{O}$. The respiratory rate was adjusted to maintain normocapnia (partial pressure of carbon dioxide in arterial blood $\left(\mathrm{PaCO}_{2}\right)$ between 35 and $45 \mathrm{mmHg}$ ). Lactated Ringer's solution $(4 \mathrm{ml} / \mathrm{kg} / \mathrm{hr})$ and pancuronium $(0.3 \mathrm{mg} / \mathrm{kg} / \mathrm{hr})$ were administered continuously throughout the experiments. Body temperature was maintained at $38^{\circ} \mathrm{C}$ using a heated mat (Medi-Therm II; Gaymar Industries, Orchard Park, NY, USA).

Both femoral arteries were catheterised for measurement of mean arterial pressure (MAP) and withdrawal of blood to induce haemorrhagic shock, respectively. Another catheter was inserted into the right femoral vein for later administration of treatments.

A 7.5-French pulmonary artery catheter (Swan-Ganz; Edwards Lifesciences, Irvine, CA, USA) was surgically introduced into the right internal jugular vein and advanced 
under continuous pressure recording into wedge position. Cardiac output was determined by bolus pulmonary artery thermodilution (Vigilance monitor; Edwards Lifesciences). All catheters and pressure transducers were filled with isotonic saline containing heparin $(5 \mathrm{U} / \mathrm{ml})$ and connected to a multiparametric data collection system (IntelliVue MP50 monitor; Philips Healthcare, Best, the Netherlands). The heart rate (HR), right atrial pressure (RAP), mean pulmonary artery pressure (MPAP), pulmonary artery occlusion pressure (PAOP) and central body temperature were also continuously monitored with the IntelliVue MP50 monitor.

The cardiac index (CI) was calculated to normalise the data for body surface area in square metres by using a conversion factor appropriate for pigs $\left(k \times \mathrm{BW}^{2 / 3}\right.$, where $k=0.09$ ) [24]. Systemic vascular resistance index (SVRI), pulmonary vascular resistance index (PVRI), left ventricular stroke work index (LVSWI), right ventricular stroke work index (RVSWI), stroke volume index (SVI), systemic oxygen delivery index $\left(\mathrm{DO}_{2} \mathrm{I}\right)$, systemic oxygen consumption $\left(\mathrm{VO}_{2} \mathrm{I}\right)$ and systemic oxygen extraction ratio $\left(\mathrm{O}_{2} \mathrm{ER}\right)$ were calculated using standard formulae [25].

Arterial and mixed venous blood were sampled at each time point for blood gas analysis, including measurement of haemoglobin $(\mathrm{Hb})$, lactate, sodium $\left(\mathrm{Na}^{+}\right)$and potassium $\left(\mathrm{K}^{+}\right)$ion levels (ABL 555 blood gas meter; Radiometer, Copenhagen, Denmark).

Two burr holes of 5-mm diameter each were placed over the right and left coronal sutures (12-mm paramedian). In the right hemisphere, an intraparenchymal probe was inserted into the cerebral cortex (15-mm depth) and secured with a single lumen bolt for measurement of $\mathrm{PbtO}_{2}$ (Neurovent-PTO; RAUMEDIC, Helmbrechts, Germany). On the left side, a fibre-optic probe (Codman ICP EXPRESS Monitoring System; Codman Neuro, Raynham, MA, USA) was inserted epidurally for continuous monitoring of ICP after sealing the cranial window with bone wax. CPP was calculated using a standard formula $(\mathrm{CPP}=\mathrm{MAP}-\mathrm{ICP})[6]$.

\section{Experimental design}

Following surgical preparation, animals were allowed to stabilise for 30 minutes before being randomly divided into one of the following four groups: (1) a sham group $(n=6)$ consisting of animals that were not subjected to haemorrhagic shock, (2) a HAEMO group $(n=12)$ that was subjected to haemorrhagic shock and did not receive treatment, (3) a LR group ( $n=14)$ that was subjected to haemorrhagic shock and treated with LR (volume equal to three times the volume bled) and (4) a TERLI group $(n=14)$ that was subjected to haemorrhagic shock and treated with terlipressin (2-mg bolus of GLYPRESSIN; Ferring Pharmaceuticals, São Paulo, Brazil).
Randomisation was previously performed, and the blind allocation of the pigs among groups was placed in numbered manila envelopes, which were opened in a consecutive manner immediately before baseline measurements were registered.

Haemorrhagic shock was induced by pressure-controlled bleeding targeting a MAP of $40 \mathrm{mmHg}$, which was maintained for 30 minutes before treatment. Data were recorded prior to blood removal (baseline), at 30 minutes after achieving the target MAP (shock) and at 5 minutes (T5), 30 minutes (T30) and 60 minutes (T60) after treatment. In some of these animals (sham group: $n=3$; HAEMO group: $n=9$; LR group: $n=9$; TERLI group: $n=9$ ), the study was continued for 1 additional hour, allowing data to be registered at 90 minutes (T90) and 120 minutes (T120) posttreatment. At the end of the study, the animals were killed with an overdose of isoflurane and potassium chloride. The intraparenchymal probe then was macroscopically inspected for insertion depth, and cortical samples of the brain were collected and immediately frozen in liquid nitrogen and stored at $-80^{\circ} \mathrm{C}$ for later analysis.

\section{Preparation of cerebral samples for Western blotting assays and thiobarbituric acid reactive substance measurement}

The samples were homogenized in ice-cold solution (200 mM mannitol, 80 mM 4-(2-hydroxyethyl)piperazine1-ethanesulfonic acid, $41 \mathrm{mM} \mathrm{KOH}, \mathrm{pH} 7.5)$ containing a protease inhibitor cocktail (Sigma-Aldrich, St Louis, MO, USA) using a POLYTRON PT 10-35 homogenizer (KINEMATICA, Lucerne, Switzerland). The homogenates were centrifuged at $4,000 \times g$ for 30 minutes at $4^{\circ} \mathrm{C}$ to remove cell debris. Protein concentrations were determined by the Bradford assay method using a Bio-Rad protein assay kit (Bio-Rad Laboratories, Hercules, CA, USA).

\section{Western blotting}

Western blotting assays were performed to assess the expression of the following proteins: AQP4, NKCC1, Bcl-x, Bax and MnSOD. Cerebral tissue samples were run on $12 \%$ polyacrylamide minigels for AQP4, Bax, Bcl-x and MnSOD and on $8 \%$ polyacrylamide minigels for NKCC1. After transfer by electroelution to polyvinylidene fluoride membranes (Amersham Hybond-P; GE Healthcare Life Sciences, Little Chalfont, UK), blots were blocked with $5 \%$ non-fat milk and $0.1 \%$ Tween 20 in Tris-buffered saline for 1 hour. Blots were then incubated overnight with an anti-AQP4 antibody (1:2,000), NKCC1 (1:500), Bcl-x antibody (1:500), Bax antibody (1:500) and MnSOD antibody (1:200). The labelling was visualised with a horseradish peroxidase-conjugated secondary antibody (anti-rabbit immunoglobulin G (IgG), diluted 1:2,000; anti-goat IgG, diluted 1:10,000; anti-mouse IgG diluted 1:2,000; or 
anti-mouse IgG, diluted 1:2,000, respectively; SigmaAldrich) using an enhanced chemiluminescence (ECL) detection system (Amersham ECL Western Blotting Detection kit; GE Healthcare Life Sciences). The ECL membranes were scanned using Alliance 4.2 (UVItec, Cambridge, UK), and the cerebral AQP4, NKCC1, Bcl-x and Bax protein expression levels were quantified using densitometry, normalizing the bands to actin expression.

\section{Thiobarbituric acid assay}

To assess the levels of TBARS, a $0.2-\mathrm{ml}$ cortical cerebral homogenate sample was diluted in $0.8 \mathrm{ml}$ of distilled water, followed by addition of $1 \mathrm{ml}$ of $17.5 \%$ trichloroacetic acid. Then, $1 \mathrm{ml}$ of $0.6 \%$ thiobarbituric acid, $\mathrm{pH} 2$, was added to the sample and placed in a boiling-water bath for 15 minutes. After the sample was allowed to cool, $1 \mathrm{ml}$ of $70 \%$ trichloroacetic acid was added and the mixture was incubated for 20 minutes. The sample was then centrifuged at $2,000 \times g$ for 15 minutes. The absorbance was recorded at $534 \mathrm{~nm}$ using a spectrophotometer, and values were calculated by using a molar extinction coefficient of $1.56 \times 105 \mathrm{M} / \mathrm{cm}$. The TBARS levels were then normalised to the total protein concentration, and the results are expressed as nanomoles per gram of protein.

\section{Statistical analysis}

Physiological and neuromonitoring parameters and arterial and mixed venous blood gas data were analysed (GraphPad Prism version 5.03 for Windows; GraphPad Software, La Jolla, CA, USA) across groups and time using two-way analysis of variance (ANOVA) tests. Tukey's tests were used for post hoc analysis. Analyses of survival were performed according to the Kaplan-Meier method and compared using Fisher's exact test. The last observation carried forward imputation method was applied throughout the study for the animals that died. Differences in the expression levels of AQP4, NKCC1, Bcl-x, Bax, MnSOD and TBARS were analysed by one-way ANOVA followed by the StudentNewman-Keuls test, and the results are presented as mean \pm standard error. For all analyses, $P<0.05$ was considered statistically significant.

\section{Results}

The blood volume withdrawn from each group was similar, averaging $60 \%$ of the estimated blood volume (HAEMO group: $1,083 \pm 124 \mathrm{ml}$; LR group: $1,162 \pm 203 \mathrm{ml}$; TERLI group: $1,011 \pm 215 \mathrm{ml}$ ). In the HAEMO group, the number of deaths following haemorrhage was significantly higher at 120 minutes (six deaths at $41 \pm 15$ minutes after shock; $P=0.0007)$. At 120 minutes after shock, one animal from the TERLI group had died (at 80 minutes after shock) (Figure 1).

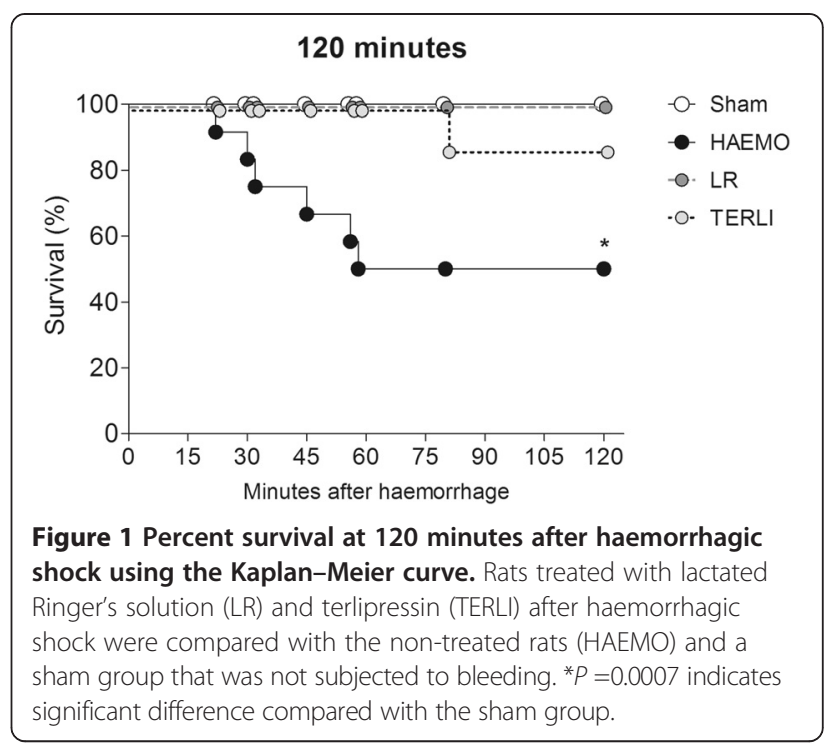

\section{Haemodynamics}

HR was significantly increased in the HAEMO, LR and TERLI groups from the time of shock to T120 compared with the sham group $(P<0.001)$. From T30 to T120, HR was significantly lower in the LR group than in the HAEMO group $(P<0.05)$ (Figure 2$)$. MAP was significantly decreased at shock in all study groups compared with the sham group $(P<0.001)$. In the HAEMO group, the MAP was significantly decreased from T5 to T120 compared with the other groups $(P<0.001)$. Compared with sham animals, MAP was significantly decreased at T60, T90 and T120 in the LR group $(P<0.001)$ and at $\mathrm{T} 5$ in the TERLI group $(P<0.001)$. No significant differences in this variable were observed from T30 to T120 between the LR and TERLI groups (Figure 2). The CI was significantly decreased from T5 to T120 in the HAEMO and TERLI groups compared with the sham group $(P<0.01)$. At the corresponding time points, the CI was significantly higher in the TERLI group than in the HAEMO group $(P<0.05)$. In the LR group, CI was higher than in the HAEMO and TERLI groups $(P<0.05)$ (Figure 2$)$.

RAP was significantly decreased $(P<0.001)$ and SVRI and PVRI were significantly increased $(P<0.01)$ from shock to T120 in the HAEMO and TERLI groups compared with the sham group $(P<0.01)$, whereas no significant differences were observed in these variables from T5 to T120 between the LR and sham groups. MPAP was significantly decreased in all groups from T5 to T120 compared with the sham group $(P<0.05)$ (Figure 2 and Table 1). In all study groups, PAOP was significantly decreased at shock compared with the sham group. In the LR group, PAOP was significantly increased at T5 and T120 compared with the HAEMO group at these corresponding time points (Table 1). LVSWI, 


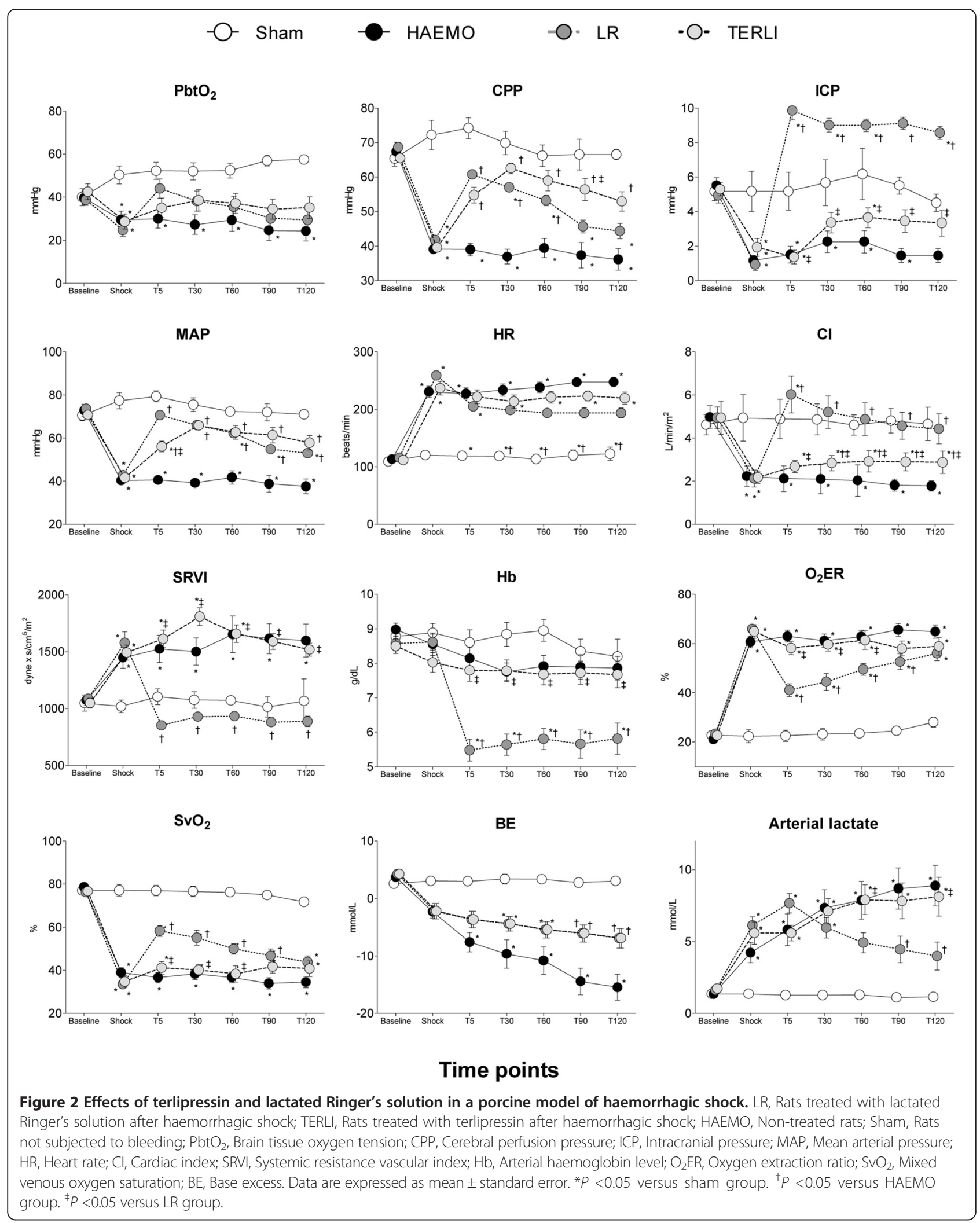


Table 1 Effects of haemorrhagic shock on haemodynamics at baseline, shock and at 5, 30, 60, 90 and 120 posttreatment

\begin{tabular}{|c|c|c|c|c|c|c|c|}
\hline & \multirow[t]{2}{*}{ Baseline } & \multirow[t]{2}{*}{ Shock } & \multicolumn{5}{|c|}{ After treatment (min) } \\
\hline & & & 5 & 30 & 60 & 90 & 120 \\
\hline \multicolumn{8}{|l|}{ RAP $(\mathrm{mmHg})$} \\
\hline Sham & $8 \pm 1$ & $9 \pm 2$ & $8 \pm 1$ & $8 \pm 1$ & $9 \pm 1$ & $7 \pm 1$ & $6 \pm 0$ \\
\hline HAEMO & $7 \pm 2$ & $2 \pm 1^{*}$ & $2 \pm 1^{*}$ & $2 \pm 1^{*}$ & $2 \pm 1^{*}$ & $2 \pm 1^{*}$ & $2 \pm 1^{*}$ \\
\hline$L R$ & $7 \pm 1$ & $2 \pm 1^{*}$ & $8 \pm 2^{\dagger}$ & $7 \pm 2^{\dagger}$ & $6 \pm 2^{*^{+}}$ & $5 \pm 2^{\dagger}$ & $5 \pm 2^{\dagger}$ \\
\hline TERLI & $7 \pm 2$ & $2 \pm 1^{*}$ & $2 \pm 1^{* \ddagger}$ & $3 \pm 1^{* \ddagger}$ & $3 \pm 1^{* \neq}$ & $2 \pm 1^{* \neq}$ & $2 \pm 1^{* \neq}$ \\
\hline \multicolumn{8}{|l|}{ MPAP $(\mathrm{mmHg})$} \\
\hline Sham & $19 \pm 1$ & $20 \pm 1$ & $20 \pm 1$ & $20 \pm 1$ & $20 \pm 1$ & $18 \pm 1$ & $18 \pm 3$ \\
\hline HAEMO & $20 \pm 3$ & $16 \pm 2^{*}$ & $17 \pm 3^{*}$ & $17 \pm 3^{*}$ & $17 \pm 4^{*}$ & $16 \pm 2^{*}$ & $16 \pm 2^{*}$ \\
\hline$L R$ & $19 \pm 2$ & $17 \pm 2^{*}$ & $22 \pm 5^{*^{+}}$ & $20 \pm 4^{\dagger}$ & $19 \pm 3^{\dagger}$ & $19 \pm 2^{\dagger}$ & $19 \pm 2^{\dagger}$ \\
\hline TERLI & $20 \pm 1$ & $16 \pm 2^{*}$ & $18 \pm 3^{t \neq}$ & $18 \pm 3^{\dagger}$ & $18 \pm 2^{\dagger}$ & $19 \pm 2^{\dagger}$ & $19 \pm 2^{\dagger}$ \\
\hline \multicolumn{8}{|l|}{ PAOP (mmHg) } \\
\hline Sham & $12 \pm 1$ & $11 \pm 2$ & $11 \pm 2$ & $11 \pm 1$ & $11 \pm 2$ & $9 \pm 1$ & $11 \pm 2$ \\
\hline HAEMO & $11 \pm 1$ & $8 \pm 2^{*}$ & $8 \pm 2^{*}$ & $8 \pm 1^{*}$ & $8 \pm 1^{*}$ & $7 \pm 1^{*}$ & $7 \pm 1^{*}$ \\
\hline LR & $11 \pm 1$ & $9 \pm 2^{*}$ & $11 \pm 2^{\dagger}$ & $10 \pm 2$ & $9 \pm 2$ & $9 \pm 2$ & $10 \pm 2^{\dagger}$ \\
\hline TERLI & $11 \pm 1$ & $8 \pm 1^{*}$ & $8 \pm 2$ & $9 \pm 1$ & $9 \pm 1$ & $9 \pm 1$ & $9 \pm 1$ \\
\hline \multicolumn{8}{|l|}{ LVSWI (g-m/m²/beat) } \\
\hline Sham & $30 \pm 7$ & $35 \pm 13$ & $35 \pm 10$ & $35 \pm 11$ & $33 \pm 6$ & $32 \pm 6$ & $29 \pm 5$ \\
\hline HAEMO & $34 \pm 6$ & $4 \pm 1^{*}$ & $3 \pm 1^{*}$ & $3 \pm 1^{*}$ & $3 \pm 1^{*}$ & $3 \pm 1^{*}$ & $3 \pm 1^{*}$ \\
\hline$L R$ & $35 \pm 4$ & $4 \pm 1^{*}$ & $19 \pm 3^{*^{+}}$ & $15 \pm 4^{* \dagger}$ & $14 \pm 4^{* \dagger}$ & $13 \pm 4^{*^{\dagger}}$ & $12 \pm 4^{*^{\dagger}}$ \\
\hline TERLI & $37 \pm 7$ & $4 \pm 1^{*}$ & $8 \pm 2^{*^{\dagger}}$ & $10 \pm 3^{* \dagger}$ & $10 \pm 3^{* \dagger}$ & $9 \pm 3^{* \dagger}$ & $8 \pm 4^{*^{\dagger}}$ \\
\hline \multicolumn{8}{|c|}{ RVSWI $\left(\mathrm{g} \times \mathrm{m} / \mathrm{m}^{2} /\right.$ beat $)$} \\
\hline Sham & $6 \pm 0$ & $7 \pm 1$ & $6 \pm 1$ & $6 \pm 1$ & $5 \pm 1$ & $7 \pm$ & $6 \pm 0$ \\
\hline HAEMO & $7 \pm 1$ & $2 \pm 0^{*}$ & $2 \pm 0^{*}$ & $1 \pm 0^{*}$ & $1 \pm 0^{*}$ & $1 \pm 0^{*}$ & $1 \pm 0^{*}$ \\
\hline$L R$ & $7 \pm 1$ & $2 \pm 0^{*}$ & $6 \pm 2^{*^{\dagger}}$ & $5 \pm 2^{*^{\dagger}}$ & $5 \pm 2^{*^{\dagger}}$ & $5 \pm 1^{*^{\dagger}}$ & $5 \pm 1^{*^{\dagger}}$ \\
\hline TERLI & $8 \pm 1$ & $2 \pm 1^{*}$ & $3 \pm 1^{*}+$ & $3 \pm 0^{* \dagger}$ & $3 \pm 1^{*^{\dagger}}$ & $3 \pm 0^{*^{\dagger}}$ & $3 \pm 1^{* \dagger}$ \\
\hline \multicolumn{8}{|l|}{$\mathrm{SVI}\left(\mathrm{ml} /\right.$ beat $\left./ \mathrm{m}^{2}\right)$} \\
\hline Sham & $44 \pm 11$ & $40 \pm 11$ & $38 \pm 11$ & $39 \pm 13$ & $41 \pm 8$ & $41 \pm 9$ & $38 \pm 11$ \\
\hline HAEMO & $42 \pm 6$ & $8 \pm 2^{*}$ & $8 \pm 2^{*}$ & $7 \pm 1^{*}$ & $7 \pm 1^{*}$ & $7 \pm 1^{*}$ & $7 \pm 1^{*}$ \\
\hline$L R$ & $43 \pm 4$ & $8 \pm 1^{*}$ & $28 \pm 4^{* \dagger}$ & $25 \pm 5^{* \dagger}$ & $24 \pm 6^{* \dagger}$ & $24 \pm 6^{* \dagger}$ & $23 \pm 6^{* \dagger}$ \\
\hline TERLI & $47 \pm 7$ & $9 \pm 1^{*}$ & $12 \pm 3^{*}$ & $13 \pm 2^{* \dagger}$ & $13 \pm 2^{* \dagger}$ & $13 \pm 3^{* \dagger}$ & $13 \pm 3^{* \dagger}$ \\
\hline
\end{tabular}

LR, Rats treated with lactated Ringer's solution after haemorrhagic shock; TERLI, Rats treated with terlipressin after haemorrhagic shock; HAEMO, Non-treated rats; Sham, Rats not subjected to bleeding; RAP, Right atrial pressure; MPAP, Mean pulmonary artery pressure; PAOP, Pulmonary artery occlusion pressure; LVSWI, Left ventricular stroke work index; RVSWI, Right ventricular stroke work index; SVI, Stroke volume index. ${ }^{*} P<0.05$ versus sham group. ${ }^{\dagger} P<0.05$ versus HAEMO group.

${ }^{\ddagger} P<0.05$ versus LR group.

RVSWI and SVI were significantly decreased in the LR and TERLI groups compared with the sham group $(P<0.01)$ and significantly increased in the HAEMO group, compared with the sham group $(P<0.01)$ (Table 1$)$.

\section{Blood gases, oxygenation and electrolytes}

$\mathrm{pH}, \mathrm{HCO}_{3}^{-}, \mathrm{BE}, \mathrm{SvO}_{2}$ and $\mathrm{DO}_{2} \mathrm{I}$ were significantly decreased, and $\mathrm{O}_{2} \mathrm{ER}$, arterial lactate and $\mathrm{K}^{+}$were significantly increased, from shock to T120 in the HAEMO, LR and TERLI groups compared with the sham group $(P<0.05)$ (Table 2$)$. In the LR and TERLI groups, $\mathrm{DO}_{2} \mathrm{I}$ was significantly increased from $\mathrm{T} 5$ to $\mathrm{T} 120$ and from $\mathrm{T} 30$ to $\mathrm{T} 120$, respectively, compared with the HAEMO group $(P<0.05)$. In the LR and TERLI groups, the $\mathrm{VO}_{2} \mathrm{I}$ was significantly increased from T5 to T120 compared with the sham group $(P<0.05)$ and significantly increased from T30 to T120 compared with the HAEMO group $(P<0.05)$. The levels of $\mathrm{Hb}$ and $\mathrm{Na}^{+}$were significantly lower from T5 to T120 in the LR group compared with the sham group $(P<0.05)$. The ratio of arterial oxygen partial pressure to fractional inspired oxygen and the level of $\mathrm{PaCO}_{2}$ did not change 
Table 2 Effects of haemorrhagic shock on blood gases, oxygenation and electrolytes at baseline, shock and at 5, 30, 60,90 and 120 minutes posttreatment

\begin{tabular}{|c|c|c|c|c|c|c|c|}
\hline & \multirow[t]{2}{*}{ Baseline } & \multirow[t]{2}{*}{ Shock } & \multicolumn{5}{|c|}{ After treatment (min) } \\
\hline & & & 5 & 30 & 60 & 90 & 120 \\
\hline \multicolumn{8}{|l|}{$\mathrm{PaCO}_{2}(\mathrm{mmHg})$} \\
\hline Sham & $47 \pm 0$ & $43 \pm 3$ & $41 \pm 2$ & $42 \pm 1$ & $42 \pm 0$ & $40 \pm 0$ & $41 \pm 1$ \\
\hline HAEMO & $42 \pm 3$ & $39 \pm 4$ & $35.6 \pm 7^{*}$ & $43 \pm 8$ & $38 \pm 6$ & $38 \pm 8$ & $38 \pm 8$ \\
\hline$L R$ & $42 \pm 4$ & $38 \pm 4$ & $42.3 \pm 3$ & $41 \pm 3$ & $40 \pm 2$ & $39 \pm 2$ & $39 \pm 2$ \\
\hline TERLI & $43 \pm 2$ & $42 \pm 4$ & $42.9 \pm 5^{\dagger}$ & $47 \pm 6^{\dagger}$ & $48 \pm 7^{\dagger}$ & $45 \pm 4^{\dagger}$ & $44 \pm 5$ \\
\hline \multicolumn{8}{|l|}{$\mathrm{DO}_{2} \mathrm{l}\left(\mathrm{ml} / \mathrm{min} / \mathrm{m}^{2}\right)$} \\
\hline Sham & $540 \pm 2$ & $571 \pm 107$ & $501 \pm 105$ & $522 \pm 108$ & $553 \pm 64$ & $543 \pm 95$ & $518 \pm 131$ \\
\hline HAEMO & $597 \pm 81$ & $243 \pm 52^{*}$ & $212 \pm 64^{*}$ & $190 \pm 37^{*}$ & $192 \pm 38^{*}$ & $194 \pm 46^{*}$ & $190 \pm 37^{*}$ \\
\hline$L R$ & $580 \pm 61$ & $237 \pm 73^{*}$ & $400 \pm 49^{*^{\dagger}}$ & $375 \pm 62^{*^{+}}$ & $361 \pm 66^{*}+$ & $344 \pm 64^{*^{\dagger}}$ & $339 \pm 59^{*^{+}}$ \\
\hline TERLI & $581 \pm 96$ & $238 \pm 27^{*}$ & $288 \pm 19^{*}$ & $307 \pm 43^{*}$ & $313 \pm 51^{*}+$ & $302 \pm 55^{* \dagger}$ & $299 \pm 73^{* \dagger}$ \\
\hline \multicolumn{8}{|l|}{$\mathrm{VO}_{2} \mathrm{I}\left(\mathrm{ml} / \mathrm{min} / \mathrm{m}^{2}\right)$} \\
\hline Sham & $121 \pm 3$ & $140 \pm 17$ & $126 \pm 28$ & $133 \pm 13$ & $139 \pm 9$ & $133 \pm 21$ & $143 \pm 24$ \\
\hline HAEMO & $126 \pm 27$ & $154 \pm 36$ & $139 \pm 40$ & $119 \pm 20$ & $123 \pm 39$ & $126 \pm 27$ & $122 \pm 21$ \\
\hline$L R$ & $129 \pm 33$ & $152 \pm 38$ & $173 \pm 37^{*}$ & $176 \pm 24^{* \dagger}$ & $182 \pm 30^{*}+$ & $178 \pm 24^{* \dagger}$ & $187 \pm 33^{*^{\dagger}}$ \\
\hline TERLI & $123 \pm 19$ & $152 \pm 21$ & $161 \pm 8^{*}$ & $174 \pm 22^{*+}$ & $176 \pm 23^{*}+$ & $172 \pm 23^{* \dagger}$ & $170 \pm 24^{* \dagger}$ \\
\hline \multicolumn{8}{|l|}{$\mathrm{K}^{+}(\mathrm{mmol} / \mathrm{L})$} \\
\hline Sham & $4.4 \pm 0.3$ & $4.3 \pm 0.0$ & $4.0 \pm 0.1$ & $4.3 \pm 0.1$ & $4.4 \pm 0.1$ & $4.4 \pm 0.5$ & $4.5 \pm 0.3$ \\
\hline HAEMO & $4.3 \pm 0.4$ & $5.6 \pm 0.9^{*}$ & $5.2 \pm 0.9$ & $5.7 \pm 0.9^{*}$ & $5.8 \pm 0.8^{*}$ & $6.0 \pm 0.6^{*}$ & $6.2 \pm 0.5^{*}$ \\
\hline$L R$ & $3.9 \pm 0.2$ & $5.8 \pm 1.5^{*}$ & $4.0 \pm 0.3^{\dagger}$ & $4.4 \pm 0.4^{\dagger}$ & $4.9 \pm 0.6^{*}+$ & $5.2 \pm 0.7^{*}$ & $5.1 \pm 1.1^{*}$ \\
\hline TERLI & $4.2 \pm 0.2$ & $5.3 \pm 0.5^{*}$ & $5.4 \pm 0.5^{*}$ & $5.0 \pm 0.5$ & $5.2 \pm 0.5^{*}$ & $5.3 \pm 0.6^{*}$ & $5.5 \pm 0.7^{*}$ \\
\hline \multicolumn{8}{|l|}{$\mathrm{Na}^{+}(\mathrm{mmol} / \mathrm{L})$} \\
\hline Sham & $140 \pm 1$ & $140 \pm 0$ & $142 \pm 1$ & $140 \pm 3$ & $141 \pm 1$ & $139 \pm 3$ & $139 \pm 1$ \\
\hline HAEMO & $139 \pm 3$ & $137 \pm 2$ & $137 \pm 3$ & $137 \pm 2$ & $137 \pm 2$ & $137 \pm 2$ & $136 \pm 2$ \\
\hline$L R$ & $141 \pm 2$ & $138 \pm 4$ & $137 \pm 3$ & $137 \pm 3^{*}$ & $136 \pm 2^{*}$ & $135 \pm 3^{*}$ & $135 \pm 2^{*}$ \\
\hline TERLI & $140 \pm 3$ & $139 \pm 3$ & $137 \pm 2$ & $138 \pm 3$ & $138 \pm 3$ & $139 \pm 3$ & $139 \pm 5$ \\
\hline
\end{tabular}

LR, Rats treated with lactated Ringer's solution after haemorrhagic shock; TERLI, Rats treated with terlipressin after haemorrhagic shock; HAEMO, Non-treated rats; Sham, Rats not subjected to bleeding; $\mathrm{PaCO}_{2}$, Partial pressure of dioxide carbon in the arterial blood; $\mathrm{DO}_{2} \mathrm{l}, \mathrm{O}_{\mathrm{O} y g e n}$ delivery index; $\mathrm{VO}_{2} \mathrm{l}$, Oxygen consumption index; $\mathrm{K}^{+}$, Potassium ion levels; $\mathrm{Na}^{+}$, Sodium ion levels. ${ }^{*} P<0.05$ versus sham group. ${ }^{\dagger} P<0.05$ versus HAEMO group.

significantly in any group during the study (Figure 2 and Table 2).

\section{Neuromonitoring}

CPP, ICP and $\mathrm{PbtO}_{2}$ were significantly decreased from shock to T60 in the HAEMO group compared with the sham animals $(P<0.05)$. Both treatments with $L R$ and TERLI were followed by a significant increase in CPP compared with the HAEMO group $(P<0.01)$, with CPP recovering to values not significantly different from those of the sham group. The LR group had the largest increase in ICP, which was observed from T5 to T120 $(P<0.05$ versus sham; $P<0.001$ versus HAEMO group; $P<0.001$ versus TERLI group). The TERLI group had no significant differences in ICP from T30 to T120 compared with the sham group. Treatments with LR and TERLI recovered $\mathrm{PbtO}_{2}$ to values similar to those in the sham group (Figure 2).
Aquaporin-4 and $\mathrm{Na}^{+}-\mathrm{K}^{+}-2 \mathrm{Cl}^{-}$co-transporter

At 60 minutes after shock, semiquantitative immunoblot analysis revealed a significant increase in the expression of AQP4 in the HAEMO group $(179 \pm 12 \%$ of sham, $P=0.0086)$, which was not reversed by treatment with LR (196 $\pm 8 \%$ of sham, $P=0.0047$ ), but was fully restored by TERLI $(125 \pm 6 \%$ of sham). In the TERLI group, the expression of AQP4 was significantly higher at 60 minutes compared with the HAEMO and LR groups $(P=0.0071)$. At 120 minutes, a significant upregulation of AQP4 was observed only in the LR group $(217 \pm 37 \%$ of sham, $P=0.0084)$, which was significantly higher than in TERLI group $(117 \pm 19 \%$ of sham, $P=0.0169)$ (Figure 3$)$. No significant increase in the expression of NKCC1 was observed in any group at 60 minutes after shock, but NKCC1 expression was significantly increased at 120 minutes in the HAEMO group $(237 \pm 47 \%$ of sham, 


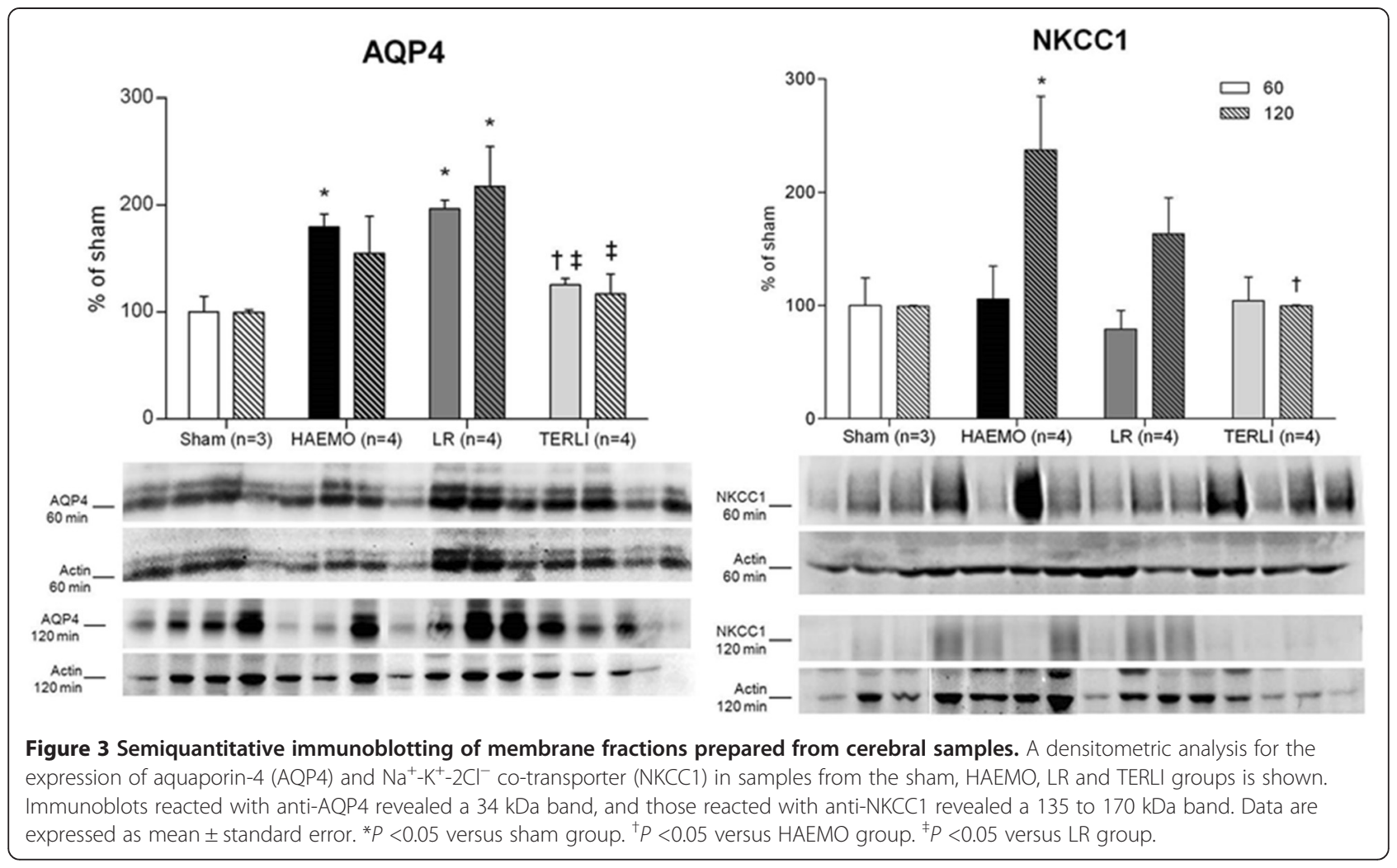

$P=0.0234)$, which was fully restored by treatment with terlipressin (100 $\pm 1 \%$ of sham, $P=0.0270)$ (Figure 3 ).

\section{Manganese superoxide dismutase and thiobarbituric acid reactive substances}

The levels of TBARS were not significantly different from the sham group in any study group at 60 minutes after shock. However, at 120 minutes after shock, these levels were clearly higher in the HAEMO group $(0.38 \pm 0.05 \mathrm{nmol} / \mathrm{mg}$ of protein; $P=0.0013)$ and LR group $(0.31 \pm 0.10 \mathrm{nmol} / \mathrm{mg}$ of protein; $P=0.0167)$, but not in the TERLI group $(0.14 \pm 0.01 \mathrm{nmol} / \mathrm{mg}$ of protein $)$ compared with the sham group $(0.03 \pm 0.01 \mathrm{nmol} / \mathrm{mg}$ of protein). At 120 minutes after shock, the levels of TBARS in the TERLI group were significantly lower than in the HAEMO group $(P<0.0001)$ and the LR group $(P=0.0394)$ (Figure 4). Animals treated with LR had the highest expression of $\mathrm{MnSOD}$ at 60 minutes after shock $(245 \pm 11 \%$ of sham, $P<0.0001)$, whereas no significant changes in the expression of MnSOD were observed in the other groups at the corresponding time point (HAEMO group: $157 \pm 10 \%$ of sham; TERLI group: $125 \pm 5 \%$ of sham). At 120 minutes after shock, the expression of MnSOD was significantly increased in the HAEMO group ( $237 \pm 14 \%$ of sham, $P=0.0081$ ), which was not reversed by LR $(244 \pm 9 \%$ of sham, $P=0.0009)$, but it was fully restored by TERLI (105 $\pm 16 \%$ of sham) (Figure 4$)$.

\section{Bax and $\mathrm{BCl}-\mathbf{x}$}

The antiapoptotic Bcl-x protein was significantly upregulated at 60 and 120 minutes after shock in the TERLI group (60 minutes: $197 \pm 17 \%$ of sham, $P=0.0038$; 120 minutes: $261 \pm 48 \%$ of sham, $P=0.0033)$, but not in the HAEMO group (60 minutes: $122 \pm 6 \%$ of sham; 120 minutes: $32 \pm 8 \%$ of sham) or LR group (60 minutes: $92 \pm 7 \%$ of sham; 120 minutes: $67 \pm 18 \%$ of sham) (Figure 5). The proapoptotic Bax protein was markedly upregulated at 60 and 120 minutes in the HAEMO group (60 minutes: $347 \pm 46 \%$ of sham, $P=0.0088$; 120 minutes: $190 \pm 31 \%$ of sham, $P=0.0154$ ) and LR group (60 minutes: $339 \pm 28 \%$ of sham, $P=0.0021$; 120 minutes: $154 \pm 16 \%$ of sham, $P=0.0129$ ), significantly higher than the TERLI group (Figure 5). The $\mathrm{Bcl}-\mathrm{x} / \mathrm{Bax}$ ratio was significantly decreased at 60 minutes after shock in the HAEMO group $(0.26 \pm 0.03, P=0.0002)$ and LR group $(0.20 \pm 0.02, P<0.0001)$ compared with the sham group $(1.00 \pm 0.05)$. At the corresponding time, animals treated with TERLI had a Bcl-x/Bax ratio $(0.77 \pm 0.19)$ significantly higher than that of the HAEMO group $(P=0.0393)$ and LR group $(P=0.0235)$. At 120 minutes after shock, the $\mathrm{Bcl}-\mathrm{x} / \mathrm{Bax}$ ratio was significantly higher in the TERLI group $(2.40 \pm 0.46)$ than in the HAEMO group $(0.17 \pm 0.05, \mathrm{p}=0.0098)$ and LR group $(0.40 \pm 0.08, P=0.0054)$, but not with that in the sham group $(1.00 \pm 0.44)$ (Figure 5). 
a

TBARS

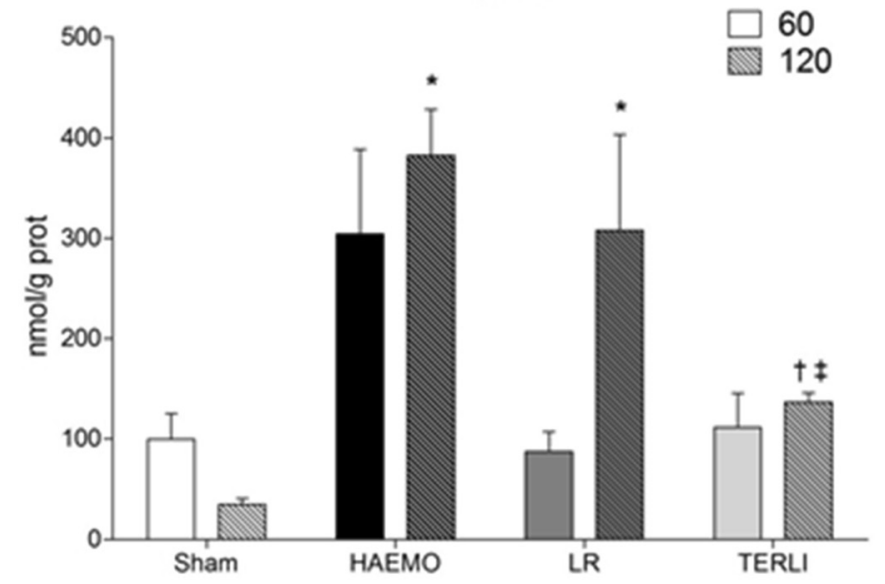

b

MnSod
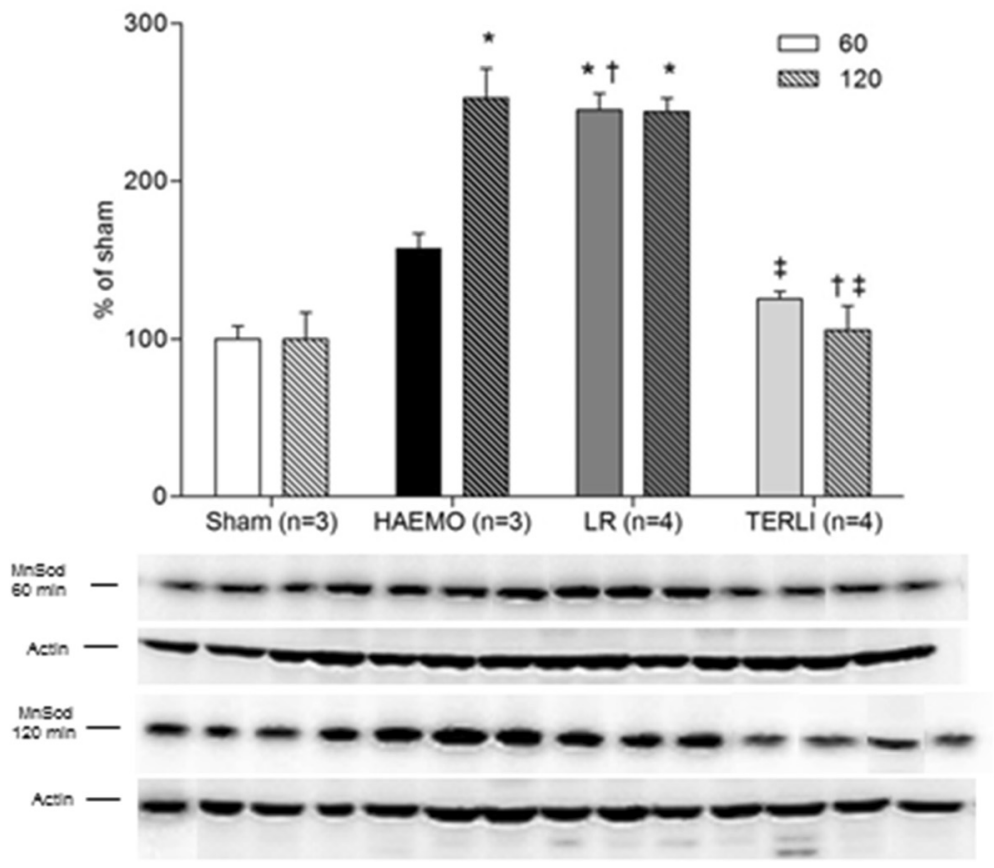

Figure 4 Changes in the level of thiobarbituric acid reactive substances and expression of manganese superoxide dismutase from cerebral samples from the sham, HAEMO, LR and TERLI groups. (a) Each bar represents the group mean \pm standard error. (b) Immunoblots reacted with antibody against manganese superoxide dismutase revealing a $24 \mathrm{kDa}$ band. ${ }^{*} P<0.05$ versus sham group. ${ }^{\dagger} P<0.05$ versus $\mathrm{HAEMO}$ group. ${ }^{\ddagger} P<0.05$ versus LR group. HAEMO, No-treatment group; LR, Lactated Ringer's solution group; TERLI, Terlipressin group.

\section{Discussion}

Haemorrhagic shock can result in global cerebral hypoxia caused by hypovolaemia and hypotension, and the haemodynamic resuscitation must restore CPP in order to prevent ischaemic injury within the brain $[6-8,26]$. The results of the present study indicate that early treatment with terlipressin can recover CPP after haemorrhagic shock and that the underlying mechanisms include regulation of water and $\mathrm{Na}^{+}$channels, inhibition of oxidative stress and decrease of apoptotic signalling within the brain. Survival times were similar at 120 minutes after haemorrhagic shock among groups, with the exception of the HAEMO group. However, whereas therapy with TERLI provided superior outcomes than LR with regard to measures of cerebral damage, it provided inferior outcomes with regard to systemic or peripheral measures of haemodynamics and tissue perfusion.

As expected, CPP was not preserved at a blood pressure below the cerebral autoregulation threshold [27], which was followed by reduction in $\mathrm{PbtO}_{2}[8,28,29]$. In the 


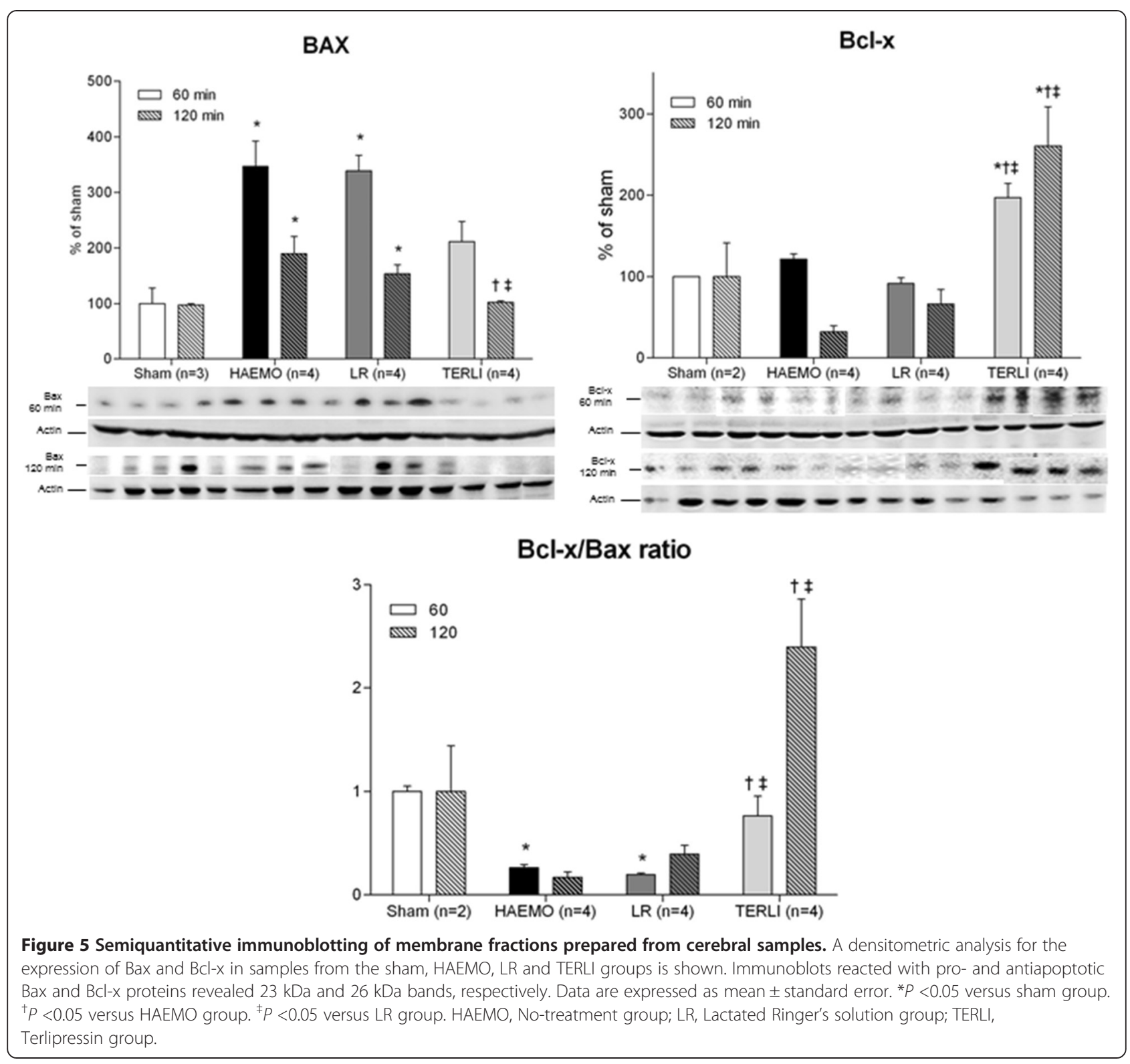

non-treated animals, these derangements were associated with upregulation of AQP4 and NKCC1. These proteins play an important role in the formation of cellular oedema in the brain by regulating water and $\mathrm{Na}^{+}$transport through the sealing junctions of the blood-brain barrier in response to cerebral ischaemia [10,30-32]. AQP4 acts by increasing water transport mainly in the pericapillary foot process of astrocytes [9], and NKCC1 acts by increasing secretion of $\mathrm{Na}^{+}, \mathrm{Cl}^{-}$and water through an intact blood-brain barrier into the brain [10]. Therefore, it was suggested that cerebral hypoperfusion was followed by ischaemic lesions in the HAEMO group. Cerebral hypoperfusion might have contributed to an accumulation of lipid peroxidation products, as reflected by the increased levels of TBARS, which might induce a compensatory increase in the expression of MnSOD [12,33,34]. Oxygen free radicals exert their pathophysiologic effects by directly attacking lipids and proteins in the biologic membranes, which can cause cellular dysfunction and induce apoptotic cell death [35]. Indeed, in the present study, the exposure of the brain to a high level of oxidative stress following haemorrhagic shock was associated with a marked shift in the $\mathrm{Bcl}-\mathrm{x} / \mathrm{Bax}$ ratio, indicating a loss of antiapoptotic ability [36]. Bcl-x and Bax are proteins that play an important role in determining the relative sensitivity of neuronal subpopulations to ischaemia. Accordingly, previous studies showed that haemorrhagic shock can induce a significant oxidative stress in the brain $[12,37]$ and that cerebral ischaemia can decrease the $\mathrm{Bcl}-\mathrm{x} / \mathrm{Bax}$ ratio [38]. Furthermore, other markers of cerebral cellular damage 
have also been described following haemorrhagic shock in other studies, such as an increased level of glycerol in brain tissue [26] and increased plasma levels of S100B [7], findings which support the presently reported results.

The direct vasoconstrictive effect of terlipressin, reflected by increased MAP and SRVI, prevented an improvement in CI but probably allowed for the redistribution of blood flow towards the cerebral circulation, leading to the restoration of CPP and $\mathrm{PbtO}_{2}$. Some effects cannot be differentiated from the common properties of any vasopressor, but it has been suggested that terlipressin can induce a selective vasoconstrictor effect according to the distribution of $\mathrm{V}_{1}$ vasopressin receptors. This hypothesis is supported by previous studies in which researchers used norepinephrine in models of haemorrhagic shock, which did not improve CPP or oxygenation $[39,40]$. Furthermore, another study showed that vasopressin, the natural terlipressin analogue, resulted in a significantly higher increase of CPP compared with norepinephrine [41]. As with the TERLI group, an increased SRVI was also found in non-treated animals; however, this was not accompanied by an increase in MAP in the HAEMO group. The increase in MAP could have restored the cerebral autoregulation in animals treated with terlipressin, which might explain the recovery in CPP and $\mathrm{PbtO}_{2}$. Another explanation for the recovery in CPP is the higher $\mathrm{PaCO}_{2}$ compared with the HAEMO group. Because $\mathrm{PaCO}_{2}$ has a linear positive correlation with cerebral blood flow [42], it could account for more cerebral vasodilation and hence better perfusion compared with non-treated animals. However, it was unclear whether terlipressin also acted directly via $V_{1}$ vasopressin receptors within the brain [43], which might also explain the recovery in ICP and, in turn, CPP. Moreover, the expression levels of both AQP4 and NKCC1 were also restored in animals treated with terlipressin, which also supports the finding that cerebral perfusion was recovered. Despite the increase in SRVI, the fact that lactate, $\mathrm{O}_{2} \mathrm{ER}$ and $\mathrm{SvO}_{2}$ were not significantly different between groups suggests that terlipressin did not impair peripheral perfusion compared with the HAEMO group. In fact, BE was less negative in the TERLI group. However, compared with the treatment with LR, terlipressin resulted in inferior outcomes with regard to measures of haemodynamics such as CI, RAP, SVRI and PVRI, which might explain the death of one animal in the TERLI group.

As with the present data, an improvement in CPP has also been described in patients with persistent arterial hypotension and acute liver failure [17], traumatic brain injury [23] and septic shock [22] who were successfully treated with terlipressin. In the present study, systemic hypoperfusion could have accounted for unreleased, and thus undetected, products of oxidative stress within the brain, which could have caused cell damage. However, if that was the case, then $\mathrm{PbtO}_{2}$ would not have recovered, unless mitochondria were incapable of using oxygen, allowing an increased availability of oxygen within the tissue. As mitochondrial function was not assessed in the present study, this explanation remains speculative. Also, oxidative damage would probably be associated with inflammation, but this was not supported by a previous study in which researchers found an improved inflammatory cytokine profile in rats treated with terlipressin compared with LR [14]. Nonetheless, the outcome was associated with an increase in the Bcl-x/Bax ratio, suggesting that if any cerebral oxidative injury or ischaemia were present, it probably was not sufficiently severe to trigger antiapoptotic signalling $[36,38]$ within the brain in terlipressin-treated animals.

Treatment with LR, however, was followed by a discrepancy between the increments in $\mathrm{PbtO}_{2}$ that was not accompanied by recovery of CPP. This discrepancy can be attributed to the systemic third-spacing of crystalloids, which would also be consistent with the decline in MAP over the course of 120 minutes [14]. This explanation is supported by the overexpression of AQP4 in the LR group, which might indicate a compensatory mechanism to eliminate excess water within the brain water [44]. An increase in brain water content can also explain the increase in ICP, which, in turn, is detrimental to the restoration of CPP. This finding is also in line with the decreased blood $\mathrm{Na}^{+}$levels in the group treated with LR compared with the sham group. Another hypothesis is that a decrease in blood viscosity after intravascular volume expansion, despite some differences in ICP, could increase cerebral blood flow [45] and thus explain the similar $\mathrm{PbtO}_{2}$ values between LR and TERLI groups. The LR group had the largest increase in ICP, but whether it induced overexpression of the brain tissue markers of water balance, oxidative stress and apoptosis is unknown. The fact is that regardless of the mechanism(s) underlying the failure of full recovery of CPP in the LR group, it remains the case that the markers of oxidative stress, TBARS and MnSOD, were overexpressed in animals treated with LR. The fluid infusion could have carried the overproduction of reactive oxygen species (ROS) throughout the tissue initiating a postischaemic reperfusion injury $[36,46,47]$. ROS regulate mechanisms via inflammatory pathways that ultimately can decrease vascular resistance [35], allowing for an increase in brain volume that could be partly responsible for unrecovered CPP in the LR group. In fact, researchers in a previous study found an increased proinflammatory cytokine profile and severe hypotension $(40 \mathrm{mmHg})$ in rats treated with $\mathrm{LR}$ after haemorrhagic shock [14]. This oxidative stress could have reduced the antiapoptotic trend of the $\mathrm{Bcl}-\mathrm{x} / \mathrm{Bax}$ ratio in the brain during postischaemic reperfusion $[36,38]$. These alterations in the expression of Bcl-x and Bax may indicate 
that mitochondria were dysfunctional, as these proteins are part of the intrinsic mitochondria-related apoptotic pathway. Therefore, similar to the considerations previously described for the terlipressin-treated animals, one hypothesis is that an increased $\mathrm{PbtO}_{2}$ could have been caused by an increased availability of oxygen because dysfunctional mitochondria are not capable of using the oxygen available in the tissue.

Some limitations of this study should be noted. First is the short observation time, which we used because the experiment was designed to determine the early cerebral effects observed during prehospital care, rather than to determine long-term functional neurologic outcome or correlation to brain histopathology. Second, $\mathrm{PbtO}_{2}$ was measured locally with a probe placed in the cerebral cortex, and therefore global ischaemia caused by a heterogeneous distribution of $\mathrm{PbtO}_{2}$ may have been underestimated with regard to the brain region analysed. Third, cerebral blood flow was not measured, because the purpose of the present study was to evaluate changes in CPP and oxygenation. Also, the anaesthetics used may be cerebroprotective and may have different effects in ICP and MAP, but these were minimised by having a sham group and another group not treated after haemorrhagic shock, which were both subjected to the same anaesthetic protocol as the treated groups. In addition, some varieties caused by different vasopressin receptors in pigs (lysine vasopressin) and humans (arginine vasopressin) might have resulted in a different haemodynamic response to terlipressin. However, these differences do not interfere with the results of our study, because the study was aimed at investigating differences between groups and changes over time rather than presenting absolute values. Finally, we used only terlipressin as a vasopressor, and therefore we are unable to report whether different vasopressors would have yielded other results.

\section{Conclusions}

Early treatment with terlipressin was effective at restoring CPP and preventing dysregulation of water balance, and oxidative and apoptotic markers within the brain, following haemorrhagic shock in our model. These results indicate that the role of this pressor agent on brain perfusion in haemorrhagic shock requires further investigation.

\section{Key messages}

- Early treatment with terlipressin recovered cerebral perfusion pressure and brain tissue oxygen tension after haemorrhagic shock in pigs.

- Terlipressin was effective for normalising cerebral markers of water balance, oxidative damage and apoptosis after haemorrhagic shock.
- These cerebral improvements were observed for at least 2 hours after haemorrhagic shock in animals treated with terlipressin.

\section{Abbreviations}

ANOVA: Analysis of variance; AQP4: Aquaporin-4; BE: Base excess; Cl: Cardiac index; CO: Cardiac output; CPP: Cerebral perfusion pressure; $\mathrm{DO}_{2}$ l: Systemic oxygen delivery index; ECL: Enhanced chemiluminescence; HAEMO: No-treatment group; Hb: Haemoglobin; HR: Heart rate; HS: Haemorrhagic shock; ICP: Intracranial pressure; IgG: Immunoglobulin G; LR: Lactated Ringer's solution group; LVSWI: Left ventricular stroke work index; MAP: Mean arterial blood pressure; MnSOD: Manganese superoxide dismutase; MPAP: Mean pulmonary artery pressure; NKCC1: $\mathrm{Na}^{+}-\mathrm{K}^{+}-2 \mathrm{Cl}^{-}$co-transporter; $\mathrm{O}_{2}$ ER: Oxygen extraction ratio; $\mathrm{PaCO}_{2}$ : Partial pressure of carbon dioxide in the arterial blood; PAOP: Pulmonary artery occlusion pressure; $\mathrm{PbtO}_{2}$ : Brain tissue oxygen tension; PVRI: Pulmonary vascular resistance index; RAP: Right atrial pressure; ROS: Reactive oxygen species; RVSWI: Right ventricular stroke work index; SVI: Stroke volume index; $\mathrm{SVO}_{2}$ : Mixed-venous oxygen saturation; SVRI: Systemic vascular resistance index; TBARS: Thiobarbituric acid reactive substance; TERLI: Terlipressin group; $\mathrm{VO}_{2}$ I: Systemic oxygen consumption.

\section{Competing interests}

The authors declare that they have no competing interests.

\section{Authors' contributions}

KKI and DAO conceived the study, designed the trial; obtained research funding; collected, analysed and interpreted the data; and drafted the manuscript and contributed substantially to its revision. ATCS, ESB, LUCC, TRS and $\mathrm{MHH}$ collected, analysed and interpreted the data and drafted the manuscript and contributed substantially to its revision. LCA and LMSM conceived the study, designed the trial, obtained research funding, supervised the conduct of the trial and data collection, provided senior advice on study design and statistical analysis, and drafted the manuscript and contributed substantially to its revision. JOCA contributed substantially to analysis and interpretation of data, provided senior advice on study design and statistical analysis, and drafted the manuscript and contributed substantially to its revision. AD and KJS analysed and interpreted data, provided senior advice on study design and contributed substantially to manuscript revision. JARF supervised the conduct of the trial and data collection, contributed to data analysis and interpretation, provided senior advice on study design and statistical analysis, and drafted the manuscript and contributed substantially to its revision. KKI takes responsibility for the article as a whole. All authors read and approved the final manuscript.

\section{Acknowledgements}

KKI, ATSC, LUCC and LMSM received grant support from Fundação de Amparo à Pesquisa do Estado de São Paulo (FAPESP 11/14386-2, 11/23845-0, 12/04128-9 and 11/00348-1). KKI received grant support from Coordenação de Aperfeiçoamento de Pessoal de Nível Superior (Capes PDSE-BEX Ciência sem Fronteiras 10646/12-4 and CAPES/PROAP 055/2012-Anestesiologia/FMUSP). ESB received grant support from Conselho Nacional de Desenvolvimento Científico e Tecnológico (CNPq 155528/2013-0 Pibic 2401). The authors are grateful for all the support provided by the laboratory technician Gilberto de Mello Nascimento from LIM-8 and research assistants Claudia Alexandria Pereira, Clayton dos Santos, Alexsandra Moraes and Eva Guiss from Anestesiologia FMUSP.

\section{Author details}

'Laboratório de Investigação Médica (LIM-08), Disciplina de Anestesiologia, Faculdade de Medicina, Universidade de São Paulo, Avenida Doutor Arnaldo, 455, $2^{\circ}$ andar, sala 2120, Cerqueira César, São Paulo, SP 01246-903, Brazil. ${ }^{2}$ Department of Neuroinflammation, Institute of Neurology, University College London (UCL), 1 Wakefield Street, 2nd floor, WC1N 1PJ, London, UK. ${ }^{3}$ Disciplina de Nefrologia, Faculdade de Medicina, Universidade de São Paulo (LIM-12 HC-FMUSP), Avenida Doutor Arnaldo, 455, 3rd floor, Cerqueira César, São Paulo, SP 01246-903, Brazil. ${ }^{4}$ Division of Medicine, University College London (UCL), Gower Street, WC1E 6BT, London, UK. ${ }^{5}$ Divisão de Anestesiologia, Hospital das Clínicas da Faculdade de Medicina da Universidade de São Paulo (HCFMUSP), Av. Dr. Enéas de Carvalho Aguiar,155, 8th floor, 05403-000, São Paulo, SP, Brazil. 
Received: 2 November 2014 Accepted: 19 February 2015 Published online: 13 March 2015

\section{References}

1. Bulger EM, May S, Kerby JD, Emerson S, Stiell IG, Schreiber MA, et al. Out-of-hospital hypertonic resuscitation after traumatic hypovolemic shock: a randomized, placebo controlled trial. Ann Surg. 2011;253:431-41.

2. Sauaia A, Moore FA, Moore EE, Moser KS, Brennan R, Read RA, et al. Epidemiology of trauma deaths: a reassessment. J Trauma. 1995;38:185-93.

3. Gutierrez G, Reines HD, Wulf-Gutierrez ME. Clinical review: hemorrhagic shock. Crit Care. 2004;8:373-81.

4. Vincent JL, De Backer D. Circulatory shock. N Engl J Med. 2013;369:1726-34.

5. Taccone FS, De Backer D. Is cerebral microcirculation really preserved in shock states? Crit Care Med. 2010;38:1008-9.

6. Meybohm P, Cavus E, Bein B, Steinfath M, Brand PA, Scholz J, et al. Cerebral metabolism assessed with microdialysis in uncontrolled hemorrhagic shock after penetrating liver trauma. Anesth Analg. 2006;103:948-54.

7. Meybohm P, Cavus E, Dörges V, Weber B, Stadlbauer KH, Wenzel V, et al. Release of protein S100B in haemorrhagic shock: effects of small volume resuscitation combined with arginine vasopressin. Resuscitation. 2008;76:449-56.

8. Cavus E, Meybohm P, Doerges V, Hugo HH, Steinfath M, Nordstroem J, et al. Cerebral effects of three resuscitation protocols in uncontrolled haemorrhagic shock: a randomised controlled experimental study. Resuscitation. 2009:80:567-72

9. Papadopoulos MC, Verkman AS. Aquaporin-4 and brain edema. Pediatr Nephrol. 2007:22:778-84.

10. Yan YP, Dempsey RJ, Sun DD. $\mathrm{Na}^{+}-\mathrm{K}^{+}-\mathrm{Cl}^{-}$cotransporter in rat focal cerebral ischemia. J Cereb Blood Flow Metab. 2001;21:711-21.

11. Zhang TJHJ, Wen DX, Hang YN, Sieber FE. Hippocampus bcl-2 and bax expression and neuronal apoptosis after moderate hypothermic cardiopulmonary bypass in rats. Anaesth Analg. 2006;102:1018-25.

12. Guven H, Amanvermez R, Malazgirt Z, Kaya E, Doganay Z, Celik C, et al. Moderate hypothermia prevents brain stem oxidative stress injury after hemorrhagic shock. J Trauma. 2002;53:66-72.

13. Moon PF, Hollyfield-Gilbert MA, Myers TL, Kramer GC. Effects of isotonic crystalloid resuscitation on fluid compartments in hemorrhaged rats. Shock. 1994:2:355-61.

14. Lee CC, Lee MT, Chang SS, Lee SH, Huang YC, Yo CH, et al. A comparison of vasopressin, terlipressin, and lactated ringers for resuscitation of uncontrolled hemorrhagic shock in an animal model. PLoS One. 2014;9:e95821.

15. Urbano J, López-Herce J, Solana MJ, Del Castillo J, Botrán M, Bellón JM. Comparison of normal saline, hypertonic saline and hypertonic saline colloid resuscitation fluids in an infant animal model of hypovolemic shock. Resuscitation. 2012;83:1159-65.

16. Morelli A, Ertmer C, Rehberg S, Lange M, Orecchioni A, Cecchini V, et al, Continuous terlipressin versus vasopressin infusion in septic shock (TERLIVAP): a randomized, controlled pilot study. Crit Care. 2009;13:R130.

17. Eefsen M, Dethloff T, Frederiksen HJ, Hauerberg J, Hansen BA, Larsen FS. Comparison of terlipressin and noradrenalin on cerebral perfusion, intracranial pressure and cerebral extracellular concentrations of lactate and pyruvate in patients with acute liver failure in need of inotropic support. J Hepatol. 2007:47:381-6.

18. Levacher S, Letoumelin P, Pateron D, Blaise M, Lapandry C, Pourriat JL. Early administration of terlipressin plus glyceryl trinitrate to control active upper gastrointestinal bleeding in cirrhotic patients. Lancet. 1995;346:865-8.

19. Narahara Y, Kanazawa H, Taki Y, Kimura Y, Atsukawa M, Katakura T, et al. Effects of terlipressin on systemic, hepatic and renal hemodynamics in patients with cirrhosis. J Gastroenterol Hepatol. 2009;24:1791-7.

20. Stadllbauer KH, Wagner-Berger HG, Wenzel V, Voelckel WG, Krismer AC, Klima G, et al. Survival with full neurologic recovery after prolonged cardiopulmonary resuscitation with a combination of vasopressin and epinephrine in pigs. Anesth Analg. 2003;96:1743-9.

21. Bayram B, Hocaoglu N, Atilla R, Kalkan S. Effects of terlipressin in a rat model of severe uncontrolled hemorrhage via liver injury. Am J Emerg Med. 2012;30:1176-82.

22. Bradley PG, Allen EK, Menon DK. Terlipressin for cerebral perfusion pressure support in a patient with septic shock. Anaesthesia. 2004;59:619-20.
23. Salluh JIF, Martins GAR, Santino MS, Araújo LV, Freitas GG, Verdeal JCR. Early use of terlipressin in catecholamine-resistant shock improves cerebral perfusion pressure in severe traumatic brain injury. Acta Anaesthesiol Scand. 2007:51:505-8.

24. Holt JP, Rhode EA, Kines H. Ventricular volumes and body weight in mammals. Am J Physiol. 1968;215:704-15.

25. Drummheller OJ. Cardiopulmonary anatomy and physiology. In: Wyka KA, Mathews PJ, Rutkowski J, editors. Foundations of respiratory care. 2nd ed. Clifton Park, NY: Delmar Cengage Learning; 2011. p. 116-70.

26. Meybohm P, Cavus E, Bein B, Steinfath M, Weber B, Scholz J, et al. Neurochemical monitoring using intracerebral microdialysis during systemic haemorrhage. Acta Neurochir (Wien). 2007;149:691-8.

27. Hickey R, Albin MS, Bunegin L, Gelineau J. Autoregulation of spinal cord blood-flow: is the cord a microcosm of the brain. Stroke. 1986;17:1183-9.

28. Chien JC, Jeng MJ, Soong WJ, Hwang B. Effects of fluid resuscitation on cerebral tissue oxygenation changes in a piglet model of hemorrhagic shock. J Chin Med Assoc. 2011;74:448-54.

29. Wan JJ, Cohen MJ, Rosenthal G, Haitsma IK, Morabito DJ, Derugin N, et al. Refining resuscitation strategies using tissue oxygen and perfusion monitoring in critical organ beds. J Trauma. 2009;66:353-7.

30. Manley GT, Fujimura M, Ma TH, Noshita N, Filiz F, Bollen AW, et al. Aquaporin-4 deletion in mice reduces brain edema after acute water intoxication and ischemic stroke. Nat Med. 2000;6:159-63.

31. Xiao F, Arnold TC, Zhang S, Brown C, Alexander JS, Carden DL, et al. Cerebral cortical aquaporin-4 expression in brain edema following cardiac arrest in rats. Acad Emerg Med. 2004;11:1001-7.

32. Wallace BK, Jelks KA, O'Donnell ME. Ischemia-induced stimulation of cerebral microvascular endothelial cell $\mathrm{Na}-\mathrm{K}-\mathrm{Cl}$ cotransport involves $\mathrm{p} 38$ and JNK MAP kinases. Am J Physiol Cell Physiol. 2012;302:C505-17.

33. Huang HF, Guo F, Cao YZ, Shi W, Xia Q. Neuroprotection by manganese superoxide dismutase (MnSOD) mimics: antioxidant effect and oxidative stress regulation in acute experimental stroke. CNS Neurosci Ther. 2012;18:811-8.

34. Chen Z, Chen HZ, Rhee P, Koustova E, Ayuste EC, Honma K, et al. Induction of profound hypothermia modulates the immune/inflammatory response in a swine model of lethal hemorrhage. Resuscitation. 2005;66:209-16.

35. Rushing GD, Britt LD. Reperfusion injury after hemorrhage: a collective review. Ann Surg. 2008;247:929-37.

36. Tsai MC, Chen WJ, Ching $\mathrm{CH}$, Chuang JI. Resuscitation with hydroxyethyl starch solution prevents nuclear factor $\mathrm{KB}$ activation and oxidative stress after hemorrhagic shock and resuscitation in rats. Shock. 2007;27:527-33.

37. Chen G, You G, Wang Y, Lu M, Cheng W, Yang J, et al. Effects of synthetic colloids on oxidative stress and inflammatory response in hemorrhagic shock: comparison of hydroxyethyl starch 130/0.4, hydroxyethyl starch 200/0.5, and succinylated gelatin. Crit Care. 2013;17:R141.

38. Krajewski S, Mai JK, Krajewska M, Sikorska M, Mossakowski MJ, Reed JC. Upregulation of bax protein levels in neurons following cerebral ischemia. J Neurosci. 1995;15:6364-76.

39. Cavus E, Meybohm P, Dorges V, Stadlbauer KH, Wenzel V, Weiss H, et al. Regional and local brain oxygenation during hemorrhagic shock: a prospective experimental study on the effects of small-volume resuscitation with norepinephrine. J Trauma. 2008;64:641-8. discussion 648-9.

40. Meybohm P, Renner J, Boening A, Cavus E, Grasner JT, Grunewald M, et al. Impact of norepinephrine and fluid on cerebral oxygenation in experimental hemorrhagic shock. Pediatr Res. 2007;62:440-4.

41. Meybohm P, Cavus E, Bein B, Steinfath M, Weber B, Hamann C, et al. Small volume resuscitation: a randomized controlled trial with either norepinephrine or vasopressin during severe hemorrhage. J Trauma. 2007:62:640-6.

42. Grubb Jr RL, Raichle ME, Eichling JO, Ter-Pogossian MM. The effects of changes in $\mathrm{PaCO}_{2}$ on cerebral blood volume, blood flow, and vascular mean transit time. Stroke. 1974;5:630-9.

43. Manning M, Stoev S, Chini B, Durroux T, Mouillac B, Guillon G. Peptide and non-peptide agonists and antagonists for the vasopressin and oxytocin $V_{1 a}, V_{1 b}, V_{2}$ and OT receptors: research tools and potential therapeutic agents. Prog Brain Res. 2008;170:473-512.

44. Papadopoulos MC, Manley GT, Krishna S, Verkman AS. Aquaporin-4 facilitates reabsorption of excess fluid in vasogenic brain edema. FASEB J. 2004;18:1291-3.

45. Bouma GJ, Muizelaar JP. Relationship between cardiac output and cerebral blood flow in patients with intact and with impaired autoregulation. J Neurosurg. 1990;73:368-74. 
46. Exo JL, Shellington DK, Bayir $H$, Vagni VA, Janesco-Feldman $K$, Ma L, et al. Resuscitation of traumatic brain injury and hemorrhagic shock with polynitroxylated albumin, hextend, hypertonic saline, and lactated Ringer's: effects on acute hemodynamics, survival, and neuronal death in mice. J Neurotrauma. 2009;26:2403-8.

47. Aksu U, Bezemer R, Yavuz B, Kandil A, Demirci C, Ince C. Balanced vs unbalanced crystalloid resuscitation in a near-fatal model of hemorrhagic shock and the effects on renal oxygenation, oxidative stress, and inflammation. Resuscitation. 2012;83:767-73.

Submit your next manuscript to BioMed Central and take full advantage of:

- Convenient online submission

- Thorough peer review

- No space constraints or color figure charges

- Immediate publication on acceptance

- Inclusion in PubMed, CAS, Scopus and Google Scholar

- Research which is freely available for redistribution 


\title{
Reduced hippocampal manganese-enhanced MRI (MEMRI) signal during pilocarpine-induced status epilepticus: Edema or apoptosis?
}

\author{
Jackeline Moraes Malheiros ${ }^{a, d}$, Daniele Suzete Persike ${ }^{b}$, \\ Leticia Urbano Cardoso de Castro ${ }^{c}$, \\ Talita Rojas Cunha Sanches c, Lúcia da Conceição Andrade c, \\ Alberto Tannús ${ }^{d}$, Luciene Covolan ${ }^{a, *}$
}

\footnotetext{
a Departamento de Fisiologia, Universidade Federal de São Paulo-UNIFESP, São Paulo 04023-06, SP, Brazil b Departamento de Neurologia e Neurocirurgia, Universidade Federal de São Paulo-UNIFESP, São Paulo, SP, Brazil

' Departamento de Nefrologia, Faculdade de Medicina da Universidade de São Paulo, São Paulo, SP, Brazil

d Centro de Imagens e Espectroscopia in vivo por Ressonância Magnética (CIERMag), Instituto de Física de São Carlos, Universidade de São Paulo (IFSC-USP), São Carlos 13566-590, SP, Brazil
}

Received 6 November 2013; received in revised form 13 January 2014; accepted 4 February 2014 Available online 19 February 2014

\author{
KEYWORDS \\ Pilocarpine; \\ Epilepsy; \\ Manganese-enhanced \\ magnetic resonance \\ imaging; \\ Edema; \\ Apoptosis; \\ Hippocampus
}

\begin{abstract}
Summary Manganese-enhanced MRI (MEMRI) has been considered a surrogate marker of $\mathrm{Ca}^{+2}$ influx into activated cells and tracer of neuronal active circuits. However, the induction of status epilepticus (SE) by kainic acid does not result in hippocampal MEMRI hypersignal, in spite of its high cell activity. Similarly, short durations of status ( 5 or $15 \mathrm{~min}$ ) induced by pilocarpine did not alter the hippocampal MEMRI, while 30 min of SE even reduced MEMRI signal Thus, this study was designed to investigate possible explanations for the absence or decrease of MEMRI signal after short periods of SE. We analyzed hippocampal caspase-3 activation (to evaluate apoptosis), $\mathrm{T}_{2}$ relaxometry (tissue water content) and aquaporin 4 expression (water-channel protein) of rats subjected to short periods of pilocarpine-induced SE. For the time periods studied here, apoptotic cell death did not contribute to the decrease of the hippocampal MEMRI
\end{abstract}

\footnotetext{
* Corresponding author. Tel.: +55 11 55792033; fax: +55 1155792033.

E-mail addresses: Icovolan@unifesp.br, lucovolan@gmail.com (L. Covolan).
} 
signal. However, $\mathrm{T}_{2}$ relaxation was higher in the group of animals subjected to 30 min of SE than in the other SE or control groups. This result is consistent with higher AQP-4 expression during the same time period. Based on apoptosis and tissue water content analysis, the low hippocampal MEMRI signal 30 min after SE can potentially be attributed to local edema rather than to cell death.

(c) 2014 Elsevier B.V. All rights reserved.

\section{Introduction}

Status epilepticus (SE) is defined as a seizure that persists for a sufficient length of time or is repeated frequently enough that recovery between attacks does not occur (CCT-ILAE, 1981). This definition was based on the persistence or repetition of the epileptic seizures rather than on the duration, although experts agreed that it should last at least $30 \mathrm{~min}$ to evoke a chronic epileptic condition (Lemos and Cavalheiro, 1995).

In the pilocarpine model of temporal lobe epilepsy (TLE), SE onset is defined as a seizure that persists for at least $5 \mathrm{~min}$, and usually it may persist from 4 to $24 \mathrm{~h}$ (Leite et al., 1990). Electroencephalographical (EEG) recordings immediately after intraperitonial pilocarpine injection have shown that low-voltage, fast activity appears in the neocortex and amygdala, while theta rhythm is evident in the hippocampus. As the behavioral manifestation of seizures becomes more severe, the theta hippocampal activity is replaced by high-voltage spiking and fast activity. EEG recordings immediately after injection have shown that pilocarpine can induce ictal epileptic events and that these EEG patterns are correlated with behavioral changes that culminate into SE [for review, see (Curia et al., 2008)].

$M R I$ is a noninvasive and high resolution imaging modality that is considered the most sensitive and specific structural neuroimaging for epilepsy, allowing several neuropathological studies. There are many MRI techniques: $T_{2}$ - and $\mathrm{T}_{1}$-weighted imaging, functional $M R I$, manganese enhanced MRI (MEMRI), arterial spin labeling (ASL), diffusion tensor imaging (DTI) that can detect not only damage caused by status epilepticus but also plastic changes in the brain that occur in response to damage [for review, see (Gröhn et al., 2011)].

Manganese-enhanced magnetic resonance imaging (MEMRI) is based on the fact that $\mathrm{Mn}^{+2}$ is a paramagnetic substance that changes both transverse and longitudinal relaxation (Korestky and Silva, 2004; Silva et al., 2004) and thus can act as a contrast agent in magnetic resonance imaging (MRI). The ability of $\mathrm{Mn}^{+2}$ to compete with $\mathrm{Ca}^{+2}$ allows it to be a marker of increased cellular activity and to trace neuronal connections (Korestky and Silva, 2004; Pautler et al., 1998).

Many animal studies have found a strong correlation between local brain activity and manganese enhancement using specific stimuli and $\mathrm{MnCl}_{2}$ systemically injected with and without transient breakdown of the blood-brain barrier (BBB) (Kuo et al., 2006; Lin and Koretsky, 1997; Pautler and Koretsky, 2002; Weng et al., 2007; Yu et al., 2005). This ability, added to the fact that $\mathrm{Mn}^{+2}$ clearly enhances the various subfields of the hippocampus (dentate gyrus (DG), CA1 (Cornu Ammonis) and CA3 (Aoki et al., 2004; Watanabe et al., 2004), suggests that MEMRI could act as an imaging marker of epileptic focus.

Considering the chronic phase of epilepsy in the kainate or pilocarpine models, recent reports provide evidence that the MEMRI hyperintensity in the DG is mostly correlated with mossy fiber sprouting (Immonen et al., 2008; Malheiros et al., 2012b; Nairismägi et al., 2005), or, alternatively, inversely correlated with the frequency of spontaneous recurrent seizures (Dedeurwaerdere et al., 2013). Although conflicting, these findings relate the MEMRI signal in the hippocampus to local increases of cell activity. However, it has been shown that manganese enhancement of the MRI signal is significantly decreased in the hippocampus in the acute and latent phases of the kainate model (Alvestad et al., 2007). These last results could be either attributed to cell damage or loss following the long duration of SE (Alvestad et al., 2007; Immonen et al., 2008). In an attempt to circumvent the possible causes of reduction in the MEMRI signal during SE (cell damage/loss), the status was fully blocked at progressive time periods after its onset $(5,15$ or $30 \mathrm{~min})$ and the cell activity and the MEMRI signal were evaluated. It resulted that short durations of status did not produce differences in the MEMRI signal ( $30 \mathrm{~min}$ of SE reduced MEMRI signal) despite increased c-fos expression (Malheiros et al., 2012a).

Based on these findings, the present study will further investigate possible causes (apoptosis cell death or tissue water content) for reduction of the MEMRI signal during SE induced by pilocarpine.

\section{Methods}

\section{Animals and study design}

All protocols were approved by the Animal Care Committee of the Universidade Federal de São Paulo (CEP $0750 / 07)$. Adult male Wistar rats $(250-300 \mathrm{~g})$ were housed 4 rats/cage and kept under controlled laboratory conditions (12 h light/12 h dark cycle with lights on at 07:00 a.m., temperature $22 \pm 1{ }^{\circ} \mathrm{C}$, air humidity $50-60 \%$, ad libitum access to food and water). Pilocarpine hydrochloride $(300 \mathrm{mg} / \mathrm{kg}$, i.p. Vegeflora, Parnaiba, Brazil) was systemically injected, and 30 min prior, animals were given scopolamine methyl bromide (1 mg/kg, i.p., Sigma, Saint Louis, MI, US) to reduce systemic cholinergic side effects. Pilocarpine animals developed SE on average 30 min after the injection. One hundred two animals were used in this study. The SE-related mortality was $22.3 \%$ and $24.7 \%$ of animals that received pilocarpine injection did not develop SE. 
MEMRI and c-fos activation

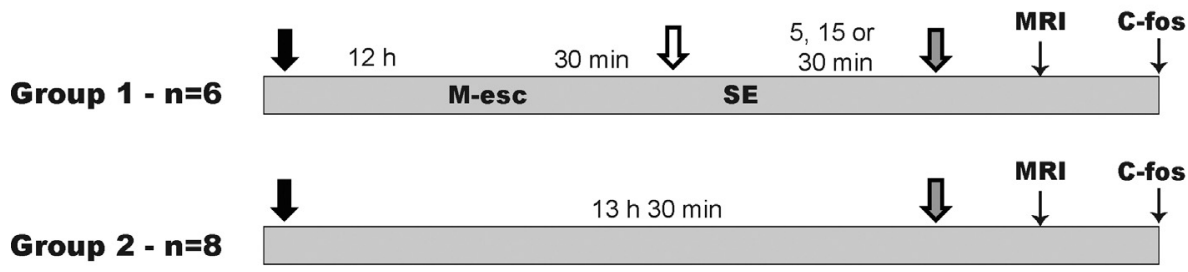

MEMRI and caspase- 3 fluorimetric assay

Group $3-n=4$

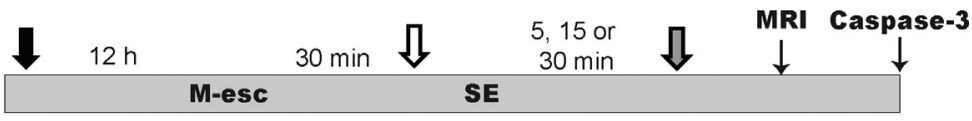

Group 4 - n=4

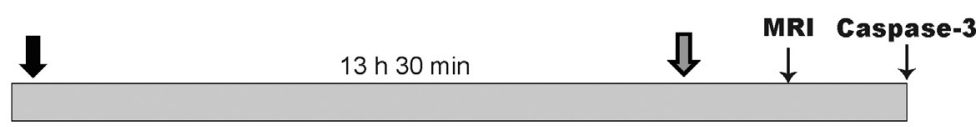

T2 relaxometry and AQP-4

Group $5-n=5$

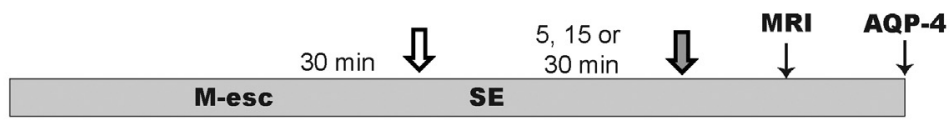

Group $6-n=5$

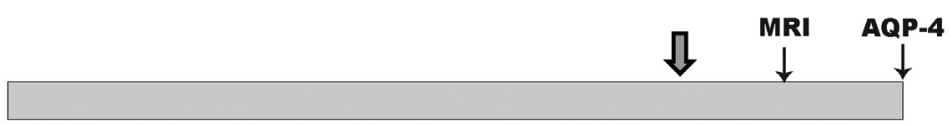

$\mathrm{MnCl}_{2} \rrbracket^{\text {Pilo }} \rrbracket^{\text {Thio }+\mathrm{dz}}$

Fig. 1 Temporal diagram depicting the groups, treatments, and procedures used in the present study. The animals were divided into six groups: Groups $1-4$ received a solution of $\mathrm{MnCl}_{2} \cdot 4 \mathrm{H}_{2} \mathrm{O}(60 \mathrm{mg} / \mathrm{kg}) 12 \mathrm{~h}$ prior to pilocarpine injection. Group 1 ( $n=6$ for each time period) and Group 3 ( $n=4$ for each time period) were designed to compare MEMRI contrast with $c$-fos expression and caspase-3 assay, respectively after SE. Groups $2(n=8)$ and $4(n=4)$ served as controls for Groups 1 and 3, respectively. These groups underwent the same protocol but did not receive pilocarpine injections. Group 5 ( $n=5$ for each time period) received pilocarpine and Group $6(n=5)$ did not experience SE. These groups were used without $\mathrm{MnCl}_{2}$ injection, and $\mathrm{T}_{2}$-weighted $\mathrm{MRI}$ was acquired to compare their aquaporin-4 expression. Abbreviations: M-esc-scopolamine methyl bromide; SE-Status epilepticus; AQ4-aquaporin 4; Pilo-pilocarpine and thio + dz-thionembutal + diazepam.

The study design is outlined in Fig. 1. Rats were divided into 6 experimental groups. Awake animals for Groups 1-4 received a solution of $\mathrm{MnCl}_{2} \cdot 4 \mathrm{H}_{2} \mathrm{O}(1 \mathrm{M})$ diluted in bicine solution $(100 \mathrm{mM}$ in deionized water) with $\mathrm{pH}$ adjusted to 7.4 using $\mathrm{NaOH}$. Final concentration of $\mathrm{MnCl}_{2}$ was $100 \mathrm{mM}$. Freshly prepared $\mathrm{MnCl}_{2}(60 \mathrm{mg} / \mathrm{kg})$ was injected intraperitoneally $12 \mathrm{~h}$ prior to pilocarpine injection when $\mathrm{Mn}^{+2}$ has already reached the hippocampus and the $\mathrm{Mn}^{+2}$ accumulation is still ongoing (Lee et al., 2005).

Behavioral seizures development was observed based on the Racine scale (Racine, 1972). The SE onset was defined after $5 \mathrm{~min}$ of continuous seizure activity. At the end of different SE time periods (5, 15 or $30 \mathrm{~min})$, all the experimental groups, including the controls, received a mixture of thionembutal + diazepam $(30+10 \mathrm{mg} / \mathrm{kg}$, i.p. $)$. Behavioral analysis in this paper supports previous encephalographic results (Mello et al., 2006) showing that this mixture terminates the SE in up to $10 \mathrm{~min}$.
Group 1 ( $n=6$ for each time period) and Group 3 ( $n=4$ for each time period) was designed to compare MEMRI with c-fos expression and caspase-3 assay, respectively, after SE. Group $2(n=8)$ and Group $4(n=4)$ served as controls for Group 1 and Group 3, respectively. They underwent the same protocol but did not experience SE (did not receive the pilocarpine injection). Group 5 ( $n=5$ for each time period) received pilocarpine and Group $6(n=5)$ did not experience $\mathrm{SE}$. These groups were not $\mathrm{MnCl}_{2}$ injected, and $\mathrm{T}_{2}$-weighted MRI was acquired to compare their aquaporin-4 expression. For Groups 1 and 2 we used exactly the same protocols as previously published (Malheiros et al., 2012a).

\section{MRI}

All MRI ( $\mathrm{T}_{1}$ and $\mathrm{T}_{2}$-weighted) were acquired $14 \mathrm{~h}$ after $\mathrm{MnCl}_{2}$. To decrease the post-SE mortality rate, the animals 

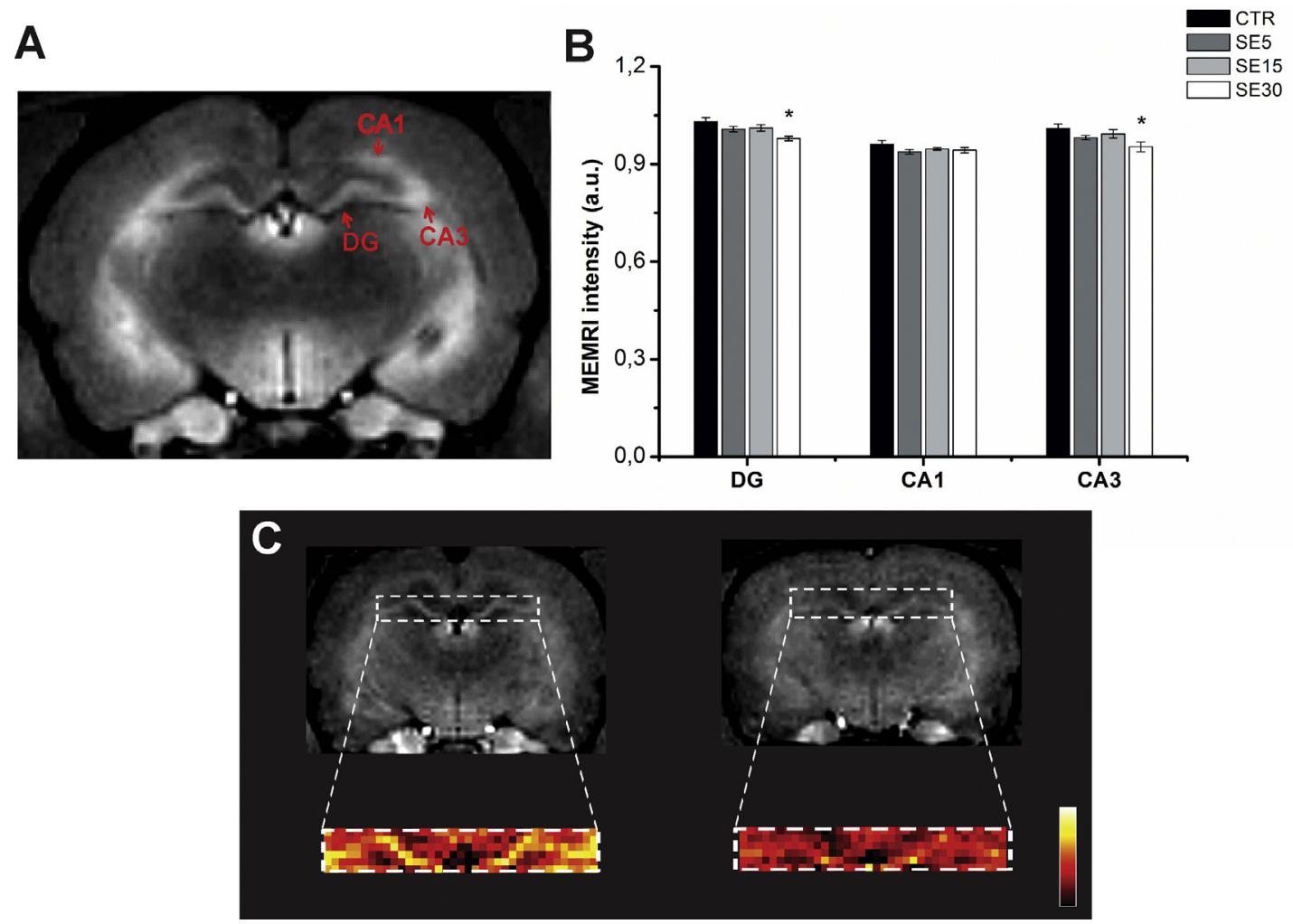

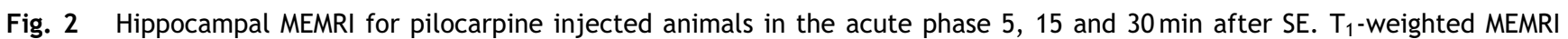
images ( $A$ and $C$ ) and MEMRI data (B). The regions of interest (ROIS) were drawn in the hippocampal sub regions DG (dentate gyrus), CA1 and CA3 (Cornu Ammonis), as represented in A. The DG was enlarged and converted from gray into a colored scale in C to show differences between the CTR and SE30 groups ( ${ }^{*} P<0.01$ ). (For interpretation of the references to color in this figure legend, the reader is referred to the web version of this article.)

(even controls treated with the mixture of thionembutal + diazepam, as above described) were placed in a supine position on the surgical table, tracheotomised, intubated (tube with approximately $0.5 \mathrm{~mm}$ diameter), and connected to a respirator for small animals (model 7025, Ugo Basile) and ventilated with ambient air $\left(21 \% \mathrm{FiO}_{2}\right)$, at a respiratory rate of 70 cycles/min and a volume of $3.5 \mathrm{~mL} /$ cycle. These ventilatory parameters were monitored during the image acquisitions according to physiological parameters of each animal.

Images were obtained in a $2 \mathrm{~T} / 30 \mathrm{~cm}$ superconducting magnet 85310HR (Oxford Instruments, Abingdon, UK) interfaced with a Bruker Avance AVIII console (Bruker-Biospin, Inc., Billerica, MA, USA) using Paravision 5.0 software. A crossed saddle radiofrequency coil (Papoti, 2006) was used as a head probe. $\mathrm{T}_{1}$-weighted FLASH (Fast Low-Angle Shot) sequence was used in animals (Groups 1-4) that were $\mathrm{MnCl}_{2}$ injected $\left(\mathrm{TR}=200 \mathrm{~ms}, \mathrm{TE}=5.8 \mathrm{~ms}\right.$, flip angle $=90^{\circ}$, 4 means, $40 \mathrm{~min} /$ animal). A volume of $40 \times 40 \times 11.2 \mathrm{~mm}^{3}$ was covered with a $192 \times 192 \times 16$ points, generating a spatial resolution of $208 \times 208 \times 700 \mu \mathrm{m}^{3}$. T2 MSME (Multi Slice Multi Echo) sequence was acquired in Groups 5 and 6 with $208 \times 208 \mu \mathrm{m}^{2}$ spatial resolution to determine the hippocampal $\mathrm{T}_{2}$ relaxation time ( 4 averages; $\mathrm{TR}=2000 \mathrm{~ms}, 15$ equally spaced echoes, $T E=15-225 \mathrm{~ms} ; \mathrm{FOV}=40 \times 40 \mathrm{~mm}$, $19 \mathrm{~min} /$ animal).

MRI data was analyzed using the Paravision 5.0 software. One author (JMM), blinded to the group's identity has manually outlined the regions of interest (ROI). Alterations in the relative signal intensity of the dentate gyrus (DG), CA1 (Cornu Ammonis) and CA3 were quantified from a single coronal section in $\mathrm{T}_{1}$-weighted $3 \mathrm{D}$ images at the anteroposterior level of $-3.6 \mathrm{~mm}$ from the bregma (Fig. 2A). The signals were calculated as the ratio between the intensity of the mean signal in the ROI and the intensity of the mean signal of the adjacent corpus callosum (baseline value). The increased intensity of the relative signal, when compared to control animals, was determined as MEMRI hyperintensity. A ROI utilized in this study, denominated $D G$, in reality includes the DG and the proximal portion of the CA3, because it was not possible to separate them for analysis (Immonen et al., 2008). $T_{2}$ relaxation time was determined by drawing bilaterally the contour of the hippocampus to define the region of interest (ROI) on the MSME images. The hippocampal level was the same as used in the analysis of $\mathrm{T}_{1}$-weighted images ( $3.6 \mathrm{~mm}$ caudal to bregma). The software tool ISA (Image Sequence Analysis) was used and the $\mathrm{T}_{2}$ calculated from a monoexponential curve.

\section{Brain tissue}

\section{C-fos immunohistochemistry}

Animals for Groups 1 and 2 were perfused transcardially, just after MRI acquisitions, with saline followed by $4 \%$ formaldehyde in 0.1 M phosphate buffer (PB, Sigma-Aldrich, $\mathrm{pH} 7.4$ ). After perfusion, the brains were then removed from the 
skull and stored at $4^{\circ} \mathrm{C}$ in $30 \%$ sucrose for $3-4$ days. Coronal sections with $30 \mu \mathrm{m}$ were cut on a cryostat and one of three consecutive coronal sections was pre-treated with hydrogen peroxidase, followed by normal goat serum (1:200) and $0.3 \%$ Triton $X-100$ for $30 \mathrm{~min}$. Sections were then (1) incubated with primary antibody (rabbit anti c-Fos 1:3000; Vector Laboratories, CA) at room temperature for $24 \mathrm{~h}$; (2) incubated with a secondary antibody (goat anti-rabbit IgG 1:200; Vector Laboratories, CA) for $2 \mathrm{~h}$ at room temperature; (3) treated with 1:100 avidin-biotin complex for $90 \mathrm{~min}$ and a nickel-intensified diaminobenzidine reaction. The sections were rinsed in phosphate buffer, dried and mounted on gelatin-coated slides and coverslipped.

Histological images were captured on a high-resolution digital camera (Nikon DXM1200), installed in a Nikon microscope (Eclipse E600FN) with a magnification of $10 \times$. Immunohistochemical labeling of $c-F o s$ in the DG, CA1 and CA3 was evaluated by quantitatively measuring grayscale values using the National Institutes of Health $(\mathrm{NIH})$ Image J software (http://rsbweb.nih.gov/ij/index.html). The grayscale values for the hippocampal sub regions were compared to those for the adjacent corpus callosum (baseline value). Sections were assessed across three different levels (rostral, medium, and caudal) of the hippocampus bilaterally, corresponding to levels $2.8,3.8$, and $4.8 \mathrm{~mm}$ caudal to the bregma (Paxinos and Watson, 1998) to exclude any possible rostro-caudal variability.

\section{Caspase- 3 fluorimetric assay}

Caspase- 3 activity was studied in $n=4$ animals per group using the method described by Thornberry et al. (1997) recently modified by Belizário et al. (2001). Rats were decapitated just after MRI acquisitions with animals still under the effects of anaesthetic. The hippocampi were dissected at $4{ }^{\circ} \mathrm{C}$ and immediately added to $20 \mathrm{mM}$ HEPES buffer ( $\mathrm{pH} 7.4$ ) that contained 2 mM EDTA, 0.1\% CHAPS, $10 \%$ sucrose, $0.1 \%$ PMSF, $0.1 \%$ benzamidin, $0.1 \%$ antipain, $0.1 \%$ TLCK, $0.1 \%$ chemostatin and $0.1 \%$ pepstatin $(5 \mathrm{ml}$ homogenization buffer/mg tissue). Homogenates were obtained by mechanically disrupting the tissue three times on dry-ice, with thawing in an ice bath, interpolated by $1 \mathrm{~min}$ of moderate vortex shaking. Samples were centrifuged at $12,000 \times g$ for $40 \mathrm{~min}$ at $4{ }^{\circ} \mathrm{C}$ to remove cellular debris. Total proteins were determined in the supernatants using the Bio-Rad Protein Assay (Bio-Rad Labs, Germany). Homogenates $\left(100 \mathrm{mg} /\right.$ protein) were incubated at $37^{\circ} \mathrm{C}$ with the tetrapeptide substrate: AspGlu-Val-Asp (Ac-DEVD-AMC, $4 \mathrm{mM}$ ) for caspase-3, in a final volume of $150 \mathrm{ml}$. For a negative control, homogenates were pre-incubated for $10 \mathrm{~min}$ at $37^{\circ} \mathrm{C}$ with commercial inhibitor to caspase- 3 (AC-DEVD-CHO, $1 \mathrm{mM})$, followed by the addition of the respective substrate. Activity was measured continuously over $2 \mathrm{~h}$ on a FlexStation 3 (Molecular Probes) Spectrofluorimeter, using $\lambda_{\mathrm{ex}}=360 \mathrm{~nm}$ and $\lambda_{\mathrm{em}}=465 \mathrm{~nm}$. Results are expressed in activity (nmol $\mathrm{AMC})$.

\section{Aquaporin 4 expression assay}

Brain tissues were homogenized in ice-cold isolation solution (200 mM mannitol, $80 \mathrm{mM}$ HEPES, $41 \mathrm{mM} \mathrm{KOH,} \mathrm{pH} \mathrm{7.5)} \mathrm{con-}$ taining protease inhibitor cocktail. The homogenates were centrifuged at low speed $(4000 \times g)$ for $15 \mathrm{~min}$ at $4{ }^{\circ} \mathrm{C}$ to remove nuclei and cell debris. Protein concentrations were determined by the Bradford assay method (Bio-Rad Protein Assay kit; Bio-Rad Laboratories, Hercules, CA).

Brain samples were run on $12 \%$ polyacrylamide minigels. After transfer by electroelution to a hydrophobic polyvinylidene difluoride membrane (Amersham Hybond-P PVDF Membrane GE Healthcare, Buckinghamshire, UK), blots were blocked with $5 \%$ milk and $0.1 \%$ Tween 20 in TBS or $1 \mathrm{~h}$. Blots were then incubated overnight with an anti-AQP4 (Santa Cruz, TX, US) antibody $(1: 10,000)$. The labeling was visualized with a horseradish peroxidase-conjugated secondary antibody (anti-rabbit IgG diluted 1:2000; Sigma) using Western blotting detection reagents, the enhanced chemiluminescence detection system ECL (GE Healthcare, Buckinghamshire, UK). The images were obtained using the chemiluminescence imaging system Alliance 4.2 (Uvitec, Cambridge, UK) and quantitative analysis of antibodies was performed using densitometry, normalizing the bands to actin (Santa Cruz, Texas, US; 1:2000 with anti-goat $1: 10,000)$ expression.

\section{Statistical analysis}

All data are presented as the mean \pm SEM (standard error of mean). A one-way analysis of variance (ANOVA) was followed by the Bonferroni post hoc test with the statistical significance set to $P<0.05$ for each analysis.

\section{Results}

\section{MEMRI}

In the dentate gyrus (DG) the MEMRI signal was similar among the SE5 $(1.008 \pm 0.008)$, SE15 $(1.011 \pm 0.010)$ and control (CTR) groups $(1.031 \pm 0.012)$ (Fig. 2B). In the same region, the SE30 MEMRI signal $(0.979 \pm 0.007, P<0.01)$ was less than that of the CTR (Fig. 2B and C).

In the CA1 (Cornu Ammonis) field, the groups SE5 $(0.938 \pm 0.007), \quad$ SE15 $(0.947 \pm 0.004)$ and SE30 $(0.943 \pm 0.008)$ displayed a MEMRI signal similar to that of the control group $(0.961 \pm 0.011)$.

In the CA3 field, as for the DG region, the MEMRI signal was similar among SE5 $(0.981 \pm 0.007)$, SE15 $(0.993 \pm 0.013)$ and control $(1.010 \pm 0.014)$ groups. However, the MEMRI signal of the SE30 group $(0.953 \pm 0.015)$ was significantly lower than the CTR $(P<0.05)$.

\section{C-fos}

Fig. 3 shows C-Fos immunohistochemical labeling in the DG $(A-D)$ region, CA1 $(E-H)$ and CA3 (I-L) fields. The densitometry analysis of $\mathrm{C}$-fos labelled cells indicated that in the DG, more c-fos expressing cells occur in the SE5 $(41.1 \pm 4.5)$, SE15 $(40.8 \pm 5.8)$ and SE30 $(40.3 \pm 5.5)$ groups than in the control $(10.3 \pm 0.8, P<0.05)$. Similar results were observed in the CA1 and CA3 fields. In the CA1 field, the mean number of $c$-fos labeled cells in the SE5 $(26.9 \pm 2.3)$, SE15 $(31.8 \pm 2.5)$ and SE30 $(25.9 \pm 3.6)$ groups is higher than in the control one $(10.9 \pm 0.7, P<0.05)$; in the CA3 field the mean number of c-fos immunolabeled cells was similarly 

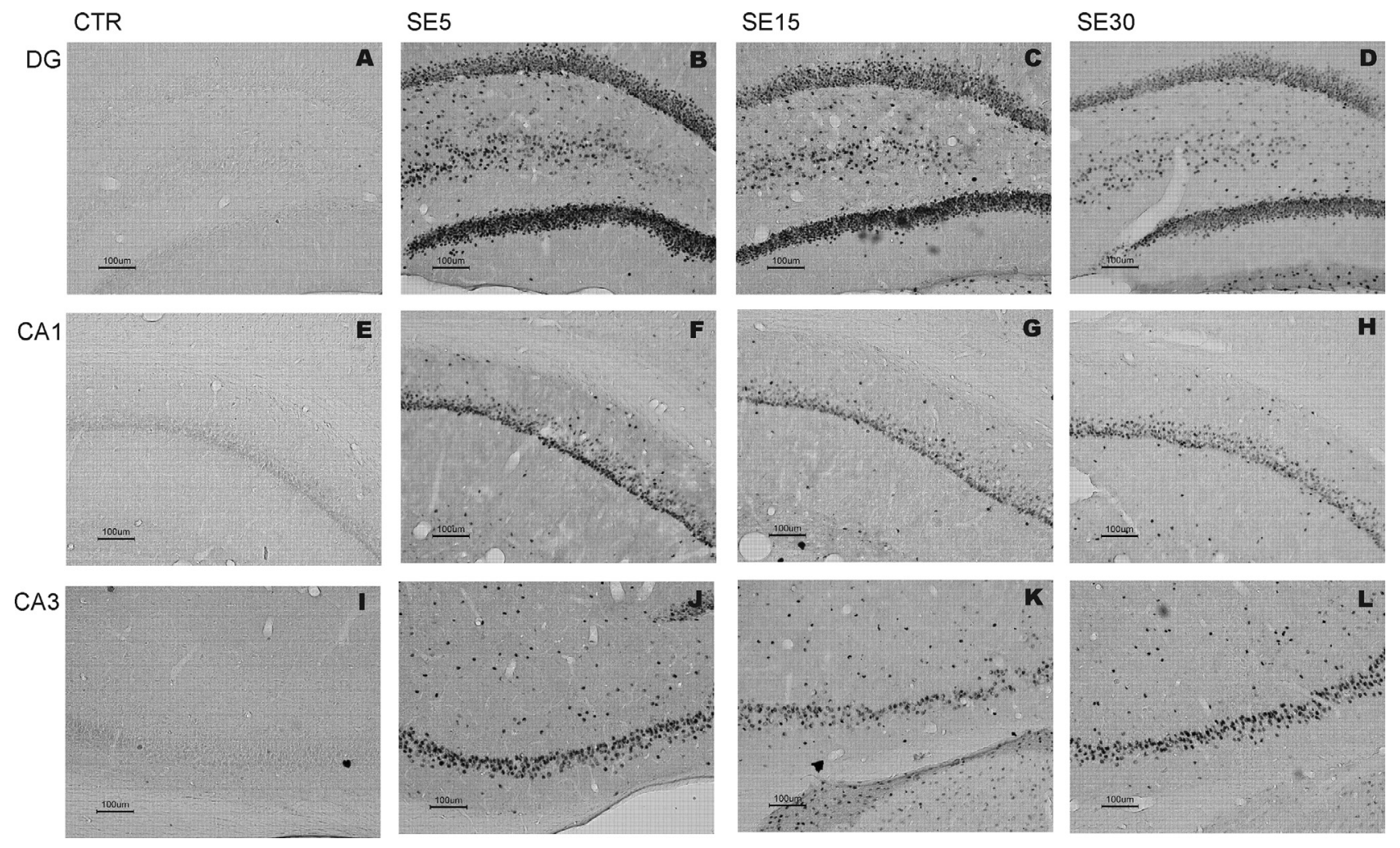

Fig. 3 Hippocampal histological analysis of c-fos expression (gray scale values) for DG (A-D), CA1 (E-H) and CA3 (I-L) for control (CTR), SE5, SE15 and SE30 groups, respectively. Pilocarpine-treated animals showed intense staining in all hippocampal sub regions unlike the controls.

higher after status, despite its duration (SE5, 20.8 \pm 2.0 ; $\mathrm{SE} 15,23.3 \pm 2.7$; SE30, $19.5 \pm 2.4$ ) than in the control group $(8.7 \pm 0.7, P<0.05)$.

No differences in the number of c-fos positively labelled cells were detected among pilocarpine-treated groups (SE5, SE15 and SE30) for any hippocampal sub region.

\section{Caspase-3}

Fig. 4A summarizes fluorimetric caspase-3 activity (nmol $A M C$ ). There were no differences between all studied groups: SE5, $129.2 \pm 9.4$; SE15, $148.9 \pm 19.7$; SE30, $153.0 \pm 8.4$ and CTR, $140.6 \pm 19.6$.

\section{$\mathrm{T} 2$ relaxometry}

Hippocampal MRI relaxometry (ms) findings are summarized in Fig. 4B. There were no differences between SE5 $(62.3 \pm 1.9)$ and SE15 $(60.7 \pm 1.9)$ groups when compared to control group (58.4 \pm 2.6$)$. In addition, $\mathrm{T}_{2}$ in the SE30 group $(70.4 \pm 2.2)$ is higher than in the control $(P<0.01)$ and SE15 $(P<0.05)$ groups.

\section{Aquaporin-4 (AQP-4)}

Aquaporin-4 expression, as measured by means of densitometry, was higher in the SE30 $(120.6 \pm 4.7)$ group than in the control $(95.2 \pm 5.6, P<0.05)$ or SE15 $(89.2 \pm 8.4, P<0.05)$, but similar to the SE5 $(105.5 \pm 0.95)$ group. There were no other differences between groups. Results are shown in Fig. 4C and D.

\section{Discussion and conclusion}

The MEMRI and c-fos expression data presented here are consistent with our own and others' previous data, which showed decrease in relative signal intensity in $T_{1}$-weighted MEMRI images in the hippocampus during pilocarpine and kainate SE (Alvestad et al., 2007; Immonen et al., 2008; Malheiros et al., 2012a). There are no identified MEMRI differences between pilocarpine-treated animals (SE5 and SE15) and controls for the dentate gyrus (DG), CA1 (Cornu Ammonis) and CA3 fields.

The experiments conducted here aimed to add some light to the proposed role of MEMRI as preclinical biomarker for the severity of epileptogenesis in animal models. Hippocampal MEMRI signal in the epileptic chronic phase was proposed to be related to local increases of cell activity after seizures (Dedeurwaerdere et al., 2013). Although the manganese enhancement was related to spontaneous seizures outcome in the chronic epilepsy phase, it does not seem to happen after acute induced seizures. It is noteworthy that the SE30 group displayed a decrease MEMRI signal even in the DG and CA3 areas, which contrasts with the high cell activity in all hippocampal sub regions (DG, CA1 and CA3) confirmed by $\mathrm{c}$-fos expression. Immediate early gene c-fos 
A

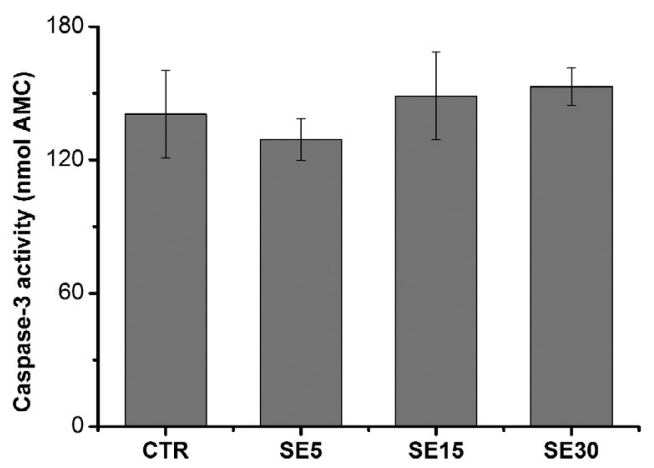

C

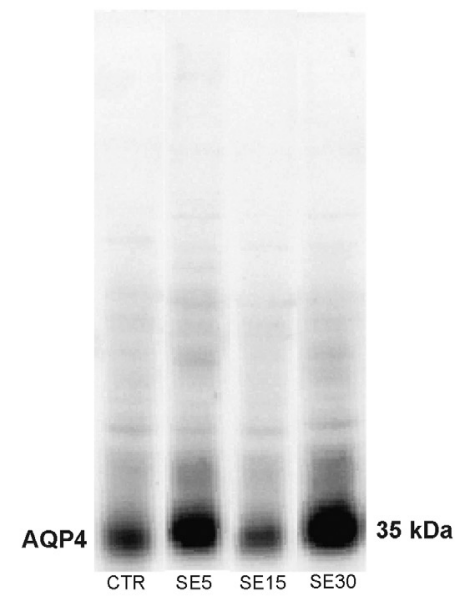

B

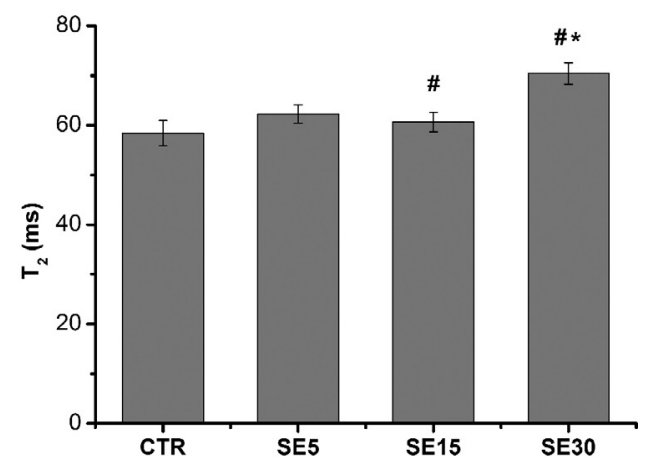

D

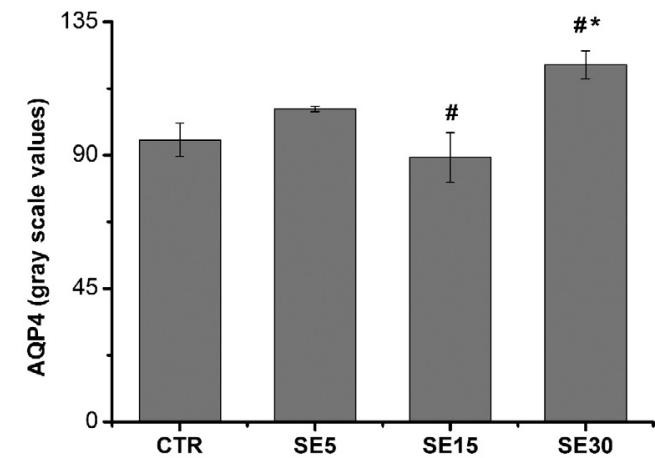

Fig. 4 Hippocampal caspase-3 and AQP4 results. (A) Caspase-3 activity was the same for both pilocarpine and control (CTR) groups. In (B), SE30 showed a $T_{2}$ (ms) value higher than the CTR ( $\left.P<0.01\right)$ and SE15 ( $\left.P<0.05\right)$. AQP4 results: (C) AQP4 protein expression (around $35 \mathrm{kDa}$ ) in different groups identified by Western-blotting and (D) grayscale values obtained from (C), indicating that AQP4 expression was different between SE30 $\times$ CTR ( $P<0.05)$ and SE30 $\times$ SE15 ( $P<0.05)$ groups.

is a marker of neurons that have been recently active, e.g., during a seizure (Sheng and Greenberg, 1990). Therefore, the absence of hippocampal MEMRI for SE30 and MEMRI signal similar to controls for SE5 and SE 15 cannot be attributed to decreased neuronal activity.

One possible explanation for the absence of MEMRI signal in the hippocampus for SE30 could be related to cell loss, once in vivo MEMRI enhancement is proportional to the $\mathrm{Mn}^{+2}$ taken into cells through voltage gated $\mathrm{Ca}^{+2}$ channels (Silva et al., 2004). However, our current results show that there is no alteration in the levels of caspase- 3 activity after pilocarpine-induced status, during the time period investigated here. Caspase- 3 activation is a mechanism of cell death (apoptosis) induced by seizures and has been detected between $24 \mathrm{~h}$ and 7 days after pilocarpine-induced status epilepticus (SE) in neurons, primarily in the hippocampus (Weise et al., 2005), although other studies have shown that active caspase- 3 occurs mainly in the astrocytes and to a lesser extent in neurons (Ferrer et al., 2000; Narkilahti et al., 2003). Regardless of which hippocampal cell population is more affected by caspase- 3 activation, it was not detectable within a few hours after SE onset, thus suggesting that after different durations of status $(5,15$ or $30 \mathrm{~min})$, apoptotic cell death is not related to reduction of MEMRI signal in the hippocampus.

In addition to cell death, local edema is often found in epileptic hippocampus, so it could by itself alter the MEMRI signal output. The current results indicate that $T_{2}$ signal hyperintensity is indeed present in SE30 group, but not in the earlier time periods. This is maybe due to increases of water content in the hippocampus reducing the manganese signal. The hippocampus of patients with mesial temporal lobe epilepsy is often hardened and shrunken, a condition known as sclerosis. Magnetic resonance imaging (MRI) reveals an increase in the $T_{2}$-weighted signal, whereas the diffusion-weighted imaging shows a higher apparent diffusion coefficient in sclerotic hippocampi, indicative of an increased water flow into the hippocampus, and accumulation of water in the brain parenchyma. In another human study, hippocampal edema and neuronal cell loss appear together (Kumar et al., 2013). Therefore, a significant increase in aquaporin-4 (AQP-4) was observed in sclerotic, but not in non-sclerotic, hippocampi obtained from patients with medically intractable temporal lobe epilepsy (Lee et al., 2004). For animals, SE induced by kainic 
acid indicate significantly greater tissue edema (AQP-4) and T2 MRI changes (Lee et al., 2012).

AQP-4 is a water-channel protein expressed strongly in the brain, predominantly in astrocyte foot processes at the borders between the brain parenchyma and major fluid compartments, including cerebrospinal fluid (CSF) and blood. This distribution suggests that AQP-4 controls water fluxes into and out of the brain parenchyma (Papadopoulos and Verkman, 2007). In interstitial edema, AQP-4 might facilitate the removal of excess extracellular brain water (Bloch et al., 2006; Bloch et al., 2005; Papadopoulos et al., 2004). Here, the AQP-4 protein expression was higher in the SE30 group than in the other studied groups. The result obtained by AQP-4 in the SE30 group is consistent with $T_{2}$ relaxation changes found in the same time period, indicating the relationship of both measures with brain edema.

In conclusion, the DG and CA3 MEMRI hypo signal seen in the SE30 group could be explained by increases of water content rather than cell death. We suggest that the $T_{2}$ relaxation changes are attributable to brain edema. Decreases in brain edema and/or cellular swelling could be mediated by AQP-4, resulting in better clearance of water excess from brain tissue. The hippocampal edema presented after $30 \mathrm{~min}$ of status changes the MRI relaxation times so that, the MEMRI signal was lower than in control group, thereby presenting a hypo signal on $\mathrm{T}_{1}$-weighted images.

\section{Disclosures and ethics}

None of the authors has any conflict of interest to disclose. We affirm that we have read the Journal' position on issues involved in ethical publication and affirm that this report is consistent with those guidelines.

\section{Acknowledgments}

We gratefully acknowledge Financial Support from FAPESP CInAPCe Program 05/56663-1 (CIERMag). J.M.M. was supported by FAPESP fellowship 07/52911-6. We thank Vegeflora Extrações do Nordeste Ltda, who kindly donated Pilocarpine hydrochloride. We are also very gratefull for Miss Elizabeth Croal for her assistance proof reading the article.

\section{References}

Alvestad, S., Goa, P.E., Qu, H., Risa, O., Brekken, C., Sonnewald, U., Haraldseth, O., Hammer, J., Ottersen, O.P., Håberg, A., 2007. In vivo mapping of temporospatial changes in manganese enhancement in rat brain during epileptogenesis. Neuroimage 38 (1), 57-66.

Aoki, I., Wu, Y.L., Silva, A.C., Lynch, R.M., Korestky, A.P., 2004. In vivo detection of neuroarchiteture in the rodent brain using manganese-enhanced MRI. Neuroimage 22, 1046-1059.

Belizário, J.E., Lorite, M.J., Tisdale, M.J., 2001. Cleavage of caspases-1, $-3,-6-8$ and -9 substrates by proteases in skeletal muscles from mice undergoing cancer cachexia. Br. J. Cancer 84 (8), 1135-1140.

Bloch, O., Auguste, K.I., Manley, G.T., Verkman, A.S., 2006. Accelerated progression of kaolin-induced hydrocephalus in aquaporin-4-deficient mice. J. Cereb. Blood Flow Metab. 26, 1527-1537.
Bloch, O., Papadopoulos, M.C., Manley, G.T., Verkman, A.S., 2005. Aquaporin-4 gene deletion in mice increases focal edema associated with staphylococcal brain abscess. J. Neurochem. 95, 254-262.

CCT-ILAE, 1981. Proposal for revised clinical and electroencephalographic classification of epileptic seizures. From the commission on classification and terminology of the international league against epilepsy. Epilepsia 22, 489-501.

Curia, G., Longo, D., Biagini, G., Jones, R.S.G., Avolia, M., 2008. The pilocarpine model of temporal lobe epilepsy. J. Neurosci. Methods 172, 143-157.

Dedeurwaerdere, S., Fang, K., Chow, M., Shen, Y.T., Noordman, I., van Raay, L., Faggian, N., Porritt, M., Egan, G.F., O’Brien, T.J., 2013. Manganese-enhanced MRI reflects seizure outcome in a model for mesial temporal lobe epilepsy. Neuroimage 68, 30-38.

Ferrer, I., Lopez, E., Blanco, R., Rivera, R., Krupinski, J., Marti, E., 2000. Differential c-Fos and caspase expression following kainic acid excitotoxicity. Acta Neuropathol.(Berl) 99 (3), 245-256.

Gröhn, O., Sierra, A., Immonen, R., Laitinen, T., Lehtimäki, K., Airaksinen, A., Hayward, N., Nairismagi, J., Lehto, L., Pitkanen, A., 2011. Multimodal MRI assessment of damage and plasticity caused by status epilepticus in the rat brain. Epilepsia 52 (Suppl. 8), 57-60.

Immonen, R.J., Kharatishvili, I., Sierra, A., Einula, C., Pitkänen, A., Gröhn, O.H., 2008. Manganese enhanced MRI detects mossy fiber sprouting rather than neurodegeneration, gliosis or seizure-activity in the epileptic rat hippocampus. Neuroimage 40, 1718-1730.

Korestky, A.P., Silva, A.C., 2004. Manganese-enhanced magnetic resonance imaging MEMRI. NMR Biomed. 17, 527-531.

Kumar, G., Mittal, S., Moudgil, S.S., Kupsky, W.J., Shah, A.K., 2013. Histopathological evidence that hippocampal atrophy following status epilepticus is a result of neuronal necrosis. J. Neurol. Sci. 334, 186-191.

Kuo, Y.T., Herlihy, A.H., So, P.W., Bell, J.D., 2006. Manganeseenhanced magnetic resonance imaging (MEMRI) without compromise of the blood-brain barrier detects hypothalamic neuronal activity in vivo. NMR Biomed. 19, 1028-1034.

Lee, D.J., Amini, M., Hamamura, M.J., Hsu, M.S., Seldin, M.M., Nalcioglu, O., Binder, D.K., 2012. Aquaporin-4-dependent edema clearance following status epilepticus. Epilepsy Res. 98, 264-268.

Lee, J.H., Silva, A.C., Merkle, H., Korestky, A.P., 2005. Manganeseenhanced magnetic resonance imaging of mouse brain after systemic administration of $\mathrm{MnCl} 2$ : dose-dependent and temporal evolution of T1 contrast. Magn. Reson. Med. 53, 640-648.

Lee, T.S., Eid, T., Mane, S., Kim, J.H., Spencer, D.D., Ottersen, O.P., de Lanerolle, N.C., 2004. Aquaporin-4 is increased in the sclerotic hippocampus in human temporal lobe epilepsy. Acta Neuropathol. (Berl.) 108, 493-502.

Leite, J.P., Bortolotto, Z.A., Cavalheiro, E.A., 1990. Spontaneous recurrent seizures in rats: an experimental model of partial epilepsy. Neurosci. Biobehav. Rev. 14, 511-517.

Lemos, T., Cavalheiro, E.A., 1995. Suppression of pilocarpineinduced status epilepticus and the late development of epilepsy in rats. Exp. Brain Res. 102, 423-428.

Lin, Y.J., Koretsky, A.P., 1997. Manganese ions enhances T1weighted MRI during brain activation: an approach to direct imaging of brain function. Magn. Reson. Med. 38, 378-388.

Malheiros, J., Longo, B., Tannús, A., Covolan, L., 2012a. Manganeseenhanced magnetic resonance imaging in the acute phase of the pilocarpine-induced model of epilepsy. Einstein (Sao Paulo) 10, 247-252.

Malheiros, J.M., Polli, R.S., Paiva, F.F., Longo, B.M., Mello, L.E., Silva, A.C., Tannus, A., Covolan, L., 2012b. Manganese-enhanced magnetic resonance imaging detects mossy fiber sprouting in the pilocarpine model of epilepsy. Epilepsia 53, 1225-1232. 
Mello, L.E.A.M., Covolan, L., Hamani, C., Smith, R.L., 2006. Excitotoxicity in status epilepticus. In: Technology, M.I.o. (Ed.), Status Epilepticus Mechanisms and Management. Technology, M.I.o..

Nairismägi, J., Pitkäen, A., Narkilahti, S., Huttunen, J., Kauppinen, R.A., Gröhn, O.H.J., 2005. Manganese-enhanced magnetic resonance imaging of mossy fiber plasticity in vivo. Neuroimage 30, 130-135.

Narkilahti, S., Pirttila, T.J., Lukasiuk, K., Tuunanen, J., Pitkanen, A., 2003. Expression and activation of caspase 3 following status epilepticus in the rat. Eur. J. Neurosci. 18 (6), 1486-1496.

Papadopoulos, M.C., Manley, G.T., Krishna, S., Verkman, A.S., 2004. Aquaporin-4 facilitates reabsorption of excess fluid in vasogenic brain edema. FASEB J. 18, 1291-1293.

Papadopoulos, M.C., Verkman, A.S., 2007. Aquaporin-4 and brain edema. Pediatr. Nephrol. 22, 778-784.

Papoti, D., 2006. Transdutores de RF para Experimentos de Imagens de Pequenos Animais. Instituto de Física de São Carlos. Universidade de São Paulo, São Carlos, pp. 144.

Pautler, R.G., Koretsky, A.P., 2002. Tracing odor-induced activation in the olfactory bulbs of mice using manganese-enhanced magnetic resonance imaging. Neuroimage 16, 441-448.

Pautler, R.G., Silva, A.C., Koretsky, A.P., 1998. In vivo neuronal tract tracing using manganese-enhanced magnetic resonance imaging. Magn. Reson. Med. 40, 740-748.

Paxinos, G., Watson, C., 1998. The Rat Brain in Stereotaxic Coordinates, 2nd edition. Academic Press, London.

Racine, R.J., 1972. Modification of seizure activity by electrical stimulation II. Motor seizure. Electroencephalogr. Clin. Neurophysiol. 32, 281-294.
Sheng, M., Greenberg, M.E., 1990. The regulation and function of c-fos and other immediate early genes in the nervous system. Neuron 4 (4), 477-485.

Silva, A.C., Lee, J.H., Aoki, I., Korestky, A.P., 2004. Manganeseenhanced magnetic resonance imaging (MEMRI): methodological and pratical considerations. NMR Biomed. 17, 532543.

Thornberry, N.A., Rano, T.A., Peterson, E.P., Rasper, D.M., Timkey, T., Garcia-Calvo, M., Houtzager, V.M., Nordstrom, P.A., Roy, S., Vaillancourt, J.P., Chapman, K.T., Nicholson, D.W., 1997. A combinatorial approach defines specificities of members of the caspase family and granzyme B. J. Biol. Chem. 272 (29), 17907-17911.

Watanabe, T., Frahm, J., Michaelis, T., 2004. Functional mapping of neural pathways in rodent brain in vivo using manganeseenhanced three-dimensional magnetic resonance imaging. NMR Biomed. 17, 554-568.

Weise, J., Engelhorn, T., Dorfler, A., Aker, S., Bahr, M., Hufnagel, A., 2005. Expression time course and spatial distribution of activated caspase-3 after experimental status epilepticus: contribution of delayed neuronal cell death to seizure-induced neuronal injury. Neurobiol. Dis. 18 (3), 582-590.

Weng, J., Chen, J., Yang, P., Tseng, W.I., 2007. Functional mapping of rat barrel activation following whisker stimulation using activity-induced manganese-dependent contrast. Neuroimage 36, 1179-1188

Yu, X., Wadghiri, Y.Z., Sanes, D.H., Turnbull, D.H., 2005. In vivo auditory brain mapping in mice with Mn-enhanced MRI. Nat. Neurosci. 8, 961-968. 
This certifies that the following individual registered for and attended:

\title{
Society of Critical Care Medicine 43rd Critical Care Congress
}

\author{
January 9-13, 2014 \\ Moscone Center \\ San Francisco, California \\ USA \\ Leticia DE CASTRO, Ms
}

Sao Paulo,

Brazil

The mission of the Society of Critical Care Medicine is to secure the highest quality care for all critically ill and injured patients. The Society of Critical Care Medicine envisions a world in which all critically ill and injured persons receive care from integrated teams of dedicated experts directed by trained and present intensivist physicians. Multiprofessional teams use knowledge, technology and compassion to provide timely, safe, effective and efficient patient-centered care.

Providing the Right Care, Right Now ${ }^{\mathrm{TM}}$ is the goal for all critical care practitioners who strive to achieve optimal patient outcomes. The Society of Critical Care Medicine (SCCM) maintains that the Right Care, Right Now ${ }^{\mathrm{TM}}$ is best provided by an integrated team of dedicated experts directed by a trained and present physician credentialed in critical care medicine (an intensivist). Right Care, Right Now ${ }^{\mathrm{TM}}$ means the Right care is delivered at exactly the Right moment in time to achieve optimal patient outcomes.

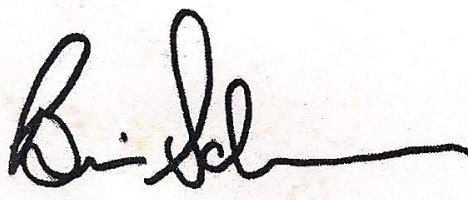

Brian Schramm, CAE Director of Business Affairs 